\title{
The Effect of Physicochemical Properties on the Multiwalled Carbon Nanotube-induced Genotoxicity and Carcinogenesis
}

\author{
Katelyn J. Siegrist
}

Follow this and additional works at: https://researchrepository.wvu.edu/etd

\section{Recommended Citation}

Siegrist, Katelyn J., "The Effect of Physicochemical Properties on the Multiwalled Carbon Nanotubeinduced Genotoxicity and Carcinogenesis" (2016). Graduate Theses, Dissertations, and Problem Reports. 6642.

https://researchrepository.wvu.edu/etd/6642

This Dissertation is protected by copyright and/or related rights. It has been brought to you by the The Research Repository @ WVU with permission from the rights-holder(s). You are free to use this Dissertation in any way that is permitted by the copyright and related rights legislation that applies to your use. For other uses you must obtain permission from the rights-holder(s) directly, unless additional rights are indicated by a Creative Commons license in the record and/ or on the work itself. This Dissertation has been accepted for inclusion in WVU Graduate Theses, Dissertations, and Problem Reports collection by an authorized administrator of The Research Repository @ WVU.

For more information, please contact researchrepository@mail.wvu.edu. 
The Effect of Physicochemical Properties on the Multiwalled Carbon Nanotube-induced Genotoxicity and Carcinogenesis

Katelyn J. Siegrist

Dissertation submitted to the School of Public Health at West Virginia University in partial fulfillment of the requirements for the degree of

Doctor of Philosophy

In

Occupational and Environmental Health Sciences

Linda M. Sargent, Ph.D., Mentor \& Co-Chair

Michael A. McCawley, Ph.D., Co-Chair

Daniel G. Panaccione, Ph.D.

Nancy Lan Guo, Ph.D

Travis L. Knuckles, Ph.D

Dale W. Porter, Ph.D.

Department of Occupational and Environmental Health Sciences

Morgantown, West Virginia

2016

Keywords: Carbon nanotubes, centrosome fragmentation, mitotic spindle disruption, aneuploidy, lung tumor promotion Copyright 2016 Katelyn J. Siegrist 


\title{
Abstract \\ The Effect of Physicochemical Properties on the Multiwalled Carbon Nanotube-induced Genotoxicity and Carcinogenesis
}

\author{
Katelyn J. Siegrist
}

Multiwalled carbon nanotubes (MWCNT) are one of the most exciting industrial materials of our time. They are used in life-saving medical therapeutics and many commercial products that could make day-to-day life seem effortless. However, previous toxicological research has demonstrated this material to be significantly genotoxic in both in vitro and in vivo models and potentially carcinogenic in the lung. The unique physiochemical properties of MWCNT make respiratory exposures likely in workers. Combining the genotoxic effects with the potential for lung deposition in the workplace, MWCNT should be considered as a potential health hazard. Altering the physiochemical properties of MWCNT has been shown to effect toxicity, however there has been limited research on how this effects the mechanism of genotoxicity and carcinogenicity.

Therefore, the aim of the first study was to determine the effect of MWCNT diameter on the mechanism of genotoxicity. Previous research has demonstrated that exposure to MWCNT material both in vitro and in vivo induces DNA damage leading to significant aneuploidy. It is known that the microtubules that make up the mitotic spindle are $20 \mathrm{~nm}$ in diameter. Therefore, human lung epithelial cells were exposed to MWCNT material 10-20 nm in diameter at occupationally-relevant doses. Significant genotoxicity was observed as arrests in the G1/S phase of the cell cycle. Exposure to MWCNT led to significantly increased mitotic spindle aberrations that were predominately monopolar in morphology and fragmented centrosomes. Exposure to the highest dose produced $62 \%$ aneuploidy cells that was significantly greater than control. Aneuploidy was the result of both gains and losses of chromosomes 1 and 4

The aim of the second study was to determine the effect of MWCNT chemical composition on the mechanism of genotoxicity. Previous research has demonstrated that eliminating metal contaminates in the MWCNT through high-temperature treatment post-synthesis (MWCNT-HT) or incorporating nitrogen into the lattice structure of the walls of MWCNT structure during synthesis (MWCNT-ND) can potentially reduce the toxicity of the pristine material (MWCNT-7). Therefore, two types of human lung epithelial cells were exposed to MWCNT-7, MWCNT-HT, and MWCNT-ND in a dose-response. Significant genotoxicity was observed in two cell types through arrests in the cell cycle that indicate centrosomal damage after exposure to each MWCNT material. Exposure to each MWCNT material also led to significantly increased mitotic spindle aberrations and fragmented centrosomes. Exposure to the highest dose of MWCNT-7, HT and ND material produced 65, 58, and $53 \%$ aneuploidy cells, respectively. Detailed chromosome analysis demonstrated significantly increased frequency of fragmented centromeres and translocations between chromosomes 1 and 4 .

The aim of the third study was to determine the mechanism of carcinogenicity of inhaling MWCNT-7 material via a two-stage initiation-promotion protocol. Previous research demonstrated the MWCNT-7 material to be significantly genotoxic and the potential for MWCNT material to be a tumor promoter. At 17 months post-exposure, 23.2, 51.9, 26.5, and $90.5 \%$ of mice from the control, initiating agent only, MWCNT-7 only, or initiating agent and MWCNT-7 group, respectively, had lung tumors. The tumor multiplicity, potency, and volume in the latter group was significantly greater than control indicating that MWCNT-7 material is a strong tumor promoter. Additionally, mice that received both initiating agent and MWCNT-7 demonstrated evidence of serosal tumors morphologically consistent with sarcomatous mesotheliomas.

In conclusion, these studies indicate that MWCNT material, regardless of physicochemical modification, is significantly genotoxic by disrupting the mitotic spindle and fragmenting centrosomes leading to significant aneuploidy. The MWCNT-7 material produced the greatest amount of aneuploidy. Inhalation exposure to this material was significantly carcinogenic and shown to work through the mechanism of tumor promotion rather than initiation. 


\section{Dedication}

I would like to dedicate this dissertation to my parents, Andrew and Rita Siegrist, for whom this work would not have been possible. Thank you for listening to me, over the last six and a half years, talk about strange things like nanotubes, mitotic spindles, and probes. Not only would you both patiently wait until I finished rambling, you would always provide me with an insightful question and reassurance I was doing a good job. You both were there when I was feeling overwhelmed and stressed by the demands of grad school with either a shoulder to cry on or with a good 'ol fashioned tough love pep talk. Since I can remember you both have always afforded me every opportunity to achieve success, both professionally and personally. I don't have the words to thank you properly.

\section{Acknowledgments}

I has been an honor to work with my mentor, Dr. Linda Sargent, for the past six and a half years. I met Linda while an undergrad as an intern at the wellness facility at NIOSH. She would come down for a personal training session, but instead we would talk about science and research. Needless to say, I was a terrible personal trainer. But, Linda recognized my potential as a scientist and offered me a job immediately following graduation as a regular fellow in her lab upstairs to study carbon nanotubes. I still can't believe she kept me around this long. I know I have not made this journey easy for either one of us, but I hope I have made her proud. I am beyond grateful; I owe her my life and my career. However, absolutely none of this work would have been possible without the training I received from a laboratory technician, David Lowry. David is much more than a technician; he's a brilliant mind, teacher, and friend. He should also be given credit for maintaining peace and sanity within the lab! I don't know what I will do without them by my side in the lab.

I would like to sincerely thank my committee members, Dr. Michael McCawley, Dr. Dan Panaccione, Dr. Nancy Lan Guo, Dr. Dale Porter, and Dr. Travis Knuckles, for providing me with insightful feedback and trusted guidance regarding the science. However, each member taught me life lessons that can't be taught in the lab. Dr. McCawley has taught me to always think outside the box, not be afraid to ask the hard questions, and know my worth. Dr. Panaccione taught me that extremely successful scientists can also be extremely kind and patient. Dr. Guo has taught me that success is not only measured from what you put on paper. Dr. Porter has taught me to always pay attention to the details. Dr. Knuckles has taught me that you have to work hard, really hard, to play hard. In addition to my committee l've had several other mentors along the way that have helped guide me through my research, student life, or professional life and deserve recognition: Dr. Michael Kashon, Dr. Todd Stueckle, Dr. Ann Hubbs, Dr. Bob Mercer, Dr. Aaron Erdely, Dr. Christa Lilly, Dr. Doug Myers, Dr. Kimberly Rauscher, Dr. Keith Zullig, and Dr. Ranjita Misra. There are many others at either NIOSH or the School of Public Health that have contributed to my degree. It really takes a village.

Lastly, I would like to thank my friends and family. My sister and brother-in-law, Andrea and Scott Christophel, have always supported my decision to go back to school and fight for what I know is right. My fellow classmates, Dr. Meagan Stabler, Dr. Termeh Feinberg, Dr. Amna Umer, Dr. Halima Ahmadi-Montecalvo, Dr. Sherry Owens, Amy Hunter MPH, Travis Goldsmith, and Maya Nye, deserve a medal for maintaining my sanity (however relative that is) and focus throughout my time in the graduate program. It was a rough ride and you guys did a great job navigating! Thank you to Mike and Kim Manuel, Adam Ware, Dr. Katie Abraham, and Anna Jaeschke, MS, MA, PhD for being incredibly supportive friends. And to my dearest friends, who are more like sisters, Lauren Branch, MPH, Veronica Milliken, MS, Katie Wilson, MA, JD, Katie Moore, MA, and Rachel Morgenstern, MPA, "Here's to strong women. May we know them, may we be them, may we raise them." 


\section{Table of Contents}

Abstract

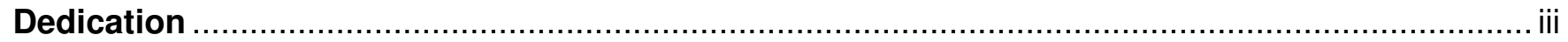

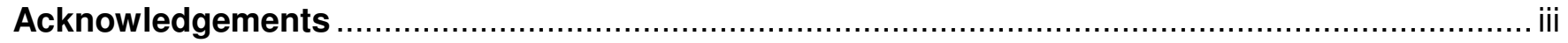

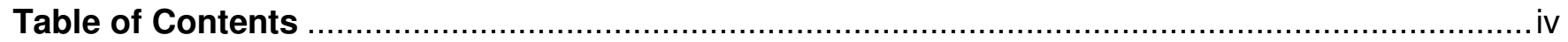

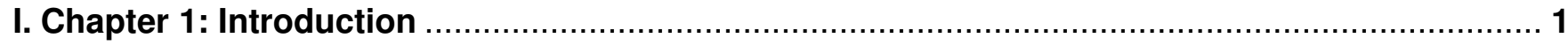

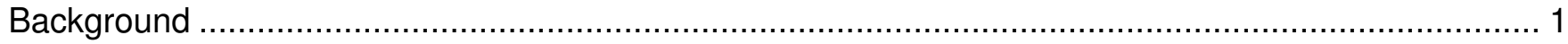

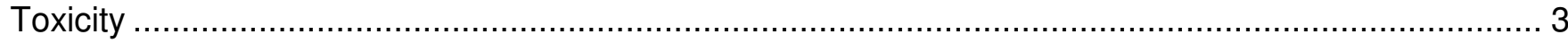

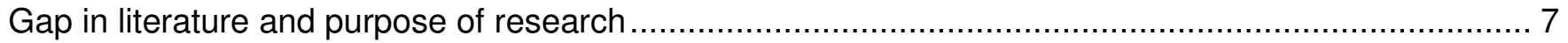

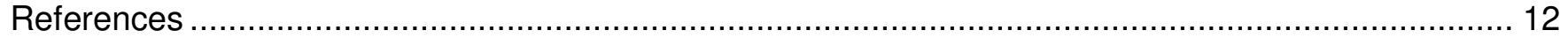

II. Chapter 2: Genotoxicity of multi-walled carbon nanotubes at occupationally relevant

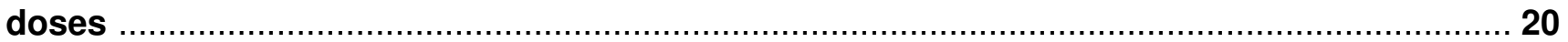

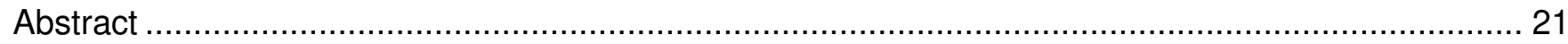

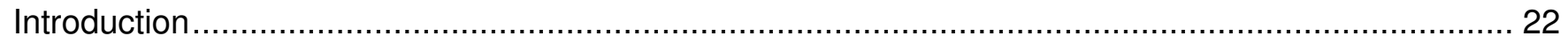

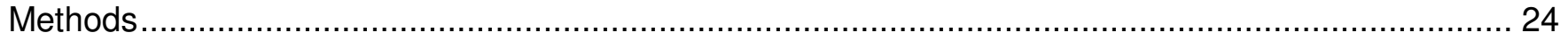

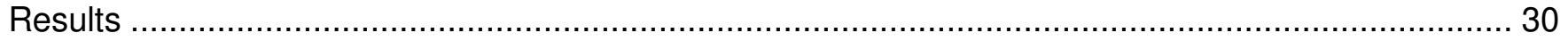

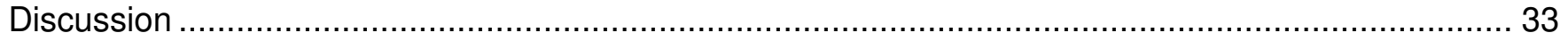

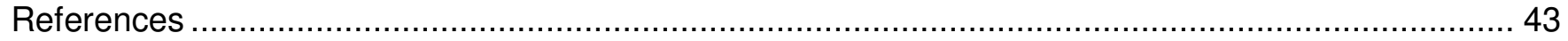

III. Chapter 3: Fragmented centromeres, translocations, aneuploidy, aberrant mitotic spindles, and fragmented centrosomes in human lung epithelial cells exposed to Mitsui-7, heat-treated, and nitrogen-doped multi-walled carbon nanotubes............................................................ 56

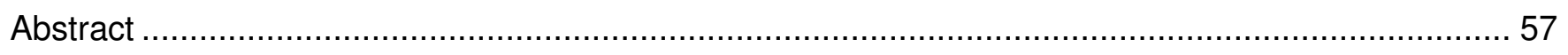

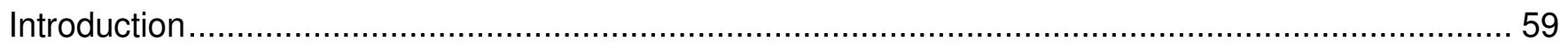

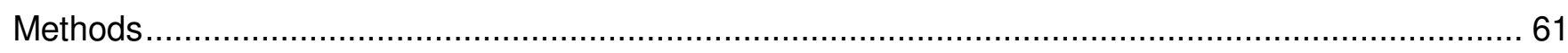

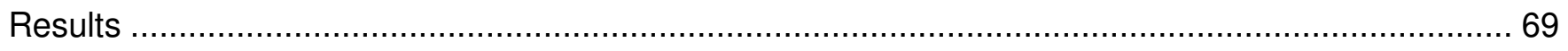

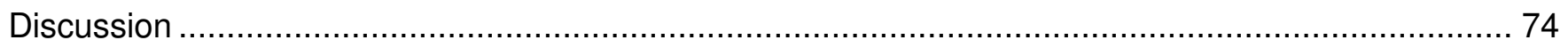

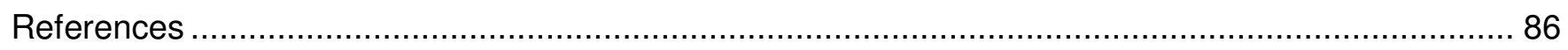

IV.Chapter 4: Promotion of lung adenocarcinoma following inhalation exposure to multi-walled

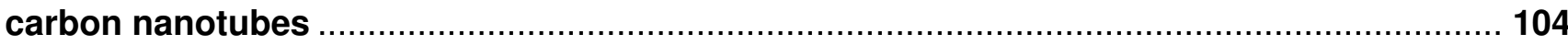

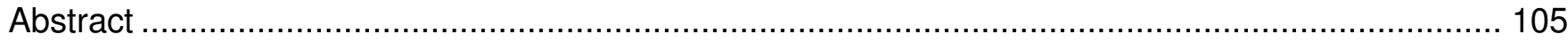

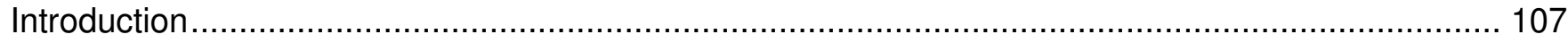

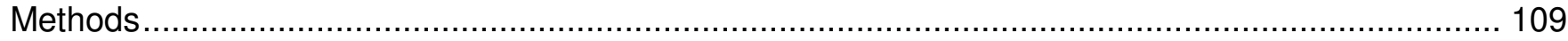

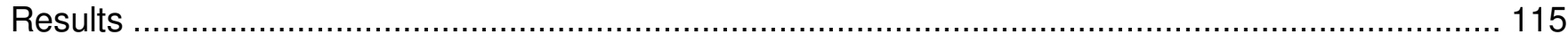

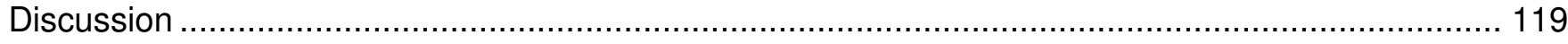

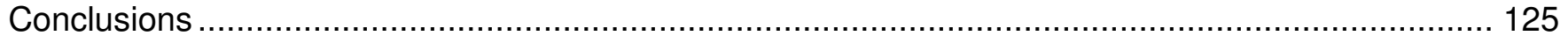




References




\section{Introduction}

Multiwalled carbon nanotubes (MWCNT) are one of the most exciting industrial materials of our time. The life-changing potential of this material has not gone unnoticed by the scientific community. Currently, millions of dollars and countless hours are poured into the research and development of MWCNT as life-saving medical therapeutics and commercial products that could make day-to-day life seem effortless; the possibilities are endless. There is great potential for engineered nanomaterials such as MWCNT to positively impact human life. However, as with any new discovery, there are risks. Research into the deleterious effects of MWCNT exposure on human health has indicated caution should be taken during the production and use of this material in the workplace [1,2]. The global production of MWCNT is projected to increase to 7,000 tons by 2025 [3] due in large part to the alteration of the unique physicochemical properties inherent to this material and the development of better products. Therefore, a thorough risk assessment of MWCNT material is imperative to determine, not only a safe dose, but also the mechanisms by which these physicochemical alterations affect toxicity specifically related to cancer.

\section{Background}

MWCNT are cylindrical carbon allotropes with multiple layers of graphene. Individual nanotubes can have a diameter of 1-250 $\mathrm{nm}$ and a length of 1-10 $\mu \mathrm{m}$. Individual MWCNT are rigid structures having incredible tensional and torsional strength in relation to their weight and size. As a bulk material MWCNT have an extremely high surface area due to the multiple walls and small size of the individual structures. MWCNT is an extremely durable material that resists enzymatic and mechanical degradation due to their atomic structure.

The high-aspect ratio, fiber-like properties, hollow core and electrical conductivity make this material highly coveted for industrial uses such as composite materials, pharmaceuticals, optics, electronics, energy production, bioengineering, and water filtration. However, aerosolization during the production and use of MWCNT is likely leading to inhalation exposures in worker populations [4]. 
The production and use of MWCNT materials is a global operation with the majority of potentially exposed workers employed by 200 companies spanning North America, Southeast Asia, and Europe. It is estimated that the global production of MWCNT material will reach over 12,800 metric tons which equates to a $\$ 1.1$ billion industry by the end of 2016 . The MWCNT market is projected to increase $10.5 \%$ annually in large part due to the industrial demand for more efficient products [3]. Therefore, the alteration of the unique physicochemical properties, thereby increasing the conductivity, surface area, strength, etc., of this nanomaterial has been driving the dramatic growth of this industry. This presents many challenges to toxicologists and other public health professionals as the risk of adverse health effects increases with increasing unknown variables. However, within this complicated equation lies the opportunity to design a safer product whether it be through direct manipulation of the material or indirect administrative and engineering controls.

Although the population of workers potentially exposed to MWCNT in the United States is small [5], the in vivo data from rodents exposed to MWCNT suggests the potential for serious health effects $[1,6]$. An analysis of 8 primary MWCNT manufacturing facilities demonstrated an airborne concentration of $10.6 \mu \mathrm{g} / \mathrm{m}^{3}$ inhalable-sized particles and $2.65 \mu \mathrm{g} / \mathrm{m}^{3}$ respirable-sized particles in the breathing zone of workers [7] which is greater than the recommended exposure limit (REL) of $1 \mu \mathrm{g} / \mathrm{m}^{3}$ [8]. A more recent exposure assessment of 14 primary and secondary MWCNT manufacturing facilities found a mean personal breathing zone concentration of $0.16 \mu \mathrm{g} / \mathrm{m}^{3}$ for respirable particles and 1.21 $\mu \mathrm{g} / \mathrm{m}^{3}$ for inhalable particles [9]. These exposure assessments can be used in the risk assessment of exposure to MWCNT.

Due to the low density and small size, MWCNT material is easily aerosolized in the workplace leading to inhalation as the primary route of exposure. The delivered dose in the lung can be modelled and estimated based on characteristics of the MWCNT aerosol particle. Size of the MWCNT aerosol particle determines the pulmonary region of deposition. Ultrafine particles (<100 nm in diameter) will deposit most frequently in the alveolar region of the lung [10]. Therefore, it is reasonable to investigate biological health effects associated with the alveoli and small airways, such as pulmonary adenocarcinoma. 
Currently, there are no reported human health effects or cancers related to occupational exposure to MWCNT material. However, a small study (sample size $n=13$ ) found significant increases in inflammatory markers (malondialdehyde (MDA), 4-hydroxy-2-hexanal (4-HHE), and n-hexanal) that were positively correlated with the presence of molybdenum, the catalyst used during synthesis of these particular MWCNT, in exhaled breath condensate of workers exposed to MWCNT in a manufacturing facility [11].

The importance of inflammation in cancer has been well documented in animal $[12,13]$ and human studies [14]. Exposure to MWCNT material has been shown to produce significant inflammation in vitro [15] and in vivo [16-18]. MWCNT material has been shown to produce other significant effects associated with tumorigenesis such as oxidative stress [19-23], fibrosis [24, 25], and genotoxicity (to be discussed below) in the lung. However, the mechanisms by which these effects are generated are poorly understood. Since human studies are not available at this time, the carcinogenicity of MWCNT must be assessed using animal and cellular studies.

\section{Toxicity}

Any damage to genetic information is known as genotoxicity and it can be measured using a myriad of techniques. The observance of DNA double strand breaks (dsb) through comet assay is a general indication of genetic damage and is commonly used in genotoxicity screening. There are many techniques used to determine the mechanism of genotoxicity such as micronucleus formation, chromosome enumeration, cell cycle analysis, and mutagenicity assays. Micronuclei can be formed by either chromosome breakage or whole chromosome loss. Enumerating chromosomes is used to determine aneuploidy, otherwise known as an abnormal number of chromosomes. Cell cycle analysis is used to measure arrests in the three phases of interphase during mitosis, G1, S and G2. During interphase the cell is preparing to divide by duplicating the DNA and other cellular components. There are checkpoints within this process to recognize and correct errors to the genetic material. Depending on which phase of the cell cycle these arrests occur can be an indication as to the mechanism of genetic damage. For example, an arrest in the $\mathrm{S}$ phase of the cell cycle could be an indication of 
damage to the centrosomes since they are duplicated in this phase. Mutagenicity assays are used to determine errors in DNA base pairs.

MWCNT material is both passively and actively transported through the cellular membrane based on its physicochemical properties, most notably size [26]. However, the nuclear membrane is disassembled during mitosis leaving the DNA, mitotic spindle, and centrosomes vulnerable to interactions with MWCNT within the cellular membrane regardless or MWCNT nuclear penetration.

The interaction between the MWCNT material and mitotic spindle is of particular importance given that the microtubules that make up the mitotic spindle are $20 \mathrm{~nm}$ in diameter [27]. Additionally, microtubules are dynamic structures depending on the polymerization and depolymerization of lipophilic tubulin proteins [27, 28]. The mitotic spindle apparatus is organized by the centrosome structure consisting of lipophilic centrin and pericentrin proteins at the spindle poles [28]. Therefore, it is reasonable to investigate mechanisms of toxicity associated with the interaction between MWCNT and these nuclear structures.

Disruptions to the mitotic spindle can lead to aberrant spindle morphologies, fragmented centrosomes, and unequal separation of the DNA, otherwise known as aneuploidy. Disruption of the mitotic spindle and aneuploidy in cultured cells is strongly correlated with in vivo carcinogenesis at occupationally-relevant doses [29-32]. Other genotoxic mechanisms have been observed in many types of cultured cells and tissues after exposure to MWCNT material, however this review will focus on effects specifically in the lung since it is the primary route of occupational exposure.

Exposure to $50 \mu \mathrm{g} / \mathrm{cm}^{2}$ Mitsui-7 MWCNT material (MWCNT-7) in murine alveolar macrophages resulted in DNA dsb measured by the comet assay [33]. A549 cells, a human lung epithelial cell line derived from an adenocarcinoma, were exposed to 5-100 $\mu \mathrm{g} / \mathrm{mL}$ MWCNT and increases in dsb were measured via the comet assay, however statistical significance varied with concentrations and exposure times [34]. DNA dsb were also observed in A549 cells following exposure to $20-40 \mu \mathrm{g} / \mathrm{cm}^{2}$ MWCNT for 4 hours [35], $12.5 \mu \mathrm{g} / \mathrm{mL}$ MWCNT for 1 hour [36], and $50 \mu \mathrm{g} / \mathrm{mL}$ of MWCNT with varying diameters and length for 3 hours [37]. MeT-5A cells, an immortalized human lung mesothelial cell line, was exposed to 5-200 $\mu \mathrm{g} / \mathrm{cm}^{2}$ MWCNT for 48 hours and a dose-dependent increase in SB was 
observed [38]. Ursini et al. measured significant increases in dsb in A549 cells and BEAS-2B cells, an immortalized human lung epithelial cell line, exposed to 10 and $40 \mu \mathrm{g} / \mathrm{mL}$ MWCNT for 24 hours [39].

Isolation of total lung cells in mice exposed to MWCNT via intratracheal (i.t.) instillation demonstrated increased DNA dsb measured by the comet assay after exposure to $128 \mu \mathrm{g} / \mathrm{mouse}$ [40] or 50 and $200 \mu \mathrm{g} /$ mouse [22]. Poulsen et al. also exposed mice to $0,18,54$, and $163 \mu \mathrm{g}$ MWCNT via i.t. installation and found increased DNA dsb in bronchial alveolar lavage (BAL) fluid cells 3 days post exposure from the 54 and $163 \mathrm{mg}$ doses of the MWCNT with a smaller diameter $(4.5 \mathrm{~nm})$ and 1 day post exposure from all doses of the MWCNT with the larger diameter $(67 \mathrm{~nm})$ [41]. Rats exposed to $0.17,0.49$, and $0.94 \mathrm{mg} / \mathrm{m}^{3}$ via whole-body inhalation for 5 days demonstrated increased DNA dsb in pulmonary cells in a dose-dependent manner either immediately or 1 month post-exposure with significance achieved at the highest dose [42].

Micronuclei formation was increased in Chinese hamster lung (CHL/IU) cells in a dosedependent manner exposed to 1.3-80 $\mu \mathrm{g} / \mathrm{mL}$ MWCNT for 24 hours and 0.02-5 $\mu \mathrm{g} / \mathrm{mL}$ MWCNT for 48 hours [43], V79 cells exposed to $0.27,0.53,1.05$, and $2.1 \mu \mathrm{g} / \mathrm{cm}^{2} \mathrm{MWCNT}$ for 24 hours demonstrated a dose-dependent increase in MN with a decrease in mitotic index [44], rat lung epithelial cells exposed to $10-50 \mu \mathrm{g} / \mathrm{mL}$ MWCNT for 48 hours [45], and A549 cells were exposed to 10 and $50 \mu \mathrm{g} / \mathrm{mL}$ MWCNT for 24 hours [23] and $12.5 \mu \mathrm{g} / \mathrm{mL}$ MWCNT for 1 hour [36]. Dose-dependent polyploidy was measured in CHL/IU cells exposed to1.3-80 $\mu \mathrm{g} / \mathrm{mL}$ MWCNT for 24 hours and 0.02-5 $\mu \mathrm{g} / \mathrm{mL}$ MWCNT for 48 hours without structural aberrations [43]. Chronic exposure of $1 \mu \mathrm{g} / \mathrm{mL}$ MWCNT in the BEAS-2B cell lead to significant anchorage-independent clonal growth and evidence of neoplastic transformation through increased chromosome aberrations specific to oncogenes measured by CGH array [46]. Carbon nanotubes have been shown to bind to $\mathrm{G}-\mathrm{C}$ rich and telomeric regions of the chromosomes resulting in conformational changes in the DNA structure $[47,48]$ which may explain the mechanism of DNA breakage.

A dose-dependent increase in MN formation was measured in type II pneumocytes isolated from rats exposed to 0.5 and $2 \mathrm{mg}$ of MWCNT via i.t. installation [45]. Mutations in the gpt locus were observed in whole lung cell samples from ICR mice exposed to four rounds of i.t. installations of $0.2 \mathrm{mg}$ 
MWCNT [22]. Statistically significant increases in $G: C$ to $C: G$ transversions in lungs from gpt transgenic mice exposed to $0.8 \mathrm{mg}$ of MWCNT via i.t. installation indicate DNA mutations caused by oxidative damage [22]. Kim et al 2014 exposed Fischer 344 rats to $0.17,0.49$, and $0.96 \mathrm{mg} / \mathrm{m}^{3}$ MWCNT material via nose-only inhalation for 28 days and found significantly increased DNA SB in isolated lung cells immediately after or 90 post exposure. There was a significant increase in ROS production in the lungs following exposure indicating an indirect mechanism of DNA damage [16]. Subcutaneous tumors were formed in a xenograft mouse model with MWCNT-induced clones of BEAS2B chronically exposed to $1 \mu \mathrm{g} / \mathrm{mL}$ in culture that showed increased DNA copy number for 17 oncogenes associated with nonsmall cell lung cancer [46].

Asbestos fibers have demonstrated a direct mechanism of carcinogenesis through the physical disruption of cellular division leading to chromosome instability such as aneuploidy and structural aberrations $[49,50]$. Asbestos fibers have an affinity for microtubules which results in interactions with the division apparatus (i.e. mitotic spindle) leading to multipolar mitoses, failed cytokinesis, and lagging chromosomes [31, 32, 51]. Such genetic effects manifested as disruptions in the cell cycle [50]. Chromosome instability (CIN) and sustained proliferation are hallmarks of cancer and are necessary components in tumor progression allowing preneoplastic cells to transform into frank neoplasms [5255]. Single-walled carbon nanotubes (SWCNT), an extremely similar carbon allotrope material, have also been shown to affect cellular division leading to aneuploidy. Exposure to SWCNT produced multipolar mitotic spindle aberrations in the BEAS-2B cell [56] and significant aneuploidy in the SAEC cell, a primary human lung epithelial cell, in a dose-dependent manner [57].

There is evidence that MWCNT toxicity follows the fiber-induced pathogenicity paradigm, much like the known fibrous carcinogen, asbestos [58]. MWCNT are extremely biopersistent materials due to their length and chemical resiliency [59] leading to prolonged cellular exposures and the potential for chronic disease outcomes. The MWCNT are able to penetrate the alveolar space, deposit, and migrate throughout the pleural interstitium and lining $[59,60]$. Tumor formation was not observed in ras $\mathrm{H} 2$ mice exposed to $75 \mathrm{mg} / \mathrm{kg}$ MWCNT subcutaneously [61], Wistar rats exposed to 2 and $20 \mathrm{mg}$ of MWCNT material via IP injection [62], or F-344 rats exposed to $10 \mathrm{mg}$ MWCNT material via intraperitoneal 
implantation [63]. Takagi et al. exposed p53 deficient and wild type mice to 0.003-3 mg MWCNT-7 material through intraperitoneal (IP) injection and measured a significantly greater increase in incidence of mesotheliomas at all doses in p53 deficient mice compared to wild type [64,65]. Another investigation found $86 \%$ of $\mathrm{F}-344$ rats to have mesotheliomas after exposure to $10 \mathrm{mg}$ MWCNT material through intrascotal injection [66]. However, these investigations did not follow the primary route of exposure.

Once inhaled, the MWCNT material is able to penetrate the deep lung and deposit at the alveolar surface [59]. There have been very few studies investigating the formation of tumors in animals exposed to MWCNT material via inhalation. Additionally, the mechanism of in vivo carcinogenicity is not known. One study demonstrates MWCNT material to be a possible tumor promoter $[64,65]$, however mutagenicity data has indicated the potential for MWCNT material to be a tumor initiator [22].

These data indicate the tumorigenic potential of pristine MWCNT material, however differences have been observed regarding physicochemical characteristics. Adenomas and adenocarcinomas were reported in C57BL/6 mice exposed to $0.1 \mathrm{mg}$ MWCNT material via i.t. installation for six months. Acid-treated MWCNT were considerably shorter than the pristine MWCNT, 0.567 and $7.71 \mu \mathrm{m}$, respectively. The pristine MWCNT material produced more tumors in the mice indicating it was more potent. The difference in effects was attributed to the physicochemical differences between the two materials [67]. Wistar rats were exposed to a high and low dose of four types of MWCNT materials with varying physicochemical properties via intraperitoneal injection and each material was found to produce mesotheliomas. However, MWCNT materials with curved structures were found to be less potent than needle-like MWCNT materials indicating that physicochemical properties can affect carcinogenicity [68]. Additionally, it was suggested that MWCNT diameter plays a part in the carcinogenicity after exposing rats to MWCNT 15, 50, and $150 \mathrm{~nm}$ in diameter via IP injection. Mesotheliomas were found in all rats exposed to $50 \mathrm{~nm}$ MWCNT material but none in rats exposed to 15 or $150 \mathrm{~nm}$ MWCNT material [69, 70].

\section{Gap in literature and purpose of the research}


There are myriad ways to alter the physicochemical characteristics of MWCNT materials and these changes could have effects on the toxicity [71, 72]. MWCNT material of varying physicochemical properties have been associated with different biological effects. Many properties have been shown to affect cellular and nuclear uptake [73], oxidative potential [74], and inflammation [75, 76], however this review will focus on the effects specific to direct interactions between MWCNT and genetic material leading to genotoxicity. Unaltered MWCNT material, otherwise known as pristine, has chemical impurities from residual metal catalyst material leftover from the synthesis process. These impurities can be removed through exposure of the pristine MWCNT material to extremely high temperatures thereby producing a purified form (MWCNT-HT). However, a reduction of metal impurities was not associated with a reduction of toxicity in V79 cells exposed to pristine and purified MWCNT material [44].

During the synthesis process the length and diameter of the individual MWCNT structures can be altered. MWCNT material shorter in length has been shown to cause less inflammation than longer MWCNT in animals exposed via IP injection $[77,78]$. Long and thick MWCNT material was demonstrated to be more inflammogenic and damaging to the DNA than short and thin MWCNT material in A549 cells and C57BI/6 mice [37]. Poulsen et al demonstrated that larger diameter was associated with increased genotoxicity and inflammation in C57BI/6J mice exposed to 10 different MWCNT via i.t. installation [79]. Double-walled carbon nanotubes (DWCNT), pristine and purified SWCNT, and MWCNT material was applied to V79 cells and genotoxicity was measured using the comet assay. The greatest genotoxic effect was found with exposure to MWCNT, the widest material, indicating that increased diameter is associated with increased toxicity [44].

Additionally, chemical composition of the MWCNT material can be altered through the synthesis process. Nitrogen can be incorporated into the lattice structure of the MWCNT walls during synthesis thereby producing a nitrogen-doped MWCNT material (MWCNT-ND). Immortalized small airway epithelia cells exposed to either pristine MWCNT-7 material or MWCNT-ND material demonstrated differences in ROS generation, proliferation, and cell cycle [80]. 
Physicochemical alterations can be made post-synthesis through chemical functionalization and acid washing. Exposing MWCNT material to a strong acid is a method of reducing residual metal catalyst. This method has also been shown to produce chemically-functionalized MWCNT materials and MWCNT materials with shorter tube lengths. Chemical functionalization of MWCNT material has been shown to be acutely less toxic than pristine MWCNT material through analysis of inflammatory regulators, oxidative stress factors, and morphology in vivo [81]. Carboxylated MWCNT material produced by washing the material with a strong acid was shown to be more genotoxic than pristine MWCNT material in the A549 and BEAS-2B cell types as measured via the comet assay [39]. However, acid washing has also been shown to degrade the MWCNT material by producing shorter tube lengths and structural defects in the nanotube walls [82]. These data indicate a need for mechanistic data related to genotoxicity for MWCNT materials of different physicochemical characteristics. Given the genotoxic similarities between asbestos and SWCNT material, we investigated the roll of diameter and chemical properties in the mechanism of MWCNT-induced genotoxicity and carcinogenicity.

There are many different types of MWCNT material and data of the carcinogenic potential for any MWCNT material is sparse. However, there is sufficient evidence that demonstrated MWCNT-7 material is uniquely toxic. These data show MWCNT-7-induced mesothelioma in rodent models exposed through either i.t. installation or IP injection which is not representative of a true workplace exposure. Additionally, the mechanism of carcinogenicity, following a two-stage initiation/promotion protocol, from exposure to MWCNT-7 material has not been determined.

Therefore, the following studies were designed to evaluate 1) the effect of MWCNT diameter on the mechanism of genotoxicity, 2) the effect of chemical alterations of MWCNT on the mechanism of genotoxicity, and 3) the mechanism of tumorigenesis of MWCNT-7 via inhalation. These studies will help in our understanding of the role physicochemical alterations play in the mechanisms of genotoxicity leading to tumor formation and also establish the carcinogenicity of MWCNT-7 in particular. The specific aims of the studies were as follows: 


\section{Study 1}

To determine the effect of MWCNT diameter on the mechanism of genotoxicity human lung epithelial cells were exposed to MWCNT material 10-20 nm in diameter at occupationally-relevant doses since microtubules of the mitotic spindle are $20 \mathrm{~nm}$ in diameter. Exposed cells were analyzed through flow cytometry for cell cycle disruptions indicating overall genotoxicity. Confocal microscopy analysis of the mitotic spindle, fluorescent in situ hybridization of chromosomes, and transmission electron microscopy of the cells were used to determine mitotic spindle aberrations, aneuploidy, centrosome integrity, and DNA integrity. It was hypothesized that MWCNT would produce significant genotoxicity via multipolar mitotic spindles and fragmented centrosomes leading to significant increases in aneuploidy.

\section{Study 2}

To determine the effect of chemical alterations of MWCNT on the mechanism of genotoxicity human lung epithelial cells were exposed to MWCNT-7, MWCNT-HT (a MWCNT-7 purified by exposure to high temperature), and MWCNT-ND in a dose-response since the latter two materials have been chemically-altered and shown to have less toxic potential. Exposed cells were analyzed through flow cytometry for cell cycle disruptions indicating overall genotoxicity. Confocal microscopy analysis of the mitotic spindle, fluorescent in situ hybridization of chromosomes, and transmission electron microscopy of the cells were used to determine mitotic spindle aberrations, aneuploidy, centrosome integrity, and DNA integrity. It was hypothesized that each MWCNT material would produce significant genotoxicity via multipolar mitotic spindles and fragmented centrosomes leading to significant increases in aneuploidy, however MWCNT-7 material would be most potent followed by MWCNT-HT and ND material.

\section{Study 3}

To determine the mechanism of carcinogenicity of MWCNT-7 material six week old, male, B6C3F1 were exposed to MWCNT-7 via inhalation following a two-stage initiation-promotion protocol 
since MWCNT-7 material has been shown to be significantly genotoxic and carcinogenic via other routes of exposure. Mice received a single IP injection of either, methylcholanthrene (MCA, an initiating agent), or vehicle control (corn oil). One week after IP injections, mice were exposed to MWCNT-7 material ( $5 \mathrm{mg} / \mathrm{m}^{3}, 5$ hours/day, 5 days/week) or filtered air (controls) for a total of 15 days. At 17 months post-exposure, mice were euthanized and examined for lung tumor formation. It was hypothesized that mice exposed to MWCNT-7 material would have tumors in the lung and the mice exposed to MCA + MWCNT would demonstrate greater tumor incidence. 


\section{References}

1. Schulte, P.A., et al., Focused actions to protect carbon nanotube workers. Am J Ind Med, 2012. 55(5): p. 395-411.

2. Kuemple, E., et al., Seeing the Forest through the Trees: Evaluating the Key Evidence and Data Gaps in Assessing the Potential Carcinogenicity of Carbon Nanotubes and Nanofibers in Humans Crit Rev Toxicol, 2016.

3. The Global Market for Carbon Nanotubes: Technologies, Production, End User Markets and Opportunities Analysis, 2015-2025. 2016, Future Markets, Inc.

4. Methner, M., et al., Field application of the Nanoparticle Emission Assessment Technique (NEAT): task-based air monitoring during the processing of engineered nanomaterials (ENM) at four facilities. J Occup Environ Hyg, 2012. 9(9): p. 543-55.

5. Schubauer-Berigan, M.K., M.M. Dahm, and M.S. Yencken, Engineered carbonaceous nanomaterials manufacturers in the United States: workforce size, characteristics, and feasibility of epidemiologic studies. J Occup Environ Med, 2011. 53(6 Suppl): p. S62-7.

6. Oberdorster, G., et al., Principles for characterizing the potential human health effects from exposure to nanomaterials: elements of a screening strategy. Part Fibre Toxicol, 2005. 2: p. 8.

7. Erdely, A., et al., Carbon nanotube dosimetry: from workplace exposure assessment to inhalation toxicology. Part Fibre Toxicol, 2013. 10(1): p. 53.

8. $\mathrm{NIOSH}$, Current intelligence bulletin 65: occupational exposure to carbon nanotubes and nanofibers. . 2013(Publication No. 2013-145).

9. Dahm, M.M., et al., Carbon Nanotube and Nanofiber Exposure Assessments: An Analysis of 14 Site Visits. Ann Occup Hyg, 2015. 59(6): p. 705-23.

10. Hinds, W.C., Aerosol technology : properties, behavior, and measurement of airborne particles. 1999, New York: Wiley.

11. Lee, J.S., et al., Health surveillance study of workers who manufacture multi-walled carbon nanotubes. Nanotoxicology, 2015. 9(6): p. 802-11. 
12. Bauer, A.K. and E.A. Rondini, Review paper: the role of inflammation in mouse pulmonary neoplasia. Vet Pathol, 2009. 46(3): p. 369-90.

13. Malkinson, A.M., Role of inflammation in mouse lung tumorigenesis: a review. Exp Lung Res, 2005. 31(1): p. 57-82.

14. Hussain, S.P. and C.C. Harris, Inflammation and cancer: an ancient link with novel potentials. Int J Cancer, 2007. 121(11): p. 2373-80.

15. He, X., et al., Multiwalled carbon nanotubes induce a fibrogenic response by stimulating reactive oxygen species production, activating NF-kappaB signaling, and promoting fibroblast-tomyofibroblast transformation. Chem Res Toxicol, 2011. 24(12): p. 2237-48.

16. Kim, J.S., et al., In vivo genotoxicity evaluation of lung cells from Fischer 344 rats following 28 days of inhalation exposure to MWCNTs, plus 28 days and 90 days post-exposure. Inhal Toxicol, 2014. 26(4): p. 222-34.

17. Porter, D.W., et al., Acute pulmonary dose-responses to inhaled multi-walled carbon nanotubes. Nanotoxicology, 2013. 7(7): p. 1179-94.

18. Porter, D.W., et al., Mouse pulmonary dose- and time course-responses induced by exposure to multi-walled carbon nanotubes. Toxicology, 2010. 269(2-3): p. 136-47.

19. Moller, P., et al., Role of oxidative stress in carbon nanotube-generated health effects. Arch Toxicol, 2014. 88(11): p. 1939-64.

20. Nymark, P., et al., Free radical scavenging and formation by multi-walled carbon nanotubes in cell free conditions and in human bronchial epithelial cells. Part Fibre Toxicol, 2014. 11: p. 4.

21. Alarifi, S. and D. Ali, Mechanisms of Multi-walled Carbon Nanotubes-Induced Oxidative Stress and Genotoxicity in Mouse Fibroblast Cells. Int J Toxicol, 2015. 34(3): p. 258-65.

22. Kato, T., et al., Genotoxicity of multi-walled carbon nanotubes in both in vitro and in vivo assay systems. Nanotoxicology, 2013. 7(4): p. 452-61.

23. Srivastava, R.K., et al., Multi-walled carbon nanotubes induce oxidative stress and apoptosis in human lung cancer cell line-A549. Nanotoxicology, 2011. 5(2): p. 195-207. 
24. Mercer, R.R., et al., Pulmonary fibrotic response to aspiration of multi-walled carbon nanotubes. Part Fibre Toxicol, 2011. 8: p. 21.

25. Mercer, R.R., et al., Distribution and fibrotic response following inhalation exposure to multiwalled carbon nanotubes. Part Fibre Toxicol, 2013. 10: p. 33.

26. Raffa, V., et al., Physicochemical properties affecting cellular uptake of carbon nanotubes. Nanomedicine (Lond), 2010. 5(1): p. 89-97.

27. Pampaloni, F. and E.L. Florin, Microtubule architecture: inspiration for novel carbon nanotubebased biomimetic materials. Trends Biotechnol, 2008. 26(6): p. 302-10.

28. Pereira, G. and E. Schiebel, Centrosome-microtubule nucleation. J Cell Sci, 1997. 110 ( Pt 3): p. 295-300.

29. Ehrlich, V.A., et al., Inhalative exposure to vanadium pentoxide causes DNA damage in workers: results of a multiple end point study. Environ Health Perspect, 2008. 116(12): p. 168993.

30. Ress, N.B., et al., Carcinogenicity of inhaled vanadium pentoxide in F344/N rats and B6C3F1 mice. Toxicol Sci, 2003. 74(2): p. 287-96.

31. Yegles, M., et al., Role of fibre characteristics on cytotoxicity and induction of anaphase/telophase aberrations in rat pleural mesothelial cells in vitro: correlations with in vivo animal findings. Carcinogenesis, 1995. 16(11): p. 2751-8.

32. Yegles, M., et al., Induction of metaphase and anaphase/telophase abnormalities by asbestos fibers in rat pleural mesothelial cells in vitro. Am J Respir Cell Mol Biol, 1993. 9(2): p. 186-91.

33. Aldieri, E., et al., The role of iron impurities in the toxic effects exerted by short multiwalled carbon nanotubes (MWCNT) in murine alveolar macrophages. J Toxicol Environ Health A, 2013. 76(18): p. 1056-71.

34. Cavallo, D., et al., Multi-walled carbon nanotubes induce cytotoxicity and genotoxicity in human lung epithelial cells. J Appl Toxicol, 2012. 32(6): p. 454-64.

35. Karlsson, H.L., et al., Copper oxide nanoparticles are highly toxic: a comparison between metal oxide nanoparticles and carbon nanotubes. Chem Res Toxicol, 2008. 21(9): p. 1726-32. 
36. Visalli, G., et al., Toxicological assessment of multi-walled carbon nanotubes on A549 human lung epithelial cells. Toxicol In Vitro, 2015. 29(2): p. 352-62.

37. Yamashita, K., et al., Carbon nanotubes elicit DNA damage and inflammatory response relative to their size and shape. Inflammation, 2010. 33(4): p. 276-80.

38. Lindberg, H.K., et al., Genotoxicity of short single-wall and multi-wall carbon nanotubes in human bronchial epithelial and mesothelial cells in vitro. Toxicology, 2013. 313(1): p. 24-37.

39. Ursini, C.L., et al., Differences in Cytotoxic, Genotoxic, and Inflammatory Response of Bronchial and Alveolar Human Lung Epithelial Cells to Pristine and COOH-Functionalized Multiwalled Carbon Nanotubes. BioMed Research International, 2014. 2014: p. 359506.

40. Cao, Y., et al., Vascular effects of multiwalled carbon nanotubes in dyslipidemic ApoE-/- mice and cultured endothelial cells. Toxicol Sci, 2014. 138(1): p. 104-16.

41. Poulsen, S.S., et al., MWCNTs of different physicochemical properties cause similar inflammatory responses, but differences in transcriptional and histological markers of fibrosis in mouse lungs. Toxicol Appl Pharmacol, 2015. 284(1): p. 16-32.

42. Kim, J.S., et al., Persistent DNA damage measured by comet assay of Sprague Dawley rat lung cells after five days of inhalation exposure and 1 month post-exposure to dispersed multi-wall carbon nanotubes (MWCNTs) generated by new MWCNT aerosol generation system. Toxicol Sci, 2012. 128(2): p. 439-48.

43. Asakura, M., et al., Genotoxicity and cytotoxicity of multi-wall carbon nanotubes in cultured Chinese hamster lung cells in comparison with chrysotile A fibers. J Occup Health, 2010. 52(3): p. 155-66.

44. Darne, C., et al., Cytotoxicity and genotoxicity of panel of single- and multiwalled carbon nanotubes: in vitro effects on normal Syrian hamster embryo and immortalized v79 hamster lung cells. J Toxicol, 2014. 2014: p. 872195.

45. Muller, J., et al., Clastogenic and aneugenic effects of multi-wall carbon nanotubes in epithelial cells. Carcinogenesis, 2008. 29(2): p. 427-33. 
46. Wu, P., et al., Focal amplification of HOXD-harboring chromosome region is implicated in multiple-walled carbon nanotubes-induced carcinogenicity. Nano Lett, 2013. 13(10): p. 4632-41.

47. Li, X., Y. Peng, and X. Qu, Carbon nanotubes selective destabilization of duplex and triplex DNA and inducing B-A transition in solution. Nucleic Acids Res, 2006. 34(13): p. 3670-6.

48. Li, X., et al., Carboxyl-modified single-walled carbon nanotubes selectively induce human telomeric i-motif formation. Proc Natl Acad Sci U S A, 2006. 103(52): p. 19658-63.

49. Cortez, B.A. and G.M. Machado-Santelli, Chrysotile effects on human lung cell carcinoma in culture: 3-D reconstruction and DNA quantification by image analysis. BMC Cancer, 2008. 8: p. 181.

50. Cortez Bde, A., et al., The fate of chrysotile-induced multipolar mitosis and aneuploid population in cultured lung cancer cells. PLoS One, 2011. 6(4): p. e18600.

51. Ault, J.G., et al., Behavior of crocidolite asbestos during mitosis in living vertebrate lung epithelial cells. Cancer Res, 1995. 55(4): p. 792-8.

52. Gordon, D.J., B. Resio, and D. Pellman, Causes and consequences of aneuploidy in cancer. Nat Rev Genet, 2012. 13(3): p. 189-203.

53. Hanahan, D. and R.A. Weinberg, Hallmarks of cancer: the next generation. Cell, 2011. 144(5): p. 646-74.

54. Pitot, H.C., Multistage carcinogenesis--genetic and epigenetic mechanisms in relation to cancer prevention. Cancer Detect Prev, 1993. 17(6): p. 567-73.

55. Pitot, H.C., et al., Critical parameters in the quantitation of the stages of initiation, promotion, and progression in one model of hepatocarcinogenesis in the rat. Toxicol Pathol, 1989. 17(4 Pt 1): p. 594-611; discussion 611-2.

56. Sargent, L.M., et al., Single-walled carbon nanotube-induced mitotic disruption. Mutat Res, 2012. $745(1-2):$ p. 28-37.

57. Sargent, L.M., et al., Induction of aneuploidy by single-walled carbon nanotubes. Environ Mol Mutagen, 2009. 50(8): p. 708-17. 
58. Donaldson, K., et al., Pulmonary toxicity of carbon nanotubes and asbestos - similarities and differences. Adv Drug Deliv Rev, 2013. 65(15): p. 2078-86.

59. Mercer, R.R., et al., Distribution and persistence of pleural penetrations by multi-walled carbon nanotubes. Part Fibre Toxicol, 2010. 7: p. 28.

60. Mercer, R.R., et al., Extrapulmonary transport of MWCNT following inhalation exposure. Part Fibre Toxicol, 2013. 10: p. 38.

61. Takanashi, S., et al., Carcinogenicity evaluation for the application of carbon nanotubes as biomaterials in rasH2 mice. Sci Rep, 2012. 2: p. 498.

62. Muller, J., et al., Absence of carcinogenic response to multiwall carbon nanotubes in a 2-year bioassay in the peritoneal cavity of the rat. Toxicol Sci, 2009. 110(2): p. 442-8.

63. Varga, C. and K. Szendi, Carbon nanotubes induce granulomas but not mesotheliomas. In Vivo, 2010. 24(2): p. 153-6.

64. Takagi, A., et al., Dose-dependent mesothelioma induction by intraperitoneal administration of multi-wall carbon nanotubes in p53 heterozygous mice. Cancer Sci, 2012. 103(8): p. 1440-4.

65. Takagi, A., et al., Induction of mesothelioma in p53+/- mouse by intraperitoneal application of multi-wall carbon nanotube. J Toxicol Sci, 2008. 33(1): p. 105-16.

66. Sakamoto, Y., et al., Induction of mesothelioma by a single intrascrotal administration of multiwall carbon nanotube in intact male Fischer 344 rats. J Toxicol Sci, 2009. 34(1): p. 65-76.

67. Yu, K.N., et al., Differential toxic responses between pristine and functionalized multiwall nanotubes involve induction of autophagy accumulation in murine lung. J Toxicol Environ Health A, 2013. 76(23): p. 1282-92.

68. Rittinghausen, S., et al., The carcinogenic effect of various multi-walled carbon nanotubes (MWCNTs) after intraperitoneal injection in rats. Part Fibre Toxicol, 2014. 11(1): p. 59.

69. Nagai, H., et al., Intraperitoneal administration of tangled multiwalled carbon nanotubes of 15 $\mathrm{nm}$ in diameter does not induce mesothelial carcinogenesis in rats. Pathol Int, 2013. 63(9): p. 457-62. 
70. Nagai, H., et al., Diameter and rigidity of multiwalled carbon nanotubes are critical factors in mesothelial injury and carcinogenesis. Proc Natl Acad Sci U S A, 2011. 108(49): p. E1330-8.

71. Braakhuis, H.M., et al., Physicochemical characteristics of nanomaterials that affect pulmonary inflammation. Part Fibre Toxicol, 2014. 11: p. 18.

72. Johnston, H.J., et al., A critical review of the biological mechanisms underlying the in vivo and in vitro toxicity of carbon nanotubes: The contribution of physico-chemical characteristics. Nanotoxicology, 2010. 4(2): p. 207-46.

73. Ali-Boucetta, $\mathrm{H}$., et al., Cellular uptake and cytotoxic impact of chemically functionalized and polymer-coated carbon nanotubes. Small, 2011. 7(22): p. 3230-8.

74. Tsuruoka, S., et al., ROS evaluation for a series of CNTs and their derivatives using an ESR method with DMPO. Journal of Physics: Conference Series, 2013. 429(1): p. 012029.

75. Gernand, J.M. and E.A. Casman, A meta-analysis of carbon nanotube pulmonary toxicity studies--how physical dimensions and impurities affect the toxicity of carbon nanotubes. Risk Anal, 2014. 34(3): p. 583-97.

76. Sager, T.M., et al., Effect of multi-walled carbon nanotube surface modification on bioactivity in the C57BL/6 mouse model. Nanotoxicology, 2014. 8(3): p. 317-27.

77. Murphy, F.A., et al., Length-Dependent Retention of Carbon Nanotubes in the Pleural Space of Mice Initiates Sustained Inflammation and Progressive Fibrosis on the Parietal Pleura. American Journal of Pathology, 2011. 178(6): p. 2587-2600.

78. Poland, C.A., et al., Carbon nanotubes introduced into the abdominal cavity of mice show asbestos-like pathogenicity in a pilot study. Nature Nanotechnology, 2008. 3(7): p. 423-428.

79. Poulsen, S.S., et al., Multi-walled carbon nanotube physicochemical properties predict pulmonary inflammation and genotoxicity. Nanotoxicology, 2016. 10(9): p. 1263-75.

80. Mihalchik, A.L., et al., Effects of nitrogen-doped multi-walled carbon nanotubes compared to pristine multi-walled carbon nanotubes on human small airway epithelial cells. Toxicology, 2015. 333: p. 25-36. 
81. Yang, S.T., et al., Pharmacokinetics, Metabolism and Toxicity of Carbon Nanotubes for

Biomedical Purposes. Theranostics, 2012. 2(3): p. 271-282.

82. Tchoul, M.N., et al., Effect of mild nitric acid oxidation on dispersability, size, and structure of single-walled carbon nanotubes. Chemistry of Materials, 2007. 19(23): p. 5765-5772.

\section{Chapter 2}

\section{Genotoxicity of multi-walled carbon nanotubes at occupationally relevant doses}

Citation: Siegrist KJ, Reynolds SH, Kashon ML, Lowry DL, Dong C, Hubbs AF, Young S, Salisbury JL, Porter DW, Benkovic SA, McCawley MA, Keane M, Mastovich JT, Bunker KL, Cena LG, Sparrow MC, Sturgeon JL, Dinu CZ, Sargent LM. Genotoxicity of multi-walled carbon nanotubes at occupationally relevant doses. Particle and Fibre Toxicology, 2014, 11:6. PMID: 24479647

\section{Authors:}

Katelyn J Siegrist ${ }^{1}$

Steven H Reynolds ${ }^{1}$

Michael L Kashon ${ }^{1}$

David T Lowry ${ }^{1}$

Chenbo Dong ${ }^{2}$

Ann F Hubbs ${ }^{1}$

Shih-Houng Young ${ }^{1}$

Jeffrey L Salisbury ${ }^{3}$

Dale W Porter ${ }^{1}$

Stanley A Benkovic ${ }^{1}$

Michael McCawley ${ }^{4}$

Michael J Keane ${ }^{1}$

John T Mastovich ${ }^{5}$

Kristin L Bunker ${ }^{5}$

Lorenzo G Cena ${ }^{1}$

Mark C Sparrow ${ }^{5}$

Jacqueline L Sturgeon ${ }^{5}$

Cerasela Zoica Dinu ${ }^{2}$ 
Linda M Sargent ${ }^{1}$

\section{Affiliations:}

${ }^{1}$ National Institute for Occupational Safety and Health, Morgantown, WV 26505, USA

${ }^{2}$ Department of Chemical Engineering, Benjamin M. Statler College of Engineering and Mineral

Resources, West Virginia University, Morgantown, WV 26505, USA

${ }^{3}$ Department of Biochemistry, Mayo Clinic, 2001st Street NW, Rochester, MN 55905, USA

${ }^{4}$ Department of Occupational \& Environmental Health Sciences, West Virginia University, Morgantown, WV 26506, USA

${ }^{5}$ RJ Lee Group Inc, 300 Hockenberg Drive, Monroeville, PA 15146, USA 


\section{Abstract}

Carbon nanotubes are commercially-important products of nanotechnology; however, their low density and small size makes carbon nanotube respiratory exposures likely during their production or processing. We have previously shown mitotic spindle aberrations in cultured primary and immortalized human airway epithelial cells exposed to single-walled carbon nanotubes (SWCNT). In this study, we examined whether multi-walled carbon nanotubes (MWCNT) cause mitotic spindle damage in cultured cells at doses equivalent to 34 years of exposure at the NIOSH Recommended Exposure Limit (REL). MWCNT induced a dose responsive increase in disrupted centrosomes, abnormal mitotic spindles and aneuploid chromosome number 24 hours after exposure to 0.024, 0.24, 2.4 and $24 \mu \mathrm{g} / \mathrm{cm}^{2} \mathrm{MWCNT}$. Monopolar mitotic spindles comprised $95 \%$ of disrupted mitoses. Three-dimensional reconstructions of $0.1 \mu \mathrm{m}$ optical sections showed carbon nanotubes integrated with microtubules, DNA and within the centrosome structure. Cell cycle analysis demonstrated a greater number of cells in S-phase and fewer cells in the G2 phase in MWCNT-treated compared to diluent control, indicating a G1/S block in the cell cycle. The monopolar phenotype of the disrupted mitotic spindles and the G1/S block in the cell cycle is in sharp contrast to the multi-polar spindle and G2 block in the cell cycle previously observed following exposure to SWCNT. One month following exposure to MWCNT there was a dramatic increase in both size and number of colonies compared to diluent control cultures, indicating a potential to pass the genetic damage to daughter cells. Our results demonstrate significant disruption of the mitotic spindle by MWCNT at occupationally relevant exposure levels. 


\section{$\underline{\text { Introduction }}$}

Carbon nanotubes (CNT) are used in many consumer and industrial products including electronic devices, protective clothing, sports equipment and medical devices as well as vehicles for drug delivery [1-3]. Due to the wide variety of applications, the nanotechnology industry is predicted to grow to one trillion dollars by 2015 [4]. The low density and small size of carbon nanotubes make respiratory exposure likely during production and processing. Indeed, recent investigations have shown that carbon nanotubes can be aerosolized under workplace conditions [5-8]. Although carbon nanotubes have a large variety of applications, their potential health effects have not been fully investigated. The low density, fiber-like geometry and durability of carbon nanotubes are characteristics shared with asbestos $[9,10]$. Single-walled and multi-walled carbon nanotubes have been shown to enter cells and induce DNA damage, sister chromatid exchange, chromosome damage and micronuclei in vitro in human keratinocytes, human breast cancer cell lines, human lung cancer epithelial cells and immortalized mouse fibroblasts (Balb/3 T3 cells) [11-15]. Micronuclear formation can result from either a high level of chromosome damage or mitotic spindle disruption. Research by Di Giorgio et al., 2011 demonstrated significant chromosome breakage by analysis of chromosome spreads as well as DNA damage by the comet assay in a mouse macrophage cell line 24-48 hours after exposure to MWCNT $(10-25 \mathrm{~nm})$ and SWCNT $(0.7-1.2 \mathrm{~nm})$ material [16]. The carbon nanotube-exposed cells also had high levels of intracellular reactive oxygen species suggesting that carbon nanotubes can cause chromosome damage through reactive oxygen species [16]. Increased DNA damage due to oxygen radicals was also observed in imprinting control region mice (ICR) mice in vivo following intratracheal installation of 0.05 or $0.2 \mathrm{mg} \mathrm{MWCNT/mouse} \mathrm{[11].} \mathrm{Carbon} \mathrm{nanotubes} \mathrm{bind} \mathrm{to} \mathrm{DNA} \mathrm{at} \mathrm{G-C} \mathrm{rich} \mathrm{regions}$ in the chromosomes including telomeric DNA $[17,18]$. The interaction with the DNA results in a conformational change. DNA intercalation and telomeric binding can induce chromosome breakage suggesting that interaction of the nanotubes with the DNA may also be a source of chromosome damage. Recent investigations have shown that acid-washed single-walled carbon nanotubes of 1-4 $\mathrm{nm}$ in diameter and one micron in length induce centrosome fragmentation, multipolar mitotic spindles and errors in chromosome number in cultured immortalized and primary lung epithelial cells [19]. 
Furthermore, exposure of cancer cell lines to MWCNT of 5-10 nm diameter and one micron in length also results in multipolar mitotic spindles [20].

Mitotic spindle disruption and aneuploidy are a concern because these effects have been observed with the carcinogenic fiber, asbestos. In vitro investigations have demonstrated that chrysotile asbestos exposure causes multipolar mitotic spindles and a G2/M block similar to SWCNT and vanadium pentoxide exposure [19,21-24]. Asbestos exposure disrupts the mitotic spindle and causes aneuploidy through amplification of the centrosome $[21,22]$. By contrast, the mitotic disruption and aneuploidy resulting from vanadium pentoxide and SWCNT is associated with fragmented centrosomes [19,23]. Furthermore, in vitro examinations of asbestos and vanadium pentoxide potency have demonstrated that the disruption of the mitotic spindle and aneuploidy in cultured cells is strongly correlated with in vivo carcinogenesis [25-28]. Together these investigations indicate the importance of genotoxicity in carcinogenesis as well as validating the significance of culture models to predict carcinogenesis. To simulate aerosol exposures in the workplace, rodents have been exposed to high aspect ratio particles by inhalation, pharyngeal aspiration or intratracheal installation. In a manner similar to asbestos, rodent pulmonary exposure to biopersistant carbon nanotubes has been shown to result in lung inflammation, epithelial cell proliferation, cellular atypia and mutations in the K-ras gene [29-32]. The lung is the principal site of carbon nanotube deposition and toxicity following aspiration or inhalation $[31,33]$. In vivo investigations have demonstrated that carbon nanotube exposure can cause macrophages without nuclei as well as dividing macrophages connected by nanotubes [30,31]. Exposure of rats to the MWCNT by pharyngeal aspiration has been shown to result in micronuclei formation in Type II epithelial cells further indicating the potential for genetic damage [13]. Inflammation, cellular proliferation, cellular atypia, mitotic spindle disruption, centrosome fragmentation and errors in chromosome number are linked with the development of cancer [34-40]. Chronic exposures to asbestos particles which induce strong inflammatory, proliferative and genotoxic responses in the lung are associated with an increased incidence of lung cancer in rodents $[41,42]$. Although the lung is the key target organ for particle toxicity, high aspect ratio carbon nanotubes have been shown to 
translocate to the subpleural space indicating that the mesothelial cells are also a potential target $[43,44]$.

The overall objective of our study was to examine the role of CNT diameter in the nanotube-induced genetic damage using carbon nanotubes prepared with the same acid washing procedure and one micron length used in our previous studies to evaluate the potential genotoxicity of the narrower SWCNT $[24,45]$. Because vanadium pentoxide has been demonstrated to induce aneuploidy and mitotic spindle disruption through fragmentation of the centrosome, we selected vanadium as the positive control for genotoxicity. Immortalized and primary lung epithelial cells were examined for the potential of MWCNTs to cause aneuploidy, mitotic spindle disruption, centrosome fragmentation, and cell cycle distribution following exposure of primary and immortalized human epithelial cells to occupationally relevant doses of 10-20 nm diameter MWCNT. Primary cells were used in the assays since the normal karyotype made it possible to determine changes in chromosome number after exposure. The concentrations chosen for the current investigation were selected to be relevant to previous in vivo exposure doses of MWCNT of $10-40 \mu \mathrm{g} / \mathrm{mouse}(0.5 \mu \mathrm{g}, 1 \mu \mathrm{g}$, and $2 \mu \mathrm{g} / \mathrm{kg}$ respectively) reported by Porter et al. (2010) [30]. In brief, the mouse lung burdens per alveolar epithelial surface area of $500 \mathrm{~cm}^{2} /$ mouse lung [46] correspond to in vitro concentrations of $0.02-0.08$ $\mu \mathrm{g} / \mathrm{cm}^{2}$. The minimal in vitro dose of $0.02 \mu \mathrm{g} / \mathrm{cm}^{2}$ MWCNT would require 4 weeks of exposure at the Occupational Safety and Health Administration (OSHA) permissible exposure limit for particles with an aerodynamic diameter of 5 microns or less of $5 \mathrm{mg} / \mathrm{m}^{3}[47,48]$. NIOSH has recently reduced the REL from $7 \mu \mathrm{g} / \mathrm{m}^{3}$ to $1 \mu \mathrm{g} / \mathrm{m}^{3}$ [49]. Although exposure to concentrations of carbon nanotubes equivalent to the current NIOSH REL of $1 \mu \mathrm{g} / \mathrm{m}^{3}$ would require 34 years to yield a equivalent exposure of the 0.024 $\mu \mathrm{g} / \mathrm{cm}^{2}$, levels of MWCNT between 0.7 and $331 \mu \mathrm{g} / \mathrm{m}^{3}$ have been measured in workplace air [6,7,5052].

\section{$\underline{\text { Methods }}$}

\section{Multi-walled carbon nanotubes acid washing}

Multi-walled carbon nanotubes produced by chemical vapor deposition (Nanolab Inc. PD15L5-20) were acid-washed to remove iron catalyst. The MWCNT were suspended in a mixture of $3: 1 \mathrm{v} / \mathrm{v}$ sulfuric acid 
$\left(\mathrm{H}_{2} \mathrm{SO}_{4}\right)$ (Fisher Scientific, Pittsburgh, PA): nitric acid $\left(\mathrm{HNO}_{3}\right)(69.5 \%$, Fisher Scientific, Pittsburgh, PA)

for 1 hour in a water bath sonicator (Branson 2510, Fisher, Pittsburgh, PA) over ice. The mixture was subsequently diluted in deionized water $(2 \mathrm{~L})$ and filtered through a $0.2 \mu \mathrm{m}$ polycarbonate membrane filter (Millipore, USA); the filtration step was repeated 6 times to remove catalysts or impurities. All cell exposure experiments were performed with one hour acid-washed MWCNT materials.

\section{Characterization of MWCNT}

Atomic force microscopy (AFM) was used to investigate the length of both pristine and acid-washed MWCNT. Commercial Si tips (Asylum Research, AC240TS, USA) were used at their original resonance frequency, varying from 50 to $90 \mathrm{kHz}$. Pristine or acid-washed nanotubes $(10 \mu \mathrm{g} / \mathrm{ml})$ were deposited on mica surfaces (9.5 mm diameter, 0.15-0.21 thickness, Electron Microscopy Sciences, USA) and dried overnight under vacuum. Scans of $10 \mu \mathrm{m} \times 10 \mu \mathrm{m}$ were acquired using tapping mode in air. At least 30 individual MWCNTs were analyzed to determine their length.

Raman spectroscopy was used to characterize the structure of both pristine and acid-washed MWCNTs. Raman analyses were performed at room temperature using a Renishaw InVia Raman Spectrometer (CL532-100, $100 \mathrm{~mW}$, USA). The excitation source used an argon ion ( $\mathrm{Ar}^{+}$) laser operating at $514.5 \mathrm{~nm}$. MWCNT (pristine or acid-washed, $1 \mathrm{mg}$ ) were mounted on a clean glass slide (Fisher, Pittsburgh, PA) and a 20x microscope objective was used to focus the laser beam to a spot size of $<0.01 \mathrm{~mm}^{2}$ and to collect the scattered light. Low energy laser of $<0.5 \mathrm{mV}$ and an exposure time of $10 \mathrm{sec}$ were used to prevent unexpected heating effects of the MWCNT samples being analyzed. Detailed scans ranging from 100 to $3200 \mathrm{~cm}^{-1}$ were acquired.

The elemental analysis of the pristine and acid-washed carbon nanotubes was examined by energy dispersive X-ray spectroscopy (EDX). Both pristine and acid-washed MWCNT (1 mg/ml in water) were vacuum-dried on silica wafers. The experiments were performed using a Hitachi S-4700 Field Emission Scanning Electron Microscope (USA) and backscattered (BSE) electron detection in a single unit and operating at $20 \mathrm{kV}$.

ICP-MS was performed to further analyze the chemical composition of the nanotubes as described previously. Carbon nanotubes were suspended in pure $\mathrm{H}_{2} \mathrm{O}(18.2 \mathrm{M} \Omega-\mathrm{cm})$ at a concentration of 1.0 
$\mathrm{mg} / \mathrm{ml}$. One $\mathrm{ml}$ of each vortexed suspension was added to a $100 \mathrm{ml}$ polytetrafluoroethylene digestion tube (CEM, Matthews, NC) along with $9.0 \mathrm{ml}$ of ultrapure $\mathrm{HNO}_{3}$ and $1.0 \mathrm{ml}$ of ultrapure $\mathrm{H}_{2} \mathrm{O}_{2}$ (Fisher Optima, Fisher Scientific, Pittsburgh, PA). Three replicate samples for each nanotube type were digested in the Microwave-Assisted Reaction System (CEM, Matthews, NC) by ramping up to $200^{\circ} \mathrm{C}$ for 15 min., holding at $200^{\circ} \mathrm{C}$ for 30 minutes, then cooling to $22^{\circ} \mathrm{C}$, adapting a procedure as previously described [100]. There was no visible carbonaceous material remaining in any of the samples after digestion. After suspension $(1 \mathrm{mg} / \mathrm{ml})$, the metal content of the nanotubes was analyzed by ICP-MS using the Perkin-Elmer Nexion 300D [101], using ${ }^{54} \mathrm{Fe},{ }^{60} \mathrm{Ni}$, and ${ }^{59} \mathrm{Co}$ isotopes. Standards were certified multi-element standards in $1 \% \mathrm{HNO}_{3}$.

\section{Dispersity analysis}

The dispersity of pristine MWCNTs and acid-washed MWCNTs in Phosphate buffered Saline (PBS, Fisher, Pittsburgh, PA) was determined by centrifuging the corresponding suspensions (initial concentration $5 \mathrm{mg} / \mathrm{mL}$ for both pristine and acid-washed MWCNTs) at $3000 \mathrm{rpm}$ for $5 \mathrm{~min}$. Subsequently, $0.8 \mathrm{~mL}$ of the supernatant mixture was filtered through a $0.2 \mu \mathrm{m}$ filter membrane. After complete drying under vacuum, the amount of pristine MWCNTs or acid-washed MWCNTs on the filter membrane was measured and the dispersity was calculated based on the starting volumes. The obtained values do not reflect the saturation dispersity.

\section{Cell culture}

Two human respiratory epithelial cell populations were used to examine the potential genetic damage to MWCNT exposure. Immortalized human bronchial epithelial cells (BEAS-2B, ATCC, Manassas, VA) cultures of passage 4-6 were used to examine the mitotic spindle integrity. The high mitotic rate of the BEAS-2B cells allows examination of sufficient number of mitotic spindles following treatment. BEAS2B cells grown in serum enriched media double every 18-20 hours and have normal mitotic spindle morphology. The high mitotic index of the BEAS-2B cells made it possible to analyze a sufficient number of mitotic spindles during the 24 hour exposure. Primary small airway respiratory epithelial cells (SAEC; Lonza, Walkersville, MD) from a normal human donor were used to determine the response of a normal cell population. In addition, the normal karyotype of the primary cells was essential for the 
examination of aneuploidy. The SAEC cells double every 20-24 hours which allowed analysis of a potential change in chromosome number and centrosome morphology of cells that have divided during the 24 hour exposure. The low mitotic index of the SAEC cells $(0.5 \%)$ prevented the analysis of mitotic spindle integrity in this cell population. The BEAS-2B and SAEC cells were therefore analyzed 24 hours after exposure to allow a sufficient number of cells that have gone through division.

BEAS-2B cells were cultured in Dulbecco's Modified Eagle Medium (DMEM) media supplemented with 10\% serum (Invitrogen, Grand Island, NY). The SAEC cultures were cultured following manufacturer's directions and using Cabrex media (Lonza, Walkersville, MD). The cell cultures were examined by electron microscopy and cytokeratin 8 and 18 staining to verify the epithelial phenotype of the cells as described previously [102].

\section{Treatment protocol}

The immortalized BEAS-2B and the primary SAEC were exposed in parallel culture dishes to MWCNT or to the positive control, vanadium pentoxide (Sigma St. Louis, MO). Three independent experiments were performed for each exposure for SAEC and BEAS-2B respectively. MWCNT and vanadium control were suspended in media and sonicated over ice for 5 minutes and 30 minutes respectively. The cells were seeded in dishes and exposed $0,0.024,0.24,2.4$ and $24 \mu \mathrm{g} / \mathrm{cm}^{2} \mathrm{MWCNT}$ or to 0.031 $\mu \mathrm{g} / \mathrm{cm}^{2}$ vanadium pentoxide when the cells were $70 \%$ confluent. The one milliliter culture was treated with $0.024, .24,2.4$ and $24 \mu \mathrm{g} / \mathrm{ml}$ respectively. Twenty-four hours after exposure all cells were prepared for analysis of apoptosis and necrosis, integrity of the mitotic spindle, as well as the centrosome and chromosome number as described below.

\section{Viability and apoptosis}

Triplicate cultures were prepared in 96 well plates (Becton Dickinson Franklin Lakes, NJ) for the analysis of viability using the Alamar Blue bioassay (Invitrogen, Carlsbad, CA), following manufactures directions as described previously [24]. Eight wells were performed for each treatment and dose. Three independent experiments were performed for the analysis of cellular toxicity by Alamar Blue. Parallel cultures were also prepared in duplicate in one milliliter chamber slides (Nunc Rochester, NY) for the analysis of apoptosis using the TUNEL assay following the manufacturer's directions (Roche, Inc., 
Indianapolis, IN) with some modifications outlined previously [24]. A minimum of 100 cells were analyzed for each sample; experiments were repeated three times for a total of 300 cells for each treatment and dose, respectively for the analysis of apoptosis by the TUNEL assay. An additional positive control, 1.68 Molar DNase (Sigma St. Louis, MO) was used for the analysis of apoptosis. Twenty-four hours after dosing, cells in the chamber slides were fixed in $4 \%$ paraformaldehyde in phosphate buffer (Sigma St. Louis, MO) and stained with DAPI (Millipore Billerica, MA). The resulting stained samples were fluorescently analyzed using a Zeiss Axiophot fluorescent microscope (Carl Zeiss Microimaging Inc. Thornwood, NY).

\section{Mitotic spindle analysis}

BEAS-2B was cultured in 1 milliliter chamber slides as described previously. Dual chambers were prepared for each treatment and each cell type. Three independent experiments were prepared for each cell type and treatment [24]. A minimum of 100 cells of good centrosome and mitotic spindle morphology were analyzed for each sample; experiments were repeated three times for a total of 300 cells for each treatment and dose, respectively. The centrosome integrity as well as the dispersion of carbon nanotubes in the cell cultures was evaluated The spindle integrity of the BEAS-2B cells was examined using dual-label immunofluorescence for tubulin and centrin to detect the mitotic spindle and the centrosomes, respectively. Primary rabbit anti-beta tubulin (Abcam, La Jolla, CA, USA) and mouse anti-centrin antibodies (a generous gift from Dr. Jeff Salisbury), and secondary Rhodamine Red goat anti-rabbit IgG and Alexa 488 goat anti-mouse IgG antibodies (Invitrogen, Carlsbad, CA) were used. The mitotic spindle and centrosome morphology were analyzed in the BEAS-2B cells using a laser scanning confocal microscope (LSM 510, Carl Zeiss Microlmaging Inc., Thornwood, NY) as previously described [103]. Briefly, a monopolar or multipolar mitotic spindle was counted as disrupted. The location of MWCNT was determined by differential interference contrast. Because the nanotubes block the light, the nanotubes produce a black image. To determine the association of the MWCNT with the microtubules of the mitotic spindle and the centrosome, serial optical slices was obtained to create a zstack and permit three-dimensional reconstruction using LightWave software [104] by TEM following methods outlined previously [103]. Briefly, cells were fixed in $2 \%$ glutaraldehyde in sodium phosphate 
buffer, $\mathrm{pH} 7.2$, for $2 \mathrm{~h}$, postfixed in osmium tetroxide, dehydrated through an ethanol series, and embedded in Spurr's resin (Sigma, St Louis, MO). Silver-gold sections were stained in $2 \%$ aqueous uranyl acetate and Reynolds' lead citrate, observed using a JEOL 1200 EX electron microscope and recorded digitally.

\section{Chromosome number by fluorescence in situ hybridization (FISH)}

Due to the necessity of a normal diploid karyotype for the analysis of chromosome number, the SAEC cells were prepared for analysis of the chromosome number. Fluorescence in situ hybridization (FISH) for human chromosomes 1 and 4 was used to determine the chromosome number (Abbott Molecular, Des Plaines, IL) according to the guidelines of the American College of Medical Genetics [105]. Three independent experiments for a total of 300 cells were evaluated for each treatment and dose. A minimum of 100 interphase cells of good FISH morphology were analyzed to determine the number of chromosome 1 and 4. The SAEC cells were photographed using a Zeiss Axiophot microscope and Genetix Cytovision software. Cells with three copies or greater than 4 copies of chromosome 1 or 4 were recorded as a gain for that chromosome. Cells with less than two copies of chromosome 1 or 4 were recorded as a loss of that chromosome. The loss and gain of both chromosomes were added to obtain the errors in chromosome number (aneuploidy).

\section{Colony formation}

Triplicate cultures of SAEC cells were grown in T25 flasks. When the cells were $70 \%$ confluent they were treated with MWCNT. After 24 hours, the cells were trypsinized, counted and plated at 500 cells/well in 6-well plates for analysis of colony formation. One month following exposure, the cells were washed with PBS, stained with $10 \%$ crystal violet solution in neutral buffered formalin (Sigma, Saint Louis, MO) and colonies counted.

\section{Cell cycle analysis for DNA content}

BEAS-2B cells were grown in six parallel T25 flasks. A total of 9 independent experiments were performed for the analysis of cell cycle. Twenty-four hours after exposure to $24 \mu \mathrm{g} / \mathrm{cm}^{2} \mathrm{MWCNT}$ or to the positive control, $5 \mu \mathrm{M}$ arsenic (Sigma, St Louis MO), the cells were washed twice with PBS and removed from the dishes with $0.25 \%$ trypsin prior to detection of the cell cycle. The cells were stained 
according to (Invitrogen) manufacturer's instructions. EdU (5-ethynyl-2'-deosyuridine) is a nucleoside analog of thymidine and is incorporated into DNA during active DNA synthesis. Detection is based on a click reaction- a copper catalyzed covalent reaction between an azide and an alkyne. Twenty-four hours after exposure to MWCNT, the cells were washed twice with PBS and incubated with EdU for 2 hours to detect cells in S-phase. Following incubation, the cells were removed from the plate using 0.25\% trypsin. After fixation and Click-iT Saponin permeabilization, $\mathrm{CuSO}_{4}$ was added to the cells to detect the EdU signal. The total amount of DNA was analyzed following incubation with 7AAD (7aminoactinomycin D) using a LSR II flow cytometer (BD Biosciences Immunocytometry Systems, San Jose, CA). Data were analyzed and plotted using FlowJo v7.2.5 software.

\section{Statistical analysis}

All analyses were performed using SAS/STAT (Version 9.3) for Windows. Chi-square analysis was used to determine statistical significance for the scoring of the mitotic spindle abnormalities and the number of cells with abnormal chromosome number. The number of viable and apoptotic cells were analyzed using analysis of variance (ANOVA). The mean of duplicate samples were used for the analysis. For cell cycle analysis, a mixed model ANOVA was used to compare the proportion of cells in $\mathrm{G} 1, \mathrm{~S}$ and $\mathrm{G} 2 / \mathrm{M}$ phase across treatment groups. Experimental block was utilized as a random factor. All differences were considered statistically significant at $p<0.05$.

\section{$\underline{\text { Results }}$}

\section{Characterization of carbon nanotubes}

Raman spectroscopy was used to characterize the structure of pristine and acid-washed MWCNTs and to determine the degree of MWCNTs functionalization after acid treatment. Figure $1 \mathrm{~A}$ shows the Raman spectra of pristine and acid-washed MWCNT. There are 4 bands identified in both pristine and acid-washed MWCNTs samples, i.e. D band around $1350 \mathrm{~cm}^{-1}$ that reflects the level of disorder in the sample, the $\mathrm{G}$ band around $1585 \mathrm{~cm}^{-1}$ indicative of the high degree order and well-structured samples, the G' band around $2690 \mathrm{~cm}^{-1}$ representing the binary disordered band and lastly the peak around 2930 $\mathrm{cm}^{-1}$ indicative of the oxidation level of the sample being characterized. As shown, the D band was wider and had a higher frequency for the acid-washed sample when compared to the pristine 
MWCNTs. The shift in the D band indicates that the acid treatment minimally altered the chemical structure of MWCNTs by disrupting the structured walls and introducing additional functional groups (carboxylic acid groups) [53]. For the acid-washed MWCNTs there was also a shift of G' band towards higher frequency; this may be due to the removal of metal catalysts, increase in the number of functional groups having electron accepting ability and decrease in the amorphous carbon. The ratio of intensity of $D$ to $G$ peaks indicate the degree of functionalization [54-56] and was 0.59 for pristine and 0.81 for $1 \mathrm{hr}$. acid-washed MWCNTs. This also confirms that the acid treatment increased the number of functional groups (i.e. free carboxylic acid groups) on the walls of the MWCNTs samples. Energy dispersive X-ray spectroscopy (EDX) confirmed the increase in the oxygen content due to the acid treatment and thus the increase in the MWCNTs degree of functionalization with free carboxylic acid groups as shown in Supplementary Figure 1. Further, the acid washing also reduced the catalyst content in the sample (Fe, 0.81). The content of the iron, cobalt and nickel were further analyzed by inductively coupled plasma-mass spectrometry (ICP-MS). Specifically, the MWCNT by ICP-MS contained $0.03 \% \mathrm{Fe} \pm 0.001,0 \%$ cobalt, and $0 \%$ Nickel [57].

The length distribution of pristine and $1 \mathrm{~h}$ acid-washed MWCNT respectively is shown in Figure 1B (at least 30 individual MWCNTs were measured for each sample). AFM analysis showed that pristine MWCNT samples had an average length of $5499 \pm 3009 \mathrm{~nm}$ while $1 \mathrm{~h}$ acid-washed MWCNTs had an average length of $825 \pm 585 \mathrm{~nm}$ respectively indicating that acid treatment led to shortening of the nanotubes. The pristine and acid washed MWCNT had a diameter of $15 \pm 5 \mathrm{~nm}$. Moreover, acid washing also increased nanotube solubility in DMEM + FBS by two-fold compared to pristine MWCNT [58] as a result of the addition of the free carboxylic acid groups [2].

\section{Mitotic spindle disruption}

Two human epithelial cell populations were examined to determine whether MWCNT induced genetic damage. Immortalized respiratory epithelial cells (BEAS-2B) were used to determine the effects of MWCNT on the mitotic spindle. Primary respiratory epithelial cells (SAEC) were included in the analysis to determine whether MWCNT induced errors in chromosome number. Treatment with acid-washed MWCNT induced a dose dependent mitotic spindle disruption (Figure 2A). The disrupted mitotic 
spindles were predominantly monopolar (Figure $2 \mathrm{~B}$ ). Figure $2 \mathrm{C}$ shows a $20 \mathrm{X}$ photomicrograph of the cultured cells with three monopolar mitotic spindles in one 40X field. Only 5-10\% of the disrupted mitotic spindles were multipolar (Figure 2D).

\section{Chromosome number}

Primary SAEC cells from a normal donor were used to investigate the effects of MWCNT on the chromosome number. The normal karyotype of the primary cells made it possible to evaluate the treatment related changes in chromosome number. FISH analysis for either chromosome 1 or 4 demonstrated a $2.25 \pm 1.0 \%$ aneuploidy in the untreated SAEC cells (Table 1 ). The frequency of the cells with abnormal chromosome number is within the range reported in adult human cells in culture $[59,60]$. By contrast, the MWCNT-treated SAEC cells had a level of aneuploidy that was comparable to the vanadium pentoxide-treated positive control cells (Figure 2D; Table 1). Abnormal chromosome number was significantly elevated following MWCNT treatment as follows: $62 \pm 7.0 \%, 24 \mu \mathrm{g} / \mathrm{cm}^{2} ; 59.0$ $\pm 6.0 \%, 2.4 \mu \mathrm{g} / \mathrm{cm}^{2} ; 49 \pm 6.0 \%, 0.24 \mu \mathrm{g} / \mathrm{cm}^{2}$ and $42 \pm 10 \%, 0.024 \mu \mathrm{g} / \mathrm{cm}^{2}$ compared with control incidence of $2.25 \pm 1.0 \%$. Treatment with $0.31 \mu \mathrm{g} / \mathrm{cm}^{2} \mathrm{~V}_{2} \mathrm{O}_{5}$ resulted in $67 \pm 6.0 \%$ aneuploid cells. The chromosome alterations in the MWCNT treated cells were predominantly gains of either chromosome 1 or 4 (Table 1). The chromosome losses accounted for $24 \%, 24 \mu \mathrm{g} / \mathrm{cm}^{2} ; 13 \%, 2.4 \mu \mathrm{g} / \mathrm{cm}^{2} ; 8 \%, 0.24$ $\mu \mathrm{g} / \mathrm{cm}^{2}$ and $12 \%, 0.024 \mu \mathrm{g} / \mathrm{cm}^{2}$. Chromosomal gains accounted for over $70 \%$ of the aneuploidy (Table 1). There was also a dose-dependent increase in the number of cells with gains of both chromosomes 1 and 4 indicating an increase in polyploid cells. The number of alterations of chromosome 1 was not statistically different than the alterations of chromosome 4, therefore; there was not a bias for a change of either chromosome.

\section{Interaction of carbon nanotubes with mitotic spindle apparatus}

The MWCNTs were 10-20 nanometers in width. Nanotubes of 10 nanometers or greater can be observed using differential interference contrast imaging. MWCNTs were observed in the cytoplasm and the nucleus (Figure 3A). The MWCNTs also had a strong association with the centrosomes as shown in Figure 3B. The high frequency of monopolar mitotic spindles allowed confirmation of the monopolar phenotype by transmission electron microscopy (TEM) as shown in Figure 3C. The 3D 
reconstructed image demonstrates strong physical associations between the carbon nanotubes, the microtubules and DNA and the centrosomes (4A-B). The 3D reconstruction further demonstrated that MWCNTs not only associated with the centrosome but inside the centrosomal structure (Figure 4C).

\section{Viability and clonal growth}

Exposure to MWCNT did not reduce viability 24 hours after treatment in either the primary SAEC or the immortalized BEAS-2B cells (Figure 5A). Vanadium pentoxide treatment resulted in reduced viability in both SAEC and the BEAS-2B cells. Seventy-two hours following exposure, the viability of the SAEC cells was significantly reduced in cells exposed to $0.024,0.24,2.4$ or $24 \mu \mathrm{g} / \mathrm{cm}^{2}$ MWCNT (Figure 5 B). Three weeks following exposure, the BEAS-2B cells had a small increase in colony formation at 0.024 $\mu \mathrm{g} / \mathrm{cm}^{2}$ (Figure $5 \mathrm{C}$ ). One month following exposure, the SAEC cells had a reduced number of colonies at the highest dose; however, exposure to $0.024,0.24$ and $2.4 \mu \mathrm{g} / \mathrm{cm}^{2}$ resulted in a dramatic increase in colony formation (Figure 5C).

\section{Cell cycle}

The impact of MWCNT-treatment on the cell cycle was evaluated by Click-iT EdU Flow Cytometry assay. Treatment with $24 \mathrm{ug} / \mathrm{cm}^{2}$ MWCNT induced a statistically significant increase in the percent of cells in S phase from $32.11 \%$ (PBS-treated) to $40.1 \%$ (Table 2). When the cells in G2 phase of the cell cycle were compared, exposure to the positive control, arsenic, resulted in $32.1 \%$ of the cells in G2 compared to $18.30 \%$ of the cells in the PBS control group thus indicating an arsenic-induced block in G2 (Table 2, p <.05).

\section{Discussion}

Since their discovery in 1991 [61] carbon nanotubes have been used for a variety of applications including fiber optics [62], conductive plastics, molecular electronics as well as biological and biomedical applications [63]. Although the durability and fiber-like structure of carbon nanotubes have raised concerns that carbon nanotubes may have effects similar to asbestos, the health effects have not been fully investigated $[64,65]$. Our data reported here are the first to show induction of monopolar mitotic spindles, aneuploidy, and a G1/S block in the cell cycle as well as a dramatic increase in colony formation following exposure to $10-20 \mathrm{~nm}$ diameter MWCNT. Exposure to $0.024 \mu \mathrm{g} \mathrm{MWCNT/ \textrm {cm } ^ { 2 }}$ 
resulted in errors in chromosome number and mitotic spindle aberrations in greater than $40 \%$ of the cells examined. The dramatic increase in MWCNT-induced colony formation and aneuploidy observed in the primary SAEC cells was significantly higher than was previously observed in SWCNT-treated cells. The proliferation of cells with a high degree of genetic damage could result in the expansion of a population of genetically-altered cells. Cell proliferation is important in the second stage of pulmonary carcinogenesis, tumor promotion, while genetic instability is observed during the progression of preneoplastic cells to frank neoplasia [40,66]. During the progression of neoplastic disease, centrosome disruption is observed. The degree of centrosome disruption and aneuploidy is important because it is correlated with tumor stage [67-69].

The level of centrosome fragmentation, mitotic spindle damage and aneuploidy following MWCNT exposure was similar to the effects of the known carcinogen and positive control, vanadium pentoxide. MWCNTs were found in association with the DNA, the microtubules, the centrosomes as well as inside the centrosome structure. A previous investigation has shown that MWCNT are incorporated into the microtubules during polymerization thus forming a microtubule/nanotube hybrid [70]. The mitotic disruption that was observed following exposure to MWCNT may be due to a number of factors including incorporation of the nanotubes into the centrosome and microtubules of the mitotic spindle resulting in failed cytokinesis, failed centrosome duplication or inhibited centrosome separation. If two spindle poles are not formed during cell division, the chromosomes are not divided equally and chromosome errors occur.

Exposures that induce monopolar mitotic spindles produce daughter cells that fail to undergo cytokinesis and have double the number of chromosomes (polyploid) [71-73]. Although the data from the current investigation demonstrated that the aneuploidy was predominantly due to a gain of chromosomal material or polyploidy, the chromosomes were also lost in a significant number of cells suggesting that the genetic damage was due to more than a failure of cytokinesis. Akasura et al. (2010) observed polyploid cells in cancer cell lines following exposure to 0.25 to $50 \mu \mathrm{g}$ MWCNT of $80 \mathrm{~nm}$ diameter [74]. Although detailed analysis of chromosome loss and gain was not possible in a cancer cell line, the study demonstrated a significant number of polyploid cells which they attributed to a failure 
of cytokinesis. Carbon nanotubes have been observed in the bridge separating dividing cells [75]. Three dimensional reconstruction of MWCNT-exposed cells in the current study and of previously published SWCNT-exposed mitotic figures have shown carbon nanotubes integrated with the microtubules, the DNA and within the centrosome structure $[19,24]$. The disruption of cell division that has been observed following carbon nanotube exposure may be due to the incorporation of the carbon nanotubes into the microtubules that make up the division apparatus.

In this study, we observed fragmented centrosomes clustered into a single pole. These results are in sharp contrast to the multipolar mitotic spindles that have been observed with narrower SWCNT $[19,20]$.

Centrosomes are duplicated in early $\mathrm{G} 1 / \mathrm{S}$ of the cell cycle. The separation of the mother and daughter centrosomes by proteolytic enzymes is necessary for the exit from $S$ phase and the formation of a bipolar mitotic spindle [76]. Incorporation of the stiff MWCNT into the centrosome may have resulted in a more rigid centrosomal structure which fractured during mitosis. In addition, the integration of the nanotubes into the centrosome structure could have prevented the proteolysis of the linker connecting duplicated mother and daughter centrioles in $\mathrm{G} 1 / \mathrm{S}$ thereby preventing the centrosome separation necessary for the formation of a bipolar spindle [76]. Furthermore the excess of cells in the S phase and significantly lower number of cells in the G2 phase in the MWCNT-treated compared to the control cells in the current investigation indicate a G1/S block and a failure to progress to $\mathrm{G} 2$. Interaction of the nanotubes into the microtubules would potentially impact many cellular process including cellular transport of organelles (lysosomes, mitochondria, Golgi apparatus and endoplasmic reticulum), RNA and protein transport as well as phagocytosis and cell movement [77]. Kinesin and dynein motors move the organelles, chromosomes, proteins and RNA. Defects in the microtubule surface have been reported to result in detaching of the motors from the microtubule and interruption of cell signaling [7780]. Aberrant cell signaling is a concern because it is important in the progression of carcinogenesis [81-83].

Although both SWCNT and MWCNT had a strong association with the microtubules that make up the mitotic spindle and induced aberrant mitotic spindles, the data suggests that the type of damage may 
be determined by the diameter of the carbon nanotubes. SWCNT of 1-2 nm in diameter [45], MWCNT of 5-10 nm [20] and the NanoLabs 10-20 nm MWCNT form hybrids with microtubules [70]. Both the SWCNT and the 10-20 nm MWCNT are incorporated into the centrosome structure. The stiffness of the nanotubes is determined by their diameter [84]. Although, carbon nanotubes have similar mechanical properties to the microtubules, the stiffness of the carbon nanotubes is a thousand-fold greater than that of the microtubules [84]. The incorporation of the more rigid MWCNT into the microtubules that make up the mitotic spindle fibers and the centrosome may reduce the elasticity of the mitotic spindle apparatus to a greater degree than the SWCNT. The elasticity of the mitotic apparatus is a critical factor in the separation of the centrosomes to organize two spindle poles as well as in the separation of the chromosomes during cell division [85].

Evidence from rodent exposure studies has demonstrated that high aspect ratio nanoparticles have carcinogenic properties $[9,64,86,87]$. Inhalation exposure is the route that most closely resembles occupational exposure. The lung is the principal target organ for carbon nanotube exposure [43]. The long thin carbon nanotubes induce inflammation, cell proliferation of type II epithelial cells and cellular atypia $[30,31,33]$. Recent investigations have shown that inhaled MWCNT migrate to the subpleural wall $[44,88]$. The fiber-like structure, evidence of carbon nanotube-induced inflammation, proliferation and cellular atypia in the lung as well as migration to the subpleural space, inflammation, macrophage injury and evidence of genotoxic damage have raised concerns that the material has carcinogenic properties similar to asbestos $[44,64,89]$. The lung and parietal pleura are the sites of asbestos-induced carcinogenesis [64,90-93]. Injection of high doses of $100 \mathrm{~nm}$ diameter MWCNT into the abdominal cavity of p53 +/- mice has been shown to induce mesothelioma on the surface of the diaphragm [94]. In a more recent investigation of p53 +/- mouse exposure, Takagi et al. demonstrated a dose response of mesothelioma development after peritoneal injection of 3-300 micrograms of Mitsui-7 MWCNT [95]. Nagi et al. investigated the role of nanotube diameter in the development of mesothelioma in a rat model [96]. Greater inflammation and mesothelioma development were observed with the $50 \mathrm{~nm}$ diameter Mitsui-7 MWCNT of 10 microns or less in length compared to nanotubes of $145 \mathrm{~nm}$ diameter and similar length [96]. The mouse studies were criticized due to the route of exposure and the 
sensitivity of the genetically modified p53 knock-out mouse strain; however, the induction of mesothelioma was significant. The demonstration of mesothelioma at high exposures combined with our findings revealing disruption of the integrity of the division apparatus further suggest a carcinogenic potential for MWCNT. A manuscript in press by Sargent et al. has demonstrated that inhaled Mitsui-7 MWCNT material promoted the formation of lung adenocarcinomas in B6C3F1 hybrid mice following 3methylcholanthrene (MCA) initiation [97]. While the data did not indicate tumor initiation by MWCNT, the exposure resulted in lung adenocarcinoma and adenoma in $90.5 \%$ of the mice exposed to MCA followed by inhaled MWCNT. The mouse lung tumors were large and $15 \%$ of the tumors were metastatic indicating tumor progression with some forms of MWCNT. Furthermore, the strong MWCNTinduced tumor promotion was observed in a hybrid mouse that is intermediate in sensitivity to lung cancer $[98,99]$. The exposure dose of the tumor promotion study of $32 \mu \mathrm{g} / \mathrm{mouse}$ is only 2.6 fold higher than the dose of the current in vitro investigation that shows significant chromosomal and mitotic spindle effects at the lowest administered dose of $0.024 \mu \mathrm{g} / \mathrm{cm}^{2}$ [19]. Although lung cancer or mesothelioma have not been observed in humans exposed to MWCTs, centrosome disruption, aneuploidy and mitotic spindle aberrations as well as recent data indicating mesothelioma as well as lung tumor promotion and progression are a concern and indicate that caution should be used to prevent respiratory exposure to workers during the production or use of commercial products.

\section{Competing interests}

The authors declare that they have no competing interests.

\section{Author's contributions}

KJS contributed to the study design, writing of the manuscript, conducted experiments and analyzed FISH signals. LMS conceived of and designed the study, analyzed the experimental results and drafted the manuscript. SHR and MLK contributed to the experimental design, acquisition of funding and writing of the manuscript. MLK also analyzed the data for statistical significance. DTL contributed to the study design, conducted the experiments as well as contributed to the analysis of the data. CD acid washed the MWCNT and performed analysis of the material. AFH contributed to the study design and writing of the manuscript and acquisition of funding. JLS was involved in acquisition of funding and writing of the 
manuscript. DWP contributed to the study design and calculations of the dose for exposure. CZD contributed to the preparation and characterization of the MWCNT and drafting the description of the manuscript. MK performed ICP-MS and drafting of the manuscript. JM, KB, MS and JS contributed to writing of the manuscript and materials characterization. LC assisted with MWCNT characterization and photography, writing of the manuscript and preparation of the figures. All authors read and approved the final manuscript.

\section{Acknowledgements}

The authors would like to thank Mike Gipple, Scientific Arts, LLC, Morgantown, WV for his help with three dimensional reconstructions, Kimberly Clough-Thomas for her help with the images and Adrienne McGraw, WVU for her help with scanning electron microscopy imaging. This work was supported by NIOH NORA $9927 Z 8 V$ and NSF EPS-1003907.

\section{Disclaimer}

Research findings and conclusions are those of the authors and do not necessarily represent the views of the National Institute for Occupational Safety and Health. 


\section{Figure and table legends}

Figure 1: A. The figure is a histogram of the Raman spectra of pristine (black) and one hour acidwashed carbon nanotubes (red). Four independent bands have been identified for both samples, i.e., D band around $1350 \mathrm{~cm}-1$, G band at $1585 \mathrm{~cm}-1$, G' band around $2690 \mathrm{~cm}-1$, and an additional band around $2930 \mathrm{~cm}-1$. Shifts in these bands are noticed for samples that have been treated with acid for 1

h. B. Histograms of length distribution of pristine (a) and $1 \mathrm{~h}$ acid-washed MWCNTs (b) as identified by tapping mode Atomic force microscopy (AFM). At least 30 nanotubes have been analyzed for each one of the samples. C. A representative bright-field image and Figure 1D shows the corresponding darkfield image of the MWCNT sample. The images demonstrated that the MWCNTs have a diameter of 10-20 nm and a typical multi-walled tubular morphology. D shows representative dark-field STEM (DFSTEM) image of the native MWCNT sample that was acquired. The analysis demonstrated low amounts of the iron catalyst. $\mathbf{E}$ shows a representative bright-field image and $\mathbf{F}$ shows the corresponding dark-field image of the MWCNT sample. The dark-field image provides atomic number contrast information. The bright $10 \mathrm{~nm}$ particle at the end of the MWCNT in F is a catalyst particle. Energy dispersive X-ray spectroscopy (EDS) showed that the catalyst particle was iron-rich. Further analysis of the MWCNT sample identified low amounts of the iron catalyst.

Figure 2: A: The bar graph demonstrates the mitotic disruption 24 hours following exposure to MWCNT. Mitotic spindle abnormalities are expressed as a percent of total mitotic figures. The abnormalities are separated into monopolar and multipolar mitotic spindles. The multipolar spindles include tripolar and quadrapolar mitotic spindles. * indicates significantly different from the unexposed control cells at $p<.01 ; \pm$ standard deviation. B: The bar graph demonstrates the distribution of the mitotic spindle abnormalities in BEAS-2B cells following exposure to MWCNT. The white bars indicate the percent of mitotic cells with one mitotic spindle pole. The solid bars indicate the percent of total mitotic cells that had a multipolar mitotic spindle apparatus. The grey bars indicate the percent of mitotic cells with either a multipolar mitotic spindle or a monopolar mitotic spindle to show the percent of cells with any disruption of the mitotic spindle apparatus. *indicates significance at $p<0.01$.; \pm standard 
deviation. 2C: The photomicrograph of a culture exposed to $0.24 \mu \mathrm{g} / \mathrm{cm}^{2} \mathrm{MWCNT}$ using a $40 \mathrm{X}$ objective. The yellow arrows indicate monopolar mitotic spindles. This figure demonstrates the typical monopolar phenotype of the cultures following exposure to MWCNT. D: The bar graph demonstrates the percent of SAEC with an aneuploid chromosome number after a 24 hour exposure to MWCNT or the positive control $\mathrm{V}_{2} \mathrm{O}_{5}$. The solid bars indicate the level of apoptosis in the exposed and control BEAS-2B. The hatched bars indicate the level of apoptosis in the exposed SAEC. MWCNT exposure induced a dramatic elevation of chromosome loss and gain at all doses of exposure at levels equal to the positive control $\mathrm{V}_{2} \mathrm{O}_{5} .{ }^{*}$ indicates significantly different from the unexposed control cells at $\mathrm{p}<.05$.

Table 1: The distribution of the aneuploidy that was contributed by chromosome 1 and by chromosome 4 is detailed in the table as "Total\% aneuploid cells". The percent of cells with a gain in chromosome 1 and/or of chromosome 4 are indicated in the table under "Gain" of each chromosome. Cells with both chromosomes gained are indicated by "Gain of both chromosomes". Cells with a loss of chromosome 1 and/or chromosome 4 are indicated in the table under "Loss" of each chromosome. *: $p$ $<0.05$ of the treated cells compared to diluent control exposed cultures; \pm standard deviation.

Figure 3: The photographs in A-C show a monopolar mitotic spindle with one pole rather than the two poles which would be expected in a normal cell. The details of the detection protocol for the mitotic spindle components and the photography using the Zeiss Confocal are in the methods section. The tubulin in $\mathbf{A}$ was stained red using Spectrum red and indirect immunofluorescence. The DNA was detected by DAPI and was blue. The nanotubes were imaged using differential interference contrast and are black. B: The nanotubes can be seen in the nucleus, in association with microtubules, the DNA and the centrosome. Serial optical sections at 0.1 micron intervals using confocal microscopy confirmed the location of the nanotubes in the nuclear DNA and the tubulin including the microtubules of the mitotic spindle. C: A high resolution TEM of a monopolar mitosis. The image was photographed at 11000X magnification.

Figure 4: A: This 3-dimension reconstruction was created from serial optical laser scanning confocal microscopy sections using immunofluorescence to identify centrosomes and microtubules while 
differential interference contrast was used to visualize aggregated MWCNT as previously described [24]. Briefly, nanotubes of 10 nanometers or greater could be visualized by their interference with transmitted light using DIC imaging. Because the nanotubes block the light, the nanotubes produce a black image. The reconstructed image shows aggregated nanotubes which appear as irregular tangled black structures located inside the cell in association with the centrosomes (green), the microtubules (red) and the DNA (blue). In this cell, the one spindle pole, the doughnut shaped DNA arrangement and the disruption of microtubule attachments to clustered centrosome fragments into a monopolar spindle apparatus suggest major perturbations in cell division. The yellow arrows indicate nanotubes in association with mitotic spindle and the DNA. B: The yellow arrows indicate the nanotubes (black) in association with the centrosomes (green) and the microtubules (red). C: The yellow arrows indicate nanotubes (black) inside the centrosome structure (green).

Figure 5: A: The bar graph represents viability of BEAS-2B and SAEC cells 24 hours following exposure to MWCNT or $\mathrm{V}_{2} \mathrm{O}_{5}$. The white bar indicates viability of BEAS-2B cells. The black bar indicates viability of SAEC cells. The viability was not reduced in either the BEAS-2B or the SAEC cells. Figure 5B: The bar graph represents the viability of BEAS-2B and SAEC cells 72 hours following exposure to MWCNT. The white bar indicates the viability of BEAS-2B cells and the black bar indicates viability of SAEC cells. MWCNT exposure resulted in reduced viability in the SAEC and the BEAS-2B at 0.024 , 0.24, 2.4 and $24 \mu \mathrm{g} / \mathrm{cm}^{2}$ compared to control cells. The exposure to $\mathrm{V}_{2} \mathrm{O}_{5}$ resulted in reduced viability in SAEC treated cells at all doses. * indicates statistical significance of the treated cells compared to control cells at $p<0.05$. Figure $5 \mathrm{C}$ : The bar graph demonstrates the clonal growth in BEAS-2B cells 3 weeks following MWCNT exposure and SAEC cells 4 weeks following exposure. The black bars indicate the mean number of colonies of BEAS-2B cells and the white bars indicate mean number of colonies in SAEC cells. *indicates significance at $p<0.05$ of treated cells.

Table 2: The table demonstrates the mean of percent of cells in $\mathrm{G} 1, \mathrm{~S}$ and $\mathrm{G} 2$ phase of the cell division 24 hours following treatment with media, $5 \mu \mathrm{M}$ arsenic or to $24 \mu \mathrm{g} / \mathrm{cm}^{2} \mathrm{MWCNT}$. The data is based on replicates of 6 that were repeated in 9 independent experiments. 
*: $p<0.05$ of the treated cells compared to diluent control exposed cultures.

Supplementary figure 1: Metal composition of Pristine and Acid-washed MWCNT. The histogram demonstrates the metal composition of the $1 \mathrm{~h}$ acid-washed MWCNTs as measured by energy dispersive X-ray spectroscopy (EDX). 


\section{References}

1. De Volder MF, Tawfick $\mathrm{SH}$, Baughman $\mathrm{RH}$, Hart AJ: Carbon nanotubes: present and future commercial applications. Science 2013, 339:535-539.

2. Liu J, Rinzler AG, Dai HJ, Hafner JH, Bradley RK, Boul PJ, Lu A, Iverson T, Shelimov K, Huffman CB, et al: Fullerene pipes. Science 1998, 280:1253-1256.

3. McAllister K, Sazani P, Adam M, Cho MJ, Rubinstein M, Samulski RJ, DeSimone JM: Polymeric nanogels produced via inverse microemulsion polymerization as potential gene and antisense delivery agents. J Am Chem Soc 2002, 124:15198-15207.

4. Bradley J, Nordan MM, Tassinari O: The Recession's Ripple Effect on Nanotech, Book The Recession's Ripple Effect on Nanotech. Boston, MA: Lux Research, Inc; 2009.

5. Erdely A, Dahm M, Chen BT, Zeidler-Erdely PC, Fernback JE, Birch ME, Evans DE, Kashon ML, Deddens JA, Hulderman $\mathrm{T}$, et al: Carbon nanotube dosimetry: from workplace exposure assessment to inhalation toxicology. Part Fibre Toxicol 2013, 10:53.

6. Han JH, Lee EJ, Lee JH, So KP, Lee YH, Bae GN, Lee SB, Ji JH, Cho MH, Yu IJ: Monitoring multiwalled carbon nanotube exposure in carbon nanotube research facility. Inhal Toxicol 2008, 20:741-749.

7. Maynard AD, Baron PA, Foley M, Shvedova AA, Kisin ER, Castranova V: Exposure to carbon nanotube material: aerosol release during the handling of unrefined single-walled carbon nanotube material. J Toxicol Environ Health A 2004, 67:87-107.

8. Yeganeh B, Kull CM, Hull MS, Marr LC: Characterization of airborne particles during production of carbonaceous nanomaterials. Environ Sci Technol 2008, 42:4600-4606.

9. Donaldson K, Murphy FA, Duffin R, Poland CA: Asbestos, carbon nanotubes and the pleural mesothelium: a review of the hypothesis regarding the role of long fibre retention in the parietal pleura, inflammation and mesothelioma. Part Fibre Toxicol 2010, 7:5.

10. Oberdorster G: Safety assessment for nanotechnology and nanomedicine: concepts of nanotoxicology. J Intern Med 2010, 267:89-105.

11. Kato T, Totsuka Y, Ishino K, Matsumoto Y, Tada Y, Nakae D, Goto S, Masuda S, Ogo S, Kawanishi $\mathrm{M}$, et al: Genotoxicity of multi-walled carbon nanotubes in both in vitro and in vivo assay systems. Nanotoxicology 2013, 7:452-461.

12. Monteiro-Riviere NA, Nemanich RJ, Inman AO, Wang $Y Y$, Riviere JE: Multi-walled carbon nanotube interactions with human epidermal keratinocytes. Toxicol Lett 2005, 155:377-384.

13. Muller J, Decordier I, Hoet PH, Lombaert N, Thomassen L, Huaux F, Lison D, Kirsch-Volders M: Clastogenic and aneugenic effects of multi-wall carbon nanotubes in epithelial cells. Carcinogenesis 2008, 29:427-433.

14. Ponti J, Broggi F, Mariani V, De Marzi L, Colognato R, Marmorato P, Gioria S, Gilliland D, Pascual Garcia C, Meschini S, et al: Morphological transformation induced by multiwall carbon nanotubes 
on Balb/3 T3 cell model as an in vitro end point of carcinogenic potential. Nanotoxicology 2013, 7:221-233.

15. Tavares AM, Louro H, Antunes S, Quarre S, Simar S, De Temmerman PJ, Verleysen E, Mast J, Jensen KA, Norppa $\mathrm{H}$, et al: Genotoxicity evaluation of nanosized titanium dioxide, synthetic amorphous silica and multi-walled carbon nanotubes in human lymphocytes. Toxicol In Vitro 2014, 28:60-69.

16. Di Giorgio ML, Di Bucchianico S, Ragnelli AM, Aimola P, Santucci S, Poma A: Effects of single and multi walled carbon nanotubes on macrophages: cyto and genotoxicity and electron microscopy. Mutat Res 2011, 722:20-31.

17. Li X, Peng Y, Qu X: Carbon nanotubes selective destabilization of duplex and triplex DNA and inducing B-A transition in solution. Nucleic Acids Res 2006, 34:3670-3676.

18. Li X, Peng Y, Ren J, Qu X: Carboxyl-modified single-walled carbon nanotubes selectively induce human telomeric i-motif formation. Proc Natl Acad Sci U S A 2006, 103:19658-19663.

19. Sargent LM, Hubbs AF, Young SH, Kashon ML, Dinu CZ, Salisbury JL, Benkovic SA, Lowry DT, Murray AR, Kisin ER, et al: Single-walled carbon nanotube-induced mitotic disruption. Mutat Res 2012, 745:28-37.

20. Rodriguez-Fernandez L, Valiente R, Gonzalez J, Villegas JC, Fanarraga ML: Multiwalled carbon nanotubes display microtubule biomimetic properties in vivo, enhancing microtubule assembly and stabilization. ACS Nano 2012, 6:6614-6625.

21. Cortez BA, Machado-Santelli GM: Chrysotile effects on human lung cell carcinoma in culture: 3-D reconstruction and DNA quantification by image analysis. BMC Cancer 2008, 8:181.

22. Cortez BD, Quassollo G, Caceres A, Machado-Santelli GM: The fate of chrysotile-induced multipolar mitosis and aneuploid population in cultured lung cancer cells. PLoS One 2011, 6:1860.

23. Ramirez P, Eastmond DA, Laclette JP, Ostrosky-Wegman P: Disruption of microtubule assembly and spindle formation as a mechanism for the induction of aneuploid cells by sodium arsenite and vanadium pentoxide. Mutat Res 1997, 386:291-298.

24. Sargent LM, Shvedova AA, Hubbs AF, Salisbury JL, Benkovic SA, Kashon ML, Lowry DT, Murray $A R$, Kisin ER, Friend $S$, et al: Induction of aneuploidy by single-walled carbon nanotubes. Environ Mol Mutagen 2009, 50:708-717.

25. Ehrlich VA, Nersesyan AK, Hoelzi C, Ferk F, Bichler J, Valic E, Schaffer A, Schulte-Hermann R, Fenech $\mathrm{M}$, Wagner $\mathrm{KH}$, Knasmuller $\mathrm{S}$ : Inhalative exposure to vanadium pentoxide causes DNA damage in workers: results of a multiple End point study. Environ Health Perspect 2008, 116:16891693.

26. Ress NB, Chou BJ, Renne RA, Dill JA, Miller RA, Roycroft JH, Hailey JR, Haseman JK, Bucher JR: Carcinogenicity of inhaled vanadium pentoxide in F344/N rats and B6C3F1 mice. Toxicol Sci 2003, 74:287-296. 
27. Yegles M, Janson X, Dong HY, Renier A, Jaurand MC: Role of fibre characteristics on cytotoxicity and induction of anaphase/telophase aberrations in rat pleural mesothelial cells in vitro: correlations with in vivo animal findings. Carcinogenesis 1995, 16:2751-2758.

28. Yegles M, Saint-Etienne L, Renier A, Janson X, Jaurand MC: Induction of metaphase and anaphase/telophase abnormalities by asbestos fibers in rat pleural mesothelial cells in vitro. $A m$ J Respir Cell Mol Biol 1993, 9:186-191.

29. Hubbs A, Castranova V, Chen BT, Frazer DG, McKinney W, Mercer RR, Kashon ML, Battelli LA, Willard P, Porter DW: Pulmonary inflammation, epithelial hyperplasia, and lymph node translocation after multi-walled carbon nanotube inhalation. Washington DC. Toxicol Sci 2011, 120:11.

30. Porter DW, Hubbs AF, Mercer RR, Wu N, Wolfarth MG, Sriram K, Leonard S, Battelli L, SchweglerBerry D, Friend S, et al: Mouse pulmonary dose- and time course-responses induced by exposure to multi-walled carbon nanotubes. Toxicology 2010, 269:136-147.

31. Shvedova AA, Kisin E, Murray AR, Johnson VJ, Gorelik O, Arepalli S, Hubbs AF, Mercer RR, Keohavong $\mathrm{P}$, Sussman $\mathrm{N}$, et al: Inhalation vs. aspiration of single-walled carbon nanotubes in C57BL/6 mice: inflammation, fibrosis, oxidative stress, and mutagenesis. Am J Physiol Lung Cell Mol Physiol 2008, 295:L552-L565.

32. Shvedova AA, Kisin ER, Mercer R, Murray AR, Johnson VJ, Potapovich Al, Tyurina YY, Gorelik O, Arepalli $\mathrm{S}$, Schwegler-Berry $\mathrm{D}$, et al: Unusual inflammatory and fibrogenic pulmonary responses to single-walled carbon nanotubes in mice. Am J Physiol Lung Cell Mol Physiol 2005, 289:L698-L708.

33. Porter DW, Hubbs AF, Chen TB, McKinney W, Mercer RR, Wolfarth MG, Battelli L, Wu N, Sriram K, Leonard S, et al: Acute pulmonary dose-responses to inhaled multi-walled carbon nanotubes. Nanotoxicology 2012, 269:136-147.

34. Bauer AK, Dwyer-Nield LD, Hankin JA, Murphy RC, Malkinson AM: The lung tumor promoter, butylated hydroxytoluene (BHT), causes chronic inflammation in promotion-sensitive BALB/cByJ mice but not in promotion-resistant CXB4 mice. Toxicology 2001, 169:1-15.

35. Bauer AK, Dwyer-Nield LD, Keil K, Koski K, Malkinson AM: Butylated hydroxytoluene (BHT) induction of pulmonary inflammation: a role in tumor promotion. Exp Lung Res 2001, 27:197-216.

36. Bauer AK, Rondini EA: REVIEW PAPER: the role of inflammation in mouse pulmonary neoplasia. Vet Pathol 2009, 46:369-390.

37. Hussain SP, Harris CC: Inflammation and cancer: an ancient link with novel potentials. Int $J$ Cancer 2007, 121:2373-2380.

38. Malkinson AM: Role of inflammation in mouse lung tumorigenesis: a review. Exp Lung Res 2005, 31:57-82.

39. Pitot HC: Endogenous carcinogenesis - the role of tumor promotion. Proc Soc Exp Biol Med 1991, 198:661-666.

40. Pitot HC: Multistage carcinogenesis - genetic and epigenetic mechanisms in relation to cancer prevention. Cancer Detect Prev 1993, 17:567-573. 
41. Markowitz SB, Levin SM, Miller A, Morabia A: Asbestos. Am J Respir Crit Care Med: Asbestosis, Smoking and Lung Cancer: New Findings from the North American Insulator Cohort; 2013.

42. Naimi Al, Cole SR, Hudgens MG, Brookhart MA, Richardson DB: Assessing the component associations of the healthy worker survivor bias: occupational asbestos exposure and lung cancer mortality. Ann Epidemiol 2013, 23:334-341.

43. Mercer R, Hubbs A, Scabilloni J, Wang L, Battelli L, Schwegler-Berry D, Castranova V, Porter D: Distribution and persistence of pleural penetrations by multi-walled carbon nanotubes. Part Fibre Toxicol 2013, 7:28.

44. Ryman-Rasmussen JP, Cesta MF, Brody AR, Shipley-Phillips JK, Everitt JI, Tewksbury EW, Moss OR, Wong BA, Dodd DE, Andersen ME, Bonner JC: Inhaled carbon nanotubes reach the subpleural tissue in mice. Nat Nanotechnol 2009, 4:747-751.

45. Sargent LM, Reynolds SH, Lowry D, Kashon ML, Benkovic SA, Salisbury JL, Hubbs AF, Keane MJ, Mastovich J, Bunker $\mathrm{KL}$, et al: Genotoxicity of multi-walled carbon nanotubes at occupationally relevant doses. Proc Am Assoc Cancer Res 2012, 53:1320. Abstract \#5464.

46. Stone KC, Mercer RR, Gehr P, Stockstill B, Crapo JD: Allometric relationships of cell numbers and size in the mammalian lung. Am J Respir Cell Mol Biol 1992, 6:235-243.

47. Hubbs A, Greskevitch M, Kuempel E, Suarez F, Toraason M: Abrasive blasting agents: designing studies to evaluate relative risk. J Toxicol Environ Health A 2005, 68:999-1016.

48. 29 CFR-Occupational Safety and Health Regulations (OSHA Standards). [http://www.osha.gov/pls/oshaweb/owadisp.showdocument?p_table 1/4STANDARDS\&p_id1/49992.

49. Health NIOSH: Current Intelligence Bulletin 65: Occupational Exposure to Carbon Nanotubes and Nanofibers. ; 2013.

50. Lee JH, Lee SB, Bae GN, Jeon KS, Yoon JU, Ji JH, Sung JH, Lee BG, Lee JH, Yang JS, et al: Exposure assessment of carbon nanotube manufacturing workplaces. Inhal Toxicol 2010, 22:369381.

51. Maynard AD, Aitken RJ: Assessing exposure to airborne nanomaterials: current abilities and future requirements. Nanotoxicology 2007, 1:26-41.

52. Methner M, Hodson L, Dames A, Geraci C: Nanoparticle Emission Assessment Technique (NEAT) for the identification and measurement of potential inhalation exposure to engineered nanomaterials-Part B: Results from 12 field studies. J Occup Environ Hyg 2010, 7:163-176.

53. British Standards Institution: Nanoparticle - Vocabulary, Book Nanoparticle - Vocabulary. Grimsby, UK: Castle PRess; 2011.

54. Porter AE, Gass M, Bendall JS, Muller K, Goode A, Skepper JN, Midgley PA, Welland M: Uptake of noncytotoxic acid-treated single-walled carbon nanotubes into the cytoplasm of human macrophage cells. ACS Nano 2009, 3:1485-1492.

55. Marcolongo G, Ruaro G, Gobbo M, Meneghetti M: Amino acid functionalization of double-wall carbon nanotubes studied by Raman spectroscopy. Chem Commun (Camb) 2007, 5:4925-4927. 
56. Datsyuk V, Kalyva M, Papagelis K, Parthenios J, Tasis D, Siokou A, Kallitsis I, Galiotis C: Chemical oxidation of multiwalled carbon nanotubes. Carbon 2008, 46:833-840.

57. Underhill DM, Goodridge HS: Information processing during phagocytosis. Nat Rev Immunol 2012, 12:492-502.

58. Dinu CZ, Zhu G, Bale SS, Anand G, Reeder PJ, Sanford K, Whited G, Kane RS, Dordick JS: Enzymebased nanoscale composites for Use as active decontamination surfaces. Adv Funct Mater 2010, 20:392-398.

59. Wiktor AE, Van Dyke DL, Stupca PJ, Ketterling RP, Thorland EC, Shearer BM, Fink SR, Stockero $\mathrm{KJ}$, Majorowicz JR, Dewald GW: Preclinical validation of fluorescence in situ hybridization assays for clinical practice. Genet Med 2006, 8:16-23.

60. Yurov YB, lourov IY, Monakhov VV, Soloviev IV, Vostrikov VM, Vorsanova SG: The variation of aneuploidy frequency in the developing and adult human brain revealed by an interphase FISH study. J Histochem Cytochem 2005, 53:385-390.

61. lijima S: Helical microtubules of graphitic carbon. Nature 1991, 354:56-58.

62. Chiu JC, Chang CM, Hsieh BZ, Lin SC, Yeh CY, Lin GR, Lee CK, Lin JJ, Cheng WH: Pulse shortening mode-locked fiber laser by thickness and concentration product of carbon nanotube based saturable absorber. Opt Express 2011, 19:4036-4041.

63. Yang WR, Thordarson P, Gooding JJ, Ringer SP, Braet F: Carbon nanotubes for biological and biomedical applications. Nanotechnology 2007, 18:412001.

64. Bonner JC, Silva RM, Taylor Aj, Brown JM, Hilderbrand SC, Castranova V, Porter DW, Elder A, Oberdörster G, Harkema JR, Bramble LA, Kavanagh TJ, Botta D, Nel A, andPinkerton KE:

Interlaboratory Evaluation of Rodent Pulmonary Responses to Engineered Nanomaterials: The NIEHS Nano GO Consortium.. Environ Health Perspect. 2013, 121:676-82.

65. Oberdorster G, Stone V, Donaldson K: Toxicology of nanoparticles: a historical perspective. Nanotoxicology 2007, 1:2-25.

66. Pitot HC, Campbell HA, Maronpot R, Bawa N, Rizvi TA, Xu YH, Sargent L, Dragan Y, Pyron M: Critical parameters in the quantitation of the stages of initiation, promotion, and progression in one model of hepatocarcinogenesis in the rat. Toxicol Pathol 1989, 17:594-611.

67. D’Assoro AB, Busby R, Suino K, Delva E, Almodovar-Mercado GJ, Johnson H, Folk C, Farrugia DJ, Vasile V, Stivala F, Salisbury JL: Genotoxic stress leads to centrosome amplification in breast cancer cell lines that have an inactive G1/S cell cycle checkpoint. Oncogene 2004, 23:4068-4075.

68. Lingle WL, Lukasiewicz K, Salisbury JL: Deregulation of the centrosome cycle and the origin of chromosomal instability in cancer. Adv Exp Med Biol 2005, 570:393-421.

69. Lingle WL, Salisbury JL: Methods for the analysis of centrosome reproduction in cancer cells. Methods Cell Biol 2001, 67:325-336.

70. Dinu CZ, Bale SS, Zhu GY, Dordick JS: Tubulin encapsulation of carbon nanotubes into functional hybrid assemblies. Small 2009, 5:310-315. 
71. Canman JC, Cameron LA, Maddox PS, Straight A, Tirnauer JS, Mitchison TJ, Fang GW, Kapoor TM, Salmon ED: Determining the position of the cell division plane. Nature 2003, 424:1074-1078.

72. Chial HJ, Giddings TH, Siewert EA, Hoyt MA, Winey M: Altered dosage of the Saccharomyces cerevisiae spindle pole body duplication gene, NDC1, leads to aneuploidy and polyploidy. ProC Natl Acad Sci U S A 1999, 96:10200-10205.

73. Hong KU, Park YS, Seong YS, Kang DM, Bae CD, Park J: Functional importance of the anaphasepromoting complex-Cdh1-mediated degradation of TMAP/CKAP2 in regulation of spindle function and cytokinesis. Mol Cell Biol 2007, 27:3667-3681.

74. Asakura M, Sasaki T, Sugiyama T, Takaya M, Koda S, Nagano K, Arito H, Fukushima S: Genotoxicity and cytotoxicity of multi-wall carbon nanotubes in cultured Chinese hamster lung cells in comparison with chrysotile A fibers. J Occup Health 2010, 52:155-166.

75. Mangum JB, Turpin EA, Antao-Menezes A, Cesta MF, Bermudez E, Bonner JC: Single-walled carbon nanotube (SWCNT)-induced interstitial fibrosis in the lungs of rats is associated with increased levels of PDGF mRNA and the formation of unique intercellular carbon structures that bridge alveolar macrophages in situ. Part Fibre Toxicol 2006, 3:15.

76. Mardin BR, Schiebel E: Breaking the ties that bind: new advances in centrosome biology. $J$ Cell Biol 2012, 197:11-18.

77. Seitz A, Kojima H, Oiwa K, Mandelkow EM, Song YH, Mandelkow E: Single-molecule investigation of the interference between kinesin, tau and MAP2c. EMBO J 2002, 21:4896-4905.

78. Nieznanska H, Dudek E, Zajkowski T, Szczesna E, Kasprzak AA, Nieznanski K: Prion protein impairs kinesin-driven transport. Biochem Biophys Res Commun 2012, 425:788-793.

79. Seitz A, Kojima H, Oiwa K, Mandelkow EM, Song YH, Mandelkow E: Tau and MAP2 inhibit attachment of kinesin: single-molecule assay of motility in the presence of MAPs. Biophys $\mathrm{J} 2002$, 82:63a-63a.

80. Thies E, Biernat $\mathrm{J}$, Mandelkow EM: MARK/Par1 kinase is a regulator of microtubule-dependent transport in axons by phosphorylating tau protein. Neurobiol Aging 2004, 25:S427-S427.

81. Lengauer C, Kinzler KW, Vogelstein B: Genetic instabilities in human cancers. Nature 1998, 396:643-649.

82. Rangaswami $\mathrm{H}$, Bulbule $\mathrm{A}$, Kundu $\mathrm{GC}$ : Osteopontin: role in cell signaling and cancer progression. Trends Cell Biol 2006, 16:79-87.

83. Rikova K, Guo A, Zeng Q, Possemato A, Yu J, Haack H, Nardone J, Lee K, Reeves C, Li Y, et al: Global survey of phosphotyrosine signaling identifies oncogenic kinases in lung cancer. Cell 2007, 131:1190-1203.

84. Pampaloni F, Florin EL: Microtubule architecture: inspiration for novel carbon nanotube-based biomimetic materials. Trends Biotechnol 2008, 26:302-310.

85. Shimamoto Y, Maeda YT, Ishiwata S, Libchaber AJ, Kapoor TM: Insights into the micromechanical properties of the metaphase spindle. Cell 2011, 145:1062-1074. 
86. Donaldson K, Aitken R, Tran L, Stone V, Duffin R, Forrest G, Alexander A: Carbon nanotubes: a review of their properties in relation to pulmonary toxicology and workplace safety. Toxicol Sci 2006, 92:5-22.

87. Donaldson K, Stone V, Seaton A, Tran L, Aitken R, Poland C: Re: Induction of mesothelioma in p53 mouse by intraperitoneal application of multi-wall carbon nanotube. $J$ Toxicol Sci 2008, 33:385-388.

88. Mercer RR, Hubbs AF, Scabilloni JF, Wang L, Battelli LA, Friend S, Castranova V, Porter DW: Pulmonary fibrotic response to aspiration of multi-walled carbon nanotubes. Part Fibre Toxicol 2011, 8:21.

89. Mercer RR, Scabilloni JF, Hubbs AF, Battelli LA, McKinney W, Friend S, Wolfarth MG, Andrew M, Castranova V, Porter DW: Distribution and fibrotic response following inhalation exposure to multiwalled carbon nanotubes. Part Fibre Toxicol 2013, 10.

90. Frost G, Darnton A, Harding $\mathrm{AH}$ : The effect of smoking on the risk of lung cancer mortality for asbestos workers in Great Britain (1971-2005). Ann Occup Hyg 2011, 55:239-247.

91. Frost G, Harding AH, Darnton A, McElvenny D, Morgan D: Occupational exposure to asbestos and mortality among asbestos removal workers: a Poisson regression analysis. Br J Cancer 2008, 99:822-829.

92. Kane AB: Animal models of malignant mesothelioma. Inhal Toxicol 2006, 18:1001-1004.

93. Metintas S, Metintas M, Ak G, Kalyoncu C: Environmental asbestos exposure in rural Turkey and risk of lung cancer. Int $J$ Environ Health Res 2012, 22:468-479.

94. Takagi A, Hirose A, Nishimura T, Fukumori N, Ogata A, Ohashi N, Kitajima S, Kanno J: Induction of mesothelioma in p53+/- mouse by intraperitoneal application of multi-wall carbon nanotube. $J$ Toxicol Sci 2008, 33:105-116.

95. Takagi A, Hirose A, Futakuchi M, Tsuda H, Kanno J: Dose-dependent mesothelioma induction by intraperitoneal administration of multi-wall carbon nanotubes in p53 heterozygous mice. Cancer Sci 2012, 103:1440-1444.

96. Nagai H, Okazaki Y, Chew SH, Misawa N, Yamashita Y, Akatsuka S, Ishihara T, Yamashita K, Yoshikawa $\mathrm{Y}$, Yasui $\mathrm{H}$, et al: Diameter and rigidity of multiwalled carbon nanotubes are critical factors in mesothelial injury and carcinogenesis. Proc Natl Acad Sci U S A 2011, 108:E1330-E1338.

97. Sargent LM, Porter DW, LM S, AF H, Lowry DT LB, KJ S, ML K, RR M, AK B, et al: Promotion of lung adenocarcinoma following inhalation exposure to multi-walled carbon nanotubes. Part Fibre Toxicol. in press.

98. Devereux TR, Anderson MW, Belinsky SA: Role of Ras protooncogene activation in the formation of spontaneous and nitrosamine-induced lung-tumors in the resistant $\mathbf{C} 3 \mathrm{~h}$ mouse. Carcinogenesis 1991, 12:299-303.

99. Malkinson AM: The genetic-basis of susceptibility to lung-tumors in mice. Toxicology 1989, 54:241-271. 
100. Chen CY, Ge CC, Lao F, Li W, Li YF, Qiu Y, Mao XY, Li B, Chai ZF, Zhao YL: Quantitative analysis of metal impurities in carbon nanotubes: efficacy of different pretreatment protocols for ICPMS spectroscopy. Anal Chem 2008, 80:9426-9434.

101. Food and Drug Administration: Guidance for Industry: Assessing the Effects of Significant Manufacturing Process Changes, Including Emerging Technologies, on teh Safety and Regulatory Status of Food Ingredients and Food Contact SUbstances, Including Food Ingredients that are Color Additives - Draft Guidance. In Book Guidance for Industry: Assessing the Effects of Significant Manufacturing Process Changes, Including Emerging Technologies, on teh Safety and Regulatory Status of Food Ingredients and Food Contact SUbstances, Including Food Ingredients that are Color Additives - Draft Guidance. Rockville, MD: Food and Drug Administration; 2012.

102. Oxford Dictionaries Online. [http://oxforddictionaries.com/].

103. Salisbury JL, D'Assoro AB, Lingle WL: Centrosome amplification and the origin of chromosomal instability in breast cancer. J Mammary Gland Biol Neoplasia 2004, 9:275-283.

104. Haas A, Fischer MS: Three-dimensional reconstruction of histological sections using modern product-design software. Anat Rec 1997, 249:510-516.

105. ACMG: Standards and guidelines for clinical genetics laboratories, in: documentation of FISH results. Bethesda, MD: American College of Medical Genetics; 2006. 
Figure 1: Raman characterization, electron microscopy analysis and length distribution of MWCNTs
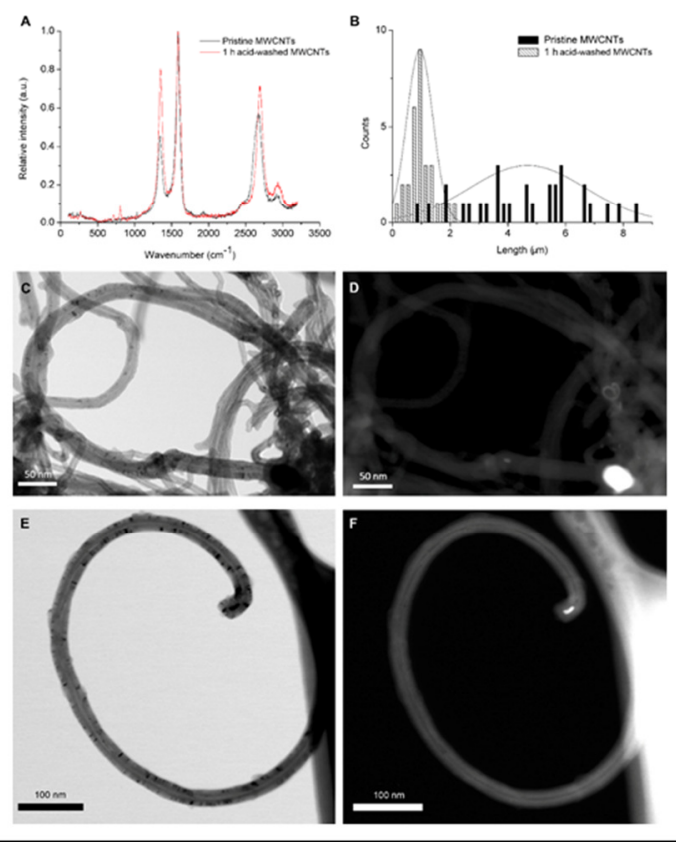

Figure 2: Mitotic disruption following treatment with MWCNT

A

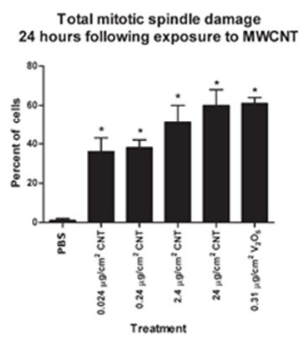

c

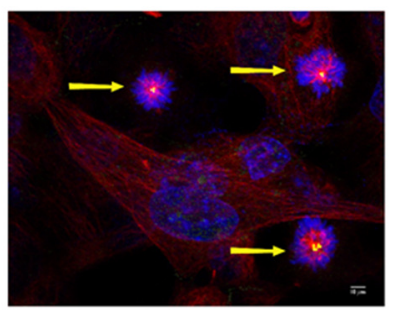
Distribution of mitotic spindle damage
24 hours following exposure to MWCNT ${ }^{80} 7$ 믐
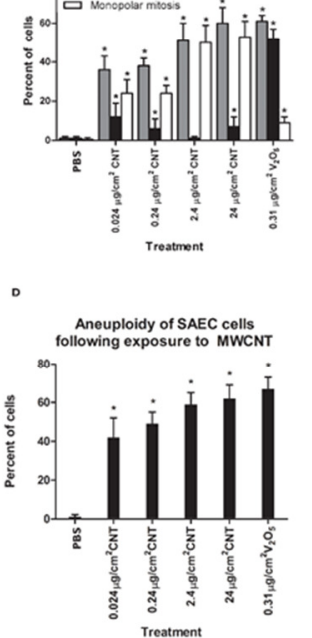

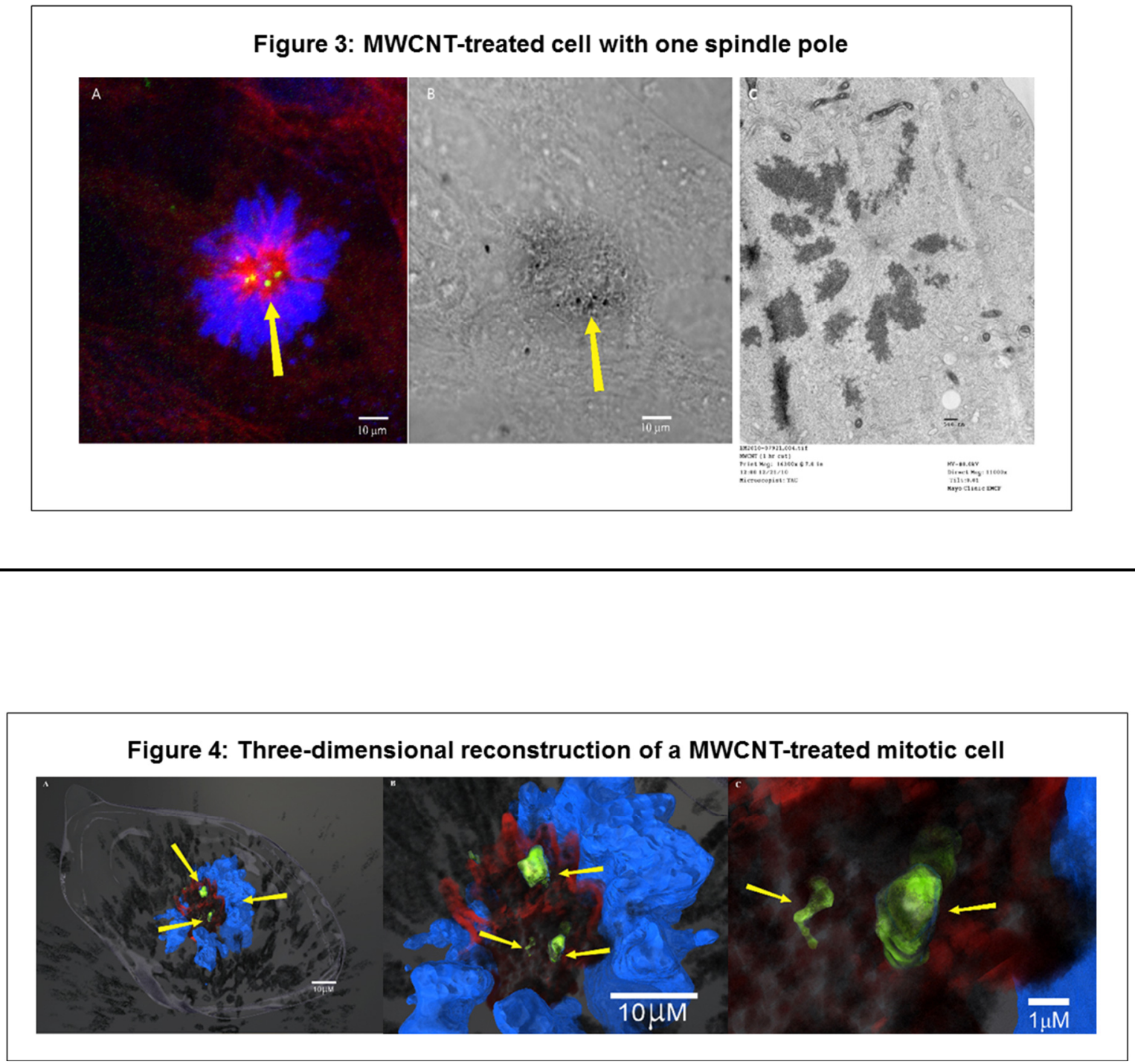


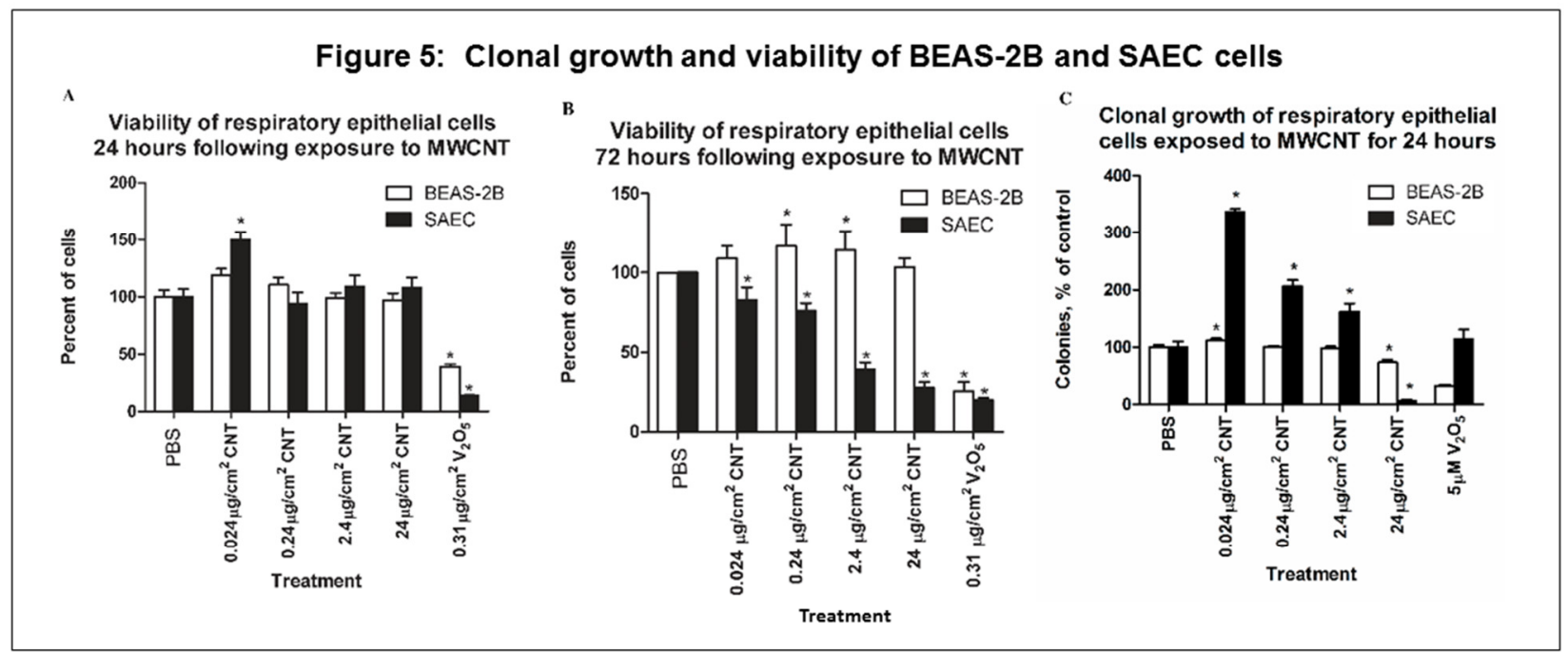




\begin{tabular}{|c|c|c|c|c|c|c|c|}
\hline \multicolumn{2}{|c|}{ Exposure } & $\begin{array}{c}\text { Total \% } \\
\text { Aneuploid cells }\end{array}$ & $\begin{array}{c}\% \text { Loss of } \\
\text { chromosome } 1\end{array}$ & $\begin{array}{c}\% \text { Gain of } \\
\text { chromosome } 1\end{array}$ & $\begin{array}{c}\% \text { Loss of } \\
\text { chromosome } 4\end{array}$ & $\begin{array}{c}\% \text { Gain of } \\
\text { chromosome } 4\end{array}$ & $\begin{array}{l}\% \text { Gain of both } \\
\text { chromosomes }\end{array}$ \\
\hline \multicolumn{2}{|c|}{ Control } & $2.25 \pm 1.0$ & $1.0 \pm 1.0$ & $1.0 \pm 1.0$ & $1.25 \pm 1.0$ & $1.0 \pm 1.0$ & 0 \\
\hline \multicolumn{2}{|c|}{$\mathbf{V}_{2} \mathbf{O}_{5}$} & $69.0 \pm 7.0^{*}$ & $23.0 \pm 5.0^{*}$ & $35.0 \pm 9.0^{*}$ & $25.0 \pm 11.0^{*}$ & $34.0 \pm 7.0^{*}$ & $19.0 \pm 6^{\star}$ \\
\hline \multirow{4}{*}{$\begin{array}{l}\text { MWCNT } \\
\mu \mathrm{g} / \mathrm{cm}^{2}\end{array}$} & 0.024 & $42 \pm 10.0^{\star}$ & $2.0 \pm 1.26$ & $15.0 \pm 2.0^{*}$ & $3.0 \pm 1.26^{\star}$ & $16.4 \pm 2.0^{*}$ & $12.0 \pm 3.0^{*}$ \\
\hline & 0.24 & $49 \pm 6.0$ & $1.7 \pm 0.7^{\star}$ & $23.7 \pm 5.0^{*}$ & $2.0 \pm 10.0^{*}$ & $25 \pm 4.0^{*}$ & $18 \pm 6.0^{*}$ \\
\hline & 2.4 & $59.0 \pm 6.0^{*}$ & $3.4 \pm 0.8^{*}$ & $26.0 \pm 3.0^{*}$ & $4.3 \pm 1.2^{\star}$ & $25 \pm 10.0^{*}$ & $23 \pm 5.0^{*}$ \\
\hline & 24 & $62 \pm 7.0^{*}$ & $7 \pm 3.0^{*}$ & $49.3 \pm 4.0^{\star}$ & $8.0 \pm 3.0^{\star}$ & $53.3 \pm 5.0^{\star}$ & $44 \pm 5.0^{\star}$ \\
\hline
\end{tabular}

\begin{tabular}{|c|c|c|c|}
\hline \multicolumn{4}{|c|}{$\begin{array}{l}\text { Table 2: Distribution of the cell cycle in } \\
\qquad 24 \text { hours after treatment }\end{array}$} \\
\hline Treatment & $\%$ G1 & $\% \mathrm{~S}$ & $\% \mathbf{G 2}$ \\
\hline Control & $43.25 \pm 5.6$ & $32.11 \pm 6.5$ & $18.30 \pm 5.3$ \\
\hline Arsenic & $35.6 \pm 6.9$ & $26.38 \pm 7.9$ & $32.10 \pm 6.7^{\star}$ \\
\hline MWCNT & $39.8 \pm 4.0$ & $40.1 \pm 5.6^{*}$ & $15.90 \pm 3.3$ \\
\hline
\end{tabular}




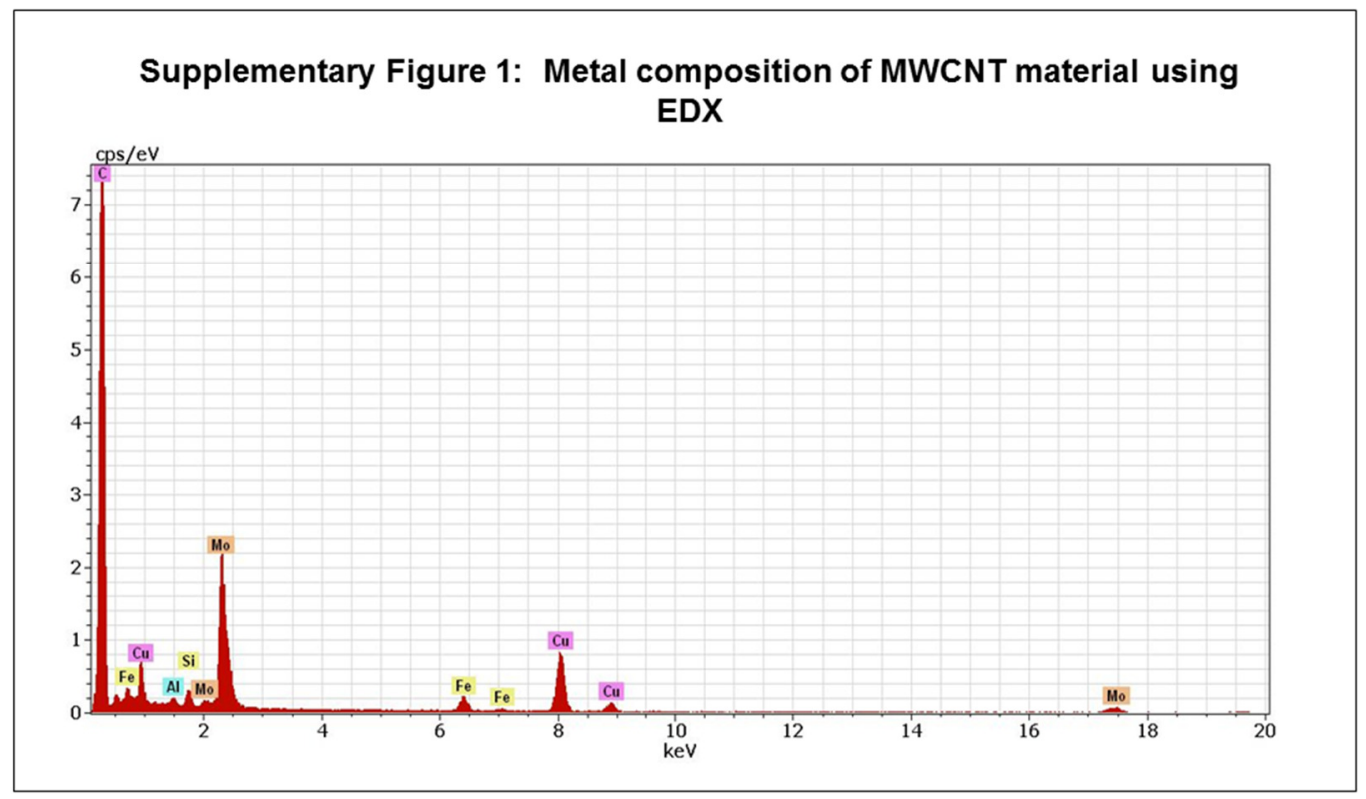




\title{
III. Chapter 3
}

Fragmented centromeres, translocations, aneuploidy, aberrant mitotic spindles, and fragmented centrosomes in human lung epithelial cells exposed to Mitsui-7, heat-treated, and nitrogendoped multi-walled carbon nanotubes

\author{
Authors: \\ Katelyn Siegrist ${ }^{1,2}$ \\ Steven H. Reynolds ${ }^{1}$ \\ Robert R. Mercer ${ }^{1}$ \\ Dale W. Porter ${ }^{1}$ \\ David Lowry ${ }^{1}$ \\ Lorenzo Cena ${ }^{3}$ \\ Michael L. Kashon ${ }^{1}$ \\ John Wiley ${ }^{4}$ \\ Jeffrey L. Salisbury ${ }^{5}$ \\ John Mastovich ${ }^{6}$ \\ Kristin Bunker ${ }^{6}$ \\ Mark Sparrow ${ }^{6}$ \\ Jason S. Lupoi ${ }^{6}$ \\ Aleksandr Stefaniak ${ }^{1}$ \\ Shuji Tsuruoka ${ }^{7}$ \\ Morinobu Endo ${ }^{7}$ \\ Mauricio Terrones ${ }^{8}$ \\ Michael McCawley ${ }^{2}$ \\ Linda M. Sargent ${ }^{1}$
}

\section{Affiliations:}

${ }^{1}$ National Institute for Occupational Safety and Health, Morgantown, WV, 26505

${ }^{2}$ West Virginia University, Morgantown, WV, 26505

${ }^{3}$ West Chester University, West Chester, PA, 19382

${ }^{4}$ East Carolina University, Greenville, NC, 27858

${ }^{5}$ Mayo Clinic, Rochester, MN, 55902

${ }^{6}$ RJ LeeGroup, Monroeville, PA, 15146

${ }^{7}$ Shinshu University, Nagano, Japan

${ }^{8}$ Pennsylvania State University, State College, PA, 16801 


\section{Abstract}

Multi-walled carbon nanotubes (MWCNT) have been used and studied extensively due to their unique physicochemical properties. Due to their low density and small size MWCNT are easily aerosolized in the workplace which makes respiratory exposures likely in workers. The International Agency for Research on Cancer (IARC) designated the pristine Mitsui-7 MWCNT (MWCNT-7) as a Group 2B carcinogen or "possibly carcinogenic to humans", but there is insufficient data to classify all other MWCNT. MWCNT exposed to very high temperatures (MWCNT-HT) or synthesized with nitrogen (MWCNT-ND) have altered physicochemical properties that have been shown to induce attenuated toxic effects. Therefore, the objective of this study was to determine the differences in genotoxicity of MWCNT-HT and ND compared to MWCNT-7. To investigate genotoxicity of MWCNT-HT and ND compared to MWCNT-7, we used two cell types, an immortalized human lung epithelial cell BEAS-2B and primary lung epithelial cell SAEC. Each MWCNT material was observed within the nucleus and associated with the DNA, mitotic spindle and centrosomes. Quantification of nuclear uptake indicated that MWCNT-7 material was taken up at a higher rate than MWCNT-HT and ND, respectively. Each MWCNT material was cytotoxic at the $24 \mu \mathrm{g} / \mathrm{mL}$ dose in both cell types after 24 and 72 hours of exposure. Twenty-four hours of exposure to the MWCNT-7 and HT material induced a significant arrest in the G1/S phase in BEAS-2B cell cycle whereas the MWCNT-ND induced a G2 arrest. Each MWCNT material produced a significant arrest in the G1 and G2 phases of the SAEC cell cycle after 24 hours of exposure. However, 72 hours of exposure resulted in a significant G1/S phase arrest. The rate of mitotic aberrations was significantly increased with exposure to each MWCNT material. Mono and multipolar mitotic aberrations were observed; however, the monopolar morphology predominated. Quantitative analysis of the centrosome and spindle pole integrity demonstrated centrosome fragmentation to be significantly increased after exposure to $0.024,0.24$,and $2.4 \mu \mathrm{g} / \mathrm{mL}$ of each MWCNT material and $24 \mu \mathrm{g} / \mathrm{mL}$ of MWCNT-HT material compared to control. Significant aneuploidy was measured in a dose-dependent manner from exposure to each MWCNT material with $24 \mu \mathrm{g} / \mathrm{mL}$, the highest dose, of MWCNT-7, HT, and ND producing a rate of $66.5,61.1$, and $55.3 \%$, respectively. 
Quantitative analysis of the chromosomes demonstrated significantly increased centromere fragmentation after exposure to each MWCNT at each dose compared to control. Additionally, translocations and insertions between centromeres of chromosomes 1 and 4 were observed. Clonal growth was increased following exposure to 0.024 and $0.24 \mu \mathrm{g} / \mathrm{mL}$ MWCNT-7, $2.4 \mu \mathrm{g} / \mathrm{mL}$ MWCNT-HT, and $0.024 \mu \mathrm{g} / \mathrm{mL}$ MWCNT-ND material. These data indicate that, while each MWCNT material investigated in this study produced significant genotoxic effects that could have serious implications regarding carcinogenic potential, the physicochemical alterations of the MWCNT-HT and ND reduced nuclear uptake and, therefore, magnitude of genotoxic effect. 


\section{Introduction}

Since their inception several decades ago, multi-walled carbon nanotubes (MWCNT) have been used and studied extensively due to their unique physicochemical properties [1]. Their high aspect ratio, rigidity, strength, electrical conductance, and durability present myriad opportunities for enhanced industrial applications. These characteristics also present opportunities for an increased risk to human health [2]. Recently, the International Agency for Research on Cancer (IARC) designated the pristine Mitsui-7 MWCNT (MWCNT-7) as a Group 2B carcinogen or "possibly carcinogenic to humans" citing multiple studies that indicate tumor growth in rodents and mechanistic evidence relevant to humans [3]. However, there is insufficient evidence to determine the carcinogenic risk imposed on workers exposed during the production or use of other MWCNT with physicochemical properties different from the MWCNT-7. Consequently, all other MWCNT have been labelled as Group 3 carcinogens or "not classifiable as to their carcinogenicity to humans". MWCNT with altered physicochemical properties have been shown to elicit variable effects relating to cellular uptake, biocompatibility, cytotoxicity, oxidative stress and generation of reactive oxygen species (ROS), pulmonary inflammation, and fibrosis indicating carcinogenic potential for these materials [4-24]. Therefore, an investigation into the genotoxicity and carcinogenic mechanisms of such materials is needed.

Exposure to MWCNT-7, in particular, has been shown to induce significant genotoxicity illustrated through several endpoints. Mouse alveolar macrophages exposed in culture to $25-100 \mu \mathrm{g} / \mathrm{mL}$ MWCNT-7 for 24 hours had significant DNA strand breaks compared to control as measured via comet assay [25]. Exposure to a much higher dose of $256 \mu \mathrm{g} / \mathrm{mL}$ MWCNT-7 for 24 hours in primary human peripheral lymphocytes produced significant genotoxicity through increased micronuclei formation [26]. However, significant increases in micronuclei were also observed in A549 cells exposed to MWCNT-7 for 6 hours in a dose response [27]. Chinese hamster lung cells exposed to MWCNT-7 for 48 hours in a dose response had a significantly greater percentage of bi- and multinucleated cells compared to control [28]. Additionally, this study found significant polyploidy in cells exposed to $5 \mu \mathrm{g} / \mathrm{mL}$ for 24 hours and 1.3 and $5 \mu \mathrm{g} / \mathrm{mL}$ for 42 hours [28]. Other types of pristine MWCNT with varied structure have been shown to produce significant genotoxicity as well. 
Pristine MWCNT 10-40 nm in diameter produced significantly increased micronuclei formation in human lymphocytes exposed to $24 \mu \mathrm{g} / \mathrm{cm}^{2}$ for 72 hours [29] and lung epithelial cells isolated from rats exposed to 0.5 and $2 \mathrm{mg}$ via intra-tracheal administration [30]. These micronuclei were found to be caused by both clastogenic and aneugenic effects indicating a dynamic mechanism of genotoxicity. RAW 264.7 macrophages were found to have significant amounts of micronuclei and structural chromosome aberrations following exposure to pristine MWCNT in a dose response [31]. Mice intratracheally-instilled with pristine MWCNT 70-110 nm in diameter had increased DNA damage in the lung in a dose-dependent manner as analyzed by Comet assay [27]. Increased micronuclei formation was observed in a dose response in type II pneumocytes isolated from rats exposed to a thinner pristine MWCNT via intratracheal installation [32]. Kim and associates, 2014, exposed Fischer 344 rats to pristine MWCNT $10-20 \mathrm{~nm}$ in diameter via nose only inhalation for 28 days and observed a significant amount of DNA damage in isolated lung cells through the Comet assay [33]. The genotoxicity illustrated in these studies can be the result of indirect mechanisms involving mutation, ROS production, and inflammatory mediators. However, there is also evidence of genotoxicity caused by a direct interaction between the MWCNT and the DNA.

Carbon nanotubes have been shown to bind to G-C rich and telomeric regions of the chromosomes resulting in conformational changes in the DNA structure $[34,35]$ which may explain the DNA breakage mentioned previously. MWCNT material can also directly interact with the mitotic spindle apparatus including the microtubules and centrosomes [36]. Cancer cell lines [37] and immortalized human bronchial epithelial cells [36] exposed to MWCNT 5-20 nm in diameter resulted in both multi- and monopolar mitotic spindle aberrations. The resultant disruption in the former lead to cell cycle arrest and aneuploidy in a primary human lung epithelial cell type. The disruption in division in these studies was caused by either amplified or fragmented centrosomes. Disruption of the mitotic spindle and aneuploidy in cultured cells is strongly correlated with in vivo carcinogenesis at occupationally-relevant doses [38-41]. Investigators using acellular systems have demonstrated that MWCNT form hybrids with the microtubules that are components of the mitotic spindle apparatus [42]. Given that the microtubules of the mitotic spindle are of similar diameter with the MWCNT material, it is theorized that 
the alteration of MWCNT diameter can have significant influences on the genotoxicity, specifically that which is the result of abnormal division.

It is suggested that toxicity of pristine MWCNT material can be mitigated by altering their physicochemical properties. Acellular studies have found that MWCNT-7 material heated to over $2000^{\circ} \mathrm{C}$ (MWCNT-HT) demonstrate increased crystallinity and purity of the individual structures [43-46], two alterations that could have significant effects on toxicity by reducing the bioavailability and reactivity of the material. Doping MWCNT with nitrogen by incorporating nitrogen into the lattice structure of the nanotube wall during synthesis or by the addition of a nitrogen-containing functional group (MWCNTND) $[47,48]$ can alter the shape, strength, and diameter of the individual structure and increase the hydrophilicity of the raw material [47-52]. MWCNT-HT and ND material have been shown to be less toxic than the MWCNT-7 due to the alteration of their unique physicochemical properties both in vitro and in vivo $[5,20,53,54]$. In the present study, we measured the cytotoxicity, nuclear uptake, and genotoxicity, as assessed through cell cycle disruption, of MWCNT-HT and ND compared to MWCNT7. The mechanisms of genotoxicity for each substance were evaluated by analyzing mitotic spindle aberrations and subsequent aneuploidy. The techniques used during these analyses allowed for the quantitative examination of centrosome integrity, spindle pole integrity, and chromosome instability (CIN). Finally, the clonal growth of exposed pulmonary epithelial cells was evaluated as a measure of carcinogenic potential.

\section{$\underline{\text { Methods }}$}

\section{Materials}

The MWCNT-7 material used in this study were a gift from Morinobu Endo and Shuji Tsuruoka (Shinshu University, Nagano, Japan) and obtained through the Mitsui \& Co., Ltd. (MWCNT-7, lot \#05072001K28) and previously characterized [55]. The MWCNT-HT and ND material are derivate of the MWCNT-7 material and were a gift from Mauricio Terrones (Pennsylvania State University, College Park, PA).

\section{Characterization}


Length and Diameter: A protocol was established for the measurements of diameter and length of raw MWCNT material using an SEM/Scanning Transmission Electron Microscope (STEM, S-5500 ultrahigh resolution SEM with STEM capabilities, Hitachi High Technologies America Inc., Schaumburg, IL 60173). The samples were prepared by adding a portion of the raw MWCNT material into a glass vial with isopropanol and sonicating for approximately 5 minutes. A TEM grid (200 mesh Cu grid coated with carbon, SPI Supplies, West Chester, PA) was then dipped into the suspension, producing a well dispersed sample. Initially, a low magnification was used $(\sim 5-10 \mathrm{kX})$ to locate fibers to measure. Once a fiber was located, the magnification was increased appropriately to measure width and length. Using the measuring tools of the electron microscope's software, straight lines were manually drawn to connect the desired distances to be measured. For length measurements, the longest straight line was drawn between two extremities of a fiber without following the curvatures of the fiber. For the width, measurements were taken drawing a straight line of the distance perpendicular to the fiber's walls. A minimum of 200 MWCNT were measured for each sample.

Purity: Scanning transmission electron microscopy (STEM) with energy dispersive X-ray spectroscopy (EDS) was used to qualitatively assess the purity of the three MWCNT materials by identifying the presence or absence of residual catalyst material in the MWCNT. Bright-field and dark-field imaging were used to identify the catalyst material and EDS was used to confirm the elemental composition. High-resolution bright-field images were collected at an accelerating voltage of $200 \mathrm{kV}$ (Hitachi HD2300A STEM, Hitachi High Technologies America, Schaumburg, IL 60173). EDS spectra were collected and showed the presence of Fe-rich catalyst material in the MWCNT-ND material (Bruker Quantax, Bruker Nano Analytics, 12489 Berlin, Germany).

Suspension properties: Dynamic light scattering techniques were used to determine the characteristics of the three MWCNT materials in suspension. Hydrodynamic $(\mathrm{DH})$ diameter of each material was measured using photon correlation spectroscopy (PCS). Zeta potential was determined for each material suspended in either water or surfactant-containing dispersion media [55]. All measurements 
were performed at $25^{\circ} \mathrm{C}$ with a $633 \mathrm{~nm}$ laser at a $90^{\circ}$ scattering angle (Zeta-sizer Nano ZS90, Malvern Instruments, Worcestershire, UK). The analyses were performed assuming a refractive index of 1.332, viscosity of $0.890 \mathrm{cP}$, dielectric constant of 78.3 and Smoluchowski approximation, $\mathrm{f}(\mathrm{ka})$ value of 1.5. Each suspension of MWCNT was subject to ultrasonic agitation using a probe sonicator (XL 2000, QSonica, Newtown, CT) fitted with a 3-mm titanium probe tip. The delivered energy, as verified calorimetrically [56], was $27,600 \mathrm{~J}$ per sample. Distilled and deionized water that was passed through a $0.025 \mu \mathrm{m}$ pore-size membrane (Anotop 25, Whatman International Ltd, Maidstone, England) was used to dilute each sample prior to analysis.

\section{Cell culture}

Two pulmonary epithelial cell types were used in this study. All cells were maintained at $37^{\circ} \mathrm{C}$ and $5 \%$ $\mathrm{CO}_{2}$ with standard aseptic procedures. Immortalized human bronchial epithelial cells (BEAS-2B, ATCC, Manassas, VA) of less than 10 passages were used to examine cytotoxicity, nuclear uptake, cell cycle arrest, mitotic aberrations, and centrosome integrity and spindle pole integrity. BEAS-2B cells were cultured in Dulbecco's Modified Eagle Medium (DMEM) media supplemented with 10\% serum (Invitrogen, Grand Island, NY) and 1\% antibiotic-antimycotic (Corning, Corning, NY). Primary small airway respiratory epithelial cells (SAEC; Lonza, Walkersville, MD) from a normal human donor were used to examine cytotoxicity, nuclear uptake, cell cycle arrest, aneuploidy, CIN, and clonal growth. The normal karyotype of the primary cells was essential for the examination of aneuploidy. The SAEC cells were cultured following manufacturer's directions and using Cabrex media (Lonza, Walkersville, MD). Epithelial phenotype was identified in both cell types, previously, through EM analysis and staining of cytokeratin 8 and 18 [36].

\section{Treatment protocol}

Preparation of materials: Stock MWCNT material was subjected to 4-6 hours of ultrasonic agitation using a 3-mm titanium probe tip sonicator (Sonics and Materials, Inc., Newtown, CT) set to 8 Khz for even dispersion. Material was kept on ice to maintain ambient temperature. Just prior to use, the stock suspensions were dispersed similarly for one minute with a 10 second pulse in order to avoid an 
increase in temperature. The media suspension containing the appropriate volume of stock MWCNT material was sonicated for 10 seconds before application to cell surface. Vanadium pentoxide $\left(\mathrm{V}_{2} \mathrm{O}_{5}\right.$, Sigma, St. Louis, MO) was suspended in $\mathrm{dH}_{2} \mathrm{O}$ and sonicated in a water bath (Branson 2510, Fisher, Pittsburgh, PA) with ice for 30 minutes immediately prior to addition to culture media. Sodium arsenite (arsenic, Sigma, St. Louis, MO) was dissolved in $\mathrm{dH}_{2} \mathrm{O}$.

Cellular exposures: The BEAS-2B and SAEC cells were seeded in parallel culture dishes according to assay protocol. Cells were exposed to MWCNT material suspended in appropriate culture media for either 24 or 72 hours depending on assay requirements. Three independent experiments were performed for each assay.

\section{Nuclear Uptake}

Confocal Raman spectroscopy was used to determine nuclear uptake and spatial orientation of each MWCNT material. Both BEAS-2B and SAEC cells were grown on glass chamber slides until $70 \%$ confluence and exposed to $24 \mu \mathrm{g} / \mathrm{mL}$ MWCNT-7, HT or ND for 24 hours. After exposure cells were washed twice with phosphate buffered saline (PBS), fixed with 100\% ethanol, and analyzed. The spectra of the MWCNT reference materials were generated using a Horiba LabRAM HR (Horiba Instruments, Edison, NJ, USA), equipped with an optical microscope, a 1024x256 pixel, Synapse CCD detector, a 600 grooves $/ \mathrm{mm}$ grating, and a $473 \mathrm{~nm}$ argon laser. The parameters used to obtain the spectral data were as follows: $100 \mu \mathrm{m}$ pinhole, 100x objective, a neutral density filter that permitted $10 \%$ of the laser power, which resulted in a laser power at the sample of 286 microwatts, and two accumulations of each spectrum, collected for 5-seconds. A Raman map was generated to permit the analysis of a larger area containing the MWCNT material, and the resultant spectral data of twenty different locations was baseline corrected and averaged using the LabSpec 6 software package. Cells were identified through brightfield imaging and Raman mapping of the cells was performed using a classical least squares (CLS) analysis for silica (glass slide), cellular protein, and MWCNT material using basis spectra. 3-D renderings were produced using these data to determine the distribution of the MWCNT material within the nucleus. Raman spectroscopy was performed using an automated stage and exposure time set to $1 \sec \times 2$ accumulations per pixel. The mapped areas were 
approximately 50x50x10 (XxYxZ) microns with a mapping step size set to 1 micron. Horiba LabSpec v6 software was used for data reduction and analysis.

Enhanced darkfield light microscopy was used to quantify nuclear uptake of each MWCNT material in the BEAS-2B cell. At 70\% confluence, BEAS-2B cells were serum starved for 24 hours and exposed to $0.024,0.24,2.4$ and $24 \mu \mathrm{g} / \mathrm{mL}$ of each MWCNT material for 24 hours. Cells were washed twice with PBS and fixed with $100 \%$ ice cold methanol. After fixation, nuclear content was fluorescently stained with DAPI (Vectashield, Vector Laboratories, Burlingame, CA) and individual MWCNT were counted using high signal-to-noise, darkfield-based illumination optics adapted to an Olympus bX-41 microscope (CytoViva, Auburn, AL 36830). Nuclear uptake was reported as a frequency of individual MWCNT penetrating the nucleus per 1,000 nuclei.

\section{Cytotoxicity}

Cytotoxicity of each MWCNT material was measured for both cell types. Cells were seeded in flatbottom 96 well plates (Becton Dickinson Franklin Lakes, NJ) and exposed to 0.024, 0.24, 2.4 and 24 $\mu \mathrm{g} / \mathrm{mL}\left(0.015,0.15,1.5\right.$ or $\left.15 \mu \mathrm{g} / \mathrm{cm}^{2}\right)$ of each MWCN material for either 24 or 72 hours. A 0.316 or $3.16 \mu \mathrm{g} / \mathrm{mL}$ or $\left(0.2\right.$ or $\left.2 \mu \mathrm{g} / \mathrm{cm}^{2}\right)$ dose of $\mathrm{V}_{2} \mathrm{O}_{5}$ was used as positive control in the BEAS-2B or SAEC cell type, respectively. Each dose was performed in triplicate per 96 well plate. Cytotoxicity was assessed using the alamarBlue cell viability assay protocol following manufactures directions (Invitrogen, Carlsbad, CA). Fluorescence was measured using a fluorescent spectrophotometer (LS50B, Perkin Elmer, Bridgeville, PA) with a $570 \mathrm{~nm}$ excitation and $585 \mathrm{~nm}$ emission wavelength. The fluorescence intensity was measured for each well. Cell viability is equivalent to a reduction in fluorescence intensity and was reported as a mean across all three experiments normalized to control.

\section{Cell cycle arrest}

Bivariate flow cytometry using the Click-iT EdU Alexa Fluor 647 flow cytometry assay kit (Molecular Probes, Eugene, OR) with 7-aminoactinomycin D (7-AAD, Invitrogen, Carlsbad, CA) allows for a more accurate analysis of the cell cycle compared to single-color methods. EdU (5-ethynyl-2'-deoxyuridine), a nucleoside analog of thymidine, is incorporated into DNA during the S phase of the cell cycle and covalently-labelled with Alexa Fluor 647 via a click chemistry reaction between an azide in the 
fluorophore and an alkyne within the EdU. The 7-AAD fluorophore is incorporated into the DNA of all fixed cells thereby staining for G1 and G2 phases of the cell cycle. BEAS-2B and SAEC cell types were seeded in T25 flasks (Falcon, Corning, NY) until 70\% confluence. BEAS-2B cells were exposed to $24 \mu \mathrm{g} / \mathrm{mL}\left(2.88 \mu \mathrm{g} / \mathrm{cm}^{2}\right)$ of each MWCNT material and $5 \mu \mathrm{M}$ arsenic for 24 hours. EdU was applied after 22 hours of exposure to allow for incorporation into the DNA. Cells were washed twice with PBS (Gibco, Waltham, MA) and $0.25 \%$ trypsin in EDTA (Gibco, Waltham, MA) was used to remove cells from the flask surface. Two exposures were analyzed for the SAEC cell type requiring separate methods. First, SAEC cells were exposed to $10 \mu \mathrm{M}$ arsenic or $24 \mu \mathrm{g} / \mathrm{mL}\left(2.88 \mu \mathrm{g} / \mathrm{cm}^{2}\right) \mathrm{MWCNT}$ material for 24 hours. EdU was applied after 12 hours of exposure. Cells were washed twice with PBS and removed from the flask with $0.25 \%$ trypsin in EDTA (Lonza, Basel, Switzerland). Second, SAEC cells were exposed to $10 \mu \mathrm{M}$ arsenic or $2.4 \mu \mathrm{g} / \mathrm{mL}\left(0.288 \mu \mathrm{g} / \mathrm{cm}^{2}\right)$ MWCNT material for 72 hours. EdU was applied after 12 hours of exposure. Cells were washed twice with PBS and fresh media was applied for a 24 hour recovery period. Each treatment was performed in triplicate. Cells were stained according to manufacturer's instructions and run through a flow cytometer (LSR II, BD Biosciences Immunocytometry Systems, San Jose, CA). Ten thousand events were collected and the dual-labelled fluorescent DNA content was analyzed (FlowJo v10, FlowJo, Ashland, OR). Gating was set to exclude debris, non-cellular material, and doublets. The percentage of cells in G1, S, and G2 phases of the cell cycle were determined via manual gating of the bivariate analysis of the two fluorescent signals and reported as an average across all experiments.

\section{Mitotic aberrations}

Laser scanning fluorescent confocal microscopy with differential interference contrast was used to analyze mitotic aberrations after exposure to each MWCNT material in the BEAS-2B cell (LSM 710, Carl Zeiss Microlmaging Inc., Thornwood, NY). The relatively high mitotic index of the BEAS-2B cell type allows for sufficient examination of dividing cells. Cells were seeded on glass chamber slides (Nunc $^{\mathrm{TM}}$ Lab-Tek $^{\mathrm{TM}}$ II, Waltham, MA) until 70\% confluence and exposed to 0.024, 0.24, 2.4 and 24 $\mu \mathrm{g} / \mathrm{mL}\left(0.0042,0.042,0.42\right.$ and $\left.4.2 \mu \mathrm{g} / \mathrm{cm}^{2}\right)$ of each MWCNT material or $0.316 \mu \mathrm{g} / \mathrm{mL}\left(0.06 \mu \mathrm{g} / \mathrm{cm}^{2}\right)$ $\mathrm{V}_{2} \mathrm{O}_{5}$ for 24 hours. After exposure, cells were washed twice and fixed with $100 \%$ ice cold methanol 
(Fisher Scientific, Waltham, MA). Dual chambers were prepared for each dose. The cells were stained for mitotic aberration analysis via fluorescent labelling of the DNA and immunofluorescent labelling of the mitotic spindle and centrosomes. The DNA was fluorescently labelled using DAPI (Vectashield, Vector Laboratories, Burlingame, CA). The $\beta$-tubulin of the mitotic spindle was labelled using a rabbit anti- $\beta$-tubulin primary antibody (Abcam, La Jolla, CA, USA) and goat anti-rabbit IgG secondary antibody conjugated with rhodamine red (Invitrogen, Carlsbad, CA). The centrosomes were labelled using mouse anti-pericentrin primary antibody (Covance, Austin, TX, USA) and goat anti-mouse IgG antibody conjugated with Alexa 488 (Invitrogen, Carlsbad, CA). Cells were examined and divisions were analyzed by photographing serial slices through the z-plane based on the depth of the cell and optical properties of the stain (Zen, Carl Zeiss Microlmaging Inc., Thornwood, NY). A minimum of 50 mitotic cells of good centrosome and mitotic spindle morphology were analyzed for each dose. Three independent experiments were conducted for a total of 150 cells included in the analysis. Quantitative analysis of aberrant mitoses was based on spindle morphology; a mitotic cell with monopolar or multipolar spindle morphology was considered aberrant. Aberration was reported as a percentage of total mitotic cells analyzed for each dose across all three experiments. Centrosome and spindle pole integrity were assessed quantitatively. The association between MWCNT material and the labelled nuclear structures was also examined qualitatively by overlaying the fluorescent images with the differential interference contrast filter. The mitotic index is equivalent to the percentage of mitotic divisions in 100 cells per dose.

\section{Chromosome analysis}

Laser scanning confocal fluorescent microscopy imaging of SAEC cells with fluorescently labelled chromosomes was used to determine aneuploidy and CIN after exposure to each MWCNT (LSM 710, Carl Zeiss Microlmaging Inc., Thornwood, NY). Cells were seeded on glass chamber slides (Nunc ${ }^{\mathrm{TM}}$ Lab-Tek ${ }^{\mathrm{TM}}$ II, Waltham, MA) until $70 \%$ confluence and exposed to $0.024,0.24,2.4$ and $24 \mu \mathrm{g} / \mathrm{mL}$ $\left(0.0042,0.042,0.42\right.$ and $\left.4.2 \mu \mathrm{g} / \mathrm{cm}^{2}\right)$ of each MWCNT material or $3.16 \mu \mathrm{g} / \mathrm{mL}\left(0.06 \mu \mathrm{g} / \mathrm{cm}^{2}\right) \mathrm{V}_{2} \mathrm{O}_{5}$ for 24 hours. After exposure, cells were washed twice and fixed with a 3:1 mixture of methanol and acetic acid (Fisher Scientific, Waltham, MA). Chromosomes 1 and 4 were labelled via fluorescence in situ 
hybridization (FISH) of centromeric DNA (Abbott Molecular, Des Plaines, IL) and fluorescently counterstained with DAPI (Vectashield, Vector Laboratories, Burlingame, CA) for nuclear content. The SAEC cell type has a normal karyotype, therefore chromosome enumeration for quantitative analysis of aneuploidy is possible. Cells were examined and scored according to the guidelines of the American College of Medical Genetics [57]. A minimum of 100 interphase cells of good FISH morphology were analyzed for each dose. Three independent experiments were performed for a total of at least 300 cells included in the analysis. Cells with three or greater than four signals for either chromosome were recorded as a gain; cells with less than two signals of either chromosome were recorded as a loss. Aneuploidy was reported as the percentage of cells with either a gain or loss for each dose across all three experiments. Use of a centromeric probe allowed for quantitative analysis of $\mathrm{CIN}$ through the frequency of centromere fragmentation including translocations and insertions between chromosomes 1 and 4.

\section{Colony formation}

Enumeration of SAEC colonies was used to determine the clonal growth after exposure to each MWCNT. Cells were seeded in T25 flasks (Falcon, Corning, NY) until 70\% confluence and exposed to $0.024,0.24,2.4$ and $24 \mu \mathrm{g} / \mathrm{mL}\left(0.00288,0.0288,0.288\right.$, and $\left.2.88 \mu \mathrm{g} / \mathrm{cm}^{2}\right)$ of each MWCNT material or $3.16 \mu \mathrm{g} / \mathrm{mL}\left(0.4 \mu \mathrm{g} / \mathrm{cm}^{2}\right) \mathrm{V}_{2} \mathrm{O}_{5}$ for 24 hours. After exposure cells were washed twice and removed from the flask surface with $0.25 \%$ trypsin in EDTA (Lonza, Basel, Switzerland). Cells were reseeded in 6well flat bottom plates (Falcon, Corning, NY) at 500 cells/well to allow for clonal growth from a single cell. Colonies were grown for one month and stained with a $10 \%$ solution of crystal violet in neutral buffered formalin (Sigma, Saint Louis, MO) to preserve and identify clonal morphology. A stereo microscope (SZX12, Olympus, Shinjuku, Japan) was used to count the colonies in each of the six wells. An average number of colonies was calculated and reported as a percentage of control.

\section{Statistical Analysis}

All analyses were performed using SAS/STAT (Version 9.4) for Windows. All analyses were performed using a mixed model ANOVA to compare treatment groups to control. Experimental block was utilized as a random factor. All differences were considered statistically significant at $p<0.05$. 


\section{$\underline{\text { Results }}$}

\section{Characterization}

Length and width: High-resolution STEM images revealed a tubular structure with multiple walls for all three MWCNT (Figure 1). Diameter and length measurements of the MWCNT-7 were conducted previously and showed a mean diameter of $49.0 \pm 13.4 \mathrm{~nm}$ and a mean length of $4.7 \pm 3.7 \mu \mathrm{m}$ [55]. The current study found the MWCNT-HT material to have a mean diameter of $56.8 \pm 23.5 \mathrm{~nm}$ and mean length of $5.1 \pm 3.6 \mu \mathrm{m}$ (Table 1). The MWCNT-ND material was found to have a mean diameter of $29.8 \pm 23.4 \mathrm{~nm}$ and mean length of $1.9 \pm 3.1 \mu \mathrm{m}$ (Table 1). These data indicate that the three MWCNT materials have similar physical dimensions.

Purity: High-resolution STEM imaging identified residual catalyst material was within the MWCNT-ND structure (Figure 2a). EDS analysis identified this material to be iron-rich (Figure 2b). Catalyst material was not identified in the MWCNT-7 or HT samples (data not shown). Previously, Porter and associates identified $0.78 \%$ trace metal content within the MWCNT-7 material through inductively coupled plasmaoptical emission spectroscopy, with sodium $(0.41 \%)$ and iron $(0.32 \%)$ being the two major contaminates [55].

Suspension: Dynamic light scattering analysis indicated DH and zeta potential measurements were similar for each of the three MWCNT materials (Table 1).

\section{Nuclear Uptake}

Raman confocal spectroscopy determined unique spectra for each MWCNT material (Figure 3a). The spectra from the MWCNT-ND material demonstrated differences in the D, G, D'-band intensities compared to the MWCNT-7 and HT material. When normalized to the G-band, the spectra for MWCNT-7 and HT material were quite similar, however the intensity of peak bands was lower in the MWCNT-HT material (Figure 3b). These data indicate differences between the three MWCNT materials regarding the carbon structure. Raman mapping of both cell types showed MWCNT material 
within the nucleus (data not shown) and MWCNT material was dispersed throughout the nucleus (Figure 4).

Quantification of nuclear uptake was measured in the BEAS-2B cell type and reported as a rate of single MWCNT penetrating the nucleus per 1,000 nuclei. Since each nucleus can contain more than one MWCNT, values greater than 100 are possible. All three MWCNT materials were found to have an affinity for the outer surface of the nucleus (Figure 5a), however nuclear penetrations were observed (Figure 5b). Rate of nuclear uptake increased in a dose-dependent manner after 24 hours of exposure to all three MWCNT materials (Figure 6). MWCNT-7 consistently exhibited a higher rate of nuclear uptake compared to MWCNT-HT and ND. For example, exposure to $2.4 \mu \mathrm{g} / \mathrm{mL}$ of MWCNT-7, HT, and ND demonstrated a rate of nuclear uptake of $121.09,29.51$, and $5.8 \%$, respectively (Figure 6). Most notably, at the lowest dose of $0.024 \mu \mathrm{g} / \mathrm{mL}$ no MWCNT-ND were observed in the nucleus, whereas at the highest dose of $24 \mu \mathrm{g} / \mathrm{mL}$ the rate of MWCNT-7 uptake was so high an accurate measurement was unobtainable.

\section{Cytotoxicity}

Measurement of fluorescence intensity using the alamarBlue cell viability assay protocol demonstrated a reduction in cell viability after 24 and 72 hours of exposure to each MWCNT material in both cell types. In the BEAS-2B cell, viability was reduced in a dose-dependent manner after exposure to each MWCNT material for 24 and 72 hours with the longer exposure time producing a greater magnitude of effect (Figures $7 a \&$ b). In the SAEC cell, viability was reduced in a dose-dependent manner after exposure to each MWCNT material for 72 hours (Figure 7d). However, exposure to only the 0.024 and $24 \mu \mathrm{g} / \mathrm{mL}$ doses of each MWCNT material for 24 hours significantly reduced in cell viability (Figure 7c).

\section{Cell Cycle}

Bivariate flow cytometry analyses of fluorescently-labelled DNA in the BEAS-2B and SAEC cells exposed to each MWCNT material demonstrated genotoxicity through significant arrests in the cell cycle (Table 2). 
After 24 hours in culture, the BEAS-2B cell population demonstrated a baseline measurement of $38.2 \pm$ $2.1,22.9 \pm 2.4$, and $36.8 \pm 2.5 \%$ of cells in the $\mathrm{G} 1, \mathrm{~S}$, and $\mathrm{G} 2$ phases of the cell cycle, respectively (Table2a). After 24 hours of exposure to $24 \mu \mathrm{g} / \mathrm{mL}$ of the MWCNT-7 and HT material a significantly higher percentage of cells were observed in the S phase (32.6 \pm 2.9 and $34.1 \pm 4.5 \%$, respectively) while a significantly lower percentage of cells were observed in the G2 phase $(24.6 \pm 2.0$ and $26.8 \pm$ $3.9 \%$, respectively) compared to control. Exposure to $5 \mu \mathrm{M}$ arsenic (positive control) for 24 hours demonstrated an inverse effect with a significantly lower percentage of cells in the S phase (17.4 \pm $2.0 \%)$ and a significantly higher percentage of cells in the G1 (44.7 $\pm 2.8 \%)$ and G2 phase (35.3 \pm 2.2\%) compared to control. Exposure to $24 \mu \mathrm{g} / \mathrm{mL}$ MWCNT-ND for 24 hours produced a higher percentage of cells in the G1 $(39.4 \pm 2.3 \%)$ and $\mathrm{S}(28.0 \pm 4.2 \%)$ phases of the cell cycle that was not significant and a significantly lower percentage of cells in the G2 phase (30.1 $\pm 3.4 \%)$ compared to control. These data indicate that 24 hours of exposure to $24 \mu \mathrm{g} / \mathrm{mL}$ of each MWCNT material produced an arrest in G1/S and arsenic produced an arrest in G1 and G2 phases of the cell cycle.

After 24 hours in culture, the SAEC cell population demonstrated a baseline measurement of $61.2 \pm$ $2.4,288 \pm 2.9$, and $8.1 \pm 0.8 \%$ of cells in the $\mathrm{G} 1, \mathrm{~S}$, and $\mathrm{G} 2$ phases of the cell cycle, respectively (Table 2b). After 24 hours of exposure to $24 \mu \mathrm{g} / \mathrm{mL}$ of MWCNT-7, HT, and ND material a significantly lower percentage of cells were observed in the $S$ phase $(10.3 \pm 4.6,4.7 \pm 1.0,13.5 \pm 1.4 \%$, respectively) while a significantly higher percentage of cells were observed in the G1 $(76.4 \pm 3.7,81.1 \pm$ $1.1,74.6 \pm 0.7 \%$, respectively) and G2 phases (10.2 $\pm 1.2,10.5 \pm 1.0,9.8 \pm 1.2 \%$, respectively) compared to control. Exposure to $10 \mu \mathrm{M}$ arsenic (positive control) for 24 hours demonstrated a similar effect with a significantly lower percentage of cells in the S phase $(25.4 \pm 3.6 \%)$ and higher percentage of cells in the $\mathrm{G} 1(63.9 \pm 2.9 \%)$ and $\mathrm{G} 2$ phases $(8.7 \pm 0.9 \%)$ that was not significant compared to control. These data indicate that 24 hours of exposure to $24 \mu \mathrm{g} / \mathrm{mL}$ of each MWCNT material and 10 $\mu \mathrm{M}$ arsenic produced an arrest in $\mathrm{G} 1$ and $\mathrm{G} 2$ phases of the cell cycle.

After 72 hours in culture, the SAEC cell population demonstrated a baseline measurement of $73.8 \pm$ $5.2,14.6 \pm 5.7$, and $11.2 \pm 1.0 \%$ of cells in the G1, S, and G2 phases of the cell cycle, respectively 
(Table 2c). After 72 hours of exposure to $2.4 \mu \mathrm{g} / \mathrm{mL}$ of MWCNT-7 and ND material a significantly higher percentage of cells were observed in the S phase $(30.5 \pm 2.7$ and $21.3 \pm 5.0 \%$, respectively $)$ while a significantly lower percentage of cells was observed in the G1 phase $(55.9 \pm 2.4$ and $67.7 \pm$ $4.8 \%$, respectively) compared to control. Exposure to $2.4 \mu \mathrm{g} / \mathrm{mL}$ MWCNT-HT material for 72 hours also produced a significantly higher percentage of cells in the S phase $(20.5 \pm 6.4 \%)$ but also a significantly lower percentage of cells in the G2 phase $(9.5 \pm 1.4 \%)$ compared to control. Exposure to $10 \mu \mathrm{M}$ arsenic for 72 hours produced a significantly lower percentage of cells in the S phase $(6.9 \pm 1.1 \%)$ and a significantly higher percentage of cells in the G2 phase (18.3 $\pm 1.4 \%)$ compared to control. These data indicate that 72 hours of exposure to $2.4 \mu \mathrm{g} / \mathrm{mL}$ of each MWCNT material induced an arrest in G1/S and $10 \mu \mathrm{M}$ arsenic induced an arrest in $\mathrm{G} 1$ and $\mathrm{G} 2$ phases of the cell cycle.

\section{Mitotic Aberration}

Confocal microscopy analysis of BEAS-2B cells with fluorescently-labelled DNA, mitotic spindle, and centrosomes demonstrated significantly higher frequency of mitotic aberrations with exposure to each MWCNT material (Table 3). After 24 hours in culture, the BEAS-2B cell population demonstrated a background rate of $7.05 \%$ mitotic aberrations with a $10 \%$ mitotic index. Exposure to 0.024 and 0.24 $\mu \mathrm{g} / \mathrm{mL}$ of MWCNT-7 material produced a significantly higher rate of mitotic aberrations (16.88 and $16.87 \%$, respectively) compared to control. Exposure to $0.24,2.4$ and $24 \mu \mathrm{g} / \mathrm{mL} \mathrm{MWCNT}-\mathrm{HT}$ material produced a significantly higher rate of mitotic aberrations $(20.13,20.55,18.07 \%$, respectively) compared to control. However, exposure only to 0.24 MWCNT-ND material produced a significantly higher rate of mitotic aberrations (23.75\%) compared to control. Observation of the mitotic spindle morphology showed that both multi-and monopolar configurations were present (Figure 8), however the monopolar morphology predominated (Table 3). Exposure to each MWCNT material lowered the mitotic index in a dose-depended manner (Table 3).

A quantitative analysis of the spindle pole and centrosome integrity demonstrated effects from exposure to each MWCNT material. Frequency of centrosome fragmentation was significantly increased after exposure to $0.024,0.24$, and $2.4 \mu \mathrm{g} / \mathrm{mL}$ of each MWCNT material and $24 \mu \mathrm{g} / \mathrm{mL}$ of 
MWCNT-HT compared to control (Figure 9). Centrosome fragments were observed organizing into either bipolar, multipolar, or monopolar spindle morphologies (Figure 10) that can progress through mitosis (Figure 11). However, centrosome fragmentation can also lead to severely disrupted mitotic spindle morphologies that cannot be classified as either morphology (Figure 12). Lagging chromosomes were observed after exposure to each MWCNT material (Figure 11). Differential interference contrast imaging found each MWCNT material throughout the nucleus of exposed cells and demonstrated an affinity between each MWCNT material and the spindle poles (Figures 10-12).

\section{Aneuploidy}

Confocal microscopy analysis of chromosomes 1 and 4 demonstrated significantly increased rates of aneuploidy with exposure to each MWCNT material in a dose response (Table 4). After 24 hours in culture, the SAEC cell population demonstrated a background rate of $9.2 \pm 3.9 \%$ total aneuploidy. Exposure to the highest dose of $24 \mu \mathrm{g} / \mathrm{mL}$ MWCNT-7, HT, and ND induced a significantly higher frequency of aneuploidy compared to control at $65.3 \pm 2.4,58.0 \pm 5.4$, and $52.8 \pm 12.2 \%$, respectively. Exposure to the lowest dose of $0.024 \mu \mathrm{g} / \mathrm{mL}$ MWCNT-7, HT, and ND also induced a significantly higher rate of aneuploidy compared to control at $53.7 \pm 11.0,40.8 \pm 14.6$, and $43.9 \pm 18.9 \%$, respectively. These effects from exposure to MWCNT were greater than that of the positive control, $\mathrm{V}_{2} \mathrm{O}_{5}$, at $39.4 \pm 10.6 \%$. Aneuploidy was predominantly due to a loss of either chromosome 1 or 4 rather than a gain in all exposure groups (Table 4). A quantitative analysis of centromere integrity demonstrated a significantly higher frequency of centromere fragmentation following exposure to each MWCNT material regardless of dose (Figure 12). Insertions and reciprocal translocations between chromosomes 1 and 4 were observed in nuclei exposed to each MWCNT material (Figure 13).

\section{Clonal Growth}

Exposure to each MWCNT material produced significant effects on clonal growth of the SAEC cells. A dramatic reduction of clonal growth was observed after exposure to $24 \mu \mathrm{g} / \mathrm{mL}$ of each MWCNT material due to inherent cytotoxicity. Exposure to 0.024 and $0.24 \mu \mathrm{g} / \mathrm{mL}$ MWCNT-7, $2.4 \mu \mathrm{g} / \mathrm{mL}$ MWCNT-HT, 
and $0.024 \mu \mathrm{g} / \mathrm{mL}$ MWCNT-ND material produced significantly greater clonal growth compared to control (Figure 14).

\section{Discussion}

Global production of MWCNT is projected to increase to 7,000 tons by 2025 in large part due to the manipulation of their unique physicochemical properties [58]. These characteristics present myriad opportunities for enhanced industrial applications albeit at a potentially increased risk to human health. IARC has designated MWCNT-7 to be a Group 2B carcinogen, however all other forms of MWCNT have been labelled as Group 3 carcinogens or "not classifiable" due to insufficient data [3]. These data will help fill the gap and provide mechanistic evidence of the carcinogenic potential of MWCNT with varying physicochemical properties compared to the MWCNT-7. We found exposure to each MWCNT material produced significant genotoxicity through flow cytometry analysis of the cell cycle. These exposures led to an increased rate of mitotic aberrations that were predominantly monopolar in morphology. Aberrant cells had compromised spindle pole and centrosome integrity as indicated by fragmented and amplified centrosomes, lagging chromosomes, and abnormal alignment of the DNA. Significant aneuploidy was measured in a dose response from exposure to each MWCNT material resulting in losses rather than gains of chromosomes 1 and 4. A quantitative assessment of CIN found an increased frequency of centromere fragmentation, translocations, and insertions of both chromosomes from exposure each material. The genetically-altered primary human lung epithelial cells were also shown to proliferate in culture one month post-exposure through increased clonal growth. These data indicate that each MWCNT material, regardless of physicochemical alteration, cause significant genotoxicity and potential carcinogenicity through common mechanisms.

Previous research has indicated the potential for reduced toxicity of MWCNT by altering their physicochemical properties. MWCNT-HT have increased crystallinity and purity than the MWCNT-7, two properties that have been shown to significantly affect bioavailability and carcinogenicity in mice [17]. MWCNT-ND have defects in the lattice structure of the MWCNT wall which can alter the shape, strength, and bioactivity of the material $[47,49,50,53]$. Surface characteristics of MWCNT such as 
functionalization, hydrophobicity, and protein corona formation can affect the internalization of the material at the cellular and nuclear membrane. Additionally, other physicochemical characteristics like length, diameter, purity, structural defects, and rigidity can affect the material's toxicity directly by interacting with nuclear structures [17]. Although each MWCNT material investigated in this study produced significant genotoxicity compared to control, the magnitude of effect regarding cytotoxicity, cell cycle arrest, and aneuploidy from exposure to the MWCNT-HT and ND was consistently attenuated.

In general, MWCNT material is extremely insoluble and difficult to disperse evenly due to non-covalent surface interactions causing a high degree of agglomeration. However, differences between the surface charge of each material are negated by the protein binding in the serum containing cell culture medium [59] and this protein corona will affect the suspension and uptake of the material. MWCNT-ND material has been shown to be relatively more soluble due to the positive charge of amine groups added during synthesis allowing for a more hydrophilic material $[12,60]$. These effects could have significant implications regarding toxicity by the difference in dispersion and uptake between the three materials investigated in this study. Indeed, the suspension characterization conducted has indicated that the MWCNT-HT and ND materials are more stable. As noted by Beck and associates (2012), PCS is a light scattering technique that expresses size as an equivalent spherical diameter and hence does not represent the actual physical dimensions of high aspect ratio particles such as MWCNT; however, values can be used for relative comparison purposes [61]. We found the MWCNT-HT and ND material to have a larger DH and greater zeta potential than the MWCNT-7 potentially leading to greater deposition of the MWCNT-7 material onto the cellular surface in culture. Quantification of each material's nuclear uptake indicated this effect with MWCNT-7 having the highest frequency of nuclear uptake followed by MWCNT-HT and ND, respectively.

We observed cell cycle arrests in response to exposure to each MWCNT material in two pulmonary epithelial cell types; BEAS-2B, an immortalized cell line with disrupted p53 regulation, and SAEC, a primary cell type with normal p53 function and regulation. BEAS-2B cells exposed to each MWCNT 
material exhibited an arrest in the G1/S phase of the cell cycle. However, exposure to each MWCNT material in the primary SAEC cell type with normal p53 function lead to an expected arrest at the G1 and G2 phases. A prolonged 72 hour exposure to each MWCNT material followed by a 24 hour recovery period demonstrated an arrest in the G1/S phase. These data could indicate either a proliferative effect from exposure or mitotic delay from the genetic damage. The difference in effect between the cell types could be due to p53 regulation. However, the SAEC cell type has been shown to be much less sensitive to MWCNT exposure (Figure 7) and has a low mitotic index. The 24 hour experiments represent one round of cellular divisions with normal p53 arresting the cells at the G1 and G2 checkpoints. The 72 hour experiments represent multiple rounds of divisions with geneticallyaltered cells that have potentially mutated making it possible to bypass the checkpoints and propagate their genetic defects. This is supported by the increase in clonal growth after exposure to 0.024 and $0.24 \mu \mathrm{g} / \mathrm{mL}$ MWCNT-7, $2.4 \mu \mathrm{g} / \mathrm{mL}$ MWCNT-HT, $0.024 \mu \mathrm{g} / \mathrm{mL}$ of MWCNT-ND material. A dosedependent increase in clonal growth was not observed for any of the MWCNT materials most likely due to differences in cytotoxicity and cellular uptake.

An arrest in any phase of the cell cycle is an indication of genetic damage that can be the result of several mechanisms. However, an arrest in the G1/S phase of the cell cycle is indicative particularly of centrosomal damage [62-64]. Qualitative analysis through confocal microscopy of the mitotic divisions revealed that each MWCNT material in this study had an affinity for the spindle poles and centrosomes (Figures 10-12). Previously, exposure to MWCNT material 10-20 nm in diameter was shown to be incorporated into the centrosomal structure through 3D reconstruction of the confocal images leading to a G1/S arrest, monopolar mitotic spindle aberrations, and significant aneuploidy [36]. In the present study, exposure to each MWCNT material produced reduced centrosome and spindle pole integrity through observations of fragmented and amplified centrosomes. These effects resulted in significantly increased rates of both mono and multipolar mitotic aberrations and CIN.

Fragmented and/or amplified centrosomes can form into a functional bipolar spindle by clustering multiple centrosomes and centrosome fragments [65]. In the present study, the fragmented 
centrosomes were observed clustering into a single pole with a bipolar spindle (Figure 11). In this case, the DNA will be separated evenly, however the daughter cells will have an abnormal amount of centrosomal material leading to a loss of spindle pole integrity in the subsequent division. Loss of spindle pole integrity can produce cell death or manifest as a multipolar division leading to aneuploidy [65]. These multipolar divisions can also show indications of centrosome clustering (Figure 10). This effect has been shown previously in human breast cancer tissue [64] and was correlated with high-risk and more aggressive phenotype [66]. Centrosomes that duplicate or fragment but do not separate into two poles creating a bipolar spindle still have the ability to go through division with a monopolar spindle morphology (Figure 10). Exposures that induce monopolar mitotic spindles produce daughter cells that fail to undergo cytokinesis and have double the number of chromosomes [65, 67, 68]. Previously, carbon nanotubes have also been observed in the bridge separating dividing cells as was observed in the present study (Figure 11) $[69,70]$. This indicates that the mechanism of aneuploidy observed after exposure to MWCNT in this study could be the result of a direct interaction with the mitotic spindle and centrosome. Interestingly, asbestos, another high aspect ratio fiber, binds to centromeric proteins causing cell cycle arrests and aneuploidy [71].

Each MWCNT material in the present study was observed throughout the mitotic spindle apparatus and there is evidence that the tubulin of the mitotic spindle can form a biohybrid with the MWCNT material [42]. MWCNT have been called the nanotechnological counterpart to microtubules based on the rigidity and resiliency of both structures [72], however microtubule diameter is static whereas MWCNT diameter can be altered. The mean diameter of the MWCNT used in the present study is slightly larger than that of the $20 \mathrm{~nm}$ microtubule. The thicker the MWCNT the greater its stiffness and resiliency [72]. It is thought that MWCNT can be incorporated into the mitotic spindle during tubulin polymerization of the microtubules at the centrosome and create a more rigid structure [36]. Therefore, changing the diameter of the MWCNT could change the potential genotoxicity of this material. Our current study showed a significantly higher rate of mitotic aberrations after exposure to each MWCNT material, albeit at different and lower doses indicating greater potency. It should be noted that the variance in effective 
doses is most likely due to differences in cytotoxicity and nuclear uptake which is dependent on each material's physicochemical properties. Additionally, analysis of mitotic aberrations requires cells to be actively dividing, therefore data can be skewed given the variability of mitotic index with increased dose of toxic material (Table 3).

The mitotic aberrations found in this study are due to loss of spindle pole integrity caused by the incorporation of each MWCNT material into the centrosome and microtubules of the mitotic spindle. This resulted in centrosome fragmentation and amplifications, failed centrosome duplication, inhibited centrosome separation, and failed cytokinesis. Loss of spindle pole integrity can also occur when the chromosomes are misaligned possibly due to interactions between the MWCNT material and DNA leading to breaks. Indeed, centromere fragmentation was observed following exposure to each MWCNT material in the present study (Figures 10-12). There are several proposed mechanisms for centromere fragmentation from exposure to MWCNT. A chromosome attaches to the mitotic spindle through the kinetochore, a protein complex surrounding the centromere. Similar to centrosome fragmentation, the physical interaction between MWCNT and DNA could produce torsional forces during chromatin condensation causing kinetochore/centromeric DNA to break away. The increased rigidity of the MWCNT hybrid microtubule structures could exert forces on the kinetochore and rip the kinetochore/centromere complex away from the chromosome. This effect has been seen previously in $\mathrm{CHO}$ cells exposed to caffeine [73]. Additionally, a disruption in the kinetochore-microtubule attachment can lead to merotelic attachments where a single kinetochore is attached to microtubules emanating from more than one pole [74]. This is indicated by a lagging chromosome during anaphase (Figure 11) and is not detected by spindle assembly checkpoints throughout mitosis [75]. Cells with fragmented centromeres can override S and G2 checkpoints as well and progress through mitosis, otherwise known as mitoses with unreplicated genomes. This will result in metaphase morphology with misaligned DNA with chromatin outside of the mitotic spindle and separate from their fragmented centromeres (Figure 12) [76]. 
Although lung cancer studies involving MWCNT exposures in humans are extremely limited due to the small exposure duration, several investigations in mice and rats have demonstrated increased mesothelioma and lung cancer after peritoneal and pulmonary exposure [17, 20, 77-80]. However, exposure to each MWCNT material resulted in significant aneuploidy in a dose-dependent manner with evidence of CIN such as translocations and insertions (Figure 14). CIN and sustained proliferation are hallmarks of cancer and are necessary components in tumor progression allowing preneoplastic cells to transform into frank neoplasms [81-83]. However, CIN in conjunction with centrosome amplification has been shown to produce more aggressive and high-risk breast cancer tumors [66] and has been correlated with tumor stage in lung cancer $[64,84,85]$ and other cancers [67-69]. Exposure to 0.024 $\mu \mathrm{g} / \mathrm{mL}$, the lowest dose, of each MWCNT in the present study produced significant aneuploidy in primary human lung epithelial cells (Table 4). This aneuploidy was predominately the result of a loss of either chromosome 1 or 4 . However, MWCNT-HT and ND produced an attenuated effect compared to MWCNT-7.

The reported differences between these three MWCNT regarding solubility, suspension, and protein corona formation do not appear to affect the genotoxic outcomes measured in a direct way but rather through their effects on nuclear penetration. These inherent differences led to less MWCNT-HT and ND material in the nucleus. In a previous study by our lab we demonstrated disrupted cellular division leading to unequal separation of the DNA as a result of exposure to $10-20 \mathrm{~nm}$ diameter MWCNT [36]. The present study suggests a similar mechanism where MWCNT were incorporated into the centrosome structure and tubulin of the mitotic spindle. It was thought that the similar diameters between the MWCNT and the mitotic spindle were driving these effects. The three MWCNT materials used in the present study were of slightly larger diameter than the MWCNT studied previously and the microtubule. Therefore, we can infer that the rigidity of these three MWCNT rather than the diameter that is the driving force leading to significant genotoxicity. Indeed, fibrous, and therefore rigid, MWCNT material produced more chromosome aberrations in $\mathrm{CHO}$ cells compared to tangled, and therefore flexible, MWCNT material [86]. The lowest dose of $0.024 \mu \mathrm{g} / \mathrm{mL}$ of each MWCNT material in the present study produced significant aneuploidy indicating that a lowest observable effect level has not 
been reached. This could have serious implications regarding carcinogenicity and the classification of MWCNT-HT and ND as a carcinogen. However, it should be noted that these two materials consistently demonstrated attenuated effects in the genotoxic outcomes measured compared to MWCNT-7. Therefore, we can conclude that although all three types of MWCNT material studied produced significant genotoxicity resulting in cell cycle arrest, mitotic aberrations, aneuploidy, CIN, and fragmented centromeres these data indicate that the MWCNT-HT and ND had an attenuated effect compared to MWCNT-7 due to the manipulation of MWCNT physicochemical properties. The reduction is most likely due to the decrease in structural defects in the walls of the nanotubes, altering the crystallinity and rigidity, and lowering the bioavailability of the material.

\section{Competing interests}

The authors declare that they have no competing interests.

\section{Author's contributions}

KJS contributed to the study conceptualization, study design, writing and drafting of the manuscript, conduction of experiments, and analysis of genotoxicity data. LMS contributed to the conceptualization and design of the study, analysis of experimental results, drafting of the manuscript, and acquisition of funding. SHR contributed to the experimental design, writing of the manuscript, and acquisition of funding. RRM contributed to the experimental design, writing of the manuscript, and performed the enhanced darkfield analysis of nuclear uptake. DWP contributed to the study design and writing of the manuscript. DHL contributed to the study design, conduction of experiments, and analysis of genotoxicity data. LC performed length and width characterization on MWCNT-HT and ND material. MLK contributed to the experimental design and statistical analysis of genotoxicity data. JH contributed to the analysis of FISH data. JLS contributed in the acquisition of funding and writing of the manuscript. JM, KB, MS, and JSL performed chemical characterization and Raman characterization of the three MWCNT materials and contributed to writing the manuscript. AS performed the characterization of suspension properties and writing the manuscript. ST, ME, and MT provided the MWCNT materials 
and contributed to writing the manuscript. MM contributed to the experimental design and writing the manuscript.

\section{Acknowledgements}

The authors would like to thank Kimberly Clough-Thomas for her help with the images. This work was supported by NIOSH NORA 939-011N and CDC/NIOSH 927-ZLDA.

\section{Disclaimer}

Research findings and conclusions are those of the authors and do not necessarily represent the views of the National Institute for Occupational Safety and Health. 


\section{Figure and Table Legends}

Figure 1: Electron micrographs of MWCNT-7, HT, and ND. The tubular structure and multiple walls can be observed in each MWCNT material.

Table 1: MWCNT-7, HT, and ND mean diameter, mean length, hydrodynamic diameter, and zeta potential were measured. *Measured previously [55].

Figure 2: MWCNT material was analyzed for catalyst contamination. A.) DF-STEM image of a MWCNT-ND with red arrow pointing to iron-rich catalyst material. B.) EDS spectrum showing iron-rich catalyst contamination in the MWCNT-ND material. The copper in the spectrum is from the copper TEM grid.

Figure 3: Raman spectra were determined for each MWCNT material. A.) Each MWCNT material has a unique spectrum with differences between D, G, and D'-bands. B.) Although the MWCNT-7 and HT material had very similar spectra, intensity of peak bands was lower in the MWCNT-HT material after normalizing to the G-band.

Figure 4: A 3D rendering of a BEAS-2B cell exposed to $24 \mu \mathrm{g} / \mathrm{mL}$ MWCNT-HT for 24 hours overlaid with Raman spectra. The red indicates silica material from the glass slide, the blue indicates nuclear protein, and the green indicates MWCNT-HT material. This image shows the MWCNT-HT material throughout the entire nucleus.

Figure 5: Enhanced-darkfield light microscopy of BEAS-2B cells exposed to $24 \mu \mathrm{g} / \mathrm{mL}$ MWCNT-HT for 24 hours. The picture on the left shows the MWCNT-HT affinity for the cells. The MWCNT appear as bright white fibers adhering to the surface of the nucleus. The image on the right is a picture of the same cells without the bright white fibers. However, the blue DAPI stain for DNA has been displaced by the MWCNT-HT material within the nucleus and, therefore, appears as a black hole (white arrows).

Figure 6: BEAS-2B cells were exposed to the three MWCNT in a dose-response for 24 hours. Nuclear uptake was reported as number of individual MWCNT structures per 1000 nuclei. MWCNT-7 
uptake at the highest dose of $24 \mu \mathrm{g} / \mathrm{mL}$ were too numerous to accurately count as indicated by the hashed bar. MWCNT-ND uptake at the lowest dose of $0.024 \mu \mathrm{g} / \mathrm{mL}$ was zero. $¥$ indicates uptake of MWCNT-7 material to be significantly different than MWCNT-HT and ND of the same dose, $\mathrm{p}<0.05$. * indicates uptake of each MWCNT material to be different from each other of the same dose, $p<0.05$.

Figure 7: BEAS-2B and SAEC cells were exposed to serial doses of MWCNT-7, HT, and ND for 24 and 72 hours. Viability was measured via the alamarBlue assay. A.) Significant cytotoxicity of BEAS2B cells exposed to $24 \mathrm{mg} / \mathrm{mL}$ of all MWCNT, $2.4 \mathrm{mg} / \mathrm{mL}$ MWCNT-7, and $0.24 \mathrm{mg} / \mathrm{mL}$ MWCNT-ND for 24 hours. B.) After 72 hours significant cytotoxicity was measured in BEAS-2B cells exposed to 24 $\mathrm{mg} / \mathrm{mL}$ and $2.4 \mathrm{mg} / \mathrm{mL}$ of all MWCNT, $0.24 \mathrm{mg} / \mathrm{mL}$ MWCNT-ND, and $0.02 \mathrm{mg} / \mathrm{mL}$ MWCNT-HT and MWCNT-ND. C.) Significant cytotoxicity of SAEC cells exposed to 24 and $0.024 \mathrm{mg} / \mathrm{mL}$ of all MWCNT for 24 hours. D.) After 72 hours significant cytotoxicity of SAEC cells exposed to 24 and $2.4 \mathrm{mg} / \mathrm{mL}$ of all MWCNT and $0.24 \mathrm{mg} / \mathrm{mL}$ of MWCNT-7 and MWCNT-HT. * indicates significantly different from control, $\mathrm{p}<0.05$

Table 2: The percent of cells in G1, S, and G2 phase of the cell cycle was recorded. A.) After 24 hours of exposure $24 \mu \mathrm{g} / \mathrm{mL}$ of MWCNT-7 and HT material produced a significant arrest in the G1/S phase whereas MWCNT-ND material produced a significant arrest in G2 phase in the BEAS-2B cell. Exposure to $5 \mu \mathrm{M}$ arsenic produced a significant arrest in $\mathrm{G} 1$ and $\mathrm{G} 2$ phases. B.) After 24 hours of exposure to $24 \mu \mathrm{g} / \mathrm{mL}$ of each MWCNT material produced a significant arrest in the G1 and G2 phases in the SAEC cell. Exposure to $10 \mu \mathrm{M}$ arsenic produced an arrest in the $\mathrm{G} 1$ and $\mathrm{G} 2$ phases that was not significant. C.) After 72 hours exposure to $2.4 \mu \mathrm{g} / \mathrm{mL}$ of each MWCNT material produced a significant arrest in the G1/S phase in the SAEC cell. Exposure to $10 \mu \mathrm{M}$ arsenic produced a similar effect. *indicates significantly different from control, $p<0.05$.

Table 3: This table demonstrates analysis of mitotic aberrations after exposure to MWCNT material in a dose response and $0.316 \mu \mathrm{g} / \mathrm{mL} \mathrm{V}_{2} \mathrm{O}_{5}$, positive control, for 24 hours. Each MWCNT exposure lead to significant increases in the rate of mitotic aberrations however a dose dependent increase was not achieved due to inherent cytotoxicity as shown by the mitotic index. Monopolar and multipolar spindle 
morphologies were observed, however monopolar predominated. *indicates significantly different from control, $\mathrm{p}<0.05$.

Figure 8: BEAS-2B cells in metaphase of cellular division after 24 hours of exposure. DNA has been stained with DAPI (blue), centrosomes have been stained with fluorescently-labelled anti-pericentrin (green dots), and mitotic spindle has been stained with fluorescently-labelled anti- $\beta$-tubulin (red). A.) Control cell with normal bipolar mitotic spindle morphology. Two centrosomes at opposite ends of the mitotic spindle apparatus and the DNA in the middle. B.) A cell exposed to $24 \mu \mathrm{g} / \mathrm{mL}$ MWCNT-HT with monopolar spindle morphology. C.) A cell exposed to $2.4 \mu \mathrm{g} / \mathrm{mL}$ MWCNT-HT with multipolar morphology.

Figure 9: BEAS-2B cells were exposed to each MWCNT material for 24 hours and observed for centrosome fragmentation. Each MWCNT material produced a significant percent of centrosome fragmentation at doses $0.024,0.24$, and $2.4 \mu \mathrm{g} / \mathrm{mL}$. At the $24 \mu \mathrm{g} / \mathrm{mL}$ dose only MWCNT-HT produced a significant increase in centrosome fragmentation. *indicates significantly different from control, $\mathrm{p}<0.05$.

Figure 10: BEAS-2B cells were exposed to each MWCNT material for 24 hours and observed for centrosome fragmentation. DNA has been stained with DAPI (blue), centrosomes have been stained with fluorescently-labelled anti-pericentrin (green dots), and mitotic spindle has been stained with fluorescently-labelled anti- $\beta$-tubulin (red). Fragmented centrosomes can organize a bipolar spindle (A), monopolar spindle (B), or multipolar spindle (C). Yellow arrow points to centrosome fragment.

Figure 11: BEAS-2B cells were exposed to each MWCNT material for 24 hours and observed for centrosome fragmentation. DNA has been stained with DAPI (blue), centrosomes have been stained with fluorescently-labelled anti-pericentrin (green dots), and mitotic spindle has been stained with fluorescently-labelled anti- $\beta$-tubulin (red). Centrosome fragments can organize into a bipolar spindle and progress through mitosis $(\mathrm{A})$ or produce lagging chromosomes (B). Arrows point to MWCNT material. 
Figure 12: BEAS-2B cells were exposed to each MWCNT material for 24 hours and observed for centrosome fragmentation. DNA has been stained with DAPI (blue), centrosomes have been stained with fluorescently-labelled anti-pericentrin (green dots), and mitotic spindle has been stained with fluorescently-labelled anti- $\beta$-tubulin (red). Centrosome fragmentation can be so great that a normal mitotic spindle cannot be formed (A\&B). Arrow points to MWCNT material at spindle pole (B).

Table 4: This table represents the percentage of aneuploidy in SAEC cells exposed to each MWCNT material and $0.316 \mu \mathrm{g} / \mathrm{mL} \mathrm{V}_{2} \mathrm{O}_{5}$, positive control, for 24 hours. Percentage is based on the total number of cells analyzed. A loss or gain of either chromosome 1 or 4 was also recorded as a percentage of total aneuploid cells. * indicates significantly different from control, $p<0.05$.

Figure 13: SAEC cells were exposed to each MWCNT material for 24 hours and observed for centrosome fragmentation. Each MWCNT material produced a significant percentage of centromere fragmentation compared to control at each dose. * indicates significantly different from control, $p<0.05$.

Figure 14: SAEC cells were exposed to each MWCNT material for 24 hours and observed for translocations and insertions between chromosomes 1 and 4 . Several nuclei of cells exposed to MWCNT material have been labelled for chromosome 1 (red dots) and chromosome 4 (green dots). Red arrow points to centromere fragment of chromosome 4. Orange arrow points to chromosome 4 inserted into chromosome 1. White arrow points to translocation between centromeres of both chromosomes.

Figure 15: Clonal growth was analyzed in SAEC cells exposed to each MWCNT material a significant difference were observed. Most notably, exposure to $24 \mu \mathrm{g} / \mathrm{mL}$ of each MWCNT material produced a dramatic reduction in clonal growth due to inherent cytotoxicity. However, exposure to 0.024 and 0.24 $\mu \mathrm{g} / \mathrm{mL}$ MWCNT-7, $2.4 \mu \mathrm{g} / \mathrm{mL}$ MWCNT-HT, and $0.024 \mu \mathrm{g} / \mathrm{mL}$ MWCNT-ND material produced significantly greater clonal growth compared to control. * indicates significantly different from control, $p<0.05$. 


\section{$\underline{\text { References }}$}

1. lijima, S., Helical microtubules of graphitic carbon. Nature Nature, 1991. 354(6348): p. 56-58.

2. Schulte, P.A., et al., Focused actions to protect carbon nanotube workers. Am J Ind Med, 2012. 55(5): p. 395-411.

3. Grosse, Y., et al., Carcinogenicity of fluoro-edenite, silicon carbide fibres and whiskers, and carbon nanotubes. Lancet Oncol, 2014. 15(13): p. 1427-8.

4. Ali-Boucetta, H., et al., Cellular uptake and cytotoxic impact of chemically functionalized and polymer-coated carbon nanotubes. Small, 2011. 7(22): p. 3230-8.

5. Carrero-Sanchez, J.C., et al., Biocompatibility and toxicological studies of carbon nanotubes doped with nitrogen. Nano Lett, 2006. 6(8): p. 1609-16.

6. Chatterjee, N., et al., Potential toxicity of differential functionalized multiwalled carbon nanotubes (MWCNT) in human cell line (BEAS2B) and Caenorhabditis elegans. J Toxicol Environ Health A, 2014. 77(22-24): p. 1399-408.

7. Frohlich, E., The role of surface charge in cellular uptake and cytotoxicity of medical nanoparticles. Int J Nanomedicine, 2012. 7: p. 5577-91.

8. Gernand, J.M. and E.A. Casman, A meta-analysis of carbon nanotube pulmonary toxicity studies--how physical dimensions and impurities affect the toxicity of carbon nanotubes. Risk Anal, 2014. 34(3): p. 583-97.

9. Haniu, H., et al., Biological responses according to the shape and size of carbon nanotubes in BEAS-2B and MESO-1 cells. Int J Nanomedicine, 2014. 9: p. 1979-90.

10. Jackson, P., et al., Characterization of genotoxic response to 15 multiwalled carbon nanotubes with variable physicochemical properties including surface functionalizations in the FE1Muta(TM) mouse lung epithelial cell line. Environ Mol Mutagen, 2015. 56(2): p. 183-203.

11. Johnston, H.J., et al., A critical review of the biological mechanisms underlying the in vivo and in vitro toxicity of carbon nanotubes: The contribution of physico-chemical characteristics. Nanotoxicology, 2010. 4(2): p. 207-46. 
12. Li, R., et al., Surface charge and cellular processing of covalently functionalized multiwall carbon nanotubes determine pulmonary toxicity. ACS Nano, 2013. 7(3): p. 2352-68.

13. Moolgavkar, S.H., R.C. Brown, and J. Turim, Biopersistence, fiber length, and cancer risk assessment for inhaled fibers. Inhal Toxicol, 2001. 13(9): p. 755-72.

14. Mrakovcic, M., et al., Carboxylated short single-walled carbon nanotubes but not plain and multi-walled short carbon nanotubes show in vitro genotoxicity. Toxicol Sci, 2015. 144(1): p. 114-27.

15. Murphy, F.A., et al., Length-dependent retention of carbon nanotubes in the pleural space of mice initiates sustained inflammation and progressive fibrosis on the parietal pleura. Am J Pathol, 2011. 178(6): p. 2587-600.

16. Murphy, F.A., et al., Length-dependent pleural inflammation and parietal pleural responses after deposition of carbon nanotubes in the pulmonary airspaces of mice. Nanotoxicology, 2013. 7(6): p. 1157-67.

17. Nagai, H., et al., Diameter and rigidity of multiwalled carbon nanotubes are critical factors in mesothelial injury and carcinogenesis. Proc Natl Acad Sci U S A, 2011. 108(49): p. E1330-8.

18. Poulsen, S.S., et al., Multi-walled carbon nanotube physicochemical properties predict pulmonary inflammation and genotoxicity. Nanotoxicology, 2016. 10(9): p. 1263-75.

19. Poulsen, S.S., et al., MWCNTs of different physicochemical properties cause similar inflammatory responses, but differences in transcriptional and histological markers of fibrosis in mouse lungs. Toxicol Appl Pharmacol, 2015. 284(1): p. 16-32.

20. Rittinghausen, S., et al., The carcinogenic effect of various multi-walled carbon nanotubes (MWCNTs) after intraperitoneal injection in rats. Part Fibre Toxicol, 2014. 11(1): p. 59.

21. Sager, T.M., et al., Effect of multi-walled carbon nanotube surface modification on bioactivity in the C57BL/6 mouse model. Nanotoxicology, 2014. 8(3): p. 317-27.

22. Tsuruoka, S., et al., ROS evaluation for a series of CNTs and their derivatives using an ESR method with DMPO. Journal of Physics: Conference Series, 2013. 429(1): p. 012029. 
23. Yamashita, K., et al., Carbon nanotubes elicit DNA damage and inflammatory response relative to their size and shape. Inflammation, 2010. 33(4): p. 276-80.

24. Yang, H., et al., Comparative study of cytotoxicity, oxidative stress and genotoxicity induced by four typical nanomaterials: the role of particle size, shape and composition. J Appl Toxicol, 2009. 29(1): p. 69-78.

25. Aldieri, E., et al., The role of iron impurities in the toxic effects exerted by short multiwalled carbon nanotubes (MWCNT) in murine alveolar macrophages. J Toxicol Environ Health A, 2013. 76(18): p. 1056-71.

26. Tavares, A.M., et al., Genotoxicity evaluation of nanosized titanium dioxide, synthetic amorphous silica and multi-walled carbon nanotubes in human lymphocytes. Toxicol In Vitro, 2014. 28(1): p. 60-9.

27. Kato, T., et al., Genotoxicity of multi-walled carbon nanotubes in both in vitro and in vivo assay systems. Nanotoxicology, 2013. 7(4): p. 452-61.

28. Asakura, M., et al., Genotoxicity and cytotoxicity of multi-wall carbon nanotubes in cultured Chinese hamster lung cells in comparison with chrysotile A fibers. J Occup Health, 2010. 52(3): p. 155-66.

29. Cveticanin, J., et al., Using carbon nanotubes to induce micronuclei and double strand breaks of the DNA in human cells. Nanotechnology, 2010. 21(1): p. 015102.

30. Muller, J., et al., Clastogenic and aneugenic effects of multi-wall carbon nanotubes in epithelial cells. Carcinogenesis, 2008. 29(2): p. 427-33.

31. Di Giorgio, M.L., et al., Effects of single and multi walled carbon nanotubes on macrophages: cyto and genotoxicity and electron microscopy. Mutat Res, 2011. 722(1): p. 20-31.

32. Muller, J., et al., Respiratory toxicity of multi-wall carbon nanotubes. Toxicol Appl Pharmacol, 2005. 207(3): p. 221-31.

33. Kim, J.S., et al., In vivo genotoxicity evaluation of lung cells from Fischer 344 rats following 28 days of inhalation exposure to MWCNTs, plus 28 days and 90 days post-exposure. Inhal Toxicol, 2014. 26(4): p. 222-34. 
34. Li, X., Y. Peng, and X. Qu, Carbon nanotubes selective destabilization of duplex and triplex DNA and inducing B-A transition in solution. Nucleic Acids Res, 2006. 34(13): p. 3670-6.

35. Li, X., et al., Carboxyl-modified single-walled carbon nanotubes selectively induce human telomeric i-motif formation. Proc Natl Acad Sci U S A, 2006. 103(52): p. 19658-63.

36. Siegrist, K.J., et al., Genotoxicity of multi-walled carbon nanotubes at occupationally relevant doses. Part Fibre Toxicol, 2014. 11: p. 6.

37. Rodriguez-Fernandez, L., et al., Multiwalled carbon nanotubes display microtubule biomimetic properties in vivo, enhancing microtubule assembly and stabilization. ACS Nano, 2012. 6(8): p. 6614-25.

38. Ehrlich, V.A., et al., Inhalative exposure to vanadium pentoxide causes DNA damage in workers: results of a multiple end point study. Environ Health Perspect, 2008. 116(12): p. 168993.

39. Ress, N.B., et al., Carcinogenicity of inhaled vanadium pentoxide in F344/N rats and B6C3F1 mice. Toxicol Sci, 2003. 74(2): p. 287-96.

40. Yegles, M., et al., Role of fibre characteristics on cytotoxicity and induction of anaphase/telophase aberrations in rat pleural mesothelial cells in vitro: correlations with in vivo animal findings. Carcinogenesis, 1995. 16(11): p. 2751-8.

41. Yegles, M., et al., Induction of metaphase and anaphase/telophase abnormalities by asbestos fibers in rat pleural mesothelial cells in vitro. Am J Respir Cell Mol Biol, 1993. 9(2): p. 186-91.

42. Dinu, C.Z., et al., Tubulin encapsulation of carbon nanotubes into functional hybrid assemblies. Small, 2009. 5(3): p. 310-5.

43. Kim, Y.A., et al., Synthesis and structural characterization of thin multi-walled carbon nanotubes with a partially facetted cross section by a floating reactant method. Carbon, 2005. 43(11): $p$. 2243-2250.

44. Endo, M., et al., Comparison study of semi-crystalline and highly crystalline multiwalled carbon nanotubes. Applied Physics Letters, 2001. 79(10): p. 1531-1533. 
45. Andrews, R., et al., Purification and structural annealing of multiwalled carbon nanotubes at graphitization temperatures. Carbon, 2001. 39(11): p. 1681-1687.

46. Huang, W., et al., 99.9\% purity multi-walled carbon nanotubes by vacuum high-temperature annealing. Carbon, 2003. 41(13): p. 2585-2590.

47. Sharifi, T., et al., Nitrogen doped multi walled carbon nanotubes produced by CVD-correlating XPS and Raman spectroscopy for the study of nitrogen inclusion. Carbon, 2012. 50(10): p. $3535-3541$.

48. Sumpter, B.G., et al., Nitrogen-Mediated Carbon Nanotube Growth: Diameter Reduction, Metallicity, Bundle Dispersability, and Bamboo-like Structure Formation. ACS Nano, 2007. 1(4): p. 369-375.

49. Meier, M.S., et al., Tearing open nitrogen-doped multiwalled carbon nanotubes. Journal of Materials Chemistry, 2008. 18(35): p. 4143-4145.

50. Terrones, M., et al., $\mathrm{N}$-doping and coalescence of carbon nanotubes: synthesis and electronic properties. Applied Physics A, 2002. 74(3): p. 355-361.

51. Ayala, P., et al., The doping of carbon nanotubes with nitrogen and their potential applications. Carbon, 2010. 48(3): p. 575-586.

52. Ganesan, Y., et al., Effect of nitrogen doping on the mechanical properties of carbon nanotubes. ACS Nano, 2010. 4(12): p. 7637-43.

53. Mihalchik, A.L., et al., Effects of nitrogen-doped multi-walled carbon nanotubes compared to pristine multi-walled carbon nanotubes on human small airway epithelial cells. Toxicology, 2015. 333: p. 25-36.

54. Porter, D.W. Safety by Design: Relative Toxicity of Pristine vs. Functionalized MWCNT. in Safe Nano Design. 2012. College of Nanoscale Science \& Engineering (CNSE), University at Albany, Albany, NY.

55. Porter, D.W., et al., Mouse pulmonary dose- and time course-responses induced by exposure to multi-walled carbon nanotubes. Toxicology, 2010. 269(2-3): p. 136-47. 
56. Taurozzi, J.S., V.A. Hackley, and M.R. Wiesner, Ultrasonic dispersion of nanoparticles for environmental, health and safety assessment--issues and recommendations. Nanotoxicology, 2011. 5(4): p. 711-29.

57. Genetics, A.C.o.M., Standard and guidlines for clinical genetics laboratories, in Documentation of FISH results. 2006: Bethesda, MD.

58. The Global Market for Carbon Nanotubes: Technologies, Production, End User Markets and Opportunities Analysis, 2015-2025. 2016, Future Markets, Inc.

59. Mu, Q., D.L. Broughton, and B. Yan, Endosomal Leakage and Nuclear Translocation of Multiwalled Carbon Nanotubes: Developing a Model for Cell Uptake. Nano letters, 2009. 9(12): p. $4370-4375$.

60. Burch, H.J., et al., Doping of carbon nanotubes with nitrogen improves protein coverage whilst retaining correct conformation. Nanotechnology, 2008. 19(38): p. 384001.

61. Beck, S., J. Bouchard, and R. Berry, Dispersibility in water of dried nanocrystalline cellulose. Biomacromolecules, 2012. 13(5): p. 1486-94.

62. Fukasawa, K., Oncogenes and tumour suppressors take on centrosomes. Nat Rev Cancer, 2007. 7(12): p. 911-924.

63. Doxsey, S., W. Zimmerman, and K. Mikule, Centrosome control of the cell cycle. Trends Cell Biol, 2005. 15(6): p. 303-11.

64. Lingle, W.L., K. Lukasiewicz, and J.L. Salisbury, Deregulation of the centrosome cycle and the origin of chromosomal instability in cancer. Adv Exp Med Biol, 2005. 570: p. 393-421.

65. Maiato, H. and E. Logarinho, Mitotic spindle multipolarity without centrosome amplification. Nat Cell Biol, 2014. 16(5): p. 386-94.

66. Denu, R.A., et al., Centrosome amplification induces high grade features and is prognostic of worse outcomes in breast cancer. BMC Cancer, 2016. 16: p. 47.

67. Asteriti, I.A., et al., Aurora-A inactivation causes mitotic spindle pole fragmentation by unbalancing microtubule-generated forces. Mol Cancer, 2011. 10: p. 131. 
68. Canman, J.C., et al., Determining the position of the cell division plane. Nature, 2003. 424(6952): p. 1074-8.

69. Mangum, J.B., et al., Single-walled carbon nanotube (SWCNT)-induced interstitial fibrosis in the lungs of rats is associated with increased levels of PDGF mRNA and the formation of unique intercellular carbon structures that bridge alveolar macrophages in situ. Part Fibre Toxicol, 2006. 3: p. 15.

70. Yasui, M., et al., Mechanism of induction of binucleated cells by multiwalled carbon nanotubes as revealed by live-cell imaging analysis. Genes Environ, 2015. 37: p. 6.

71. MacCorkle, R.A., et al., Intracellular protein binding to asbestos induces aneuploidy in human lung fibroblasts. Cell Motil Cytoskeleton, 2006. 63(10): p. 646-57.

72. Pampaloni, F. and E.L. Florin, Microtubule architecture: inspiration for novel carbon nanotubebased biomimetic materials. Trends Biotechnol, 2008. 26(6): p. 302-10.

73. Brinkley, B.R., et al., Movement and segregation of kinetochores experimentally detached from mammalian chromosomes. Nature, 1988. 336(6196): p. 251-4.

74. Gregan, J., et al., Merotelic kinetochore attachment: causes and effects. Trends Cell Biol, 2011. 21(6): p. 374-81.

75. Sacristan, C. and G.J. Kops, Joined at the hip: kinetochores, microtubules, and spindle assembly checkpoint signaling. Trends Cell Biol, 2015. 25(1): p. 21-8.

76. Beeharry, N., et al., Centromere fragmentation is a common mitotic defect of $S$ and G2 checkpoint override. Cell Cycle, 2013. 12(10): p. 1588-97.

77. Sargent, L.M., et al., Promotion of lung adenocarcinoma following inhalation exposure to multiwalled carbon nanotubes. Part Fibre Toxicol, 2014. 11: p. 3.

78. Nagai, H., et al., Intraperitoneal administration of tangled multiwalled carbon nanotubes of 15 nm in diameter does not induce mesothelial carcinogenesis in rats. Pathol Int, 2013. 63(9): p. 457-62.

79. Kasai, T., et al., Lung carcinogenicity of inhaled multi-walled carbon nanotube in rats. Part Fibre Toxicol, 2016. 13(1): p. 53. 
80. Suzui, M., et al., Multiwalled carbon nanotubes intratracheally instilled into the rat lung induce development of pleural malignant mesothelioma and lung tumors. Cancer science, 2016. 107(7): p. 924-35.

81. Gordon, D.J., B. Resio, and D. Pellman, Causes and consequences of aneuploidy in cancer. Nat Rev Genet, 2012. 13(3): p. 189-203.

82. Hanahan, D. and R.A. Weinberg, Hallmarks of cancer: the next generation. Cell, 2011. 144(5): p. 646-74.

83. Pitot, H.C., Multistage carcinogenesis--genetic and epigenetic mechanisms in relation to cancer prevention. Cancer Detect Prev, 1993. 17(6): p. 567-73.

84. D'Assoro, A.B., et al., Genotoxic stress leads to centrosome amplification in breast cancer cell lines that have an inactive G1/S cell cycle checkpoint. Oncogene, 2004. 23(23): p. 4068-75.

85. Lingle, W.L. and J.L. Salisbury, Methods for the analysis of centrosome reproduction in cancer cells. Methods Cell Biol, 2001. 67: p. 325-36.

86. Sasaki, T., et al., <i>In vitro</i> chromosomal aberrations induced by various shapes of multiwalled carbon nanotubes (MWCNTs). Journal of Occupational Health, 2016. advpub. 


\section{Figures and Tables}

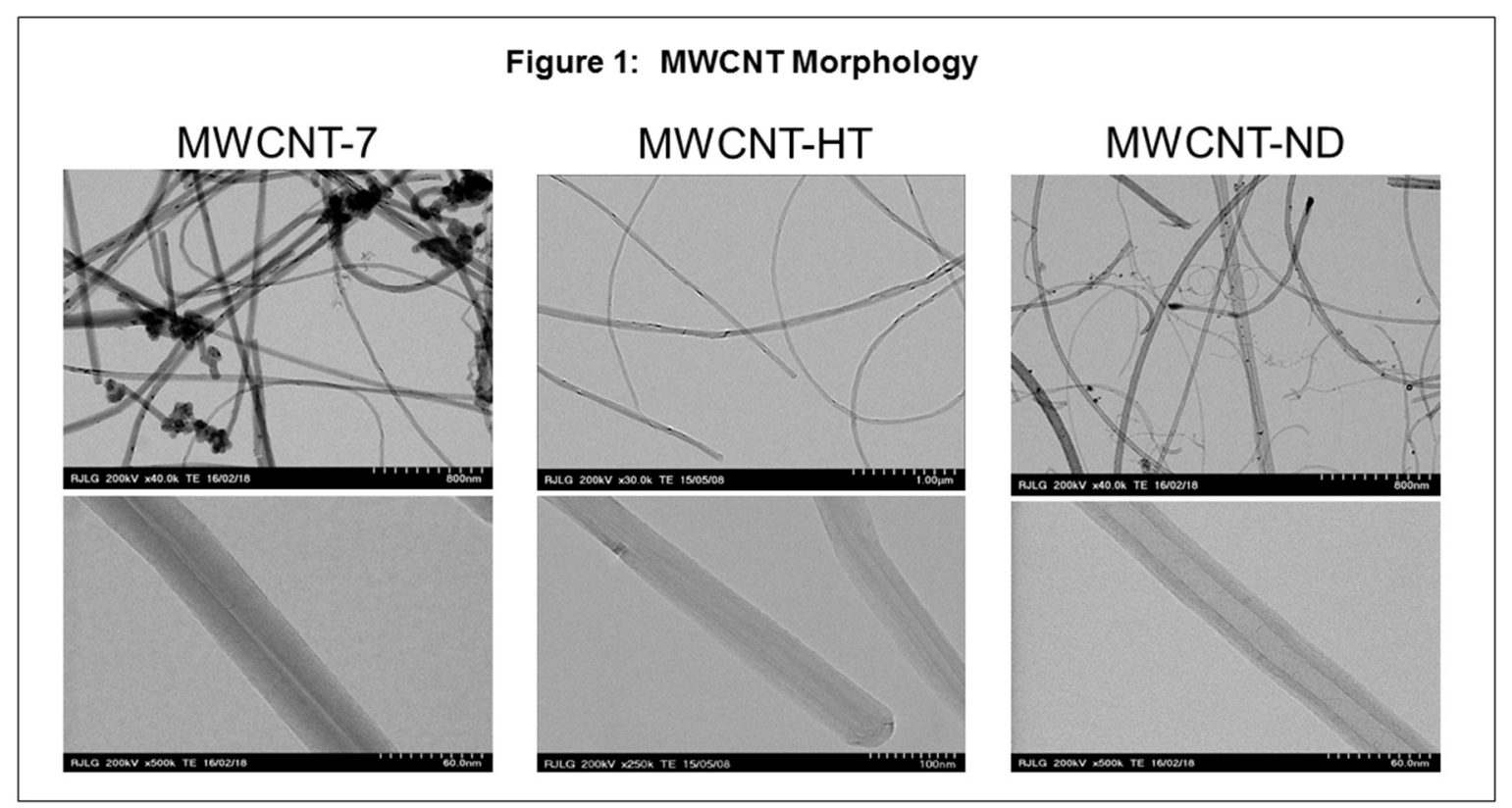

Figure 2: STEM and EDS Analysis for MWCNT Chemical Composition Iron-rich catalyst material

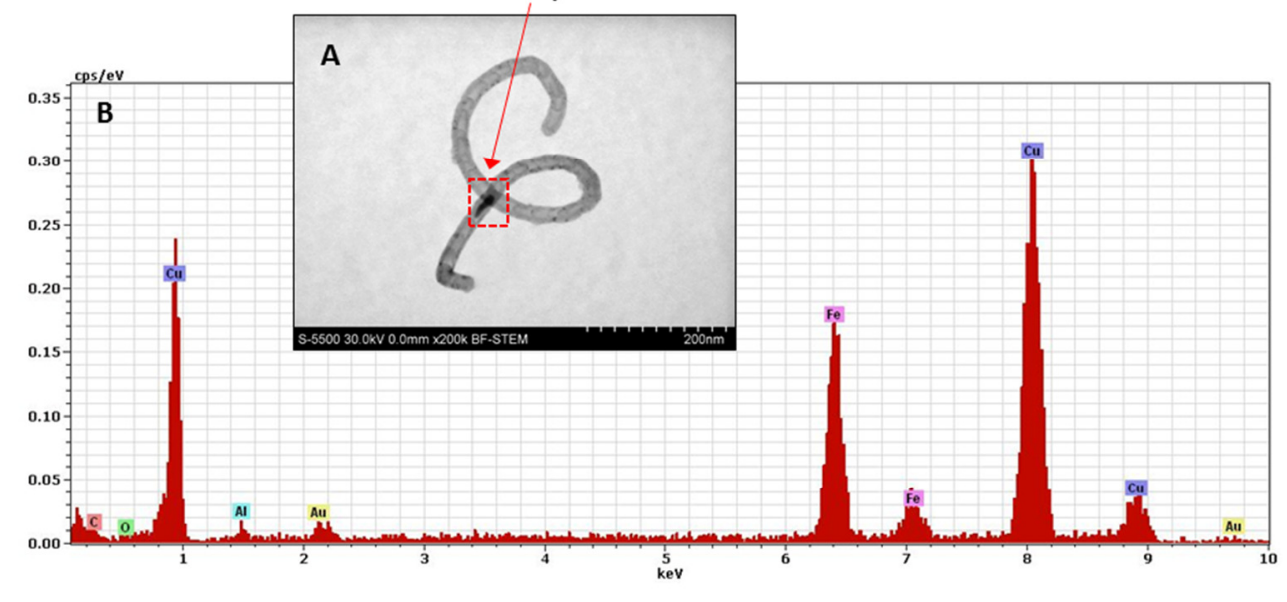


Figure 3: Ramen Spectroscopy for MWCNT Material

A

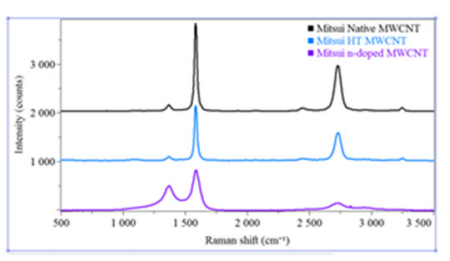

B

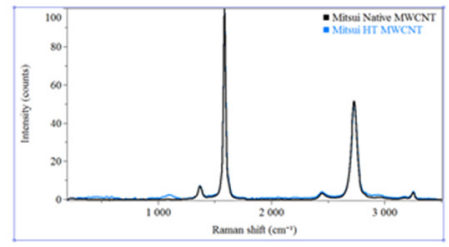

Figure 4: Nuclear Uptake of MWCNT Material using Roman Confocal Microscopy

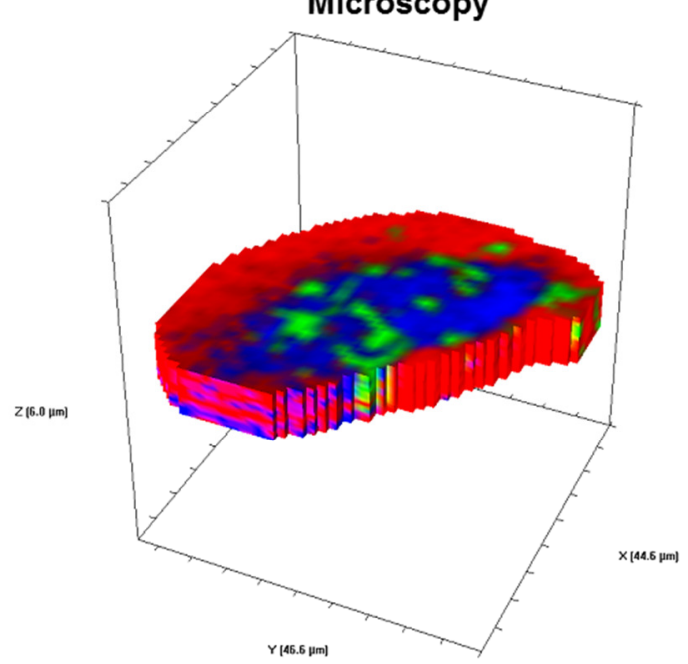

95 
Figure 5: Nuclear Uptake of MWCNT Material using Enhanced Darkfield Microscopy
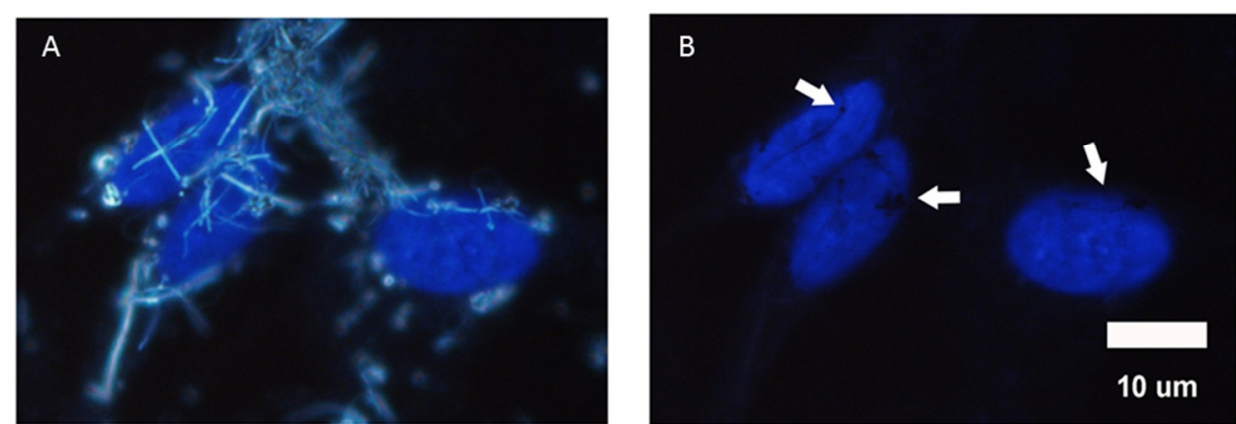

Figure 6: Quantification of Nuclear Uptake

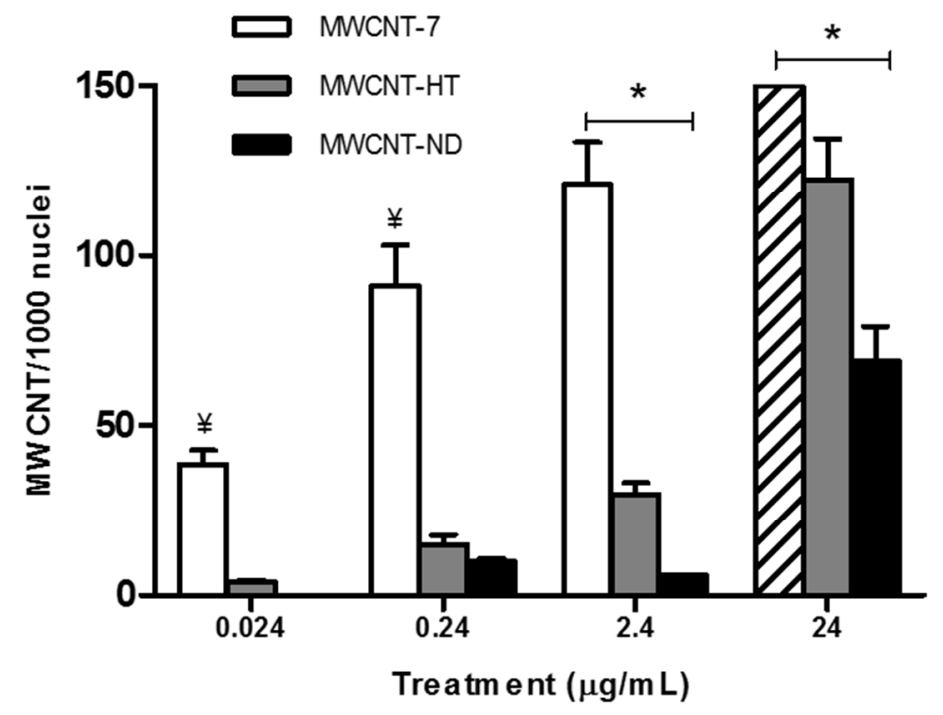


Figure 7: Cytotoxicity of MWCNT Material

A BEAS-2B 24 hours

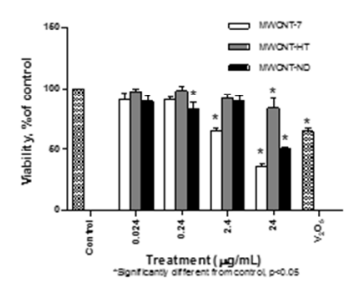

C SAEC 24 hours

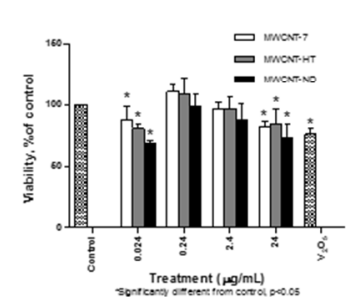

B BEAS-2B 72 hours

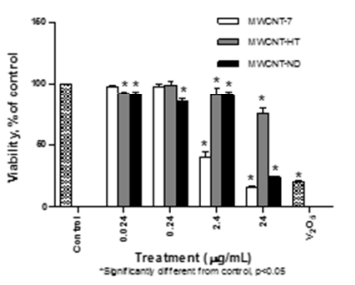

D SAEC 72 hours

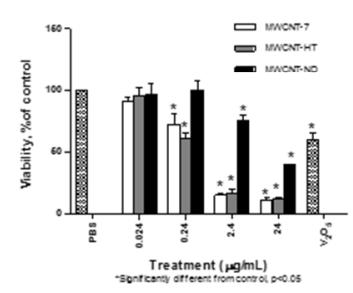

Figure 8: Mitotic Spindle Morphology

A

B

c 
Figure 9: Centrosome Fragmentation

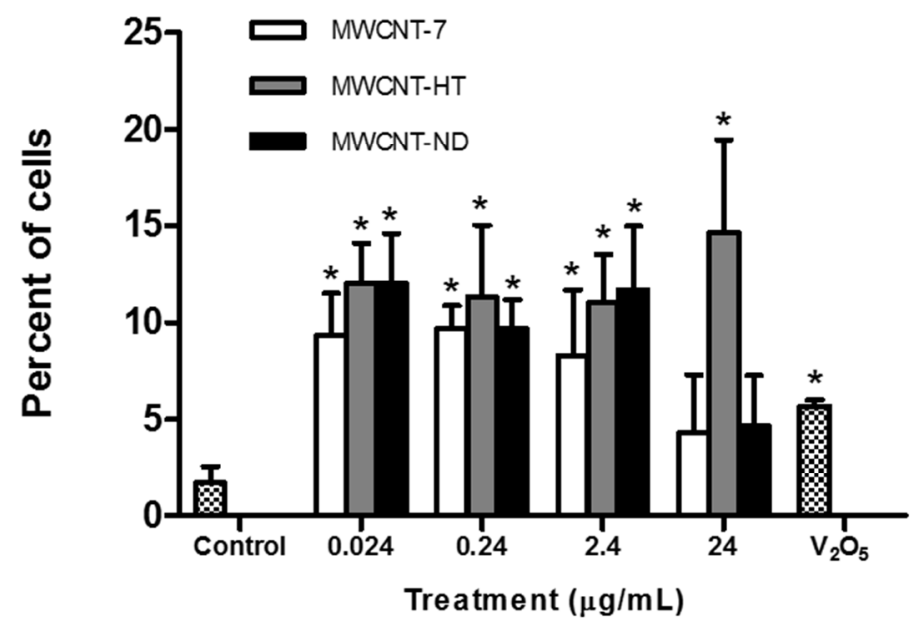

Figure 10 : Mitotic Spindle Morphology with Fragmented Centrosomes
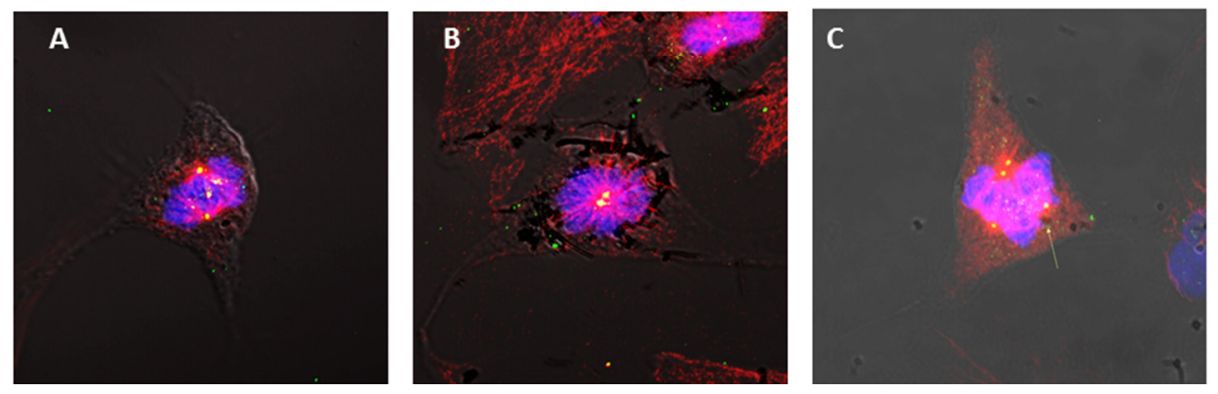


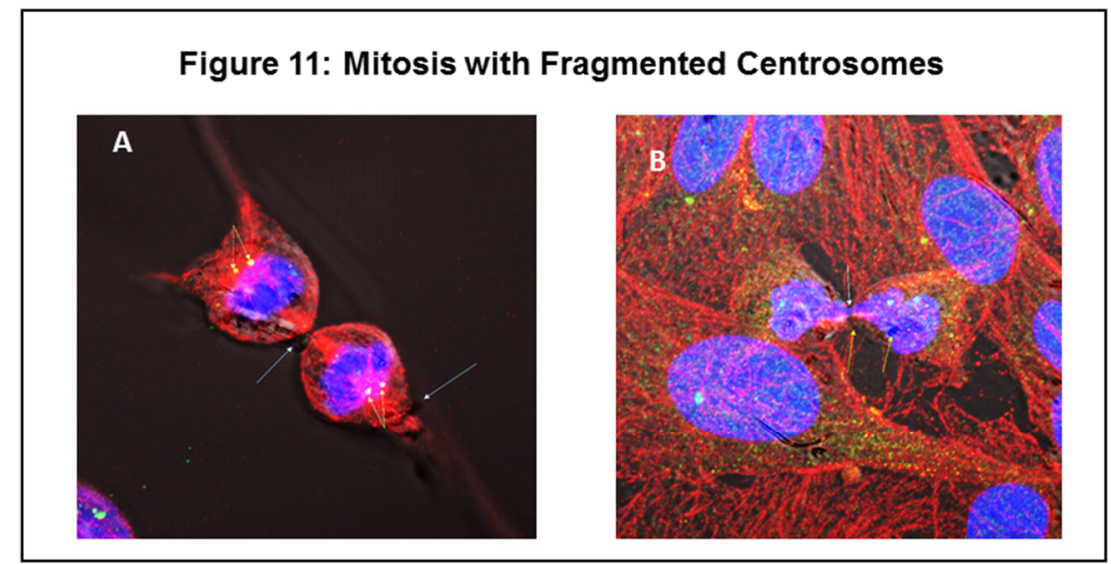

Figure 12: Aberrant Mitosis with Fragmented Centrosomes
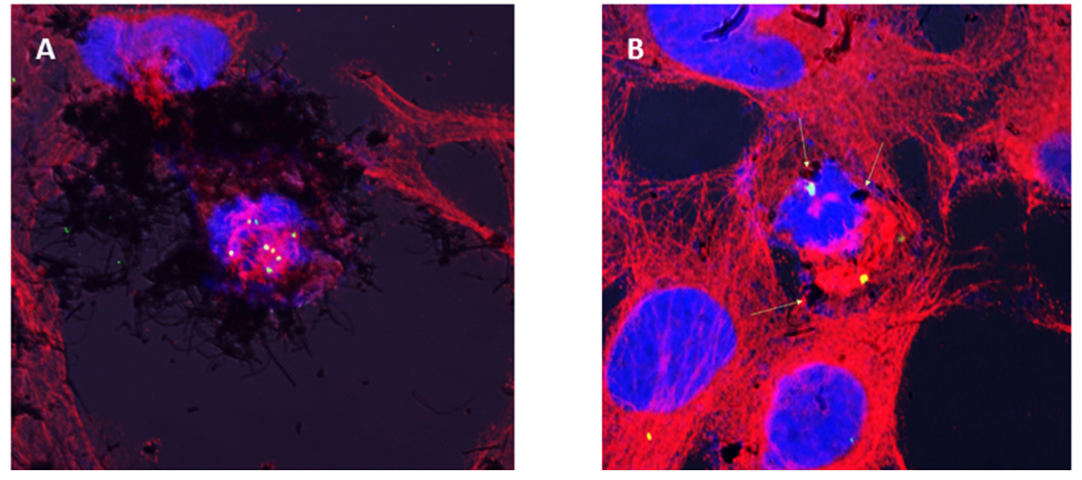
Figure 13: Centromere Fragmentation

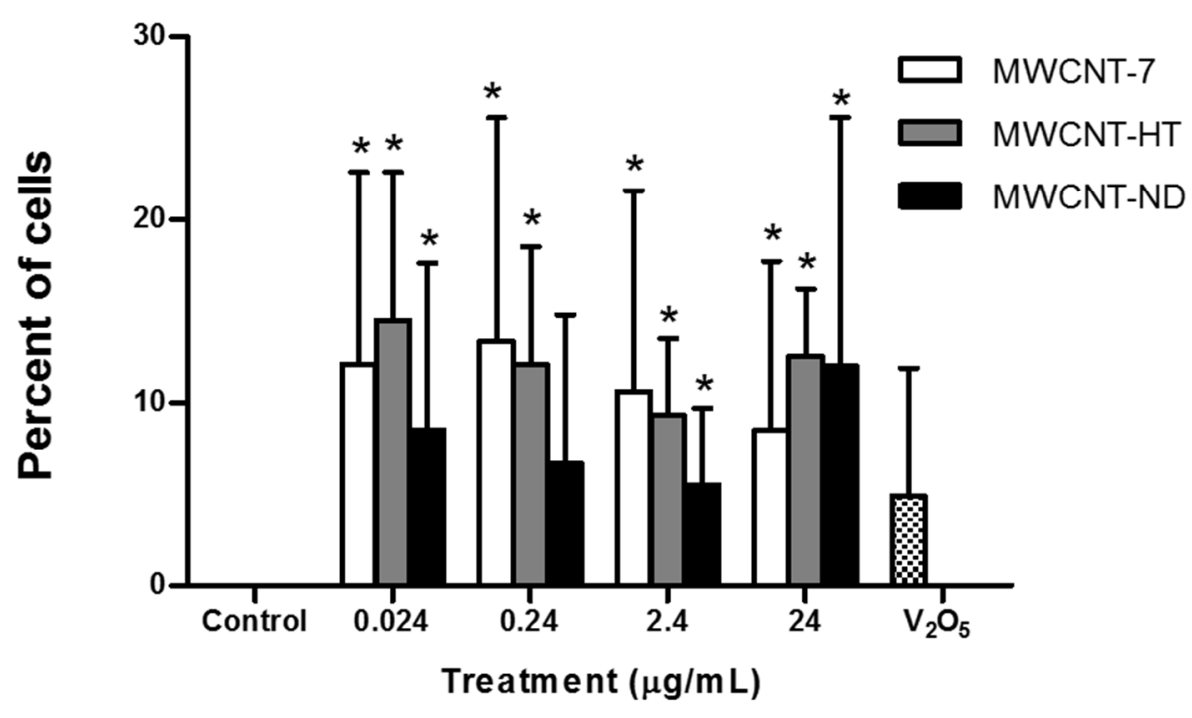

Figure 14: Centromere fragmentation, translocation, and insertion

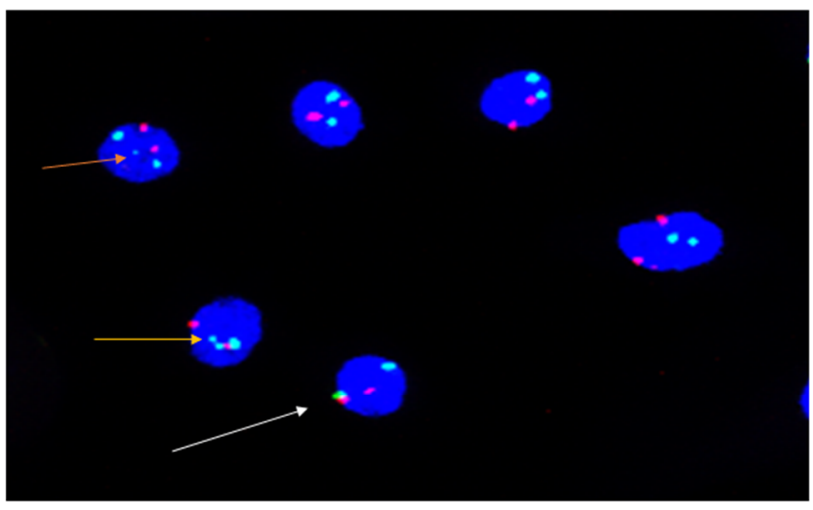




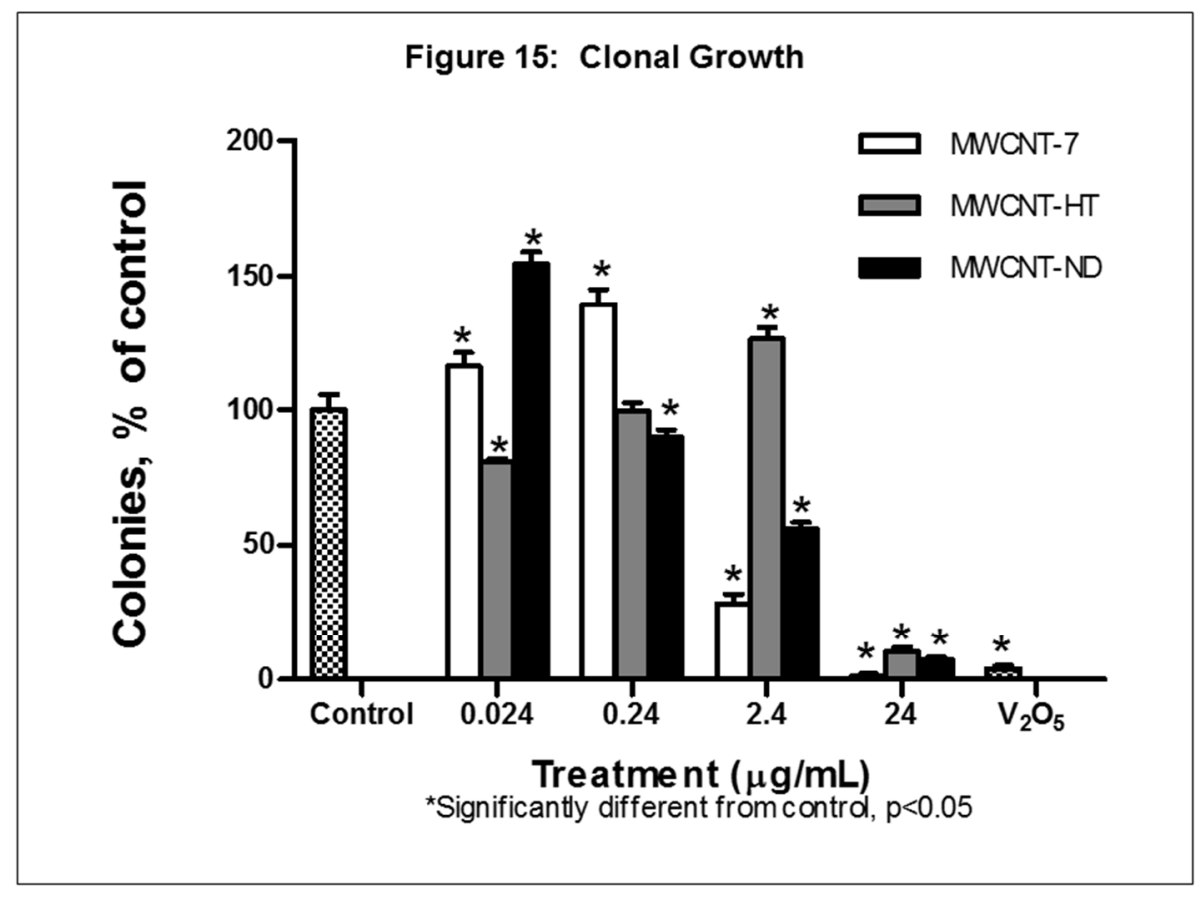

Table 1: Characterization of MWCNT Material

\begin{tabular}{llll}
\hline Measure & MWCNT-7 & MWCNT-HT & MWCNT-ND \\
\hline Mean diameter $(\mathrm{nm})$ & $49.0 \pm 13.4^{\star}$ & $56.8 \pm 23.5$ & $29.8 \pm 23.4$ \\
Mean length $(\mu \mathrm{m})$ & $4.7 \pm 3.7^{*}$ & $5.1 \pm 3.6$ & $1.9 \pm 3.1$ \\
Hydrodynamic diameter $(\mathrm{nm})$ & $411.1 \pm 15.6$ & $499.0 \pm 15.3$ & $431.9 \pm 18.3$ \\
Zeta potential in water $(\mathrm{mV})$ & $-39.5 \pm 1.0$ & $-50.6 \pm 1.3$ & $-49.3 \pm 1.5$ \\
Zeta potential in DM $(\mathrm{mV})$ & $-11.0^{*}$ & $-13.3 \pm 1.6$ & $-12.9 \pm 0.835$ \\
\hline
\end{tabular}


Table 2: Cell Cycle Analysis

A BEAS-2B cells exposed to $24 \mu \mathrm{g} / \mathrm{mL}$ MWCNT for 24 hours

\begin{tabular}{llll}
\hline Treatment & $\% \mathrm{G} 1$ & $\% \mathrm{~S}$ & $\% \mathrm{G} 2$ \\
\hline Control & $38.2 \pm 2.1$ & $22.9 \pm 2.4$ & $36.8 \pm 2.5$ \\
Arsenic & $44.7 \pm 2.8^{*}$ & $17.4 \pm 2.0^{*}$ & $35.3 \pm 2.2^{*}$ \\
MWCNT-7 & $42.2 \pm 4.2$ & $32.6=2.9^{*}$ & $24.6 \pm 2.0^{*}$ \\
MWCNT-HT & $36.2 \pm 1.7$ & $34.1=4.5^{*}$ & $26.8 \pm 3.9^{*}$ \\
MWCNT-ND & $39.4 \pm 2.3$ & $28.0=4.2$ & $30.1 \pm 3.4^{*}$ \\
\hline
\end{tabular}

B SAEC cells exposed to $24 \mu \mathrm{g} / \mathrm{mLMWCNT}$ for 24 hours

\begin{tabular}{llll}
\hline Treatment & $\% \mathrm{G} 1$ & $\% \mathrm{~S}$ & $\% \mathrm{G} 2$ \\
\hline Control & $61.2 \pm 2.4$ & $288 \pm 2.9$ & $8.1 \pm 0.8$ \\
Arsenic & $63.9 \pm 2.9$ & $25.4 \pm 3.6^{*}$ & $8.7 \pm 0.9$ \\
MWCNT-7 & $76.4 \pm 3.7^{*}$ & $10.3 \pm 4.6^{*}$ & $10.2 \pm 1.2$ \\
MWCNT-HT & $81.1 \pm 1.1^{*}$ & $4.7 \pm 1.0^{*}$ & $10.5 \pm 1.0^{*}$ \\
MWCNT-ND & $74.6 \pm 0.7^{*}$ & $13.5 \pm 1.4^{*}$ & $9.8 \pm 1.2^{*}$ \\
\hline
\end{tabular}

C SAEC cells exposed to $2.4 \mu \mathrm{g} / \mathrm{mLMWCNT}$ for 72 hours

\begin{tabular}{llll}
\hline Treatment & $\% \mathrm{G} 1$ & $\% \mathrm{~S}$ & $\% \mathrm{G} 2$ \\
\hline Control & $73.8 \pm 5.2$ & $14.6 \pm 5.7$ & $11.2 \pm 1.0$ \\
Arsenic & $72.2 \pm 2.2$ & $6.9 \pm 1.1^{*}$ & $18.3 \pm 1.4^{*}$ \\
MWCNT-7 & $55.9 \pm 2.4^{*}$ & $30.5 \pm 2.7^{*}$ & $12.7 \pm 1.2$ \\
MWCNT-HT & $69.6 \pm 5.5$ & $20.5 \pm 6.4^{*}$ & $9.5 \pm 1.4^{*}$ \\
MWCNT-ND & $67.7 \pm 4.8^{*}$ & $21.3 \pm 5.0^{*}$ & $10.5 \pm 1.5$ \\
\hline
\end{tabular}

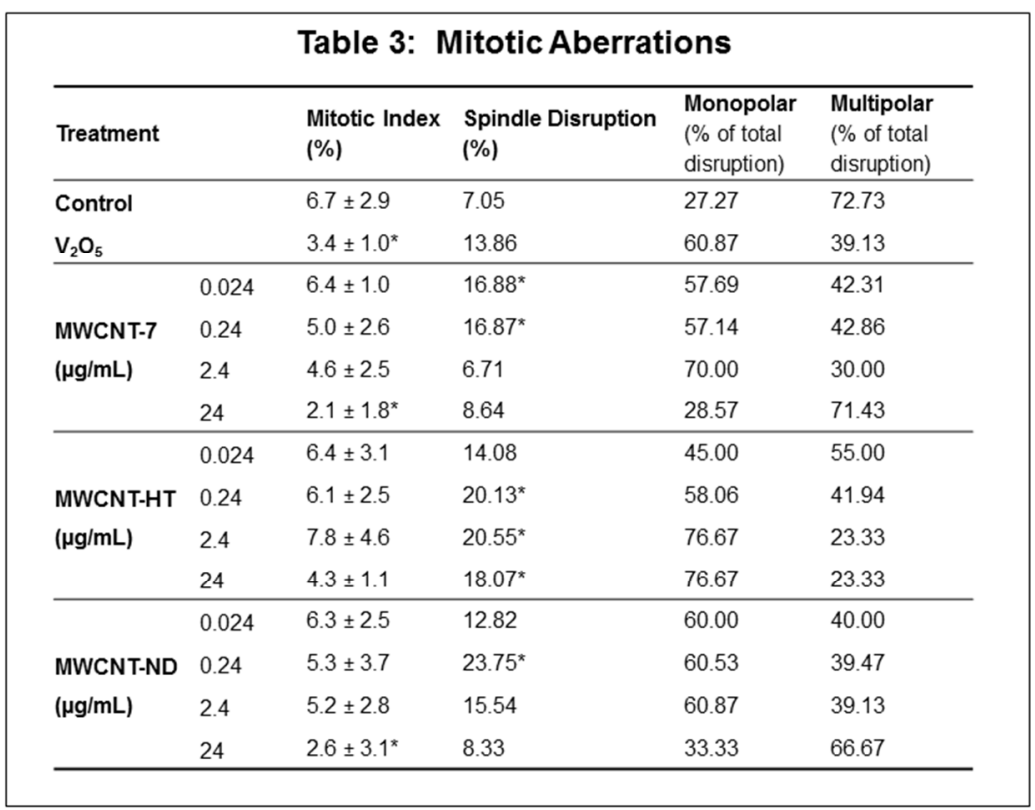




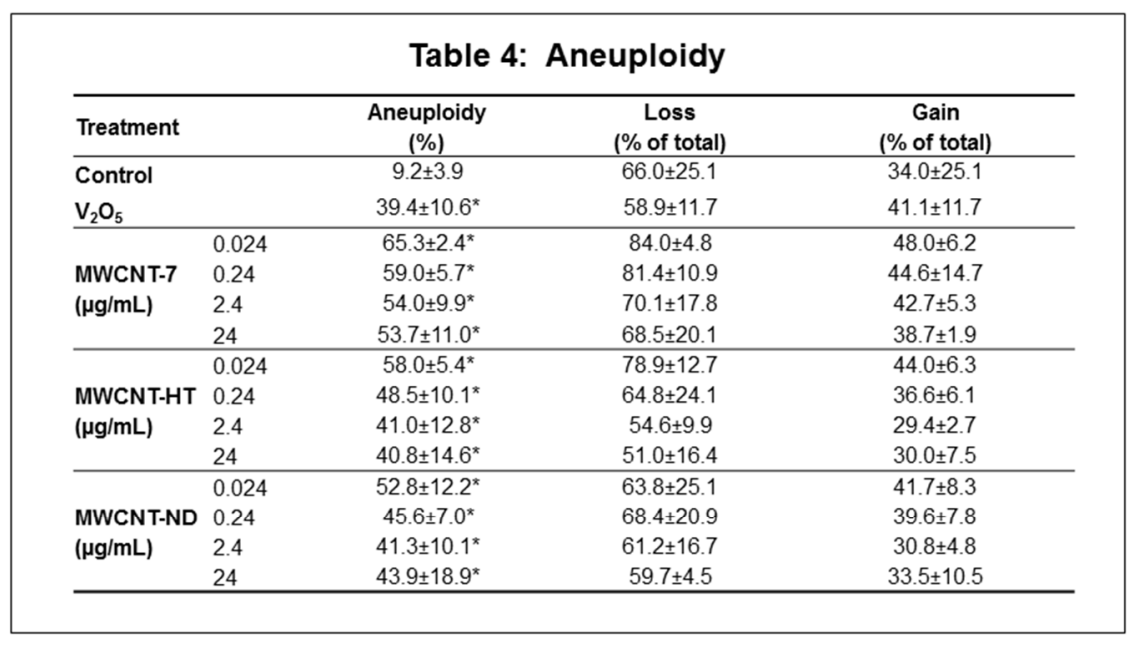




\section{Chapter 4}

\section{Promotion of lung adenocarcinoma following inhalation exposure to multi-walled carbon nanotubes}

Citation: Sargent LM, Porter DW, Staska LM, Hubbs AF, Lowry DT, Battelli L, Siegrist KJ, Kashon ML, Mercer RR, Bauer AK, Chen BT, Salisbury JL, Frazer D, McKinney W, Andrew M, Tsuruoka S, Endo M, Fluharty KL, Castranova V, Reynold SH. Promotion of lung adenocarcinoma following inhalation exposure to multi-walled carbon nanotubes. Particle and Fibre Toxicology, 2014, 11:3. PMID: 24405760

Authors:

Linda M. Sargent ${ }^{1}$

Dale W. Porter ${ }^{1}$

Lauren M. Staska ${ }^{2}$

Ann F. Hubbs ${ }^{1}$

David T. Lowry ${ }^{1}$

Lori Battelli ${ }^{1}$

Katelyn J. Siegrist ${ }^{1}$

Michael L. Kashon ${ }^{1}$

Robert R. Mercer ${ }^{1}$

Alison K. Bauer ${ }^{3}$

Bean T. Chen ${ }^{1}$

Jeffrey L. Salisbury ${ }^{4}$

David Frazer ${ }^{1}$

Walter McKinney ${ }^{1}$

Michael Andrew ${ }^{1}$

Shuji Tsuruoka ${ }^{5}$

Morinobu Endo 5

Kara L. Fluharty ${ }^{1}$

Vince Castranova ${ }^{1}$

Steven H. Reynolds ${ }^{1}$

\section{Affiliations:}

${ }^{1}$ National Institute for Occupational Safety and Health, Morgantown, WV 26505, USA

${ }^{2}$ Integrated Laboratory Systems, Durham, NC, USA 27713

${ }^{3}$ University of Colorado, Aurora CO, 80045

${ }^{4}$ Mayo Clinic, Rochester MN 55905

${ }^{5}$ Shinshu University, Nagano, Japan 380-8533 


\section{Abstract}

Background: Engineered carbon nanotubes are currently used in many consumer and industrial products such as paints, sunscreens, cosmetics, toiletries, electronic processes and industrial lubricants. Carbon nanotubes are among the more widely used nanoparticles and come in two major commercial forms, single-walled carbon nanotubes (SWCNT) and the more rigid, multi-walled carbon nanotubes (MWCNT). The low density and small size of these particles makes respiratory exposures likely. Many of the potential health hazards have not been investigated, including their potential for carcinogenicity. We, therefore, utilized a two stage initiation/promotion protocol to determine whether inhaled MWCNT act as a complete carcinogen and/or promote the growth of cells with existing DNA damage. Six week old, male, B6C3F1 mice received a single intraperitoneal (ip) injection of either the initiator methylcholanthrene (MCA, $10 \mu \mathrm{g} / \mathrm{g}$ BW, i.p.), or vehicle (corn oil). One week after i.p. injections, mice were exposed by inhalation to MWCNT ( $5 \mathrm{mg} / \mathrm{m}^{3}, 5$ hours/day, 5 days/week) or filtered air (controls) for a total of 15 days. At 17 months post-exposure, mice were euthanized and examined for lung tumor formation.

Results: Twenty-three percent of the filtered air controls, $26.5 \%$ of the MWCNT-exposed, and $51.9 \%$ of the MCA-exposed mice, had lung bronchiolo-alveolar adenomas and lung adenocarcinomas. The average number of tumors per mouse was $0.25,0.81$ and 0.38 respectively. By contrast, $90.5 \%$ of the mice which received MCA followed by MWCNT had bronchiolo-alveolar adenomas and adenocarcinomas with an average of 2.9 tumors per mouse 17 months after exposure. Indeed, $62 \%$ of the mice exposed to MCA followed by MWCNT had bronchiolo-alveolar adenocarcinomas compared to $13 \%$ of the mice that received filtered air, $22 \%$ of the MCA-exposed, or $14 \%$ of the MWCNT-exposed. Mice with early morbidity resulting in euthanasia had the highest rate of metastatic disease. Three mice exposed to both MCA and MWCNT that were euthanized early had lung adenocarcinoma with evidence of metastasis (5.5\%). Five mice (9\%) exposed to MCA and MWCNT and 1 (1.6\%) exposed to 
MCA developed serosal tumors morphologically consistent with sarcomatous mesotheliomas, whereas mice administered MWCNT or air alone did not develop similar neoplasms.

Conclusions: These data demonstrate that some MWCNT exposures promote the growth and neoplastic progression of initiated lung cells in B6C3F1 mice. In this study, the mouse MWCNT lung burden of $31.2 \mu \mathrm{g} /$ mouse approximates feasible human occupational exposures. Therefore, the results of this study indicate that caution should be used to limit human exposures to MWCNT. 


\section{$\underline{\text { Introduction }}$}

The nanotechnology industry is a multibillion dollar industry and is expected to reach a trillion dollars by 2015 [1]. Carbon nanotubes are long thin nanoparticles that are composed of a single wall (SWCNT) or multiple walls (MWCNT) of graphene sheets rolled into tubes. MWCNT have potential applications in many consumer and industrial settings including medical devices, batteries, the automobile industry, electronic processes and the aerospace industry [2,3]. Carbon nanotubes are light and easily aerosolized making workplace exposure to nanoparticles a potentially significant source of human exposure. The material resists degradation and may persist in the body for extended periods of time [4, 5]. The respiratory tract is a likely route of exposure due to the low density and small size of airborne nanoparticles. Similar to inhaled asbestos fibers, MWCNT deposited in the lungs of mice by pharyngeal aspiration or inhalation produced histologic changes including inflammation and fibrosis as well as hypertrophied and hyperplastic bronchiolar and alveolar epithelial cells [4, 6-8]. Additional changes in some alveolar epithelial Type II cells of MWCNT-exposed mice include cellular atypia [8]. MWCNT can reach the alveolar region, the interstitium, and the pleural space after both aspiration and inhalation [8-10]. Some macrophages that contain MWCNT particles have been observed without nuclei and with MWCNT connecting dividing chromosomes indicating that carbon nanotubes may be capable of inducing errors in cell division in vivo following either aspiration or inhalation exposure [8]. Type II cells from rodents exposed to MWCNT been shown to have micronuclei, indicating either a higher level of chromosome damage or mitotic spindle disruption [11]. In vitro investigations have demonstrated that carbon nanotubes disrupt the cell division apparatus and induce errors in chromosome number [11-14].

The multistage nature of cancer has been described in liver, skin, mammary, and lung models for cancer [15-18]. Carcinogenic agents can act in one or all of the stages of the neoplastic process. Initiating agents typically cause a heritable change in DNA while tumor promoters induce proliferation of DNA damaged cells to form visible preneoplastic or benign clones [19]. During the last stage of neoplastic development (progression) malignant characteristics, karyotypic instability, and frank 
neoplasms appear [19]. A complete carcinogen can act at all three stages. Cellular proliferation is a feature of the second phase of pulmonary carcinogenesis (promotion) $[16,17]$. Of interest, epithelial hyperplasia and cellular atypia were observed in mice exposed to MWCNT in vivo [8]. Therefore, the potential for carcinogenicity is of particular concern. In addition, previous studies have indicated the potential for carbon nanotubes to act during the progression of cells from preneoplastic and early benign lesions to carcinoma as shown by their ability to disrupt the mitotic spindle and induce chromosome alterations $[17,19]$. Investigations of MWCNT carcinogenicity have demonstrated that intraperitoneal or intrascrotal injection of MWCNT results in mesotheliomas in p53 +/- transgenic mice and Fischer rats, respectively $[20,21]$. The high-dose and agglomeration of the $3 \mathrm{mg}$ MWCNT exposure used in the Takagi et al. study have been questioned since it resulted in a high death rate due to gastrointestinal occlusion [22]. However, a more recent study demonstrated the induction of mesothelioma after intraperitoneal injection of as little as $3 \mu \mathrm{g}$ of MWCNT in mice [23]. Because the physical properties of MWCNT make respiratory exposure likely during the production and processing of commercial products and pulmonary exposures in rodents have indicated a potential for genotoxicity, inflammation, cell proliferation, cellular atypia, and migration to the pleural space in a manner similar to other long thin fiber-like materials that are carcinogenic, there is an urgent need to examine the potential for cancer in an animal model following inhalation of carbon nanotubes.

The overall objective of this study was to determine whether inhalation of MWCNT produced lung tumors in adult, male B6C3F1 mice using a two-stage, initiation-promotion protocol. The B6C3F1 mouse is the strain used by the National Toxicology Program to evaluate chemicals for potential carcinogenicity [24]. The B6C3F1 hybrid is of intermediate susceptibility for spontaneous lung tumor formation, however the strain is less sensitive than the sensitive/intermediate 020 and BALB/cByJ strains $[25,26]$. In addition, there is a wealth of information on the spontaneous tumor response and lifespan of the B6C3F1 mouse strain [25, 27-29]. This is the first investigation to examine the potential carcinogenicity of carbon nanotubes using a multi-stage carcinogenesis model in the B6C3F1 mouse lung. 


\section{Methods}

\section{Materials}

MWCNT used in this study were obtained from Hodogaya Chemical Company (Mitsui-7 MWNT-7, lot \#061220-31) and were manufactured using a floating reactant catalytic chemical vapor deposition method followed by high temperature thermal treatment in argon at $2500^{\circ} \mathrm{C}$ using a continuous furnace [99]. The bulk material was characterized by high-resolution transmission electron microscopsy under a Philips CM 20 transmission electron microscope (TEM) with an EDS (EDAX/4p1) as described previously [100]. MWCNT trace metal contamination of $1.32 \%$ with iron being the major metal contaminant was $1.06 \%$ [101].

\section{MWCNT inhalation exposure and aerosol characterization}

The MWCNT aerosol was generated using an acoustical-based computer controlled whole body inhalation system designed and constructed by McKinney et al., 2009 [100]. In brief, the inhalation exposure system combines air flow controllers, aerosol particle monitors, data acquisition devices, and custom software with automated feedback control to achieve constant and repeatable exposure chamber temperature, relative humidity, pressure, aerosol concentration, and particle size distributions. The generator produces airborne particles continuously for long periods of time with minimal fluctuations during an exposure period. The uniformity of test atmosphere in the chamber was evaluated to have a total variation of $<5 \%$. In this study, the MWCNT aerosol mass concentration was continuously monitored with a Data RAM (DR-40000 Thermo Electron Co, Franklin, MA), and gravimetric determinations ( $37 \mathrm{~mm}$ cassettes with $0.45 \mu \mathrm{m}$ pore-size Teflon filters) were used to calibrate and verify the Data RAM readings. Chen et al. have provided a detailed characterization of MWCNT samples taken from the animal exposure chamber [102]. In addition, cascade impactors (MOUDI, Models 110 and 115, MSP Co., Shoreview, MN) were used to determine the mass-based particle size distributions by fractionating the particles into 15 size fractions ranging from $10 \mathrm{~nm}$ to 18 $\mu \mathrm{m}$. The mass median aerodynamic diameter was determined to be $1.59 \mu \mathrm{m}$ and geometric standard 
deviation of 1.69. The count mode aerodynamic diameter was $0.42 \square \mathrm{m}[101,102]$. The target concentration of the mouse exposure was $5 \mathrm{mg} / \mathrm{m}^{3}$ for a duration of 5 hours/day for 15 days, with an accumulative exposure dose of $375 \mathrm{mg} / \mathrm{m}^{3} \times \mathrm{hr}$. The values of detailed exposure parameters were presented in Supplementary table 1. Based on data from Data RAM and filter samples, the mean concentrations among the 5 exposures were consistent at $4.6-4.7 \mathrm{mg} / \mathrm{m}^{3}$ with a daily variation between 4-8\%. Depending on the concentration measured daily, the exposure time was adjusted accordingly to result in the target dose of $375 \mathrm{mg} / \mathrm{m}^{3} \times \mathrm{hr}$. The mean exposure time per day was 320-330 minutes with a daily variation between 1-3\%. The accumulated dose was measured between 372 and $379 \mathrm{mg} / \mathrm{m}^{3} \mathrm{x}$ hours and therefore was very close to the target dose of $375 \mathrm{mg} / \mathrm{m}^{3} \times \mathrm{hr}$. In brief, the study was well conducted to fulfill the exposure design.

\section{Initiation promotion protocol}

Six week old male B6C3F1 mice (Jackson Laboratories, Bar Harbor, ME) were housed singly in a polycarbonate ventilated cage with HEPA-filtered air. Male mice were selected for the investigation because the preliminary data showing dose response, proliferation of type II cells, cellular atypia and migration of particles following carbon nanotube exposure were gathered using male mice [7-9, 103]. The mice were fed ad libitum with Harlan 7913 irradiated NIH-31 modified 6\% rodent chow. The initiation, promotion protocol developed previously by Alvin Malkinson was followed [15]. After a one week acclimation period, mice (60/group) were randomly assigned to a treatment group. The mice were treated following a two stage (initiation-promotion) protocol. An initiation-promotion protocol involved the administration of a low dose of a DNA damaging agent (methylcholanthrene, MCA) followed by administration of a suspected carcinogen that would promote the growth of DNA damaged cells (MWCNT). All mice received a single dose of either MCA (10 $\mu \mathrm{g} / \mathrm{g} \mathrm{BW,} \mathrm{i.p.)} \mathrm{or} \mathrm{vehicle} \mathrm{(corn} \mathrm{oil).}$ One week after receiving MCA, mice were exposed to MWCNT by whole body inhalation $\left(5 \mathrm{mg} / \mathrm{m}^{3}, 5\right.$ hours/day) or filtered air (controls) for 15 days. Mice were euthanized 17 months after exposure to allow time for tumor development. Mice were divided into five blocks with staggered test substance administration start and end dates. 
Because animals developing lung tumors have non-specific symptoms but may develop general signs of pain and distress, animals were monitored weekly for overt signs of morbidity and changes in body weight. Animals with skin lesions, ruffled fur, lethargy, shaking, penis or anal prolapse, erratic movements or paralysis were closely monitored for further signs of distress. Animals that had a loss of $20 \%$ or greater of body weight, were hunched or developed hind leg paralysis were euthanized for morbidity prior to the terminal sacrifice.

\section{Foreign material in lung tissues}

MWCNT burden determinations were made using a procedure previously developed with minor modification [38]. After euthanasia, lungs were removed and frozen at $-80 \mathrm{oC}$ and preserved for further processing. The lung tissue was digested in $25 \% \mathrm{KOH} / \mathrm{methanol}(\mathrm{w} / \mathrm{v})$ at $60^{\circ} \mathrm{C}$ overnight, followed by centrifugation at $16,000 \times \mathrm{g}$ for 10 minutes. The supernatant was removed; the remaining pellet was mixed with $50 \% \mathrm{HNO}_{3} /$ methanol $(\mathrm{v} / \mathrm{v})$, and incubated at $60^{\circ} \mathrm{C}$ overnight, followed by centrifugation (16,000 x g, 10 minutes). After centrifugation, the supernatant was removed, and the pellet was resuspended in $10 \% \mathrm{NP}-40(\mathrm{v} / \mathrm{v})$ in $\mathrm{dH}_{2} \mathrm{O}$, followed by 30 second sonication using cup horn sonicator. MWCNT standards were processed in parallel with the lung samples. The optical densities of the solutions were measured at $700 \mathrm{~nm}$ using a UV/visible spectrophotometer. Lung MWCNT content was determined from a standard curve.

\section{Necropsy, histopathology and tumor counts}

Groups of mice were divided into five blocks with staggered test substance administration start and end dates. The lungs and any masses from mice euthanized early were noted and the tissues collected for pathological analysis. The mice euthanized early, due to signs of morbidity [8], were analyzed separately from animals that were sacrificed 17 months after exposure. Mice were euthanized with an overdose of $\geq 100 \mathrm{mg} / \mathrm{kg}$ bodyweight pentobarbital and exsanguinated. The lungs were fixed by intratracheal perfusion with $1 \mathrm{ml}$ of $10 \%$ neutral buffered formalin. The mice were then necropsied following standard techniques [45]. Masses and lesions seen grossly were recorded on individual animal necropsy records (IANRs). The length, width and height of masses were measured in the MCA, 
air, MWCNT and MCA+MWCNT-treated mice, using a digital caliper. The calculations of the tumor volumes for spherical masses were done using $(4 / 3 \pi)\left(r^{3}\right)$ and for non-spherical masses (Length $x$ Width $x$ Height). All gross lesions and masses were then collected and fixed in $10 \%$ neutral buffer formalin (NBF). Lungs and any lesions were trimmed the same day and processed overnight. Tissues were embedded in paraffin, and sectioned at approximately $5 \mu \mathrm{m}$. Hematoxylin and eosin (H \& E) stained slides were prepared each of the five separate lung lobes and from masses seen at necropsy. The tumor counts were based on histopathological analysis.

Slides were examined by a board certified veterinary pathologist using light microscopy or polarized light, which was occasionally used to confirm the presence or absence of foreign material (presumptive test material). The severity of non-neoplastic lesions was graded on a 4-point scale of minimal (1), mild (2), moderate (3), or marked (4) using an adaptation of previously described methods [104].

Presumptive MWCNT (foreign material) was recorded when present without severity grade [104]. Focal adenomatous alveolar hyperplasia was characterized by increased numbers of crowded alveolar epithelial cells that outlined contiguous alveolar septa in discrete, generally random locations (Fig. 3). Severity was considered minimal, mild, moderate, or marked if roughly $<5,5-10,11-20$, or $>20$ contiguous alveoli were affected, respectively. Severity was increased or decreased a grade based on cell density and crowding. Histologic diagnoses were entered into the Provantis ${ }^{\circledR}$ data collection and management system. All lung slides from $10 \%$ of the mice in the terminal sacrifice were randomly selected for evaluation by a second board-certified veterinary pathologist who independently evaluated the slides while blinded to the interpretation of the study pathologist. There was $100 \%$ concordance on the diagnosis of neoplasia and $87 \%$ concordance on the diagnosis of adenocarcinoma versus adenoma. The differences were in the diagnosis of adenocarcinoma versus adenoma were considered by both the peer review and study pathologist to involve borderline lesions where such differences would be expected.

Tumor multiplicity (Table 2) was analyzed two ways. First, the number of tumors was divided by the number of animals that had tumors in each treatment group and was labeled "mean \# of lung tumor per 
mice with tumors". Secondly, the multiplicity was determined by dividing the number of tumors by the number of animals in the treatment group and was labeled "lung multiplicity adjusted by the total number of mice" (Table 2).

\section{Immunofluorescent detection of markers for mesothelioma}

Immunofluoresecent staining for mesothelial proteins were performed on sarcomatous tumors of the peritoneal and epididymal surface in mice exposed to both MWCNT and MCA. Proteins identified by immunofluorescence were cytokeratins (wide spectrum), vimentin and podoplanin based upon their previously described expression in mouse or human mesothelioma [34, 105-107]. To localize sites of vimentin and podoplanin expression to sites of cytokeratin expression, the immunofluorescence staining used double labeling for: 1) cytokeratin and vimentin, and 2) cytokeratin and podoplanin. Immunofluorescence was selected because it is more sensitive for identifying fluorescence in long, thin cytoplasm such as in alveolar type I cells or normal mesothelial cells (Battelli et al., 2001).

For immunofluorescent staining, slides were deparaffinized, antigenicity was retrieved using EDTA, and non-specific reactivity was blocked with normal donkey serum (017-000-121, Jackson ImmunoResearch Laboratories, West Grove, PA), as previously described [108]. Two primaries from different species were used for each double label. Primary antibodies were hamster anti-podoplanin (NB600-1015, Novus Biologicals, Littleton, CO), mouse anti-pancytokeratin (C2652, Sigma-Aldrich, St Louis, MO), rabbit anti-vimentin (GTX62264, GeneTex, Irvine, CA), and rabbit anti-wide spectrum cytokeratin (rabbit ab9377). Secondary anti-bodies were DyLight 488, donkey anti-mouse (715-486150, lot\# 97733, Jackson ImmunoResearch Laboratories, West Grove, PA), DyLight 594 goat antihamster (107-515-142, lot 90054, Jackson ImmunoResearch Laboratories, West Grove, PA), Dylight $488 \mathrm{~F}(\mathrm{ab}) 2$ donkey anti-rabbit and DyLight 594 donkey anti-rabbit (711-516-152, lot 97356, Jackson ImmunoResearch Laboratories, West Grove, PA). Nuclei were stained using DAPI Fluoro Pure and slides were cover slipped with Prolong anti-fade reagent. Negative control slides were treated identically except that the primary antibody was replaced with non-immune serum from the same 
species as the primary antibody. Positive control slides were the normal mesothelial lining of the liver and lung.

\section{Enhanced-darkfield light microscopy imaging of nanoparticles}

Carbon nanotubes in sections from exposed lungs were assessed using an enhanced-darkfield optical system as previously described [6]. Nanomaterials, such as carbon nanotubes, have dimensions less than the wavelength of light, have closely packed atoms, and typically have a refractive index significantly different from that of biologic tissues and/or mounting medium. These characteristics produce significantly greater scattering of light by nanoparticles than by the surrounding tissues and are visible with high contrast when examined with an enhanced-darkfield optical system designed to image scattered light in the section.

The optical system consisted of high signal-to-noise, darkfield-based illumination optics adapted to an Olympus BX-41 microscope (CytoViva, Auburn, AL 36830). Sections for dark-field examination were cut from paraffin blocks and collected on ultrasonically cleaned, laser cut slides (Schott North America Inc., Elmsford, N.Y. 10523) to avoid nanoparticle contamination from the ground edges of traditional slides. After staining with hematoxylin and eosin, sections were coverslipped with Permount. After alignment of the substage oil immersion optics with a 10x objective, sections were examined with $60 x$ air or 100x oil immersion objectives. Enhanced darkfield images were taken with a $2048 \times 2048$ pixel digital camera (Dage-MTI Excel digital camera XLMCAT, Michigan City, In 46360).

\section{Statistical analysis}

All analyses were performed using SAS/STAT version 9.3 for Windows. Binary outcomes of tumor incidence (tumor or not) for each type and for the total were analyzed using Fishers Exact test. Tumor counts were analyzed using Poisson regression for total tumor counts. In cases where Poisson regression demonstrated overdispersion a negative binomial regression was used. All analyses were stratified by promoter. Using the Proc Lifetest procedure in SAS, the log-rank test gave a p-value of 0.1609 for any differences among the 4 treatment groups with respect to the survival curves. Stratifying 
by initiator, the p-value with respect to the difference between MWCNT and Air was 0.3055, and 0.1288 for the corn oil and MCA treated animals respectively.

\section{$\underline{\text { Results }}$}

\section{Foreign material observed during histopathology assessment}

The initial MWCNT lung burden of the mice exposed to MWCNT was determined to be $31.2 \pm 0.9 \mu \mathrm{g}$ MWCNT/lung. Light microscopic analysis demonstrated foreign material (presumptive MWCNT) in the lungs of all mice in the MWCNT and MCA+ MWCNT groups, but not in MCA or Air control animals 17

months following exposure (Table 1). By light microscopy, the foreign material was approximately 0.5 to $5 \mu \mathrm{m}$ in length, finely granular to elongated, blocked light with transmitted light (appeared black) and had bright whitish birefringence under polarized light (Figs. 1A and 1B). Commonly seen in the cytoplasm of cells at terminal bronchioles and alveolar ducts, foreign material was either in presumptive macrophages or epithelial cells lining the airways, or in macrophages within connective tissue adjacent to airway epithelium (Table 1). It was also present in macrophages that formed occasional random small clusters in airways or alveoli, and were seen extracellularly in connective tissue and between cells. The diagnostic term "foreign material" was exclusively used to indicate the presumptive test article (MWCNT).

\section{Enhanced darkfield imaging of MWCNT}

Imaging using CytoViva technology demonstrated MWCNT fibers in the lungs of MWCNT-exposed mice thus confirming the presence of MWCNT material observed by light microscopic analysis in the mouse tissues 17 months following exposure to the material. MWCNT material was observed by light microscopy in the interstitium of the lung (Figure 2A). With enhanced darkfield imaging MWCNT appear as bright fibrous structures. MWCNT were observed in alveolar tissue as shown in Figure $2 \mathrm{~B}$. MWCNT were also present within the alveolar macrophages (data not shown). In addition, enhanced darkfield analysis demonstrated MWCNT in the diaphragm (Figure 2C).

\section{Hyperplasia and macrophage infiltration in the lung}

Regenerative alveolar epithelial hyperplasia is a common reaction of the murine lung to inhaled 
toxicants, including particles, while primary alveolar epithelial hyperplasia is believed to be a preneoplastic change. In humans, the form of primary bronchoalveolar hyperplasia considered preneoplastic is known as atypical adenomatous hyperplasia [30-33]. Therefore, in this paper, we have designated foci of marked, focal alveolar epithelial hyperplasia resembling human atypical adenomatous hyperplasia as focal adenomatous hyperplasia. Focal adenomatous alveolar hyperplasia was characterized by increased numbers of crowded alveolar epithelial cells that outlined contiguous alveolar septa in discrete, generally random locations (Figure 3). Animals with foci of focal adenomatous hyperplasia and macrophage infiltration were noted. The number of animals or incidence of focal adenomatous alveolar epithelial hyperplasia, macrophage infiltration, foreign material, and multifocal adenomatous bronchioloalveolar hyperplasia in the terminal bronchiole/alveolar duct regions were increased in both groups exposed to MWCNT (MCA+ and MCA-). The incidence of focal adenomatous hyperplasia was greatest in the MCA+MWCNT group relative to MWCNT, MCA and Air groups (Table 1). Focal alveolar epithelial hyperplasia was scored as marked (adenomatous) in $2 \%$, $2 \%, 5 \%$, or $27 \%$ of mice in the air, MCA, MWCNT, or MCA+ MWCNT groups, respectively.

Incidences of macrophage infiltration were higher in the MWCNT or MCA+ MWCNT groups relative to the air or MCA groups (Table 1). It was seen as occasional, random, small clusters of macrophages in airways or alveoli, or as slightly increased numbers in interstitial connective tissues often near terminal bronchioles or alveolar ducts.

\section{Lung adenoma and adenocarcinoma}

The incidences, or number of mice with tumors, of bronchiolo-alveolar adenoma, bronchiolo-alveolar adenocarcinoma, and their combined incidence was greatest in the MCA+MWCNT group relative to the other groups for each individual lung lobe and for the entire lung considered as a single tissue (Table 2).

Bronchiolo-alveolar adenomas were focal, densely cellular, slightly compressive masses that distorted alveolar architecture and replaced alveolar spaces (Figure 4). The masses were composed of proliferative epithelial cells that formed irregular papillary structures, ribbons, or solid clusters separated 
by delicate, fibrovascular stroma. The cells were polygonal, moderately uniform in size, and had small to moderate amounts of eosinophilic, occasionally vacuolated cytoplasm. Nuclei were small, round to oval, moderately uniform with inconspicuous nucleoli, and mitoses were few to absent. At terminal sacrifice, the percent of mice (incidence) with bronchiolo-alveolar adenomas in the MCA followed by air and MCA+ MWCNT groups were 33\% and 76\%, respectively, exceeding the air (11\%) and MWCNT (18\%) groups. The NTP has reported a range of 2-30\% lung adenomas in vehicle control B6C3F1 male mice thus indicating that the mice in the current study have a spontaneously-occurring lung adenoma incidence within the range expected in this mouse strain (Table 3) [24]. Furthermore, the morphology of bronchiolo-alveolar adenomas in the groups that received MCA and/or MWCNT did not differ appreciably from the spontaneously occurring neoplasms in the air group.

In contrast to bronchiolo-alveolar adenomas, bronchiolo-alveolar adenocarcinomas had increased cellular atypia, higher nuclear to cytoplasmic ratios, and larger nucleoli (Figure 5A). Several cytologic patterns were often present within the same mass, and included ribbons, papillary structures, or solid clusters (Figure 5B and 5C). The incidences of bronchiolo-alveolar adenocarcinomas in the MCA and MCA+ MWCNT groups were $22 \%$ and $62 \%$, respectively, exceeding the air (13\%) and MWCNT (14\%) groups (Table 3). The incidence of bronchiolo-alveolar adenocarcinoma in the MCA+ MWCNT group (62\%) greatly exceeded the NTP historical vehicle control range of 4-24\% for male B6C3F1 mice [24]. The combined incidences of bronchiolo-alveolar adenoma and bronchiolo-alveolar adenocarcinoma in the MCA or MCA+MWCNT groups were $51.9 \%$ and $90.5 \%$, exceeding the air $(23.2 \%)$ and MWCNT only (26.5\%) groups, and exceeding or greatly exceeding the NTP historical vehicle control range for male B6C3F1 mice (14-40\%), respectively [24].

The number of bronchiolo-alveolar adenomas and bronchiolo-alveolar adenocarcinomas was increased in the MCA and MCA+MWCNT groups relative to the Air or MWCNT groups (Table 3). The numbers of these neoplasms were greatest in the MCA+MWCNT group relative to the other groups. The MCA+MWCNT treated mice had a mean of 2.9 tumors/mouse compared to 0.81 in MCA, 0.25 air alone and 0.38 MWCNT-treated mice (Table 2). The volume of the lung occupied by tumor was greater in the 
MCA+MWCNT compared to the other groups (Figure 6). Three mice exposed to both MCA and MWCNT that were euthanized early had tumors with evidence of local invasion of the lung tissue (5.5\%). Figure 5D demonstrates lung adenocarcinoma tissue invading a vein.

Animals that were euthanized early were analyzed separately from the mice that were euthanized 17 months after exposure (Table 3). Four air control mice were euthanized early due to morbidity. Specifically, these air-exposed control mice were terminated due to a $20 \%$ loss of their body weight. One of the four air controls had a dental tumor at euthanasia. No other lesions or lung tumors were observed in the air mice either grossly or by pathological analysis. Six of the animals exposed only to MWCNT were euthanized early due to morbidity. These mice were euthanized due to significant weight loss and one animal was found to have an enlarged heart. Two of these mice had liver tumors. No lung tumors were observed in the early euthanized mice that were only exposed to MWCNT. Six animals treated with MCA followed by air were euthanized early due to a $20 \%$ or greater weight loss. One MCA mouse had a lung adenoma and one mouse had a lung adenocarcinoma. Thirteen of the animals treated with MCA followed by MWCNT were euthanized due to significant weight loss. Seven animals treated with MCA followed by MWCNT had lung tumors (Table 3). The life table demonstrates the time period of early deaths (Figure 7). The mean age of death of the animals that were euthanized early was as follows: $11.18 \pm 2.08$ months in the air group, $12.28 \pm 0.72$ months in the MCA group, $10.63 \pm 1.27$ months in the MWCNT treatment group and $11.22 \pm 1.58$ months in the MCA+MWCNTtreated group (Supplementary Figure 1). There was not a significant difference in the age of death between groups.

\section{Serosal tumors}

Malignant serosal tumors morphologically consistent with malignant sarcomatous mesotheliomas were seen in five mice (9\%) in the MCA+MWCNT group and one mouse (2\%) in the MCA group (Table 4, Figure 8). Consistent with the serosal dissemination of malignant mesotheliomas, multiple tissues were affected in four of the six affected mice. Spontaneous mesotheliomas in B6C3F1 mice are rare [24]. In recent years, a series of immunologic markers have been developed to augment the morphologic 
diagnosis of mesothelioma in man [34, 35]. For that reason, we further characterized the serosal tumors by immunofluorescence (IF) for vimentin, cytokeratin, and podoplanin in at least one tumor from each affected mouse. All presumptive sarcomatous mesotheliomas stained positively for podoplanin and vimentin. Podoplanin staining was strongly positive in all tumors evaluated from 5 mice and in one mouse varied from weakly to strongly positive in three different serosal tumors. Two wide-specrum cytokeratin antibodies were used because of the variable cytokeratin staining of sarcomatous mesotheliomas in man (Figure 9) [36, 37]. Cytokeratin staining with a mouse anti-wide spectrum cytokeratin antibody was negative in four mice and equivocal in two. Cytokeratin staining with a rabbit anti-pancytokeratin antibody was negative in tumors from four mice and equivocal to faintly positive in tumors from two mice.

\section{Discussion}

The primary objective of this investigation was to evaluate if exposure to aerosolized MWCNT promotes the growth of DNA damaged cells and/or is a complete carcinogen. To accomplish this, mice were exposed to aerosolized MWCNT ( $5 \mathrm{mg} / \mathrm{m}^{3}, 5$ hours/day) for 15 days. Initial MWCNT lung burden in these mice was $31.2 \pm 0.9 \mu \mathrm{g} \mathrm{MWCNT/mouse} \mathrm{[38].} \mathrm{In} \mathrm{order} \mathrm{to} \mathrm{evaluate} \mathrm{the} \mathrm{relationship} \mathrm{of} \mathrm{these}$ MWCNT lung burdens to human MWCNT exposures, we compared the MWCNT lung burdens in these mice with potential human occupational exposures. OSHA has not yet established exposure limits for carbon nanotubes; however, MWCNT are regulated as respirable particulates not otherwise regulated (PNOR). The PNOR have an OSHA Permissible Exposure Limit (PEL) of $5 \mathrm{mg} / \mathrm{m}^{3}$ [39]. NIOSH recently published a Current Intelligence Bulletin with a Recommended Exposure Limit (REL) of 1 $\mu \mathrm{g} / \mathrm{m}^{3}$ for carbon nanotubes which is 5000 -fold lower than the OSHA PNOR PEL [40].

Assuming a mouse alveolar epithelium surface area of $0.05 \mathrm{~m}^{2}$ [41], the $31.2 \mu \mathrm{g}$ MWCNT lung burden

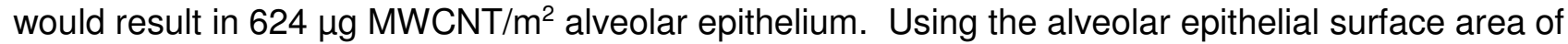
$102 \mathrm{~m}^{2}$ for human, the equivalent human lung burden would be $63.6 \mathrm{mg}$ [41].

If the MWCNT mass median aerodynamic diameter $(M M A D)=1.5 \mu \mathrm{m}$ were used, minute ventilation of $20 \mathrm{~L} /$ minute for a person performing light work [42] and an alveolar deposition fraction of 30\% [43] (for 
240 work days per year), the equivalent lung burden in workers exposed at the previous draft REL for CNT of $7 \mu \mathrm{g} / \mathrm{m}^{3}$ would be achieved in approximately 13 years [44]. This indicates that the mouse MWCNT lung burdens in this study approximate feasible human occupational exposures.

Inhalation of multi-walled carbon nanotubes (MWCNT) for 15 days following a single intraperitoneal injection of the known initiator MCA led to increased incidence and numbers of bronchiolo-alveolar adenomas and bronchiolo-alveolar adenocarcinomas in B6C3F1 male mice. The combined incidence of bronchiolo-alveolar adenomas and bronchiolo-alveolar carcinomas of $90.5 \%$ for the MCA+MWCNT group greatly exceeded that in groups of mice exposed to air or MCA and the NTP historical vehicle control range for $\mathrm{B} 6 \mathrm{C} 3 \mathrm{~F} 1$ male mice [24]. Additionally, the numbers of bronchiolo-alveolar adenomas or bronchiolo-alveolar adenocarcinomas were greatest in the MCA+MWCNT group compared to other groups. The data demonstrate that MWCNT may act as a carcinogen that promotes the growth of initiated lung cells, resulting in the development of lung adenocarcinoma.

The strong tumor promotion that was observed in the current study may have resulted from a combination of effects that have been observed following exposure to carbon nanotubes. MWCNT material was observed in the diaphragm and in the lungs, both within macrophages and the interstitium. MWCNT are internalized by macrophages following pulmonary exposure. In addition, MWCNT material has been observed in the interstitium. MWCNT exposure has been shown to induce fibrosis as early as seven days post-exposure $[8,10,45]$. In previous experiments, the post-exposure pulmonary distribution, pulmonary fibrotic response and transport of MWCNT to systemic organs was examined at various times post-exposure, from 1 to 336 days [46, 47]. Fibrillar collagen in the lungs was specifically stained and the quantity of fibrillar collagen in the alveolar region was measured by morphometry. These measurements of fibrillar collagen in the alveolar region of the lungs demonstrated a fibrotic response to inhaled MWCNT which was significantly above vehicle controls and progressively increased throughout the 336 days post-exposure study period [46]. These studies have demonstrated that inhaled MWCNTs are deposited throughout the alveolar region of the lungs and are retained in the alveolar tissue. Additionally MWCNT were demonstrated in the visceral pleura, plueral space and 
parietal space [9]. MWCNT that penetrate the visceral pleural induce pleural inflammation and cell proliferation in a manner similar to asbestos $[8,48,49]$. MWCNT have further been shown to penetrate the cytoplasmic membrane and nuclear envelope [50, 51].

Asbestos and MWCNT also induce inflammation, fibrosis, cell proliferation and cellular atypia in the lung $[8,48,49]$. Cell proliferation and inflammation are important events in the promotion of cancer [16, 17, 52-55]. Indeed in the current study, inhaled MWCNT induced dramatic hyperplasia and a moderate increase in adenomas however, the increase in adenomas was not statistically significant. In addition, MWCNT exposure did not result in an increased number of adenocarcinomas. The significant hyperplastic response that was observed after exposure to MWCNT material without prior initiation indicates that the material was a tumor promoter. The dramatic increase in adenomas and adenocarcinomas after MCA initiation followed by MWCNT-exposure demonstrate that inhaled MWCNT material is a strong tumor promoter. Strong tumor promoters increase the growth of chemically initiated as well as spontaneously initiated cells $[56,57]$. Although the data of the current investigation do not indicate that inhaled MWCNT material act as tumor initiators, the data demonstrate the strongest promotion response observed in the lung using occupationally relevant material $[15,52$, 58-60]. The data further indicate that MWCNT may initiate lung responses similar to the carcinogenic fiber asbestos [4, 61-63].

The dimensions of the nanotubes as well as their surface properties are important in the inflammatory response. Pulmonary exposure to SWCNT and MWCNT causes inflammation and fibrosis; however, the inflammatory response following MWCNT exposure is more pronounced than the response observed following SWCNT exposure $[8,64,65]$. The degree of inflammation resulting from asbestos and MWCNT is determined by the diameter and the length $[4,66,67]$. Carbon nanotubes of approximately $50 \mathrm{~nm}$ in diameter cause more inflammation than nanotubes of less than $20 \mathrm{~nm}$ or greater than $150 \mathrm{~nm}$ [67]. In addition, the rigid MWCNT of $40-50 \mathrm{~nm}$ diameter and at least 4 microns long were the most inflammatory $[67,68]$. Although these studies indicate that the diameter and length of carbon nanotubes may alter MWCNT-induced carcinogenicity further investigations are required to 
fully characterize the role of the dimensions as well as the physical properties in the carcinogenic response.

Classical multistep carcinogenesis models involve initiation, promotion and progression. Exposure to a genotoxic agent initiates a population of genetically altered cells which expand in number through the action of promoters and undergo additional genetic changes during the progression process [16, 17, 69]. Several studies suggest both genotoxicity and promotion from the classical carcinogenic high aspect ratio particle, asbestos. Oxidant generation from inflammation has been shown to damage the DNA and can initiate cancer [54]. Asbestos and carbon nanotubes have been shown to induce disruption of the cell division apparatus and errors in chromosome number (aneuploidy) in vitro [12, 14, 70]. The long, thin asbestos fibers of less than $0.25 \square \mathrm{m}$ diameter and at least 5 microns in length are the most genotoxic $[71,72]$. The mutagenicity of asbestos fibers is correlated with the potency as a carcinogen [73]. Evidence from epidemiological studies has demonstrated that asbestos can act as a tumor promoter at low doses as well as a tumor initiator at longer and/or higher exposure levels [74]. In several human epidemiology studies, smoking exposure and asbestos interact in a more than additive fashion in causing lung cancer [75-79]. There are multiple mutagens in cigarette smoke that have the potential to initiate cancer [80]. Humans are also potentially exposed to many other mutagens that could initiate cancer such as radon, polychlorinated biphenyls, hexavalent chromium, naphthalene and benzo-a-pyrene in diesel exhaust [81-85]. Thus, it is plausible to suggest MWCNT could potentially act as promoters in individuals who smoke or are exposed to other initiators.

Previous studies to examine rodent exposure to asbestos by inhalation or pharyngeal aspiration have shown that asbestos is carcinogenic in the rat lung by this route but only weakly positive in the mouse [86-88]. The data demonstrating that asbestos induces mitotic spindle disruption and aneuploidy would suggest that asbestos would be a strong tumor promoter; however, asbestos has not been administered in an initiation/promotion protocol in a mouse model. Although lung cancer has not been observed in either rats or mice following the intraperitoneal injection of asbestos or carbon nanotubes, mesothelioma has been reported. Abdominal or scrotal injection of mice with asbestos or long thin 
MWCNT of at least 3.9 micron in length and $50 \mathrm{~nm}$ in diameter caused mesotheliomas in p53 +/transgenic mice and Fischer rats [20, 21]. Recent investigations demonstrated that intraperitoneal injection of as little as $3 \square \mathrm{g}$ of MWCNT in genetically modified mice (p53+/-) induced mesothelioma [23]. By contrast, an IP exposure of Wistar rats to short MWCNT of $<1$ micron in length resulted in mesothelioma in 5/150 MWCNT-exposed animals but those findings were not statistically significant due to a high peritoneal mesothelioma rate in the control group [89]. The high background rate of peritoneal mesotheliomas (1/26) is unusual for the Wistar rat [89-91]. A subsequent study demonstrated that high exposures (1 and $10 \mathrm{mg} / \mathrm{rat}$ ) of thin, rigid MWCNT by intraperitoneal injection caused mesotheliomas (54). When the diameter of the nanotubes was considered, MWCNT of $50 \mathrm{~nm}$ in diameter were more carcinogenic than nanotubes of less than $20 \mathrm{~nm}$ or greater than $150 \mathrm{~nm}$ [67]. These findings suggest that the diameter and length are critical in the carcinogenic response to MWCNT, a finding that is similar to classical studies of asbestos fiber carcinogenicity [92].

A limitation of the current study is that suitable non-carcinogenic particle controls do not exist in this model. We considered using the short multi-walled carbon nanotubes investigated by Muller et al, as a potential negative control [89]. However, since the interpretation of the Muller et al study is affected by the unusual high background rate of peritoneal mesothelioma in the control group, this particle cannot be considered a confirmed negative control nor could we identify any carbon nanotube as a confirmed negative particle control for a carcinogenicity study. The identification of a suitable negative control nanotube will require further carcinogenicity studies that have yet to be published.

Malignant mesothelioma in humans has three major histologic patterns: epithelial, sarcomatous (sarcomatoid), and biphasic [93, 94]. Using standard histopathology, the major differential diagnoses for malignant mesothelioma include broncho-alveolar adenocarcinoma of the lung, metastatic carcinoma and metastatic sarcoma [94].The diagnosis of malignant mesothelioma in humans can be supported by staining for proteins commonly expressed in mesotheliomas, including calretinin, cytokeratins, mesothelin, WT-1 and podoplanin (D2-40) [34].Podoplanin is among the markers most consistently expressed in human malignant sarcomatous mesotheliomas [34, 95]. The malignant serosal tumors 
seen in the mice in our study consistently expressed podoplanin. However, the staining for cytokeratins was negative to equivocal, a finding that is also sometimes seen in sarcomatous mesothelioma in humans $[35,36]$. One review noted that only $13 \%$ of human sarcomatous mesotheliomas were positive for cytokeratin 5/6 and none were positive for seven other epithelial markers [37]. However, in one study using a cocktail of mouse anti-human monoclonal antibodies, $93 \%$ of the cases of human sarcomatous mesotheliomas demonstrated cytokeratin expression [96]. However, there are protein sequence differences between human and mouse cytokeratins. In addition, even with blocking steps, indirect immunohistochemistry using mouse antibodies on mouse tissues results in some degree of binding of the secondary anti-mouse $\lg G$ antibody with endogenous $\lg$ located in the mouse tissue. It is for this reason that we used both a mouse monoclonal antibody and a rabbit anti-pancytokeratin antibody to stain for cytokeratins in this study. However, the negative to equivocal staining of the serosal tumors for cytokeratins in this study should be interpreted with an understanding that mesotheliomas are very rare in the mouse and that techniques for identifying mesothelioma markers in mice are not as advanced as they are for identifying those markers in human tissue. The negative staining does not mean that there are no cytokeratins in the serosal tumors of our study, only that no cytokeratins could be identified with the antibodies used in this study.

In humans, podoplanin staining in the absence of cytokeratin staining can be seen in several different sarcomas as well as in malignant mesothelioma [34, 97]. The malignant serosal tumors seen in this study were morphologically consistent with malignant sarcomatous mesotheliomas with five of the six tumors involving multiple peritoneal serosal surfaces. The remaining malignant serosal tumor was limited to the male urogenital tract, a common site for mesothelioma in rats but not in control mice [98]. In humans, a diagnosis of cytokeratin negative sarcomatous mesothelioma is usually made by excluding other potential diagnoses [36]. Given the rarity of mesotheliomas in the mouse, we could not exclude other diagnoses with absolute certainty [24]. Thus, the characteristics of these tumors are consistent with, but not diagnostic of, mesothelioma. The principal differential diagnosis is pleural sarcoma. 
These tumors are considered similar to the serosal tumors diagnosed as pleural sarcomas or malignant mesenchymal neoplasms in the classical asbestos studies in rats conducted by Stanton and coworkers who noted their comparability to human mesotheliomas [92].

\section{Conclusions}

This study is the first to demonstrate that inhalation exposure to some MWCNTs promotes the growth of initiated lung cells in a wildtype mouse. Ninety percent of the mice exposed to MCA followed by MWCNT had lung adenocarcinoma and adenomas (mean of $2.9 /$ mouse) compared to $23 \%$ of the filtered air controls (mean of 0.25 /mouse), $26.5 \%$ of the MWCNT-exposed (mean of $0.38 /$ mouse), and $51.9 \%$ of the MCA followed by air-exposure (mean of $0.81 /$ mouse). The data therefore demonstrate that inhaled MWCNT are strong promoters of pulmonary adenomas and adenocarcinomas in B6C3F1 mice. Furthermore, the strong tumor promotion response observed following exposure to MWCNT was observed in a hybrid mouse that is intermediate in sensitivity to lung cancer [25, 26]. Because this B6C3F1 hybrid is used by the NTP to determine potential carcinogenesis, the study can be compared to a wealth of historical data generated by the NTP [24].

Furthermore, the current investigation suggests that inhaled MWCNT can promote the growth of malignant serosal tumors consistent with sarcomatous mesothelioma. MWCNT inhalation increased the incidence from $2 \%$ in the MCA exposed mice to $9 \%$ in the MCA+MWCNT, a 4.5 fold increase. However, malignant serosal tumors are uncommon tumors in mice and their potential promotion by MWCNT is of concern. NIOSH is undertaking an inhalation exposure designed to further evaluate the potential for MWCNT to cause mesothelioma. The mouse MWCNT lung burdens in the investigation are relevant to feasible human occupational exposures. While extrapolation to human health is premature, humans working with MWCNT may be exposed to numerous tumor initiators in the course of their daily lives. Results from this study suggest that caution should be taken during production and processing to limit human inhalation exposures to MWCNT. 
Disclaimer: Research findings and conclusions are those of the authors and do not necessarily represent the views of the National Institute for Occupational Safety and Health.

Acknowledgement: This work was supported by a Grant-in-Aid for Specially Promoted Research from the Ministry of Education, Culture, Sports, Science and Technology of Japan (MEXT) (No. 19002007) (ME), the Exotic Nanocarbon Project, Japan Regional Innovation Strategy Program by the Excellence, JST (Japan Science and Technology Agency) (ME, ST) The authors would like to thank Ms. Kim Clough Thomas, National Institute for Occupational Safety and Health, Morgantown, WV 26505 for her assistance with the figures. 


\section{Figure and table legends}

Table 1: The table shows the number of animals or incidence of hyperplasia, macrophage infiltration and foreign material that was observed by light microscopy. The foreign material was material that blocked the light during microscopic evaluation during pathological examination. The material was seen as black particles in the section. The foreign material as seen in all of the animals treated with MWCNT. Macrophage infiltration was observed in $5 \%$ of the Air, $9 \%$ of the MCA and, $65 \%$ of the MWCNT-exposed and $93 \%$ of the MCA+ followed by MWCNT-exposed. Focal adenomatous hyperplasia (focal hyperplasia not considered reactive) was seen in $12.2 \%$ of the Air, $14.8 \%$ of the MCA,$+ 28.5 \%$ of the MWCNT and $64.3 \%$ of the MCA+MWCNT animals. ${ }^{* *}$ indicates a statistically significant difference at $p<.05$ compared to corresponding control * indicates a statistically significant difference at $\mathrm{p}<.0001$ compared to corresponding control.

Figure 1: A. The figure is a low magnification image of MWCNT deposition in the lungs. Macrophages in alveolar spaces of the right apical lobe of the lung contain intracytoplasmic, black, elongate to finely granular particulate material (presumptive MWCNT). (40x). B. Using polarized light, the low magnification image demonstrates presumptive MWCNT are seen in macrophages in the right apical lung lobe of mouse treated with MWCNT. The material in the macrophages are birefringent. (40x).

Figure 2: A. The figure is an example of typical images from light and enhanced darkfield imaging of MWCNT in lungs and diaphragm. The light micrograph of H\&E stained section demonstrates MWCNT (black fibers) in the alveolar interstitium of a MWCNT Air exposed animal 17 months following inhalation exposure. This micrograph shows an example of MWCNT present within the alveolar interstium. Light microscope image using 100x oil immersion objective. Magnification bar is 10 microns. B. The micrograph is an enhanced darkfield image from the lung of an animal 17 months following exposure to MWCNT. The central area of the micrograph shows a region of alveolar wall with numerous MWCNT fibers present. The MWCNT are bright white due to imaging of scattered light over a broad range of wavelengths by this nanomaterial. Lung tissue, which does not significantly scatter light, is brown-to-orange and airspaces are black. The enhanced darkfield microscope image was 
photographed using a 100x oil immersion objective. The magnification bar is 20 microns. C. An enhanced darkfield imagine showing MWCNT in the diaphragm. MWCNT (indicated by the upper two arrows) are bright white. Nuclei are brown-to-orange, muscle cells are green and red blood cells are yellow. The parietal pleural border is indicated by the arrow in the lower part of the figure. Enhanced darkfield microscope image using 100x oil immersion objective. Magnification bar is 20 microns.

Figure 3: Focal adenomatous hyperplasia in a mouse exposed to i.p corn oil and inhaled MWCNT. A.) At low magnification, a focus of bronchoalveolar hyperplasia forms a discrete, hypercellular focus that retains normal alveolar architecture (bar $=200$ microns). B.) At higher magnification, the hypercellularity is attributable to a population of hypertrophied epithelial cells characterized by moderate anisokaryosis and mild karyomegaly. To distinguish these foci from foci of reactive hyperplasia and because of morphologic similarities to atypical adenomatous hyperplasia in the human lung, we have used the term focal adenomatous hyperplasia for these foci. MWCNT were sometimes seen within or near these foci (bar $=50$ microns)

Table 2: The table shows a summary of the number of tumors identified by histopathology in the corn oil/air control, MCA followed by air-treated, corn oil followed by MWCNT-treated and the MCA followed by MWCNT exposed mice 17 months following exposure $(n=56$ in the air, 54 in the MCA, 49 in the MWCNT and 42 in the MCA followed by MWCNT groups). The tissues were preserved by airway fixation using neutral buffered formalin and the number of tumors was confirmed by histological analysis. ${ }^{*}$ indicates significant difference from corresponding control at $p<.0001$.

Figure 4: The figure is a representative pulmonary bronchio-alveolar adenoma from a male B6C3F1 mouse treated with MCA + MWCNT. The mass is composed of relatively uniform cells that compressed the surrounding lung tissue. The photo with taken with a $4 x$ objective. The magnification bar is 200 microns. B. Figure $4 \mathrm{~B}$ is a photomicrograph of a pulmonary bronchiolo-alveolar adenoma from a MCA +MWCNT treated mouse. The focal, moderately cellular mass involved a bronchiole. The mass was composed of relatively uniform cells that distorted and replaced alveolar architecture. The image was photographed using a 20x objective. The magnification bar is 50 microns. $\mathrm{C}$. The light micrograph is a 
higher magnification of the H\&E stained section demonstrating MWCNT (black fibers) in the tissue surrounding the bronchiolo-alveolar adenoma (arrows 1,2 and 3). The light microscope image was taken using 100x oil immersion objective. The magnification bar is 20 microns.

Figure 5: A. The photomicrograph shows a right cardiac lung lobe of a MCA + MWCNT-treated mouse that contains a bronchiolo-alveolar adenocarcinoma (white arrow). A bronchiolo-alveolar adenoma (black arrow) is in the adjacent lung lobe. (2x). The magnification bar is 500 microns. $\mathrm{B}$. The figure is a photomicrograph of a bronchiolo-alveolar adenocarcinoma in the right cardiac lobe of a mouse lung treated with MCA + MWCNT (20x). This infiltrative adenocarcinoma filled $\sim 85 \%$ of the lobe on histologic cross section. The scale bar is $\mathbf{2 0 0}$ microns. C. The photomicrograph is a higher magnification of the bronchiolo-alveolar adenocarcinoma of the right cardiac lobe in figure B showing heterogeneous growth and pleomorphic cytologic features (40x). The scale bar is 50 microns. D. The photomicrograph shows a metastasis of the bronchiolo-alveolar adenocarcinoma in the right cardiac lobe of a mouse lung 17 months following treatment with MCA + MWCNT (40x). The arrow demonstrates a metastasis in a pulmonary vein. The scale bar is 50 microns.

Table 3: The table demonstrates the pathological changes in air controls, MCA followed by air, MWCNT followed by air and in MCA followed by MWCNT exposure. The MCA+MWCNT-treated group had a significant number of early deaths $(p<.0001)$. In addition, MCA+MWCNT-treated mice euthanized early had an elevated number of adenomas and adenocarcinomas in $62 \%$ of the mice treated with MCA+MWCNT compared to $33 \%$ of the MCA, and $0 \%$ of the MWCNT or air controls. * indicates significance at $p<.0001$.

Seventeen months following exposure, mice exposed to MCA followed by MWCNT had a significantly increased number of adenomas and adenocarcinomas in $90.5 \%$ of the exposed group compared to $26.5 \%$ of the mice exposed to corn oil followed by MWCNT, $51.9 \%$ of the MCA followed by air and $23.2 \%$ of the air controls $(p<.0001)$. The number of adenocarcinomas were significantly increased in $62 \%$ of the animals exposed to MCA followed by MWCNT when compared to $22 \%$ of the MCA followed 
by air, $13 \%$ of the air controls and $14 \%$ of the MWCNT alone groups. ${ }^{*}$ indicates significance at $\mathrm{p}<.0001$.

Figure 6: The figure demonstrates the volume of the lung occupied by tumor per individual mouse. The volume of the lung occupied by tumor was greater in the MCA + MWCNT (361 mm3+/-18.72) compared to the mice treated with MCA (202.61 mm3+/-36.75). The MWCNT group had an average tumor volume of $107.88 \mathrm{~mm} 3+/-28.70$ compared to the negative control, Air group, with a volume of $22.29 \mathrm{~mm} 3+/-3.93$. *Indicates a significant difference compared to the respective air control group at $\mathrm{p}<.0001$.

Figure 7: The life table in Figure 7 shows the percent of mice alive in each treatment group at 30 weeks after exposure to the time of sacrifice 70 weeks after exposure. The MCA + MWCNT treated animals had a greater number of early deaths than the MWCNT, the MCA or the Air treated mice.

Table 4: The table demonstrates the pathological changes in 6 mice euthanized early due to signs of morbidity. Five mice (9\%) exposed to MCA and MWCNT and $1(1.6 \%)$ exposed to MCA developed malignant serosal tumors consistent with sarcomatous mesotheliomas, whereas mice administered MWCNT or air alone did not develop similar neoplasms.

Figure 8: A. The photomicrograph shows a pulmonary vein in the right cardiac lung lobe that contained variably-sized polygonal to spindloid cells similar to those on the diaphragm (Figure 8B). The arrow indicates a metastasis of the malignant serosal tumor $(20 \times)$. The magnification bar is 50 microns. B. The skeletal muscle of the diaphragm in the photomicrograph is infiltrated by a nodular mass composed of variably-sized polygonal to spindloid cells (malignant serosal tumors). (20x). The magnification bar is 50 microns.

Figure 9: In A, the lining mesothelium (solid arrows) stained positively for podoplanin in this double label immunofluorescent image of diaphragm. The cells beneath the mesothelial lining are also red due to expression of podoplanin and these are cells of a malignant serosal tumor. In B, only the single label green fluorescence is shown to demonstrate weak expression of cytokeratins in the lining mesothelium 
(solid arrow), while staining of the subjacent tumor for cytokeratins is equivocal. In C, a double label immunofluorescent image demonstrates a malignant serosal tumor between the liver and gall bladder that is lined by reactive mesothelium (solid arrow) which stains red for podoplanin as well as green for cytokeratins. The cells of the subjacent malignant serosal tumor stain weakly red for podoplanin. In D, the photomicrograph shows this same tumor but only the green fluorescence for cytokeratins. The reactive mesothelium lining the malignant serosal tumor (solid arrow) stains green for cytokeratins while the serosal tumor has no evidence of cytokeratin expression. The normal mesothelium lining the liver is weakly positive for cytokeratins (dashed arrow). The epithelium lining the gall bladder (open arrow) strongly expresses cytokeratins. Magnification bar is $50 \mu \mathrm{m}$.

Supplementary figure 1: This figure represents the average age, in weeks, of each mouse that died prematurely per exposure group. Error bars represent standard deviation.

Supplementary table 1: The table summarizes the mean exposure concentration of MWCNT material in the inhalation chamber for each of the animal exposure periods. The data is expressed in milligrams of MWCNT per meter cubed as well as the total MWCNT concentration for 5 hours per day for a total of 15 days. The measurements of the MWCNT material was based on data collected from Data RAM and filter samples. 


\section{$\underline{\text { References }}$}

1. Bradley, J., M.M. Nordan, and O. Tassinari, The Recession's Ripple Effect on Nanotech. 2009, Lux Research, Inc.: Boston, MA.

2. Endo, M., M.S. Strano, and P.M. Ajayan, Potential applications of carbon nanotubes. Carbon Nanotubes, 2008. 111: p. 13-61.

3. Tenne, R., et al., Inorganic nanotubes and fullerene-like structures (IF). Carbon Nanotubes, 2008. 111: p. 631-671.

4. Donaldson, K., et al., Asbestos, carbon nanotubes and the pleural mesothelium: a review of the hypothesis regarding the role of long fibre retention in the parietal pleura, inflammation and mesothelioma. Part Fibre Toxicol, 2010. 7: p. 5.

5. Mercer, R.R., et al., Distribution and persistence of pleural penetrations by multi-walled carbon nanotubes. Particle and Fibre Toxicology, 2010. 7.

6. Mercer, R.R., et al., Pulmonary fibrotic response to aspiration of multi-walled carbon nanotubes. Part Fibre Toxicol, 2011. 8: p. 21.

7. Mercer, R.R., et al., Distribution and fibrotic response following inhalation exposure to multiwalled carbon nanotubes. Particle and Fibre Toxicology, 2013. 10.

8. Porter, D.W., et al., Mouse pulmonary dose- and time course-responses induced by exposure to multi-walled carbon nanotubes. Toxicology, 2010. 269(2-3): p. 136-47.

9. Mercer, R.R., et al., Extrapulmonary transport of MWCNT following inhalation exposure. Part Fibre Toxicol, 2013. 10(1): p. 38.

10. Ryman-Rasmussen, J.P., et al., Inhaled carbon nanotubes reach the subpleural tissue in mice. Nat Nanotechnol, 2009. 4(11): p. 747-51. 
11. Muller, J., et al., Clastogenic and aneugenic effects of multi-wall carbon nanotubes in epithelial cells. Carcinogenesis, 2008. 29(2): p. 427-33.

12. Sargent, L.M., et al., Single-walled carbon nanotube-induced mitotic disruption. Mutat Res, 2012. 745(1-2): p. 28-37.

13. Sargent, L.M., S.H. Reynolds, and V. Castranova, Potential pulmonary effects of engineered carbon nanotubes: in vitro genotoxic effects. Nanotoxicology, 2010. 4: p. 396-408.

14. Sargent, L.M., et al., Genotoxicity of multi-walled carbon nanotubes at occupationally relevant doses. Cancer Res, 2012. $72(8$ (Suppl 1)): p. Abstract \#5464.

15. Malkinson, A.M., et al., Butylated hydroxytoluene exposure is necessary to induce lung tumors in BALB mice treated with 3-methylcholanthrene. Cancer Research, 1997. 57(14): p. 28322834.

16. Pitot, H.C., Multistage Carcinogenesis - Genetic and Epigenetic Mechanisms in Relation to Cancer Prevention. Cancer Detection and Prevention, 1993. 17(6): p. 567-573.

17. Pitot, H.C., et al., Critical parameters in the quantitation of the stages of initiation, promotion, and progression in one model of hepatocarcinogenesis in the rat. Toxicol Pathol, 1989. 17(4 Pt 1): p. 594-611; discussion 611-2.

18. Slaga, T.J., Overview of Tumor Promotion in Animals. Environmental Health Perspectives, 1983. 50(Apr): p. 3-14.

19. Pitot, H.C. and Y.P. Dragan, Stage of Tumor Progression, Progressor Agents, and Human Risk. Proceedings of the Society for Experimental Biology and Medicine, 1993. 202(1): p. 37-43.

20. Sakamoto, Y., et al., Induction of mesothelioma by a single intrascrotal administration of multiwall carbon nanotube in intact male Fischer 344 rats. J Toxicol Sci, 2009. 34(1): p. 65-76. 
21. Takagi, A., et al., Induction of mesothelioma in p53+/- mouse by intraperitoneal application of multi-wall carbon nanotube. J Toxicol Sci, 2008. 33(1): p. 105-16.

22. Ichihara, G., et al., Re: Induction of mesothelioma in p53 mouse by intraperitoneal application of multi-wall carbon nanotube. J Toxicol Sci, 2008. 33(3): p. 381-2.

23. Takagi, A., et al., Dose-dependent mesothelioma induction by intraperitoneal administration of multi-wall carbon nanotubes in p53 heterozygous mice. Cancer Science, 2012. 103(8): p. 14401444.

24. Program, N.T. NTP Historical Controls Report All Routes and Vehicles, May 2011. B6C3F1 mice, NTP 2000 diet. 2011; Available from: http://ntpserver.niehs.nih.gov/ntp/Historical_Controls/NTP2000_2011/HistCont2011_Mice_AllRoutes.pdf.

25. Devereux, T.R., M.W. Anderson, and S.A. Belinsky, Role of Ras Protooncogene Activation in the Formation of Spontaneous and Nitrosamine-Induced Lung-Tumors in the Resistant C3h Mouse. Carcinogenesis, 1991. 12(2): p. 299-303.

26. Malkinson, A.M., The Genetic-Basis of Susceptibility to Lung-Tumors in Mice. Toxicology, 1989. 54(3): p. 241-271.

27. Hutt, J.A., et al., Life-span inhalation exposure to mainstream cigarette smoke induces lung cancer in B6C3F1 mice through genetic and epigenetic pathways. Carcinogenesis, 2005. 26(11): p. 1999-2009.

28. Pandiri, A.R., et al., Differential transcriptomic analysis of spontaneous lung tumors in B6C3F1 mice: comparison to human non-small cell lung cancer. Toxicol Pathol, 2012. 40(8): p. 1141-59.

29. Wakamatsu, N., et al., Overview of the molecular carcinogenesis of mouse lung tumor models of human lung cancer. Toxicologic Pathology, 2007. 35(1): p. 75-80. 
30. Dixon, D., et al., Lungs, Pleura, and Mediastinum, in Pathology of the Mouse, R.R. Maronpot, G.A. Boorman, and B.W. Gaul, Editors. 1999, Cache River Press: Vienna, IL. p. 293-332.

31. Foley, J.F., et al., Proliferative Lesions of the Mouse Lung - Progression Studies in Strain-a Mice. Experimental Lung Research, 1991. 17(2): p. 157-168.

32. Malkinson, A.M., Genetic-Studies on Lung-Tumor Susceptibility and Histogenesis in Mice. Environmental Health Perspectives, 1991. 93: p. 149-159.

33. Ress, N.B., et al., Carcinogenicity of inhaled vanadium pentoxide in F344/N rats and B6C3F1 mice. Toxicol Sci, 2003. 74(2): p. 287-96.

34. Husain, A.N., et al., Guidelines for Pathologic Diagnosis of Malignant Mesothelioma A Consensus Statement from the International Mesothelioma Interest Group. Archives of Pathology \& Laboratory Medicine, 2009. 133(8): p. 1317-1331.

35. Sandeck, H.P., et al., Re-evaluation of histological diagnoses of malignant mesothelioma by immunohistochemistry. Diagnostic Pathology, 2010. 5.

36. Husain, A.N., et al., Guidelines for pathologic diagnosis of malignant mesothelioma: a consensus statement from the International Mesothelioma Interest Group. Arch Pathol Lab Med, 2009. 133(8): p. 1317-31.

37. Marchevsky, A.M., Application of immunohistochemistry to the diagnosis of malignant mesothelioma. Archives of Pathology \& Laboratory Medicine, 2008. 132(3): p. 397-401.

38. Porter, D.W., et al., Acute pulmonary dose-responses to inhaled multi-walled carbon nanotubes. Nanotoxicology, 2012. 269: p. 136-47.

39. Administration, O.S.a.H. 29 CFR-Occupational Safety and Health Regulations (OSHA

Standards). In Toxic and Hazardous Substances 2006; Available from:

http://www.osha.gov/pls/oshaweb/owadisp.show_document?p_table. 
40. Health, N.I.f.O.S.a., Current Intelligence Bulletin 65: Occupational Exposure to Carbon Nanotubes and Nanofibers. . 2013.

41. Stone, K.C., et al., Allometric relationships of cell numbers and size in the mammalian lung. American journal of respiratory cell and molecular biology, 1992. 6(2): p. 235-43.

42. Galer, D.M., et al., Scientific and Practical Considerations for the Development of Occupational Exposure Limits (Oels) for Chemical-Substances. Regulatory Toxicology and Pharmacology, 1992. 15(3): p. 291-306.

43. Task, et al., Deposition and Retention Models for Internal Dosimetry of the Human Respiratory Tract. Health Physics, 1966. 12: p. 173.

44. National Institute for Occupational Safety and Health, Current Intelligence Bulletin: Occupational Exposure to Carbon Nanotubes and Nanofibers, D.o.H.a.H. Services, Editor. 2010 draft document,: Online.

45. Hubbs, A.F., et al., Acute respiratory toxicologic pathology of inhled multi-walled carbon nanotubes. Vet Pathol, 2008. 45(5): p. 786.

46. Mercer, R.R., et al., Distribution and fibrotic response following inhalation exposure to multiwalled carbon nanotubes. Part Fibre Toxicol, 2013. 10(1): p. 33.

47. Porter, D.W., et al., Acute pulmonary dose-responses to inhaled multi-walled carbon nanotubes. Nanotoxicology, 2012. Epub ahead of print.

48. Kane, A.B., Animal models of malignant mesothelioma. Inhal Toxicol, 2006. 18(12): p. 1001-4.

49. Poland, C.A., et al., Carbon nanotubes introduced into the abdominal cavity of mice show asbestos-like pathogenicity in a pilot study. Nature nanotechnology, 2008. 3(7): p. 423-8.

50. Monteiro-Riviere, N.A., et al., Multi-walled carbon nanotube interactions with human epidermal keratinocytes. Toxicology Letters, 2005. 155(3): p. 377-384. 
51. Muller, J., et al., Structural defects play a major role in the acute lung toxicity of multiwall carbon nanotubes: toxicological aspects. Chem Res Toxicol, 2008. 21(9): p. 1698-705.

52. Bauer, A.K., et al., Toll-like receptor 4 in butylated hydroxytoluene-induced mouse pulmonary inflammation and tumorigenesis. Journal of the National Cancer Institute, 2005. 97(23): p. 17781781.

53. Bauer, A.K. and E.A. Rondini, REVIEW PAPER: The Role of Inflammation in Mouse Pulmonary Neoplasia. Veterinary Pathology, 2009. 46(3): p. 369-390.

54. Hussain, S.P. and C.C. Harris, Inflammation and cancer: an ancient link with novel potentials. Int J Cancer, 2007. 121(11): p. 2373-80.

55. Malkinson, A.M., Role of inflammation in mouse lung tumorigenesis: A review. Experimental Lung Research, 2005. 31(1): p. 57-82.

56. Nebert, D.W., A. Puga, and V. Vasiliou, Role of the Ah receptor and the dioxin-inducible [Ah] gene battery in toxicity, cancer, and signal transduction. Annals of the New York Academy of Sciences, 1993. 685: p. 624-40.

57. Xu, Y.H., et al., Criteria, Mechanisms, and Potency Evaluation for Tumor Promoters - Dioxin as a Model. Chemosphere, 1992. 25(1-2): p. 227-230.

58. Bauer, A.K., et al., The lung tumor promoter, butylated hydroxytoluene (BHT), causes chronic inflammation in promotion-sensitive BALB/CByJ mice but not in promotion-resistant CXB4 mice. Toxicology, 2001. 169(1): p. 1-15.

59. Bauer, A.K., et al., Butylated hydroxytoluene (BHT) induction of pulmonary inflammation: A role in tumor promotion. Experimental Lung Research, 2001. 27(3): p. 197-216. 
60. Rondini, E.A., D.M. Walters, and A.K. Bauer, Vanadium pentoxide induces pulmonary inflammation and tumor promotion in a strain-dependent manner. Part Fibre Toxicol, 2010. 7: p. 9.

61. Donaldson, K., et al., Asbestos, carbon nanotubes and the pleural mesothelium: a review of the hypothesis regarding the role of long fibre retention in the parietal pleura, inflammation and mesothelioma. Particle and Fibre Toxicology, 2010. 7.

62. Stanton, M.F., R. Blackwell, and E. Miller, Experimental pulmonary carcinogenesis with asbestos. Am Ind Hyg Assoc J, 1969. 30(3): p. 236-44.

63. Stanton, M.F. and M.W. Layard, Carcinogenicity of natural and man-made fibers. Adv. Clin. Oncol., 1978. 1: p. 181-187.

64. Ryman-Rasmussen, J.P., et al., Inhaled multi-walled carbon Nanotubes potentiate airway fibrosis in murine allergic asthma. Am. J. Respir. Cell Mol. Biol., 2008: p. 2008-02760C.

65. Shvedova, A.A., et al., Inhalation vs. aspiration of single-walled carbon nanotubes in C57BL/6 mice: inflammation, fibrosis, oxidative stress, and mutagenesis. Am J Physiol Lung Cell Mol Physiol, 2008. 295(4): p. L552-65.

66. Murphy, F.A., et al., Length-dependent retention of carbon nanotubes in the pleural space of mice initiates sustained inflammation and progressive fibrosis on the parietal pleura. Am J Pathol, 2011. 178(6): p. 2587-600.

67. Nagai, H., et al., Diameter and rigidity of multiwalled carbon nanotubes are critical factors in mesothelial injury and carcinogenesis. Proc Natl Acad Sci U S A, 2011. 108(49): p. E1330-8.

68. Murphy, F.A., et al., Length-dependent pleural inflammation and parietal pleural responses after deposition of carbon nanotubes in the pulmonary airspaces of mice. Nanotoxicology, 2012. 
69. Barrett, J.C., Mechanisms of multistep carcinogenesis and carcinogen risk assessment. Environ Health Perspect, 1993. 100: p. 9-20.

70. Cortez, B.D., et al., The Fate of Chrysotile-Induced Multipolar Mitosis and Aneuploid Population in Cultured Lung Cancer Cells. Plos One, 2011. 6(4).

71. Yegles, M., et al., Role of fibre characteristics on cytotoxicity and induction of anaphase/telophase aberrations in rat pleural mesothelial cells in vitro: correlations with in vivo animal findings. Carcinogenesis, 1995. 16(11): p. 2751-8.

72. Yegles, M., et al., Induction of metaphase and anaphase/telophase abnormalities by asbestos fibers in rat pleural mesothelial cells in vitro. Am J Respir Cell Mol Biol, 1993. 9(2): p. 186-91.

73. Huang, S.X., et al., Role of mutagenicity in asbestos fiber-induced carcinogenicity and other diseases. J Toxicol Environ Health B Crit Rev, 2011. 14(1-4): p. 179-245.

74. Zeka, A., R. Gore, and D. Kriebel, The two-stage clonal expansion model in occupational cancer epidemiology: results from three cohort studies. Occupational and Environmental Medicine, 2011. 68(8): p. 618-624.

75. Frost, G., A. Darnton, and A.H. Harding, The effect of smoking on the risk of lung cancer mortality for asbestos workers in Great Britain (1971-2005). Ann Occup Hyg, 2011. 55(3): p. 239-47.

76. Frost, G., et al., Occupational exposure to asbestos and mortality among asbestos removal workers: a Poisson regression analysis. Br J Cancer, 2008. 99(5): p. 822-9.

77. Markowitz, S.B., et al., Asbestos, Asbestosis, Smoking and Lung Cancer: New Findings from the North American Insulator Cohort. Am J Respir Crit Care Med, 2013.

78. Metintas, S., et al., Environmental asbestos exposure in rural Turkey and risk of lung cancer. Int J Environ Health Res, 2012. 22(5): p. 468-79. 
79. Wraith, D. and K. Mengersen, Assessing the combined effect of asbestos exposure and smoking on lung cancer: a Bayesian approach. Stat Med, 2007. 26(5): p. 1150-69.

80. Hecht, S.S., Carcinogenicity studies of inhaled cigarette smoke in laboratory animals: old and new (vol 26, pg 1488, 2005). Carcinogenesis, 2005. 26(11): p. 2029-2029.

81. Cachada, A., et al., Levels, sources and potential human health risks of organic pollutants in urban soils. Science of the Total Environment, 2012. 430: p. 184-192.

82. Danadevi, K., et al., Genotoxic evaluation of welders occupationally exposed to chromium and nickel using the Comet and micronucleus assays. Mutagenesis, 2004. 19(1): p. 35-41.

83. Guimaraes, A.C., et al., Cytogenetic biomonitoring of inhabitants of a large uranium mineralization area: the municipalities of Monte Alegre, Prainha, and Alenquer, in the State of Para, Brazil. Cell Biol Toxicol, 2010. 26(5): p. 403-19.

84. Jeffrey, A.M., et al., Metabolic activation of nitropyrenes and diesel particulate extracts. Res Rep Health Eff Inst, 1990(34): p. 1-30.

85. Ulfvarson, U., et al., Effects of Exposure to Vehicle Exhaust on Health. Scandinavian Journal of Work Environment \& Health, 1987. 13(6): p. 505-512.

86. Mauderly, J.L., Relevance of particle-induced rat lung tumors for assessing lung carcinogenic hazard and human lung cancer risk. Environmental Health Perspectives, 1997. 105: p. 13371346.

87. Reeves, A.L., et al., Experimental asbestos carcinogenesis. Environ Res, 1971. 4: p. 496-511.

88. Yee, H., et al., Immunohistochemical study of fibrosis and adenocarcinoma in dominantnegative p53 transgenic mice exposed to chrysotile asbestos and benzo(a)pyrene. J Environ Pathol Toxicol Oncol, 2008. 27(4): p. 267-76. 
89. Muller, J., et al., Absence of carcinogenic response to multiwall carbon nanotubes in a 2-year bioassay in the peritoneal cavity of the rat. Toxicol Sci, 2009. 110(2): p. 442-8.

90. Poteracki, J. and K.M. Walsh, Spontaneous neoplasms in control Wistar rats: a comparison of reviews. Toxicol Sci, 1998. 45(1): p. 1-8.

91. Walsh, K.M. and J. Poteracki, Spontaneous neoplasms in control Wistar rats. Fundam Appl Toxicol, 1994. 22(1): p. 65-72.

92. Stanton, M.F., et al., Relation of particle dimension to carcinogenicity in amphibole asbestoses and other fibrous minerals. J Natl Cancer Inst, 1981. 67(5): p. 965-75.

93. Allen, T.C., Recognition of histopathologic patterns of diffuse malignant mesothelioma in differential diagnosis of pleural biopsies. Arch Pathol Lab Med, 2005. 129(11): p. 1415-20.

94. Craighead, J.E., et al., The pathology of asbestos-associated diseases of the lungs and pleural cavities: diagnostic criteria and proposed grading schema. Report of the Pneumoconiosis Committee of the College of American Pathologists and the National Institute for Occupational Safety and Health. Arch Pathol Lab Med, 1982. 106(11): p. 544-96.

95. Chu, A.Y., et al., Utility of D2-40, a novel mesothelial marker, in the diagnosis of malignant mesothelioma. Mod Pathol, 2005. 18(1): p. 105-10.

96. Klebe, S., et al., Sarcomatoid mesothelioma: a clinical-pathologic correlation of 326 cases. Mod Pathol, 2010. 23(3): p. 470-9.

97. $\mathrm{Xu}, \mathrm{Y}$., et al., High-level expression of podoplanin in benign and malignant soft tissue tumors: immunohistochemical and quantitative real-time RT-PCR analysis. Oncol Rep, 2011. 25(3): p. 599-607.

98. McConnell RF, et al., Proliferative Lesions of the Testes in Rats with Selected Examples from Mice. . Guides for Toxicologic Pathology. , ed. STp/ARP/AFIP. 1992, Washington, DC. 
99. Kim, Y.A., et al., Synthesis and structural characterization of thin multi-walled carbon nanotubes with a partially facettd cross section by a floating reactant method. Carbon, 2005. 43: p. 22432250.

100. McKinney, W., T. Chen, and D. Frazer, Computer controlled multi-walled carbon nanotube inhalation exposure system. Inhal Toxicol, 2009. 21: p. 1053-1061.

101. Porter, D.W., et al., Acute pulmonary dose-responses to inhaled multi-walled carbon nanotubes. Nanotoxicology, 2012.

102. Chen, B.T., et al., Multi-Walled Carbon Nanotubes: Sampling Criteria and Aerosol Characterization. Inhal Toxicol, 2012. 24: p. 798-820.

103. Porter, D.W., et al., Differential mouse pulmonary dose and time course responses to titanium dioxide nanospheres and nanobelts. Toxicol Sci, 2012. 131(1): p. 179-93.

104. Battelli, L.A., et al., Crystalline silica is a negative modifier of pulmonary cytochrome P-4501A1 induction. J Toxicol Environ Health A, 2008. 71(8): p. 521-32.

105. LaRocca, P.J. and J.G. Rheinwald, Coexpression of simple epithelial keratins and vimentin by human mesothelium and mesothelioma in vivo and in culture. Cancer Res, 1984. 44(7): p. 2991-9.

106. Servais, E.L., et al., Mesothelin Overexpression Promotes Mesothelioma Cell Invasion and MMP-9 Secretion in an Orthotopic Mouse Model and in Epithelioid Pleural Mesothelioma Patients. Clinical Cancer Research, 2012. 18(9): p. 2478-2489.

107. Shirai, M., et al., Mixed Type of Malignant Mesothelioma in an Aged Male ICR Mouse. J Toxicol Pathol, 2011. 24(3): p. 169-72.

108. Hubbs, A.F., et al., Respiratory and olfactory cytotoxicity of inhaled 2,3-pentanedione in Sprague-Dawley rats. Am J Pathol, 2012. 181(3): p. 829-44. 


\section{Figures and Tables}

Figure 1: Foreign material observed by light microscopy and polarized light

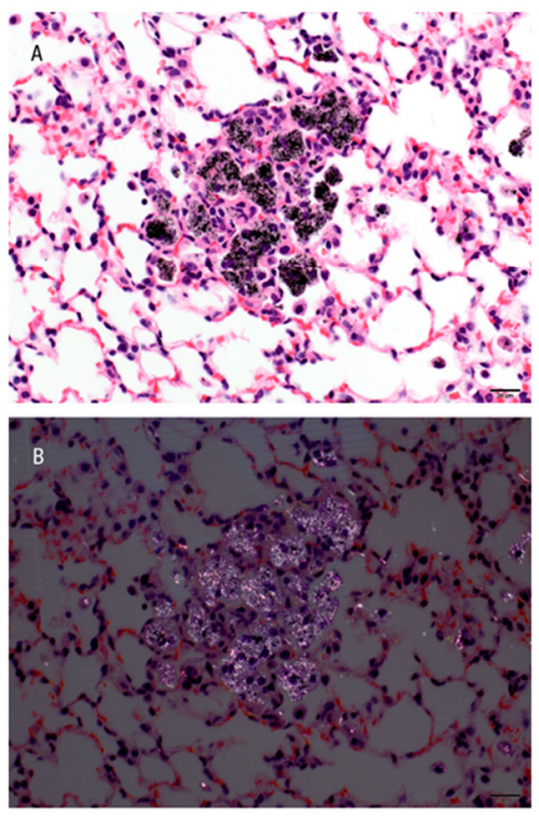

Figure 2: CytoViva Imaging
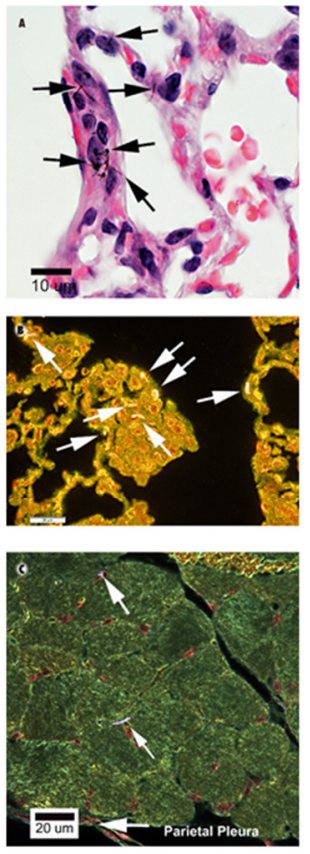

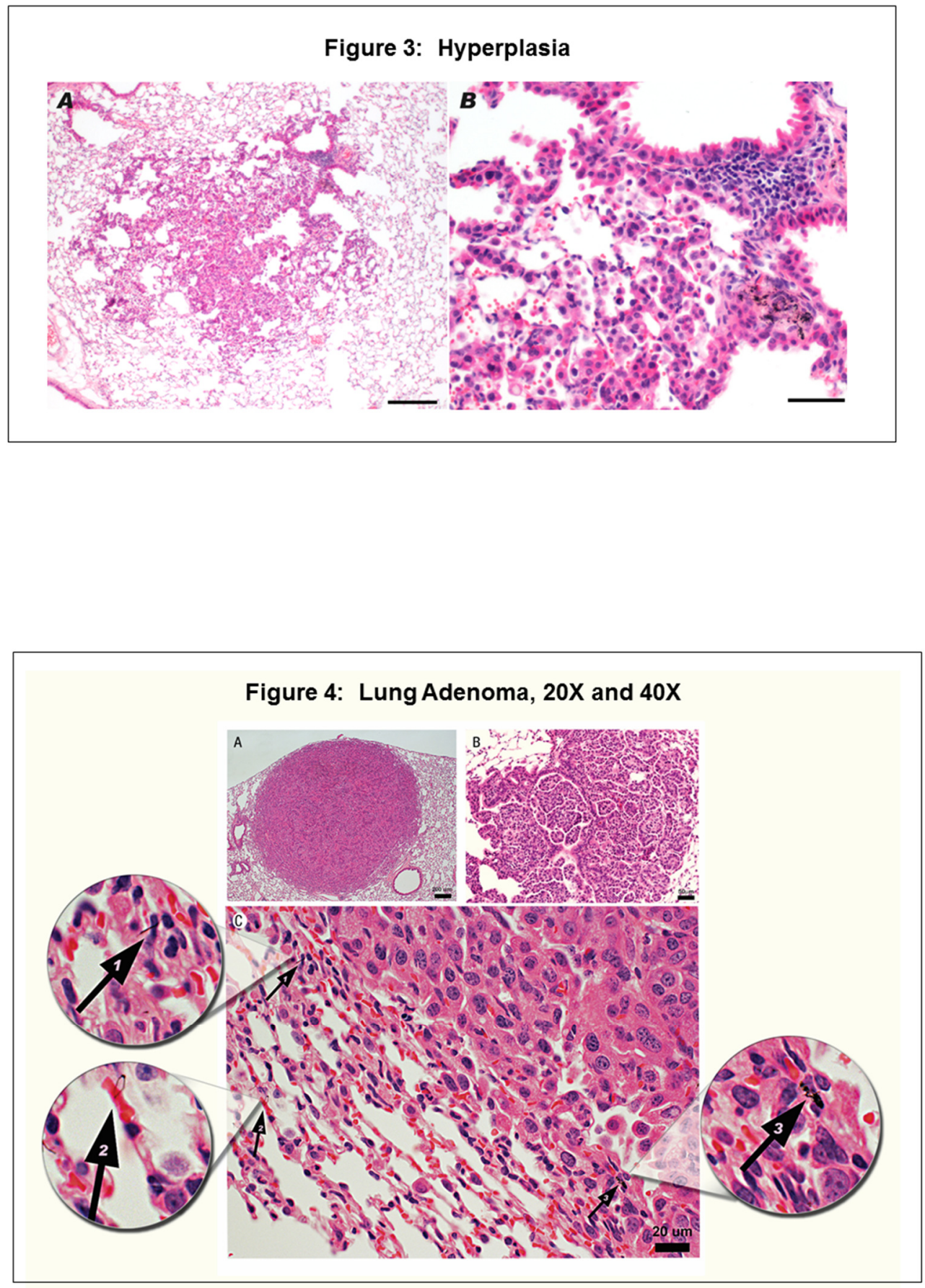

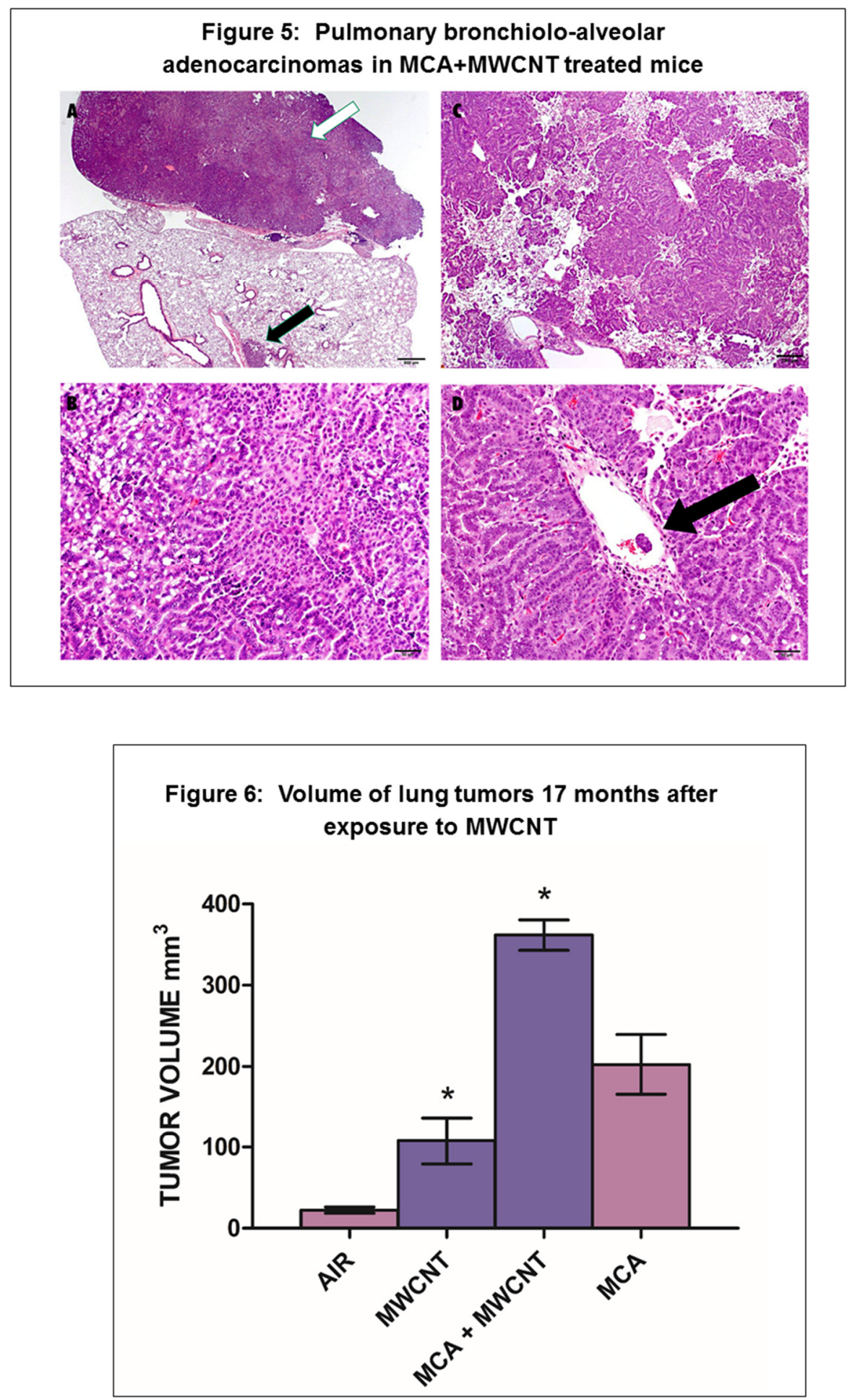


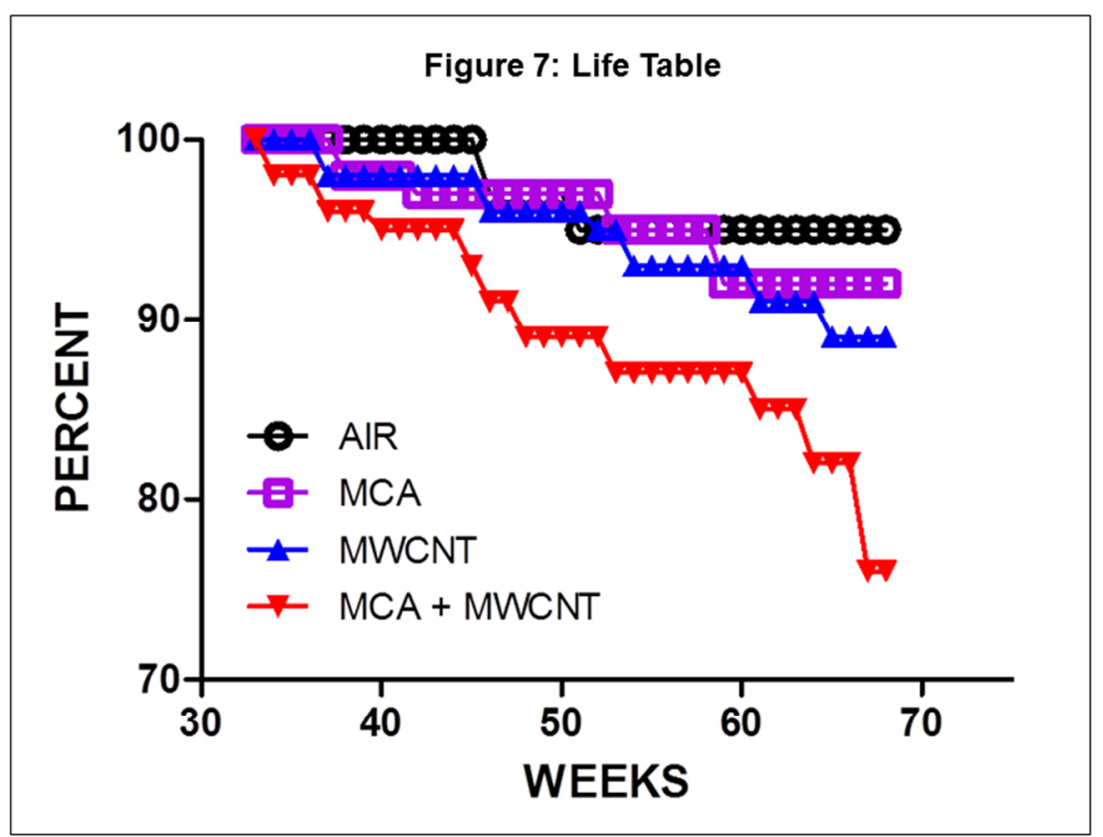

Figure 8: Malignant serosal tumors in the lung and diaphragm
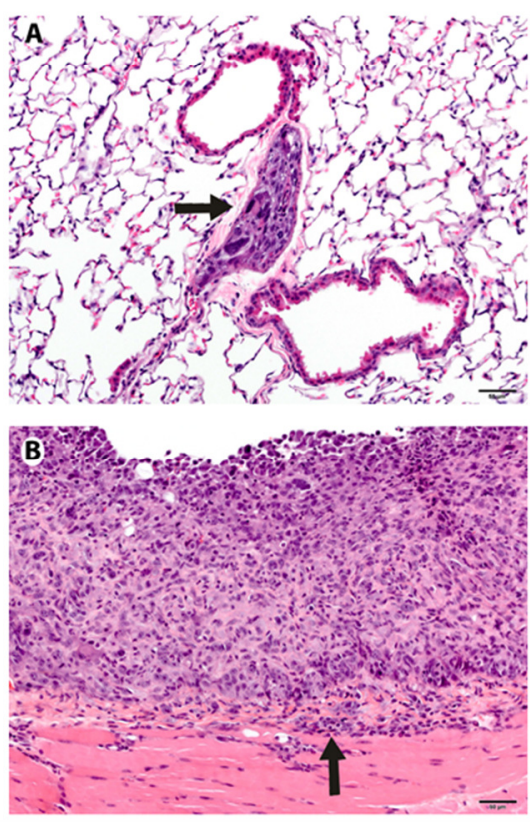
Figure 9: Immunofluorescent staining for podoplanin and cytokeratins in malignant serosal tumors

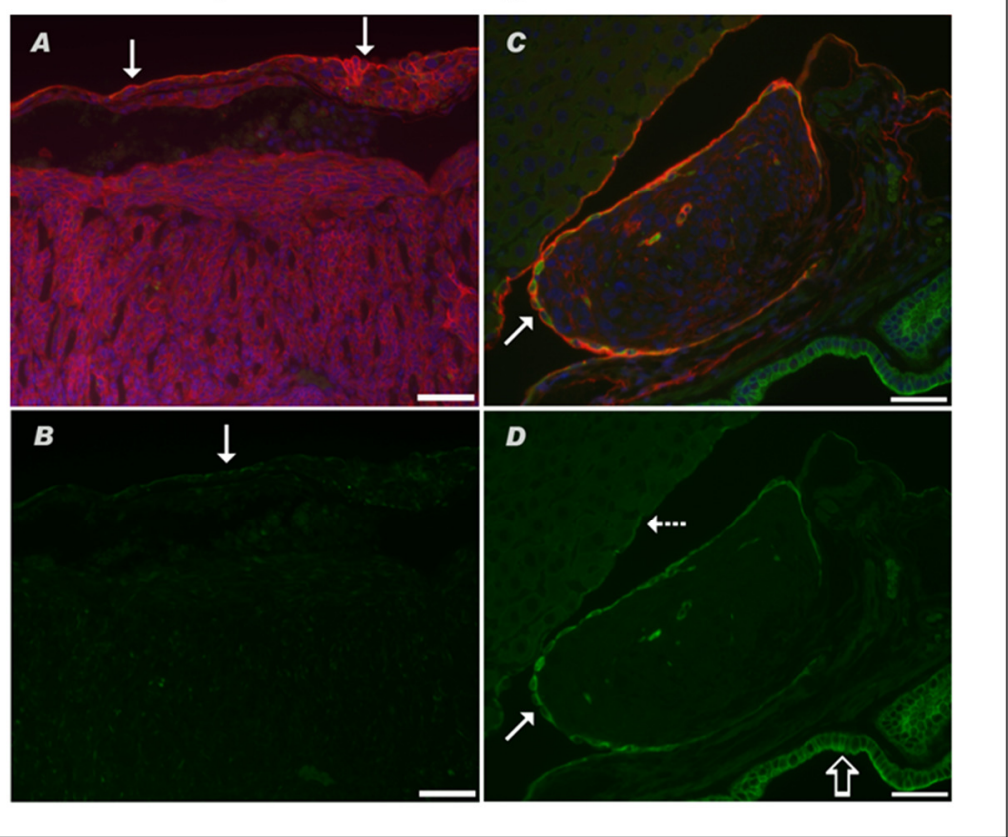


Table 1: Incidence of focal adenomatous hyperplasia, macrophage infiltration and foreign material in the lung by light microscopy

Focal alveolar adenomatous hyperplasia, macrophage infiltration and foreign material observed in MWCNT-treated mice 17 months following exposure

\begin{tabular}{llcc}
\hline & Air & MCA & MWCNT \\
\hline Number of animals/group & 56 & 54 & 49 \\
Number animals with positive foreign material & 0 & 0 & 42 \\
Macrophage infiltration & 3 & $99^{*}$ & $32^{*}$ \\
Number animals with positive for focal adenomatous alveolar hyperpasia & 7 & $89^{*}$ & $14^{*}$ \\
\hline
\end{tabular}

Statistical significance at ${ }^{*} \mathrm{p}<.0001$

Table 2: Incidence and multiplicity of lung tumors in B6C3F1 mice 17 months following exposure to Mitsui-7 MWCNT

\begin{tabular}{|c|c|c|c|c|c|}
\hline Treatment & $\begin{array}{c}\text { Total number } \\
\text { of mice }\end{array}$ & $\begin{array}{l}\text { Percent of animals } \\
\text { with tumors }\end{array}$ & $\begin{array}{l}\text { Total number of } \\
\text { lung tumors }\end{array}$ & $\begin{array}{l}\text { Lung tumors/total } \\
\text { number of animals }\end{array}$ & $\begin{array}{c}\text { Number of } \\
\text { adenocarcinomas/group }\end{array}$ \\
\hline AIR & 56 & 23.2 & 17 & $0.25 \pm 0.166$ & 7 \\
\hline MCA & 54 & $51.9^{*}$ & $41^{*}$ & $0.81 \pm 0.167$ & $14^{*}$ \\
\hline MWCNT & 49 & 265 & 20 & $0.38 \pm 0.185$ & 7 \\
\hline MCA + MWCNT & 42 & $90.5^{*}$ & $133^{*}$ & $2.9 \pm 0.386^{*}$ & $56^{*}$ \\
\hline
\end{tabular}


Table 3: Incidence of lung tumors in early euthanized mice and mice 17 months after exposure

\begin{tabular}{|c|c|c|c|c|c|c|c|c|}
\hline \multirow[t]{2}{*}{ Euthanasia } & \multicolumn{4}{|c|}{ Early sacrifice } & \multicolumn{4}{|c|}{ Terminal sacrifice } \\
\hline & Air & $\mathrm{MCA}$ & MWCNT & $M C A+M W C N T$ & Air & MCA & MWCNT & $\mathrm{MCA}+\mathrm{MWCNT}$ \\
\hline Number of animals & 4 & 6 & 6 & 13 & 56 & 54 & 49 & 42 \\
\hline $\begin{array}{l}\text { Number of Bronchiolo-alveolar } \\
\text { adenomas }\end{array}$ & 0 & 1 & 0 & 4 & 6 & $18^{*}$ & 9 & $32 *$ \\
\hline $\begin{array}{l}\% \text { of mice with one or more } \\
\text { Bronchiolo-alveolar adenoma }\end{array}$ & $0 \%$ & $17 \% *$ & $0 \%$ & $31 \% *$ & $11 \%$ & $33 \% *$ & $18 \%$ & $76 \% *$ \\
\hline $\begin{array}{l}\text { Number of Bronchiolo-alveolar } \\
\text { adenocarcinomas }\end{array}$ & 0 & 1 & 0 & 7 & 7 & 12 & 7 & 26 \\
\hline $\begin{array}{l}\% \text { of mice with Bronchiolo-alveolar } \\
\text { Adenocarcinomas }\end{array}$ & $0 \%$ & $17 \% *$ & $0 \%$ & $54 \% *$ & $13 \%$ & $22 \% *$ & $14 \%$ & $62 \% *$ \\
\hline $\begin{array}{l}\text { Number of mice with one or } \\
\text { more- Bronchiolo-alveolar adenoma } \\
\text { and/or Bronchio-alveolar } \\
\text { adenocarcinomas }\end{array}$ & 0 & 2 & 0 & 8 & 13 & $28^{*}$ & 13 & $38 *$ \\
\hline Percent of mice with lung tumors & $0 \%$ & $33 \%$ & $0 \%$ & $62 \% *$ & $23.2 \%$ & $51.9 \% *$ & $26.5 \%$ & $90.5 \% *$ \\
\hline
\end{tabular}




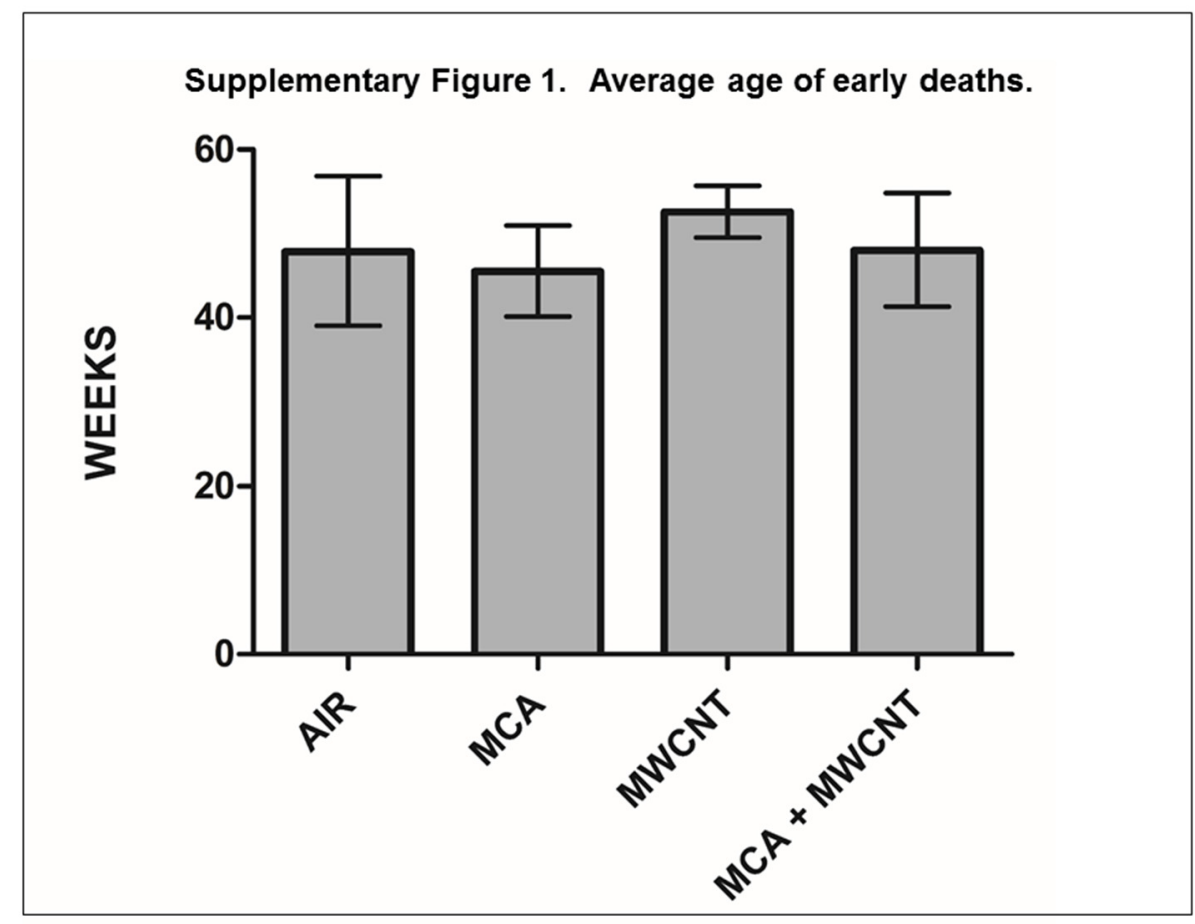

Supplementary table 1: Summary of MWCNT exposures in the MWCNT/Cancer Study

\begin{tabular}{|c|c|c|c|c|c|}
\hline \multicolumn{5}{|c|}{ Daily Exposure Concentration and Duration } & \multirow{2}{*}{$\begin{array}{c}\text { Accumulated Exposure Dose } \\
\begin{array}{c}\text { Conc } \times \text { Time } \\
\mathrm{mg} / \mathrm{m}^{3} \times \mathrm{hr}\end{array}\end{array}$} \\
\hline Exp \# & $\begin{array}{c}\text { Mean Conc. } \\
\mathrm{mg} / \mathrm{m}^{3}\end{array}$ & $\begin{array}{c}\text { Variation, } \\
\%\end{array}$ & $\begin{array}{c}\text { Mean Exp. } \\
\text { Time/day, } \\
\text { min }\end{array}$ & $\begin{array}{c}\text { Variation, } \\
\%\end{array}$ & \\
\hline 1 & 4.6 & 6.6 & 327 & 2.5 & 372 \\
\hline 2 & 4.7 & 7.4 & 323 & 1.5 & 379 \\
\hline 3 & 4.6 & 4.5 & 326 & 1.7 & 375 \\
\hline 4 & 4.6 & 5.4 & 328 & 2.7 & 376 \\
\hline 5 & 4.6 & 7.5 & 323 & 1.6 & 373 \\
\hline
\end{tabular}




\section{Summary}

\section{Introduction}

Lung cancer is the leading cause of cancer-related deaths in the United States [1] and occupational exposures to carcinogens accounts for approximately 9 to 15 percent of all diagnosed cases [2]. IARC has recognized MWCNT-7 material as a Group 2B carcinogen; however, data are still lacking regarding mechanisms, physiocochemical alterations, and relatability to human exposures [3].

\section{Summary of key findings}

The purpose of this project was to determine the effect of physicochemical alterations of MWCNT on the genotoxicity and carcinogenicity of the material. The mechanistic data collected for MWCNT 10$20 \mathrm{~nm}$ in diameter (Chapter 2) and MWCNT-7, MWCNT-HT, and MWCNT-ND (Chapter 3) has helped fill the gap in knowledge. The MWCNT-7 material was shown in Study 3 (Chapter 4) to be a significant tumor promoter and was the first study to show this effect via inhalation route of exposure. The MWCNT material used in Study 1 had a mean diameter similar to the mitotic spindle which was the target structure involved in the hypothesized mechanism of genotoxicity. The MWCNT-7, HT, and ND materials were slightly larger in diameter than the mitotic spindle with chemical alterations induced by high temperature treatment and nitrogen-doping during synthesis, thereby increasing purity or solubility, respectively. The MWCNT-7 material has been shown previously to be genotoxic and tumorigenic in animals due to its rigidity and structure. However, animal studies using this particular material have never been conducted using whole-body inhalation, an applicable route of exposure.

The MWCNT material in Study 1 demonstrated a significant G1/S cell cycle arrest in the BEAS-2B cells after 24 hours of exposure indicating genotoxic damage. Analysis of the mitotic spindle revealed a significant increase in cell division aberrations in the BEAS-2B cell after 24 hours of exposure that were predominantly monopolar in morphology. This result was different from multipolar spindle morphologies found in previous studies of SWCNT and asbestos in culture, and, therefore, unexpected. The mitotic spindle aberrations led to significantly increased aneuploidy in the primary SAEC cell that were the result of gains rather than losses of either chromosomes 1 or $4[4,5]$. This is an indication of failed cytokinesis where the incorporation of MWCNT material within the microtubule prevents the 
separation of dividing cells. Indeed, we observed MWCNT material in the bridge of cytokinesis and throughout the mitotic spindle structure. Additionally, we observed MWCNT material interacting with spindle poles and centrosomes. This interaction caused centrosomes to fragment.

In the Study 2 the genotoxicity of MWCNT-7, HT, and ND material was measured in two cell types, BEAS-2B and SAEC. In the BEAS-2B cell, $24 \mu \mathrm{g} / \mathrm{mL}$ of each MWCNT material produced an arrest in the G1/S phase of the cell cycle compared to control after 24 hours of exposure. In the SAEC cell, 24 $\mu \mathrm{g} / \mathrm{mL}$ of each MWCNT material produced an arrest in the $\mathrm{G} 1$ and $\mathrm{G} 2$ phases of the cell cycle after 24 hours of exposure. After 72 hours of exposure, $2.4 \mu \mathrm{g} / \mathrm{mL}$ of each MWCNT material produced an arrest in the G1/S phase of the cell cycle after a 24 hour recovery. The differences between the effects observed in each cell type and exposure time could be an indication of increased proliferation, mitotic delay, or p53 regulation. BEAS-2B cells were exposed to each MWCNT material for 24 hours in a dose-response to observe mitotic spindle aberrations. A dose-dependent effect was not observed due to inherent cytotoxicity of the MWCNT materials resulting in low mitotic index; however, the percentage of mitotic aberrations was significantly increased after exposure to each MWCNT material. Mitotic aberrations were predominately monopolar in morphology, similar to study 1 . Spindle pole and centrosome integrity were compromised as observed through amplified and fragmented centrosomes. SAEC cells were exposed to each MWCNT material for 24 hours in a dose-response to enumerate chromosomes 1 and 4. A dose-dependent increase in the percentage of aneuploidy was observed for MWCNT-7, HT, and ND material with the lowest dose of $0.024 \mu \mathrm{g} / \mathrm{mL}$ producing a greater effect than the positive control, $\mathrm{V}_{2} \mathrm{O}_{5}$, with $53.7 \pm 11.0,40.8 \pm 14.6$, and $43.9 \pm 18.9 \%$ aneuploidy, respectively. Analysis of the centromere revealed centrosome fragmentation after exposure to each MWCNT material. Clonal growth assays demonstrated that cellular proliferation was increased after exposure to each MWCNT material in the SAEC, albeit at difference doses. Although each MWCNT material produced significant genotoxicity, there was an attenuation of effect for the MWCNT-HT and ND material. These effects were most likely due to the reduction in nuclear uptake of these two materials compared to MWCNT-7. 
Inhalation of MWCNT-7 material was shown to produce significant tumor promotion in the B6C3F1 mouse model. Mice were IP injected with either MCA, known DNA damaging agent, or corn oil (vehicle control) and then exposed to either air or MWCNT via inhalation. Exposure to MCA+MWCNT produced 90.5\% incidence of bronchioalveolar adenomas and adenocarcinomas, combined, whereas exposure to MCA alone produced an incidence of $51.9 \%$. Exposure to control air produced an incidence of $23.2 \%$ and exposure to MWCNT alone produced $26.5 \%$ of mice with both bronchioalveolar adenoma and adenocarcinoma. Spontaneous mesotheliomas in B6C3F1 mice are rare, however malignant serosal tumors morphologically consistent with malignant sarcomatous mesotheliomas were seen in five mice (9\%) exposed to MCA+MWCNT and one mouse (2\%) exposed only to MCA. These data demonstrate that inhalation exposure to MWCNT material alone does not produce a significant increase in tumor formation, however exposure to MWCNT following exposure to an initiating substance produces a highly significant increase in tumor formation indicating MWCNT material to be a strong tumor promotor.

\section{Discussion}

MWCNT are synthesized through several methods that involve the use of a metal catalyst attracting free carbon atoms. A MWCNT in this state is labelled as "pristine", but detailed physical and chemical analysis demonstrates otherwise. Pristine MWCNT have many structural defects in the graphene lattice of its walls and contain a significant amount of metal impurities leftover from the catalyst. These characteristics have been shown to negatively impact the efficiency of this material in industrial products. Covalent chemical functionalization, high-temperature treatment, elemental doping during synthesis, and chemical coating are just a few methods that have been utilized to alter the characteristics of MWCNT material for industrial purposes. These methods can change both the chemical and physical properties of this material and affect toxicity.

These physicochemical changes not only affect the industrial usage of this material, but also the toxicological outcomes. Gernand and Casman (2014) performed a meta-analysis of carbon nanotube pulmonary toxicity studies to determine this effect [6]. They found MWCNT metallic impurities, length, diameter, aggregate size, and surface area to be significantly correlated with toxicity endpoints 
involving bronchioalveolar lavage fluid [6]. Additionally, Poulsen et al. (2016) investigated the in vivo inflammatory and genotoxic effects of MWCNT with varying physicochemical properties and found surface area, length, and diameter to be significant predictors of toxicity [7].

Mitsui-7 MWCNT are the most widely studied carbon nanotube. MWCNT have been acid washed which produces shorter tubes with carboxylic acid functional groups. High-temperature treatment over $2200^{\circ} \mathrm{C}$ anneals the outermost wall creating a more crystalline structure and removes catalytic impurities leftover from synthesis [8-11]. The addition of ammonia during the synthesis of MWCNT through catalytic chemical vapor deposition (CCVD), produces a material with greater electrical capacity $[12,13]$. This nitrogen-doped MWCNT has nitrogen either incorporated into the lattice structure of the graphene wall or as an amine functional group [14, 15]. MWCNT-ND are typically larger in diameter and shorter due to the nitrogen incorporation [13, 16-18] .

Pristine MWCNT (10-20 nm) have similar diameter and physical properties to that of the microtubules that make up the division apparatus [19] and form hybrids with the microtubules [20]. By altering the physiochemical properties of MWCNTs these hybrids could be eliminated and toxicity reduced. Additionally, they have been shown to disrupt cellular division [21]. MWCNTs have similar diameter and physical properties to that of the microtubules that form the mitotic spindle and, therefore, form hybrids with the microtubules [20]. Furthermore, MWCNT have been observed inside the centrosome (mitotic spindle pole) through confocal microscopy. These interactions with the mitotic spindle disrupt the separation of chromosomes into the dividing cells and causes abnormal chromosome numbers, otherwise known as aneuploidy [21]. Disruption of the mitotic spindle pole is common in many solid tumors including lung cancer $[22,23]$. The resulting aneuploidy is a key event in the progression of cancer and is correlated with tumor stage [24]. Previously, CNT material has been shown to interact with the mitotic spindle and inhibit cytokinesis in vivo as indicated by the observation of carbon bridges observed between two daughter macrophages [25].

Carbon nanotubes also have a high affinity for DNA inducing conformation changes and mutations [26, 27]. Specifically, CNT can intercalate with the DNA and bind to G-C rich sequences in 
the chromosomes and cause a destabilization in the helix structure leading to chromosome breakage and chromosome instability [26].

Physicochemical alterations produced differences in cellular and nuclear uptake of the material. Studies $1 \& 2$ utilized lung epithelial cells and there is debate as to the mechanism of uptake for this cell type. Alveolar cells from the hamster lung have been shown to transform to actively phagocytose asbestos particles in culture [28]. However, CNT material has also been shown to passively diffuse through the cellular membrane.

Chemical functionalization has been shown to affect nuclear uptake of nanomaterials. Silica nanoparticles with amine or carboxylated functionalization remain in the cytoplasm of murine macrophages whereas noncharged particles can enter the nucleus [29]. However, localization in the nucleus is not a prerequisite for action on the DNA and other nuclear structures. Degradation of the nuclear membrane is a necessary step in the process of mitosis allowing any nanomaterial crossing the cellular membrane to gain access to nuclear components and genetic material [30].

Physicochemical alterations can also have effects on the suspension properties in vitro, in vivo, and in the workplace. Zeta potential is a measure of dispersion of suspended particles in a liquid medium and is based on the electrostatic repulsion between these two substances. The magnitude of zeta potential, whether positive or negative, will indicate the degree of stability for the suspension.

The addition of proteins, such as pulmonary surfactants, have been shown to improve the stability of nanomaterials in suspension [31]. A protein corona can surround the nanomaterial which affects the pharmacokinetics and pharmacodynamics of the substance leading to differences in toxicity. Furthermore, physicochemical characteristics of the nanomaterial can influence the protein corona. Pristine nanomaterials typically have more structural defects allowing for stronger electrostatic and covalent bonds with proteins, such as albumin and fibrinogen [32]. However, there is conflicting evidence since chemical functionalization with carboxyl and amine groups demonstrated lower zeta potentials, increased hydrodynamic diameter, and increased amounts of protein loading on CNT material indicating increase hydrophilicity and suspension stability [33]. Indeed, Study 2 reported a decrease in suspension stability of MWCNT suspended in surfactant containing dispersion media 
measured through zeta potential. Traditional measurement techniques for nanotoxicology have been debated since nanomaterials have been shown to either skew results or possess unique qualities not measurable with the currently technology [34]. As noted by Beck et al. (2016), PCS is a light scattering technique that expresses size as an equivalent spherical diameter and hence does not represent the actual physical dimensions of high aspect ratio particles such as MWCNT [35]. However, these values are used as the accepted method for zeta potential and hydrodynamic diameter.

According to Mariato and Logorinto a tripolar cell can complete cytokinesis, maintain viability, yet it will be aneuploidy [36]. A quadripolar cell will not complete cytokinesis and either die when p53 is activated or become polyploid and cycle again if p53 is mutated. A cell with a bipolar spindle with clustered centrosomes will usually maintain a normal karyotype. However, the next cell cycle and division will produce aneuploidy or micronuclei due to amplified centrosomes. A monopolar spindle will behave similar to a quadripolar cell by not undergoing cytokinesis and becoming polyploid. Amplified centrosomes can occur from fragmentation or defects in centriole cohesion leading to premature separation of the centrioles during the cell cycle. Carboxylated MWCNT material from Study 1 and MWCNT-7, HT, and ND material from Study 2 have the unique ability to interact with the centromere in addition to their affinity for tubulin and centrin. This interaction with the centromere and ability to fragment has not been seen by any other carbonaceous nanomaterial.

The objectives of Studies $1 \& 2$ were to determine the effect of either diameter or chemical alterations on the genotoxicity of MWCNT. Each MWCNT material investigated in these studies produced significant effects regardless of the size or functionalization of the material. Therefore, we can conclude that the rigidity and structure of the MWCNT drive the mechanism of genotoxicity, whereas differences can occur between material regarding cellular and nuclear uptake. The IARC committee recognized gaps in mechanistic data regarding physicochemical alterations of MWCNT material and effects on cellular proliferation [3]. Clonal growth analysis of the MWCNT-7, HT, and ND material has shown that each material has the ability to significantly increase proliferation in primary lung epithelial cells, however the affective doses are different. Additionally, these in vitro doses are 
occupationally-relevant. However, given the significant effects at the lowest dose a no observable effect level has not been achieved.

The International Agency for Research on Cancer (IARC) designated the pristine Mitsui-7 MWCNT (MWCNT-7) as a Group 2B carcinogen or "possibly carcinogenic to humans" [37]. Without a doseresponse cancer study in vivo or epidemiological evidence of lung cancer a Group 1 classification cannot be reached. There is also insufficient evidence to determine the carcinogenic risk imposed on workers exposed during the production or use of other MWCNT with varying physicochemical properties. Therefore, all other MWCNT have been labelled as Group 3 carcinogens or "not classifiable as to their carcinogenicity to humans". MWCNT with altered physicochemical properties might have different health effects and must be studied extensively [38-40]. There have been several studies published demonstrating MWCNT-7 material to be significantly carcinogenic in rats producing bronchioalveolar carcinomas via inhalation [41] and malignant mesotheliomas via intratracheal installation [42].

A significant gap remains as to the deposition of MWCNT material in the pleural mesothelium, chronic retention and clearance, and translocation to other organs. Although study 3 determined that inhalation of MWCNT-7 following administration of DNA damaging reagent MCA induced significantly increased focal adenomatous alveolar hyperplastic lesions in mice providing evidence of pre-neoplastic changes similar to human bronchio-alveolar adenocarcinoma, the mechanism is not understood. Gene expression studies have provided some information pertaining to MWCNT-induced oncogenes [43].

The $31.2 \pm 0.9 \mu \mathrm{g}$ MWCNT/mouse lung burden achieved in Study 3 is equivalent to 266 years of human exposure at the National Institute for Occupational Safety and Health (NIOSH) recommended exposure limit (REL) of $1 \mu \mathrm{g} / \mathrm{m}^{3}$ [44] assuming the entire workplace exposure material is of inhalable size and a 10\% alveolar deposition fraction (Appendix A). NIOSH has recently conducted exposure assessments in eight MWCNT primary or secondary manufacturing facilities in the U.S. and measured a geometric mean concentration of $4.21 \mu \mathrm{g} / \mathrm{m}^{3}$ at the inhalable fraction [45]. The $31.2 \pm 0.9 \mu \mathrm{g}$ MWCNT/mouse lung burden is equivalent to 63 years of human exposure based on this recent workplace exposure assessment, assuming a 10\% alveolar deposition fraction. The deposition fraction is based on a $1.5 \mu \mathrm{m}$ mass median aerodynamic diameter with $2 \mu \mathrm{m}$ geometric standard deviation for 
MWCNT material [46]. It should be noted that the exposure assessment indicated mean concentrations as high as $79.6 \mu \mathrm{g} / \mathrm{m}^{3}$ at one facility [45].

Currently, there are no data regarding length of worker exposures to MWCNT. However, the worker population has been characterized as transient and growing by as much as $115 \%$ in one year [47]. An exposure assessment of six primary and secondary MWCNT manufacturing sites determined limited and improper use of PPE (respirators, surgical and dust masks) and engineering controls (fume hoods, glove boxes, HEPA filter vacuums, enclosed processes) [48]. The authors noted a common practice was to shut down engineering controls during the production and use of MWCNT materials to reduce the loss of product. Therefore, it can be inferred that workers are at risk of inhaling MWCNT material in the workplace resulting in a tumorigenic equivalent dose.

\section{Future research \& Conclusions}

The physical interaction between MWCNT material and nuclear structures leads to significant genotoxicity in lung epithelial cells and carcinogenicity in a rodent model at occupationally-relevant doses. These data indicate that chemical and physical alteration of the MWCNT have only limited effects on the magnitude of genotoxicity specifically relating to cellular division. However, these alterations can affect nuclear internalization of the material. The overall hypothesis is that carbon nanotubes induce mitotic spindle disruption and aneuploidy by interaction with the lipophilic mitotic spindle tubulin, kinetochore fibers as well as DNA. The degree of rigidity and the lipophilicity of the carbon nanotubes is directly correlated to the extent of the disruption of the mitotic apparatus. The most aneugenic carbon nanotubes are the most carcinogenic.

Recently, there has been a proactive effort within the nanotechnology industry to reduce the dustiness of workplace environments by either coating MWCNT material (such as with metal oxides or polymer epoxies) or using them in composites. These alterations have been shown reduce proinflammatory and fibrogenic cytokines in the mouse lung $[49,50]$. Therefore, an investigation of the genotoxicity, and the potential reduction, is warranted for these materials.

In vivo data have been provided regarding indirect mechanisms leading to genotoxicity and carcinogenicity, such as oxidative stress and inflammation. However, only Muller et al. have shown 
pristine MWCNT material to interact with the DNA in type II pneumocytes isolated from the lungs of rats exposed via i.t. installation leading to MN with evidence of both clastogenic and aneugenic mechanisms [51]. Therefore, research is needed to investigate the mechanisms of genotoxicity for MWCNT-7 material and MWCNT material with varying physicochemical properties in vivo. The data from Study 3 demonstrate MWCNT-7 material is a significant tumor promoter and, therefore, incomplete carcinogen. However, other recent studies have indicated this material as a complete carcinogen [41, 42]. Therefore, an in vivo dose response of the carcinogenicity of MWCNT-7 material is necessary. Since Study 3 and Suzui et al. have demonstrated MWCNT-7 material to produce malignant mesothelioma, there is a need for these mechanisms to be explored in mesothelial cells [42]. Lastly, there is a great need to test the various mechanistic endpoints leading to cancer, oxidative stress, inflammation, fibrosis, and genotoxicity, concurrently with exposure to MWVNT in vivo. 


\section{$\underline{\text { References }}$}

1. (NPCR), N.P.o.C.R., United States Cancer Statistics (USCS). CDC, 2010.

2. Alberg, A.J. and J.M. Samet, Epidemiology of lung cancer. Chest, 2003. 123(1): p. 21S-49S.

3. Kuemple, E., et al., Seeing the Forest through the Trees: Evaluating the Key Evidence and Data Gaps in Assessing the Potential Carcinogenicity of Carbon Nanotubes and Nanofibers in Humans Crit Rev Toxicol, 2016.

4. Sargent, L.M., et al., Single-walled carbon nanotube-induced mitotic disruption. Mutat Res, 2012. 745(1-2): p. 28-37.

5. Sargent, L.M., et al., Induction of aneuploidy by single-walled carbon nanotubes. Environ Mol Mutagen, 2009. 50(8): p. 708-17.

6. Gernand, J.M. and E.A. Casman, A meta-analysis of carbon nanotube pulmonary toxicity studies--how physical dimensions and impurities affect the toxicity of carbon nanotubes. Risk Anal, 2014. 34(3): p. 583-97.

7. Poulsen, S.S., et al., Multi-walled carbon nanotube physicochemical properties predict pulmonary inflammation and genotoxicity. Nanotoxicology, 2016. 10(9): p. 1263-75.

8. Kim, Y.A., et al., Synthesis and structural characterization of thin multi-walled carbon nanotubes with a partially facetted cross section by a floating reactant method. Carbon, 2005. 43(11): $p$. 2243-2250.

9. Andrews, R., et al., Purification and structural annealing of multiwalled carbon nanotubes at graphitization temperatures. Carbon, 2001. 39(11): p. 1681-1687.

10. Huang, W., et al., 99.9\% purity multi-walled carbon nanotubes by vacuum high-temperature annealing. Carbon, 2003. 41(13): p. 2585-2590.

11. Endo, M., et al., Comparison study of semi-crystalline and highly crystalline multiwalled carbon nanotubes. Applied Physics Letters, 2001. 79(10): p. 1531-1533. 
12. Garc, et al., Magnetic and Electrical Properties of Nitrogen-Doped Multiwall Carbon Nanotubes Fabricated by a Modified Chemical Vapor Deposition Method. Journal of Nanomaterials, 2015. 2015: p. 14.

13. Terrones, M., et al., $N$-doping and coalescence of carbon nanotubes: synthesis and electronic properties. Applied Physics A, 2002. 74(3): p. 355-361.

14. Sharifi, T., et al., Nitrogen doped multi walled carbon nanotubes produced by CVD-correlating XPS and Raman spectroscopy for the study of nitrogen inclusion. Carbon, 2012. 50(10): p. $3535-3541$.

15. Sumpter, B.G., et al., Nitrogen-Mediated Carbon Nanotube Growth: Diameter Reduction, Metallicity, Bundle Dispersability, and Bamboo-like Structure Formation. ACS Nano, 2007. 1(4): p. 369-375.

16. Meier, M.S., et al., Tearing open nitrogen-doped multiwalled carbon nanotubes. Journal of Materials Chemistry, 2008. 18(35): p. 4143-4145.

17. Ayala, P., et al., The doping of carbon nanotubes with nitrogen and their potential applications. Carbon, 2010. 48(3): p. 575-586.

18. Ganesan, Y., et al., Effect of nitrogen doping on the mechanical properties of carbon nanotubes. ACS Nano, 2010. 4(12): p. 7637-43.

19. Pampaloni, F. and E.L. Florin, Microtubule architecture: inspiration for novel carbon nanotubebased biomimetic materials. Trends in Biotechnology, 2008. 26(6): p. 302-310.

20. Dinu, C.Z., et al., Tubulin Encapsulation of Carbon Nanotubes into Functional Hybrid Assemblies. Small, 2009. 5(3): p. 310-315.

21. Sargent, L., et al., Genotoxicity of multi-walled carbon nanotubes at occupationally relevant doses. 2013.

22. Salisbury, J.L., A.B. D'Assoro, and W.L. Lingle, Centrosome amplification and the origin of chromosomal instability in breast cancer. Journal of Mammary Gland Biology and Neoplasia, 2004. 9(3): p. 275-283. 
23. Lingle, W.L., et al., Centrosome amplification drives chromosomal instability in breast tumor development. Proceedings of the National Academy of Sciences, 2002. 99(4): p. 1978-1983.

24. Aardema, M.J., et al., Aneuploidy: a report of an ECETOC task force. Mutation ResearchReviews in Mutation Research, 1998. 410(1): p. 3-79.

25. Mangum, J.B., et al., Single-Walled Carbon Nanotube (SWCNT)-induced interstitial fibrosis in the lungs of rats is associated with increased levels of PDGF mRNA and the formation of unique intercellular carbon structures that bridge alveolar macrophages In Situ. Particle and Fibre Toxicology, 2006. 3(1): p. 15.

26. Li, X., et al., Carboxyl-modified single-walled carbon nanotubes selectively induce human telomeric i-motif formation. Proc Natl Acad Sci U S A, 2006. 103(52): p. 19658-63.

27. Thongkumkoon, P., et al., Direct nanomaterial-DNA contact effects on DNA and mutation induction. Toxicol Lett, 2014. 226(1): p. 90-7.

28. Suzuki, Y., J. Churg, and T. Ono, Phagocytic Activity of the Alveolar Epithelial Cells in Pulmonary Asbestosis. The American Journal of Pathology, 1972. 69(3): p. 373-388.

29. Nabeshi, H., et al., Effect of surface properties of silica nanoparticles on their cytotoxicity and cellular distribution in murine macrophages. Nanoscale Res Lett, 2011. 6(1): p. 93.

30. Frohlich, E., The role of surface charge in cellular uptake and cytotoxicity of medical nanoparticles. Int J Nanomedicine, 2012. 7: p. 5577-91.

31. Porter, D.W., et al., Mouse pulmonary dose- and time course-responses induced by exposure to multi-walled carbon nanotubes. Toxicology, 2010. 269(2-3): p. 136-47.

32. Sengupta, B., et al., Influence of carbon nanomaterial defects on the formation of protein corona. RSC advances, 2015. 5(100): p. 82395-82402.

33. Shannahan, J.H., et al., Comparison of nanotube-protein corona composition in cell culture media. Small, 2013. 9(12): p. 2171-81.

34. Doak, S.H., et al., Confounding experimental considerations in nanogenotoxicology. Mutagenesis, 2009. 24(4): p. 285-93. 
35. Beck, S., J. Bouchard, and R. Berry, Dispersibility in water of dried nanocrystalline cellulose. Biomacromolecules, 2012. 13(5): p. 1486-94.

36. Maiato, H. and E. Logarinho, Mitotic spindle multipolarity without centrosome amplification. Nat Cell Biol, 2014. 16(5): p. 386-94.

37. Grosse, Y., et al., Carcinogenicity of fluoro-edenite, silicon carbide fibres and whiskers, and carbon nanotubes. Lancet Oncol, 2014. 15(13): p. 1427-8.

38. Donaldson, K., et al., Asbestos, carbon nanotubes and the pleural mesothelium: a review of the hypothesis regarding the role of long fibre retention in the parietal pleura, inflammation and mesothelioma. Part Fibre Toxicol, 2010. 7: p. 5.

39. Murphy, F.A., et al., Length-dependent pleural inflammation and parietal pleural responses after deposition of carbon nanotubes in the pulmonary airspaces of mice. Nanotoxicology, 2013. 7(6): p. $1157-67$.

40. Nagai, H., et al., Diameter and rigidity of multiwalled carbon nanotubes are critical factors in mesothelial injury and carcinogenesis. Proc Natl Acad Sci U S A, 2011. 108(49): p. E1330-8.

41. Kasai, T., et al., Lung carcinogenicity of inhaled multi-walled carbon nanotube in rats. Part Fibre Toxicol, 2016. 13(1): p. 53.

42. Suzui, M., et al., Multiwalled carbon nanotubes intratracheally instilled into the rat lung induce development of pleural malignant mesothelioma and lung tumors. Cancer science, 2016. 107(7): p. 924-35.

43. Snyder-Talkington, B.N., et al., mRNAs and miRNAs in whole blood associated with lung hyperplasia, fibrosis, and bronchiolo-alveolar adenoma and adenocarcinoma after multi-walled carbon nanotube inhalation exposure in mice. J Appl Toxicol, 2015.

44. NIOSH, Current intelligence bulletin 65: occupational exposure to carbon nanotubes and nanofibers. . 2013(Publication No. 2013-145).

45. Erdely, A., et al., Carbon nanotube dosimetry: from workplace exposure assessment to inhalation toxicology. Part Fibre Toxicol, 2013. 10(1): p. 53. 
46. Chen, B.T., et al., Multi-walled carbon nanotubes: sampling criteria and aerosol characterization. Inhal Toxicol, 2012. 24(12): p. 798-820.

47. Schubauer-Berigan, M.K., M.M. Dahm, and M.S. Yencken, Engineered carbonaceous nanomaterials manufacturers in the United States: workforce size, characteristics, and feasibility of epidemiologic studies. J Occup Environ Med, 2011. 53(6 Suppl): p. S62-7.

48. Dahm, M.M., et al., Occupational exposure assessment in carbon nanotube and nanofiber primary and secondary manufacturers. Ann Occup Hyg, 2012. 56(5): p. 542-56.

49. Taylor, A.J., et al., Atomic layer deposition coating of carbon nanotubes with aluminum oxide alters pro-fibrogenic cytokine expression by human mononuclear phagocytes in vitro and reduces lung fibrosis in mice in vivo. PLoS One, 2014. 9(9): p. e106870.

50. Bishop, L., et al., A life cycle analysis of carbon nanotube toxicity to provide context to potential health effects. In press, 2016.

51. Muller, J., et al., Clastogenic and aneugenic effects of multi-wall carbon nanotubes in epithelial cells. Carcinogenesis, 2008. 29(2): p. 427-33. 


\section{Appendix}

\section{Appendix A - Estimation of work-years to reach human equivalent dose}

Assuming a 10\% deposition fraction (MMAD $1.5 \mu \mathrm{m}$ and GSD $2 \mu \mathrm{m}$ )

\section{Exposure assessment from Erdely et al 2013}

$$
\begin{aligned}
\text { Human equivalent lung dose }(\mu \mathrm{g}) & =\left(\frac{\text { Mouse lung dose }(\mu \mathrm{g})}{\text { MouseAlvSA }(\mathrm{m} 2)}\right) \times \text { HumanAlvSA }\left(\mathrm{m}^{2}\right) \\
63,852 \mu \mathrm{g} & =\left(\frac{31.3 \mu \mathrm{g}}{0.05 \mathrm{~m}^{2}}\right) \times 102 \mathrm{~m}^{2}
\end{aligned}
$$

Work years $(\mathrm{yr})=$ Human-equivalent deposited lung dose $(\mu \mathrm{g}) /$ [Exposure conc $\left(\mu \mathrm{g} / \mathrm{m}^{3}\right) \times$ Air intake $\left(9.6 \mathrm{~m}^{3} / 8-\mathrm{hr} \mathrm{d}\right) \times$ Workdays per year $\times$ DFalv]

$$
\text { Work years }(\mathrm{yr})=\frac{\text { Human equivalent lung dose }(\mu \mathrm{g})}{\left(\text { Exposure } \frac{\mu \mathrm{g}}{\mathrm{m}^{3}}\right) \times \text { Air intake } x \text { Work Days } x \text { DFalv }}
$$

Air intake $=20 \mathrm{~L} / \mathrm{min} \times 0.001 \mathrm{~m} / \mathrm{L} \times 8 \mathrm{hr} /$ day $\times 60 \mathrm{~min} / \mathrm{hr}=9.6 \mathrm{~m}^{3} / \mathrm{d}$

$$
63 \mathrm{yr}=\frac{63,852 \mu \mathrm{g}}{\left(4.21 \frac{\mu \mathrm{g}}{m^{3}}\right) \times 9.6 \frac{\mathrm{m}^{3}}{d} \times 250 \mathrm{~d} \times 0.1}
$$

\section{NIOSH REL}

$$
\begin{aligned}
& \text { Human equivalent lung dose }(\mu \mathrm{g})=\left(\frac{\text { Mouse lung dose }(\mu \mathrm{g})}{\text { MouseAlvSA }(\mathrm{m} 2)}\right) \times \text { HumanAlvSA }\left(\mathrm{m}^{2}\right) \\
& 63,852 \mu \mathrm{g}=\left(\frac{31.3 \mu \mathrm{g}}{0.05 \mathrm{~m}^{2}}\right) \times 102 \mathrm{~m}^{2}
\end{aligned}
$$

Work years $(\mathrm{yr})=$ Human-equivalent deposited lung dose $(\mu \mathrm{g}) /$ [Exposure conc $\left(\mu \mathrm{g} / \mathrm{m}^{3}\right) \times$ Air intake $\left(9.6 \mathrm{~m}^{3} / 8\right.$-hr d) $\times$ Workdays per year $\times$ DFalv]

$$
\text { Work years }(\mathrm{yr})=\frac{\text { Human equivalent lung dose }(\mu \mathrm{g})}{\left(\text { Exposure } \frac{\mu \mathrm{g}}{m^{3}}\right) x \text { Air intake } x \text { Work Days } x \text { DFalv }}
$$

Air intake $=20 \mathrm{~L} / \mathrm{min} \times 0.001 \mathrm{~m}^{3} / \mathrm{L} \times 8 \mathrm{hr} /$ day $\times 60 \mathrm{~min} / \mathrm{hr}=9.6 \mathrm{~m}^{3} / \mathrm{d}$ 


$$
266 \mathrm{yr}=\frac{63,852 \mu \mathrm{g}}{\left(1 \frac{\mu \mathrm{g}}{m^{3}}\right) \times 9.6 \frac{m^{3}}{d} \times 250 d \times 0.1}
$$




\section{Curriculum Vitae}

\section{Katelyn Jayne Siegrist}

4030 Pinehurst Drive, Morgantown, WV 26505

(304)886-5417, kate.siegrist1@gmail.com

\section{Education}

$\begin{array}{lcc}\quad \underline{\text { Institution }} & \underline{\text { Degree }} & \underline{\text { Year }} \\ \text { West Virginia University, Morgantown, WV } & \text { PhD } & \mathbf{2 0 1 2 - 2 0 1 6} \\ \text { School of Public Health } & \\ \begin{array}{l}\text { Occupational and Environmental Health Sciences } \\ \text { Dissertation "Genotoxicity of multi-walled carbon nanotubes at occupationally-relevant doses" }\end{array}\end{array}$

Committee Chairs: Dr. Linda Sargent \& Dr. Michael McCawley

West Virginia University, Morgantown, WV School of Medicine

Major: Exercise Physiology, Minor: Dance

\author{
BS \\ Cum Laude
}

\section{Honors and Awards}

Nanotoxicology Congress Travel Award

Outstanding Graduate Student Travel Award-Society of Toxicology-

Nanotoxicology Specialty Section

Shepard Award Nomination - Center for Disease Control

$2010,2012,2013$

Best Paper -Society of Toxicology- Inhalation and Respiratory Toxicology

Specialty Section

Best Graduate Student Oral Presentation-Allegheny-Erie-SOT

West Virginia Promise Scholarship Award

West Virginia University Achievement Award

Pi Beta Phi Fraternity for Women Chapter President \& Vice President

\section{Relevant Experience and Skills}

- Mentored and trained undergraduate students

- Preparation of metaphase chromosome spreads, human and mouse

- Fluorescent in situ hybridization (FISH) of metaphase spreads and fixed tissue

- Immunohistochemical staining

- Analysis of mitotic spindle integrity

- Tissue culture, mammalian, bacteria and yeast

- Polymerase Chain Reaction (PCR), Real Time PCR, and nick translation

- Mouse handling, anesthesia, euthanasia, and dissection

- Mouse treatment, intraperitoneal injection and pharyngeal aspiration

- Mouse lung perfusion

- Mouse genotyping

- DNA and protein preparation from bacteria, yeast, animal cells and tissue

- DNA and protein measurements and quality check

- Confocal and fluorescent microscopy and photography 
- Agarose gel electrophoresis

- Primary cell preparations of lung tissue

- Carbon nanotube handling, dispersion and washing

- Flow cytometry sample preparation and analysis

- Human tissue microdissection

- SOP development

- CASPER surveying

\section{Employment}

Institution

National Institute for Occupational Safety and

Health

Morgantown, WV

Health Effects Laboratory Division

National Institute for Occupational Safety and

Health

Morgantown, WV

Health Effects Laboratory Division

West Virginia University Health Sciences Center

Morgantown, WV

\section{National Institute for Occupational Safety and}

Health

Morgantown, WV

Wellness Center

West Virginia University Healthcare

Morgantown, WV

Pediatric/Child Development/Emergency

Department

Harpers Ferry Family Medicine

Harpers Ferry, WV
Iob Title

Biologist/Regular Fellow August 2014-

December 2016

Biologist/Regular Fellow

August 2010-

August2012

January 2010-

May 2010

May 2009-

Wellness Center Intern

December 2009

June 2007-May

2010

December 2008-

Job Shadow

January 2009

\section{Professional Organizations/Memberships}

Society of Toxicology

Student member

Allegheny-Erie Society of Toxicology

Student member

American Industrial Hygiene Association

Student member

American Public Health Association

Student member

Pi Beta Phi Fraternity for Women

Alumna Advisor

\section{Committee Participation}

Graduate Student Advisory Committee to the Associate Provost for Graduate

2013-2014

Academic Affairs

\section{Teaching Experience}


Institution

West Virginia

University

West Virginia

University
Course

OEHS 732, Occupational

Injury Prevention, 1

semester.

OEHS 622, Public Health

Toxicology, 1 semester.
Position \& Duties

Teaching Assistant. Taught one prepared one lecture, conducted one in-classroom activity, developed, implemented, and graded final project for Master's level students.

Teaching Assistant. Prepared and taught one lecture on pulmonary toxicology, graded exams, graded final presentations.

\section{Publications}

1. Siegrist KJ, Reynolds SH, Mercer RR, Porter DW, Lowry DT, Cena L, Kashon ML, Salisbury JL, Mastovich J, Bunker K, Sparrow M, Tsuruoka S, Endo M, Terrones M, McCawley M, Sargent LM. Genotoxicity of Pristine, Heat-treated and Nitrogen-doped Multi-walled Carbon Nanotubes at Occupationally Relevant Doses. In preparation.

2. Bishop L, Cena L, Orandle M, Yanamala N, Dahm M, Birch E, Evans DE, Kodali V, Eye T, Battelli L, Zeidler-Erdely PC, Casuccio G, Bunker K, Stefaniak AB, Sager T, Afshari A, Schwegler-Berry D, Kang J, Siegrist KJ, Mitchell CA, Lowry DT, Kashon ML, Mercer RR, Geraci CL, SchubauerBerigan MK, Sargent LM, Erdely A. A life cycle approach to carbon nanotube toxicity to provide context to potential health effects. In preparation.

3. Siegrist KJ, Reynolds S, Kashon ML, Lowry DT, Dong C, Hubbs AF, Young S, Salisbury J, Benkovic S, McCawley M, Keane MJ, Mastovich J, Bunker K, Cena L, Sturgeon J, Dinu C, Sargent L [2014]. Genotoxicity of multi-walled carbon nanotubes at occupationally relevant doses. Part Fibre Toxicol 11(6):1-15.

4. Sargent L, Porter DW, Staska L, Hubbs AF, Lowry DT, Battelli LA, Siegrist KJ, Kashon ML, Mercer R, Bauer A, Chen TB, Salisbury J, Frazer DG, McKinney W, Andrew ME, Tsuruoka S, Endo M, Fluharty K, Castranova V, Reynolds S [2013]. Promotion of lung adenocarcinoma following inhalation exposure to multi-walled carbon nanotubes. Part Fibre Toxicol 11(3).

5. Sargent L, Hubbs AF, Young S, Kashon ML, Dinu C, Salisbury J, Benkovic S, Lowry DT, Murray AR, Kisin E, Siegrist KJ, Battelli LA, Mastovich J, Sturgeon J, Bunker K, Shvedova AA, Reynolds S [2012]. Single-walled carbon nanotube-induced mitotic disruption. Mutat Res 745(1-2):2837.

6. Kisin E, Murray AR, Sargent L, Lowry DT, Chirila M, Siegrist KJ, Schwegler-Berry DE, Leonard SS, Castranova V, Fadeel B, Kagan V, Shvedova AA [2011]. Genotoxicity of carbon nanofibers: are they potentially more or less dangerous than carbon nanotubes or asbestos? Toxicol Appl Pharmacol 252(1):1-10.

\section{Abstracts}

1. Siegrist K, Reynolds S, Mercer R, Porter D, Lowry D, Cena L, Kashon M, Salisbury J, Mastovich J, Bunker K, Sparrow M, Wiley J, Tsuruoka S, Endo M, Terrones M, McKinstry K, McCawley M, Sargent L [2016]. Genotoxicity of Pristine, Heat-treated and Nitrogen-doped Multi-walled Carbon Nanotubes at Occupationally Relevant Doses abstract. Conf. Proceedings:259 \#224.

2. Siegrist K, Reynolds S, Mercer R, Porter D, Lowry D, Wiley J, Cena L, Kashon M, Stefaniak A, Salisbury J, Mastovich J, Bunker K, Sparrow M, Tsuruoka S, Endo M, Terrones M, McKinstry K, McCawley M, Sargent L [2016]. Genotoxicity of Pristine, Heat-treated and Nitrogen-doped Multi-walled Carbon Nanotubes at Occupationally Relevant Doses. abstract, University of Colorado, Denver, CO, June 21

3. Davis T, Siegrist K, Sargent L, Holland L [2016]. Affinity Binding Analysis of Peptide-Carbon Nanotube Interaction to substantiate Occupational Toxicity Study and Aid in Intervention. abstract, Allegheny-Erie Regional Chapter of the Society of Toxicology Annual Meeting, Morgantown, WV, May 18-19, 2016 
4. Mitchell C, Siegrist K, Reynolds S, Lowry D, Kashon M, Bishop L, Erdely A, Bonner JC, Parsons GN, McClure CD, Sargent L [2016]. An evaluation of genotoxicity from as-produced and postproduction modifications of multi-walled carbon nanotubes. abstract, Allegheny-Erie Regional Chapter of the Society of Toxicology Annual Meeting, Morgantown, WV, May 18-19, 2016

5. Siegrist K, Reynolds S, Mercer R, Porter D, Lowry D, Cena L, Kashon M, Salisbury JL, Mastovich J, Bunker K, Sparrow M, Wiley JE, Tsuruoka S, Endo M, Terrones M, McKinstry K, McCawley M, Sargent L [2016]. Genotoxicity of Pristine, Heat-treated and Nitrogen-doped Multi-walled Carbon Nanotubes at Occupationally Relevant Doses. abstract, Allegheny-Erie Regional Chapter of the Society of Toxicology Annual Meeting, Morgantown, WV, May 18-19, 2016

6. Siegrist K, Reynolds S, Mitchell C, Lowry D, Kashon M, Bishop L, Erdely A, Bonner JC, Parsons GN, McClure CD, Sargent L [2016]. An evaluation of genotoxicity from as-produced and postproduction modification of multi-walled carbon nanotubes abstract. Toxicologist 150(1):419\# PS 2782.

7. Siegrist K, Reynolds S, Mercer R, Porter D, Lowry D, Cena L, Kashon M, Salisbury JL, Mastovich J, Bunker K, Sparrow M, Tsuruoka S, Endo M, Terrones M, McCawley M, Sargent L [2016]. Genotoxicity of Pristine, Heat-treated, and Nitrogen-doped Multi-walled Carbon Nanotubes at Occupationally Relevant Doses abstract. Toxicologist 150(1):416-417-\# PS 2773.

8. Siegrist K, Reynolds S, Mercer R, Porter D, Lowry D, Cena L, Kashon M, Salisbury JL, Mastovich J, Bunker K, Sparrow M, Tsuruoka S, Endo M, Terrones M, McCawley M, Sargent L [2015]. Genotoxicity of Mitsui-7, Heat-treated and Nitrogen-doped Multi-walled Carbon Nanotubes at Occupationally Relevant Doses. abstract, Allegany-Erie Society of Toxicology Spring Meeting, Morgantown WV, June 3-4, 2015

9. Siegrist KJ, Reynolds S, Mercer R, Porter DW, Lowry DT, Kashon ML, Salisbury JL, Mastovich J, Bunker K, Sparrow M, Tsuruoka S, Endo M, McCawley M, Sargent L [2015]. Lessening Genotoxicity Using Nitrogen-doping of Multiwalled Carbon Nanotubes abstract. Toxicologist 144(1):266 \#1245.

10. Siegrist KJ, Reynolds S, Porter DW, Lowry DT, Kashon ML, McCawley M, Salisbury JL, Mastovich J, Bunker K, Sparrow M, Sargent L [2014]. Lessening Cytotoxicity Using Nitrogendoping of Multi-walled Carbon Nanotubes. abstract, Allegheny-Erie Society of Toxicology Spring Meeting, Morgantown, WV, May 15-16, 2014

11. Siegrist KJ, Sargent L, Porter DW, Lowry DT, Kashon ML, Hubbs AF, Salisbury J, Mastovich J, Bunker K, Sparrow M, Tsuruoka S, Endo M, Reynolds S [2013]. Cytotoxicity of Native and Nitrogen-doped Multi-walled Carbon Nanotubes. abstract. Toxicologist, 2014 Society of Toxicology Annual Meeting, Phoenix, Arizona, March 23-27, 2014

12. Siegrist KJ, Reynolds S, Lowry DT, Kashon ML, Hubbs AF, Young S, Dong C, Benkovic S, Salisbury J, Keane MJ, Mastovich J, McCawley M, Bunker K, Cena L, Sturgeon J, Dinu C, Sargent L [2013]. Genotoxicity of multi-walled carbon nanotubes at occupationally relevant doses. abstract, 2013 Allegheny Erie Society of Toxicology Meeting, Morgantown, WV, May 30-31, 2013

13. Sargent L, Porter DW, Lowry DT, Battelli LA, Siegrist KJ, Kashon ML, Chen TB, Frazer DG, Staska L, Hubbs AF, McKinney W, Andrew ME, Tsuruoka S, Endo M, Castranova V, Reynolds S [2013]. Multi-walled carbon nanotube-induced lung tumors abstract. Toxicologist 132(1):98\#4.

14. Sargent L, Reynolds S, Lowry DT, Kashon ML, Benkovic S, Salisbury J, Hubbs AF, Young S, Siegrist K, Keane MJ, Mastovich J, Bunker K, Sturgeon J, Cena L, Zoica Dinu C [2012]. Genotoxicity of multi-walled carbon nanotubes at occupationally relevant doses abstract. Proc Am Assoc Cancer Res 53:1320-\#5465.

15. Sargent L, Dinu C, Young S, Salisbury J, Benkovic S, Lowry DT, Hubbs AF, Kashon ML, Siegrist K, Battelli LA, Chirila M, Mastovic J, Sturgeon J, Bunker K, Reynolds S [2011]. Understanding the basis of carbon nanotube-induced genotoxicity. abstract, Nanomaterials and Worker Health Conference, Madison, WI, June 2-3, 2011 
16. Kisin E, Murray AR, Sargent L, Lowry DT, Siegrist KJ, Chirila M, Schwegler-Berry DE, Leonard SS, Castranova V, Fadeel B, Kagan VE, Shvedova AA [2011]. Comparative genotoxicity of fibrous particles: carbon nanofibers, single-walled carbon nanotubes and asbestos abstract. Toxicologist 120(2):252.

17. Sargent L, Porter DW, Staska L, Lowry DT, Hubbs AF, Kashon ML, Battelli LA, Mercer R, Chen TB, Frazer DG, Siegrist KJ, Castranova V, Reynolds S.In vivo carcinogenicity of multi-walled carbon nanotubes. abstract, Spring 2014 Nanotechnology Science Meeting, Cincinnati, OH, April 14-16, 2014

\section{Presentations}

1. Siegrist KJ, Reynolds SH, Mercer RR, Porter DW, Lowry DT, Cena L, Kashon ML, Salisbury JL, Mastovich J, Bunker K, Sparrow M, Tsuruoka S, Endo M, Terrones M, McCawley M, Sargent LM. Genotoxicity of Pristine, Heat-treated and Nitrogen-doped Multi-walled Carbon Nanotubes at Occupationally Relevant Doses. WVU Department of Physiology and Pharmacology Speaker Seminar, WV, October 2015.

2. Siegrist KJ, Reynolds S, Lowry DT, Kashon ML, Hubbs AF, Young S, Dong C, Benkovic S, Salisbury J, Keane MJ, Mastovich J, McCawley M, Bunker K, Cena L, Sturgeon J, Dinu C, Sargent L. Genotoxicity of multi-walled carbon nanotubes at occupationally relevant doses. AE-SOT Regional Meeting, Morgantown, WV, May 30-31 2013.

\section{Related Training Courses}

Entering Mentoring, A Seminar to Train a New Generation of Scientists

Chemical Storage, NIOSH

Hazard Communication, NIOSH

Hazardous Waste, NIOSH

Blood borne Pathogens, NIOSH

Biosafety in Microbiological and Biomedical Labs, NIOSH

Writing Winning Grant Proposals

Community Assessment for Public Health Emergency Response (CASPER)

\section{Computer Skills}

- $\quad$ Microsoft Word, Excel, PowerPoint, and Outlook 2007, 2010, 2013

- Graph Pad Prism, v2

- Zen lite 2012

- Cytovision

- $\quad$ SAS 9.3

- FlowJo10

- EndNote

- AutoCad

- Prezi 
